PNNL-18090

WTP-RPT-183, Rev. 0

U.S. DEPARTMENT OF ENERGY

Prepared for the U.S. Department of Energy under Contract DE-AC05-76RL01830

\title{
Development and Demonstration of Ultrafiltration Simulants
}

\author{
RL Russell \\ JM Billing \\ DE Rinehart \\ RA Peterson \\ HD Smith
}

February 2009 


\title{
DISCLAIMER
}

This report was prepared as an account of work sponsored by an agency of the United States Government. Neither the United States Government nor any agency thereof, nor Battelle Memorial Institute, nor any of their employees, makes any warranty, express or implied, or assumes any legal liability or responsibility for the accuracy, completeness, or usefulness of any information, apparatus, product, or process disclosed, or represents that its use would not infringe privately owned rights. Reference herein to any specific commercial product, process, or service by trade name, trademark, manufacturer, or otherwise does not necessarily constitute or imply its endorsement, recommendation, or favoring by the United States Government or any agency thereof, or Battelle Memorial Institute. The views and opinions of authors expressed herein do not necessarily state or reflect those of the United States Government or any agency thereof.

\author{
PACIFIC NORTHWEST NATIONAL LABORATORY \\ operated by \\ BATTELLE \\ for the \\ UNITED STATES DEPARTMENT OF ENERGY \\ under Contract DE-AC05-76RL01830
}

Printed in the United States of America

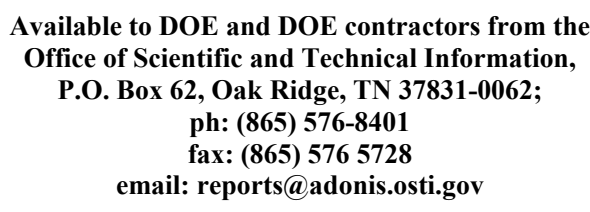

email: reports@adonis.osti.gov

\author{
Available to the public from the National Technical Information Service, \\ U.S. Department of Commerce, 5285 Port Royal Rd., Springfield, VA 22161 \\ ph: (800) 553-6847 \\ fax: (703) 605-6900 \\ email: orders@nits.fedworld.gov \\ online ordering: http://www.ntis.gov/ordering.htm
}


PNNL-18090

WTP-RPT-183, Rev. 0

\title{
Development and Demonstration of Ultrafiltration Simulants
}

\author{
RL Russell DE Rinehart \\ JM Billing HD Smith \\ RA Peterson
}

February 2009

Test specification: 24590-PTF-TSP-RT-06-006, Rev. 0

Test plan: TP-RPP-WTP-469, Rev. 0 and TP-RPP-WTP-509, Rev. 0

Test exceptions: 24590-WTP-TEF-RT-07-00008

R\&T focus area: Pretreatment

Test Scoping Statement: None

Prepared for the U.S. Department of Energy

under Contract DE-AC05-76RL01830

Pacific Northwest National Laboratory

Richland, Washington 99352 
PNNL-18090

WTP-RPT-183, Rev. 0

\section{Completeness of Testing}

This report describes the results of work and testing specified by Test Specification, 24590-PTF-TSP-RT-06-006, Rev. 0 and Test Plans TP-RPP-WTP-469, Rev. 0 and TP$R P P-W T P-509$, Rev. 0 . The work followed the quality assurance requirements outlined in the Test Specification and Test Plan. The descriptions provided in this report are an accurate account of both the conduct of the work and the data collected. Test plan results are reported. Also reported are any unusual or anomalous occurrences that are different from expected results. The test results and this report has been reviewed and verified.

Approved:

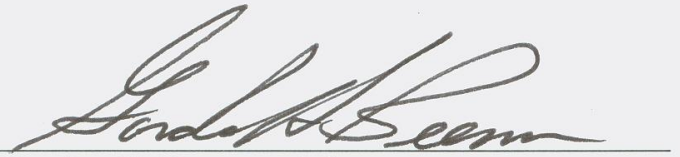

Gordon H. Beeman, Manager WTP R\&T Support Project

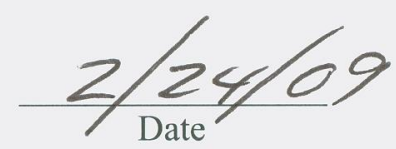




\section{Contents}

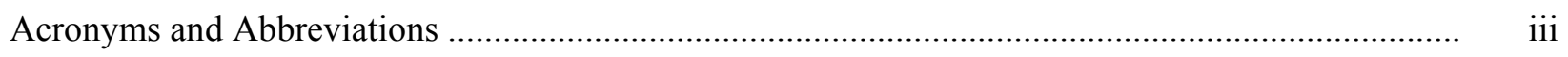

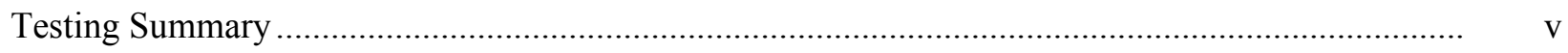

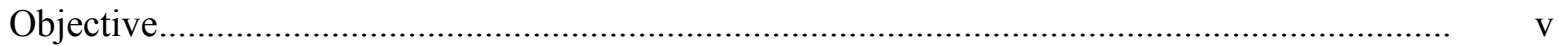

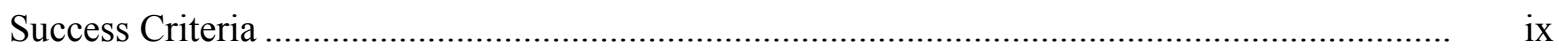

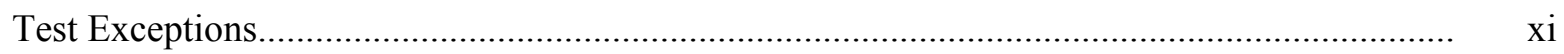

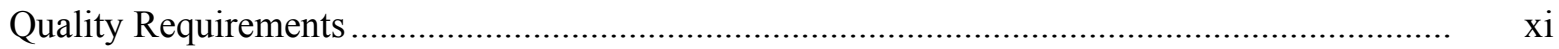

R\&T Test Conditions............................................................................................ xii

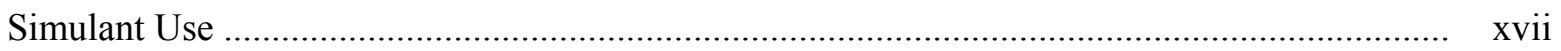

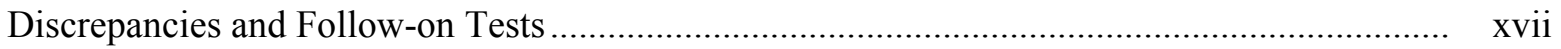

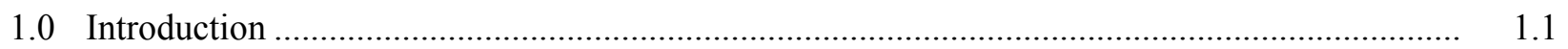

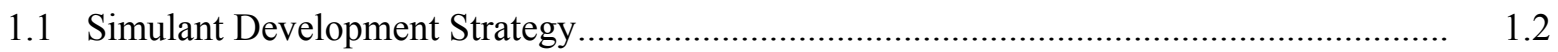

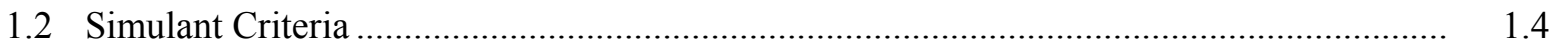

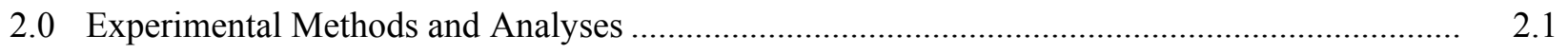

2.1 Filtration/Leaching Apparatus........................................................................... 2.1

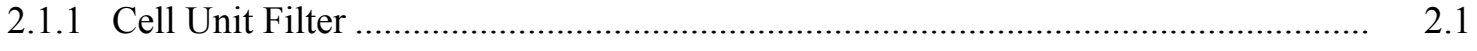

2.1.2 Cross Flow Ultrafiltration/Leaching Apparatus ................................................. 2.3

2.1.3 Instrumentation and Data-Acquisition System.................................................. 2.6

2.1.4 Operations of Crossflow Ultrafiltration and Sampling ......................................... 2.8

2.1.5 Baseline Testing of Filter ........................................................................... 2.8

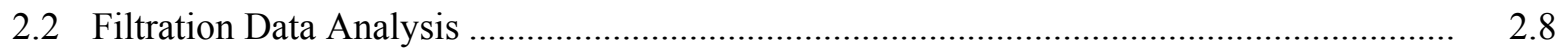

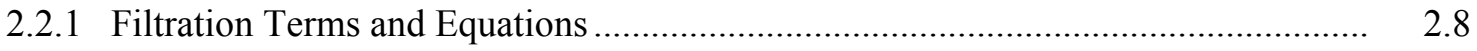

2.2.2 Filtration Test Matrix ........................................................................... 2.10

2.2.3 Dewatering Operation Analysis ............................................................................ 2.11

2.2.4 Effects of Rheology and Particle Size ................................................................. 2.11

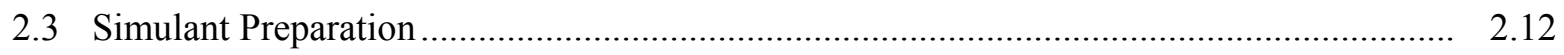

3.0 High-Solids Filtration Performance............................................................................. 3.1

3.1 Ultrafiltration Simulant Centrifuge Screening Tests .................................................. 3.1

3.1.1 Centrifuge Screening Test Results ............................................................... 3.1

3.1.2 Simulant Physical Characterization................................................................... 3.7

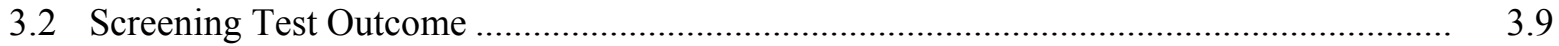

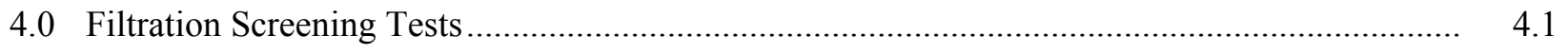

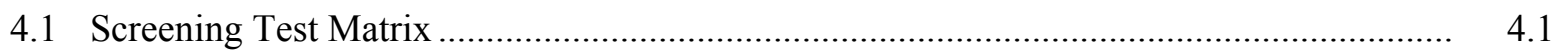

4.1.1 Centrifuged Solids Tests ……........................................................................ 4.1

4.1.2 Particle-Size Distribution (Fines) Tests ............................................................. 4.3

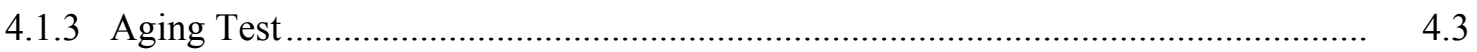

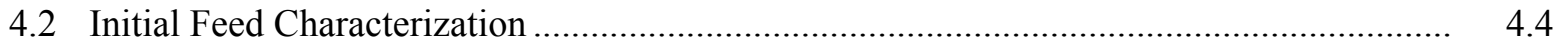




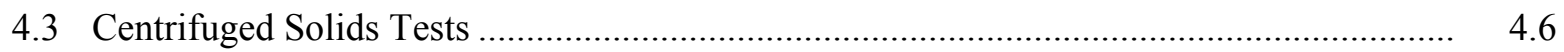

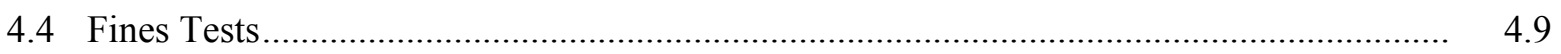

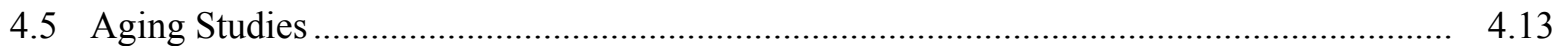

4.6 Filtration Screening Test Outcomes ….......................................................................... 4.14

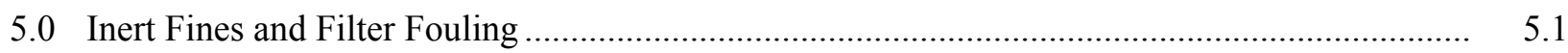

5.1 Inert Fines Filter Flux Adjustment ............................................................................ $\quad 5.2$

5.2 Alternate Inert Fines Tests ........................................................................... 5.12

5.3 Outcome from Inert Fines and Fines Fouling Tests ........................................................ 5.13

6.0 Blended Component Simulant Filtration Demonstration ....................................................... 6.1

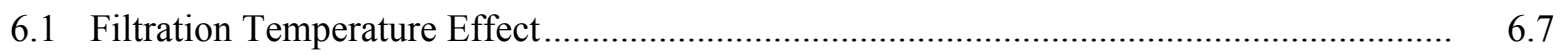

6.1.1 Initial Slurry Dewatering......................................................................... 6.7

6.1.2 Post-Caustic Leaching Dewatering ....................................................................... 6.9

6.1.3 Post-Caustic Leach Washing and Dewatering ................................................... 6.11

6.1.4 Oxidative Leach Washing and Dewatering ........................................................ 6.15

6.1.5 Filtration Temperature Effect Conclusions ............................................................. 6.18

6.2 Simulant Production Scale Up ........................................................................... 6.19

6.2.1 Initial Slurry Dewatering.............................................................................. 6.21

6.2.2 Post-Caustic Leach Dewatering .................................................................... 6.23

6.2.3 Caustic Leach Washing and Dewatering........................................................ 6.25

6.2.4 Chromium Slurry Addition ......................................................................... 6.27

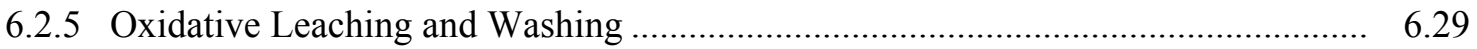

6.2.6 Vendor Simulant Production Conclusions ......................................................... 6.32

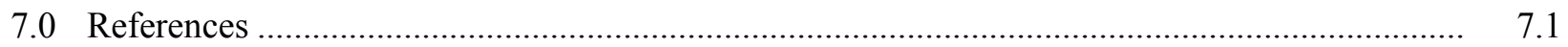

Appendix A: Recipe for Simulant Preparation …................................................................... A.1

Appendix B: Summary of Centrifugation Test Data................................................................... B. 1

Appendix C: Rheology Measurement Methods ........................................................................... C.1

Appendix D: Letters of Request for Approval for Test Plan Hold Points ........................................ D. D. 


\section{Figures}

1.1. Components of Blended Simulant

1.2. Example of a Dewatering Curve at a Constant Transmembrane Pressure (TMP) and Axial Velocity (AV).....

2.1. Crossflow Ultrafiltration Element ................................................................................. 2.2

2.2. Crossflow Ultrafiltration Assembly Sketch (Not to Scale) ...................................................... 2.2

2.4. Crossflow Ultrafiltration Assembly ................................................................................... 2.3

2.5. Piping Diagram of Crossflow Ultrafiltration Testing Apparatus (Not to Scale) ....................... 2.3

2.6. Crossflow Ultrafiltration Testing Apparatus ................................................................... 2.4

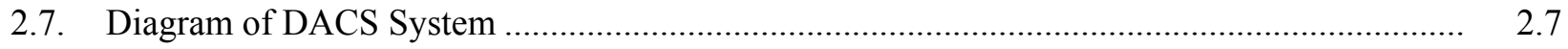

2.8. Digital Images of DACS Display Windows ...................................................................... 2.8

2.9. Example of a Dewatering Curve at a Constant TMP and AV ............................................. 2.12

2.10. Flowsheet of Filtration Simulant Preparation.................................................................... 2.14

3.1. Measured Wt\% Solids of Tank Waste Samples Centrifuged at $1000 \mathrm{G}$ for 30 Minutes........... 3.4

3.2. Simulant Slurry Wt\% UDS after Centrifugation at $1000 \mathrm{G}$ for 30 Minutes (see Table 3.3 for slurry compositions) ................................................................................................. 3.5

3.3. Centrifugation Results for the Centrifuge Simulants (see Table 3.3 for slurry compositions)... 3.5

3.4. Observed Effect of Indicated Variables on Centrifuged Solids Volume in Response to Centrifugation at $1000 \mathrm{G}$ for Samples in Table 3.3 ............................................................. 3.6

3.5. Wt\% UDS in Settled Slurry Simulant as a Function of Centrifuge Generated Compaction Pressure for Crossflow Ultrafiltration Slurry Simulants \#7, \#8, and \#10 ................................ 3.7

4.1. Example of No Effect of Sonication on P2 Slurry with Fines............................................... 4.5

4.2. Example of Agglomerate Disruption by Sonication of Dewatered P3 Slurry .......................... 4.5

4.3. Example of Agglomerate Formation by Sonication of Final P3 Slurry .................................. 4.6

4.4. Test C1b — Leached Slurry Simulant \#8: Permeate Flux vs. Wt\% UDS ….............................. 4.7

4.5. Test P3b - Inert Sludge Solids Simulant \#10: Permeate Flux vs. Wt\% UDS ......................... 4.8

4.6. Initial Feed Simulant \#7: Permeate Flux vs. Wt\% UDS .....................................................

4.7. Low-Solids Filter Flux for Simulant \#7 (Test P4a) Initial Feed Based on Table 2.1 ............... 4.10

4.8. Low-Solids Filter Flux for Simulant \#7 (Test P5) with $\mathrm{d}_{5}$ Fines Addition Based on

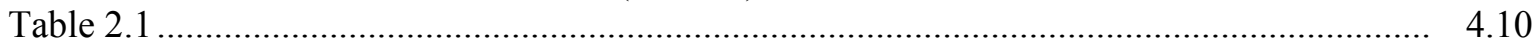

4.9. Low-Solids Filter Flux for Simulant \#7 (Test P6a) with $d_{10}$ Fines Addition Based on

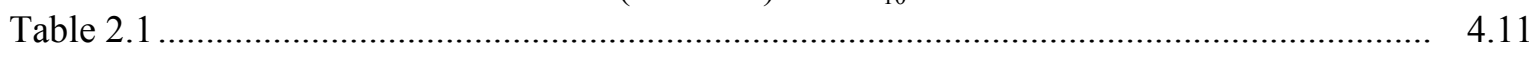

4.10. Low-Solids Filter Flux for Simulant \#8 (Test C1a) with Leached Solids Based on Table 2.1

4.11. Low-Solids Filter Flux for Simulant \#8 (Test P1) with $\mathrm{d}_{5}$ Fines Addition Based on Table 2.1

4.12. Low-Solids Filter Flux for Simulant \#8 (Test P2a) with $d_{10}$ Fines Addition Based on Table 2.1 
5.1. Measured PSDs for the Inert Materials Used in the Fouling Tests ...................................... 5.2

5.2. Testing Scheme for Fines Fouling Tests ........................................................................ 5.3

5.3. Filter Flux of Fe-Rich Slurry With and Without Zirconium Oxide and No Back-Pulsing......... 5.4

5.4. Filter Flux of Fe-Rich Slurry with and Without Zirconium Oxide and Back-Pulsing .............. $\quad 5.5$

5.5. Additional Tests Performed........................................................................................ 5.6

5.6. Filter Flux of Fe-Rich Slurry With and Without $25 \mathrm{Wt} \%$ of the UDS Zirconium Oxide at $25^{\circ} \mathrm{C}$.

5.7. Filter Flux of Fe-Rich Slurry With and Without $25 \mathrm{Wt} \%$ of the UDS Zirconium Oxide with Back-Pulsing at $25^{\circ} \mathrm{C}$

5.8. Filter Flux of Fe-Rich Slurry With and Without $25 \mathrm{Wt} \%$ Zirconium Oxide with BackPulsing at $45^{\circ} \mathrm{C}$.

5.9. Effect of $\mathrm{ZrO}_{2}$ and $\mathrm{Na}_{2} \mathrm{C}_{2} \mathrm{O}_{4}$ on Filter Flux of Fe-Rich Slurry at $25^{\circ} \mathrm{C}$

5.10. Effect of $\mathrm{ZrO}_{2}$ and $\mathrm{Na}_{2} \mathrm{C}_{2} \mathrm{O}_{4}$ on Filter Flux of Fe-Rich Slurry with Back-Pulsing at $25^{\circ} \mathrm{C}$......

5.11. Strontium Carbonate Flux Before and After Fines Testing.

5.12. Flux of $5 \mathrm{Wt} \%$ UDS $\mathrm{Fe}_{2} \mathrm{O}_{3}$ Simulant at $25^{\circ} \mathrm{C}$

6.1. PSD Volume Distribution Showing the Effect of Sonication on CBM-1 .............................. 6.3

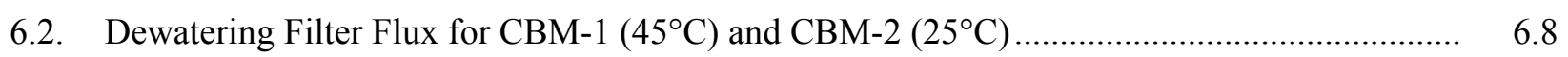

6.3. PSD Volume Distribution of Dewatered CBM-1 and CBM-2 _........................................... 6.9

6.4. Post-Caustic Leaching Dewatering Filter Flux for CBM-1 $\left(45^{\circ} \mathrm{C}\right)$ and CBM-2 $\left(25^{\circ} \mathrm{C}\right) \ldots \ldots \ldots \ldots . \quad 6.10$

6.5. PSD Volume Distribution of Post-Caustic Leaching Dewatered CBM-1 and CBM-2 ............ 6.11

6.6. Caustic Leach Washing Filter Flux at $45^{\circ} \mathrm{C}(\mathrm{CBM}-1)$.......................................................... 6.12

6.7. Caustic Leach Washing Filter Flux at $25^{\circ} \mathrm{C}(\mathrm{CBM}-2)$........................................................ 6.13

6.8. Comparison of Caustic Leach Washing Filter Fluxes at $45^{\circ}(\mathrm{CBM}-1)$ and $25^{\circ} \mathrm{C}(\mathrm{CBM}-2) \ldots \ldots .6 .13$

6.9. PSD Volume Distribution of Post-Caustic Leach Washed CBM-1 and CBM-2 .................... 6.14

6.10. Post-Oxidative Leaching Washing Filter Fluxes at $45^{\circ} \mathrm{C}(\mathrm{CBM}-1)$ and $25^{\circ} \mathrm{C}(\mathrm{CBM}-2) \ldots \ldots \ldots . .6 .15$

6.11. PSD Volume Distribution of Post-Oxidative Leached CBM-1 and CBM-2 …....................... 6.16

6.12. PSD Volume Distribution of Post-Oxidative Leached and Washed (Final) CBM-1 and CBM-2.

6.13. Dewatering Filter Flux for CBM-3, CBM-4, and CBM-5 .............................................. 6.22

6.14. PSD Volume Distribution of CBM-3, CBM-4, and CBM-5 after Dewatering ....................... 6.23

6.15. Post-Caustic Leach Dewatering Filter Flux for CBM-3, CBM-4, and CBM-5 ....................... 6.24

6.16. PSD Volume Distribution of CBM-3, CBM-4, and CBM-5 After Post-Caustic Leach and Dewatering

6.17. Filter Flux During Caustic Leach Washing for CBM-3, CBM-4, and CBM-5 ...................... 6.26

6.18. PSD Volume Distribution of CBM-3, CBM-4, and CBM-5 after Caustic Leach Washing....... 6.27

6.19. Dewatering of Slurry after CrOOH Addition in CBM-3, CBM-4, and CBM-5 ..................... 6.28

6.20. PSD Volume Distribution of CBM-4, and CBM-5 After Chromium Addition and Washing ... 6.29

6.21. PSD Volume Distribution of CBM-3, CBM-4, and CBM-5 After Oxidative Leaching ........... 6.30

6.22. Post-Oxidative Leached Washing of CBM-3, CBM-4, and CBM-5 ................................... 6.31

6.23. PSD Volume Distribution of the Final Slurry from CBM-3, CBM-4, and CBM-5 ................ 6.32 


\section{Tables}

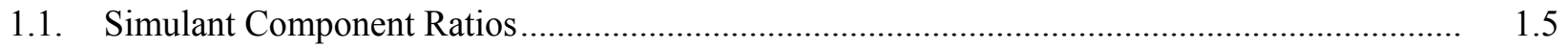

1.2. Complete Leaching Cycle Time Requirements ............................................................... 1.5

2.1. Filtration Test Matrix Operating Conditions ................................................................. 2.10

2.2. Chemical Components Used to Produce Starting Simulant Sludge Solids ............................. 2.15

2.3. Chemical Components Used to Produce Starting Simulant Sodium Aluminosilicate .............. 2.15

2.4. Chemical Components Used to Produce Starting Simulant Supernate ................................... 2.15

3.1. Parameters for the Compressive Yield Strength............................................................... 3.2

3.2. Ultrafiltration Simulant Component Test Ratios ................................................................ 3.3

3.3. Ultrafiltration Simulants for the Screening Test Matrix ....................................................... 3.4

3.4. Averaged Gel Point as a Function of Centrifugal Force....................................................... 3.7

3.5. Results of the PSD Analysis on a Volume Basis for the Centrifuge Simulants ....................... 3.8

3.6. Bingham Plastic Model Fits for the Centrifuge Simulants .................................................... 3.9

4.1. Size of Fines in Actual Tank Waste .................................................................................. 4.1

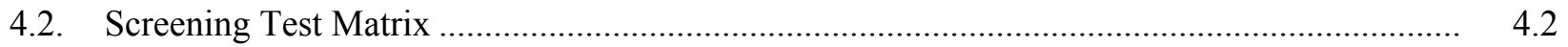

4.3. PSD Analysis for Simulant \#8 and for Proposed $\mathrm{ZrO}_{2}$ Fines ...............................................

4.4. Physical-Property Measurements of the Low-Solids Slurries ............................................... 4.4

5.1. Inert Fines Materials Used in the Crossflow Ultrafiltration Fouling Tests .............................. 5.1

6.1. Filtration Simulant UDS Composition in Grams per kg of UDS ........................................ 6.1

6.2. Compositions of Iron-Rich Sludge Used in the Blended Component Simulant Testing............ $\quad 6.2$

6.3. Physical-Property Measurements of Initial Blended Component Slurries .............................. 6.2

6.4. Results of Rheological Fitting Analysis for Initial Blended Component Slurries.................... 6.3

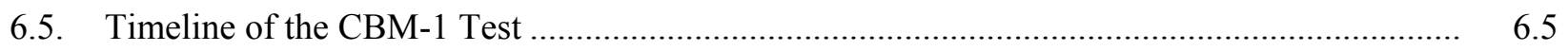

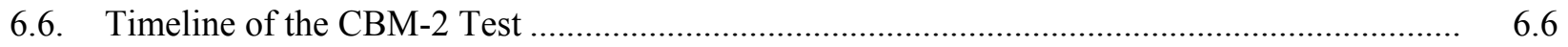

6.7. Physical-Property Measurements of Dewatered Blended Component Slurries ....................... $\quad 6.8$

6.8. Results of Rheological Fitting Analysis for Dewatered Blended Component Slurries ............. $\quad 6.9$

6.9. Physical-Property Measurements of Post-Caustic Leaching Dewatered Blended Component Slurries

6.10. Results of Rheological Fitting Analysis for Post-Caustic Leaching Dewatered Blended Component Slurries

6.11. Caustic Wash Concentrations ....................................................................................... 6.12

6.12. Physical-Property Measurements of Post-Caustic Leach Washed Blended Component Slurries.

6.13. Results of Rheological Fitting Analysis for Post-Caustic Leach Washed Blended Component Slurries

6.14. Physical-Property Measurements of Post-Oxidative Leached Component Slurries.................. 6.16

6.15. Results of Rheological Fitting Analysis for Post-Oxidative Leached Blended Component Slurries 
6.16. Physical-Property Measurements of Post-Oxidative Leached and Washed (Final) Blended Component Slurries

6.17. Timeline of the CBM-3 Test

6.18. Timeline of the CBM-4 Test

6.19. Timeline of the CBM-5 Test

6.20. Physical-Property Measurements of Dewatered Blended Component Slurries

6.21. Results of Rheological Fitting Analysis for Dewatered Blended Component Slurries

6.22. Physical-Property Measurements of Post-Caustic Leached and Dewatered Blended Component Slurries

6.23. Results of Rheological Fitting Analysis for Post-Caustic Leached and Dewatered Blended Component Slurries

6.24. Physical-Property Measurements of Caustic Leached and Washed Blended Component Slurries

6.25. Results of Rheological Fitting Analysis for Caustic Leached and Washed Blended Component Slurries

6.26. Physical-Property Measurements of Chromium Added and Dewatered Blended Component Slurries

6.27. Results of Rheological Fitting Analysis for Chromium Added and Dewatered Blended Component Slurries

6.28. Physical-Property Measurements of Oxidatively Leached Blended Component Slurries

6.29. Results of Rheological Fitting Analysis for Oxidatively Leached Blended Component Slurries.

6.30. Physical-Property Measurements of Final Dewatered Blended Component Slurries 6.31

6.31. Results of Rheological Fitting Analysis for Final Dewatered Blended Component Slurries.....

6.32. Cycle Time Requirements 


\section{Acronyms and Abbreviations}

\begin{tabular}{|c|c|}
\hline AFA & Anti-Foam Agent \\
\hline $\mathrm{AV}$ & Axial Velocity \\
\hline $\mathrm{BNI}$ & Bechtel National, Incorporated \\
\hline CBM & Crossflow Ultrafiltration Blended Matrix Tests \\
\hline DACS & Data Acquisition Collection System \\
\hline DI & De-Ionized \\
\hline DOE & U.S. Department of Energy \\
\hline EFRT & External Flowsheet Review Team \\
\hline HLW & High-Level Waste \\
\hline $\mathrm{ICP}$ & Ion Coupled Plasma \\
\hline IRP & Issue Response Plan \\
\hline ITR & Internal Technical Review \\
\hline LAW & Low-Activity Waste \\
\hline M\&TE & Measuring and Test Equipment \\
\hline NAS & Sodium Aluminosilicate \\
\hline PEP & Pretreatment Engineering Platform \\
\hline PNNL & Pacific Northwest National Laboratory \\
\hline PSD & Particle-Size Distribution \\
\hline psid & Pounds per Square Inch-Differential \\
\hline psig & Pounds per Square Inch-Gauge \\
\hline PTF & Pretreatment Facility \\
\hline QA & Quality Assurance \\
\hline QAM & Quality Assurance Manual \\
\hline QAP & Quality Assurance Plan \\
\hline
\end{tabular}


QARD

$\mathrm{R} \& \mathrm{~T}$

RPP-WTP

RTD

SBMS

SEM

SIPP

SWRI

TMP

UDS

WTP

XRD
Quality Assurance Requirements and Description (document)

Research \& Technology

River Protection Project-Hanford Tank Waste Treatment and Immobilization Plant Support Program

Resistance Temperature Detector

Standards-Based Management System

Scanning Electron Microscope

Semi-Integrated Pilot Plant

Southwest Research Institute

Transmembrane Pressure

Undissolved Solids

Hanford Tank Waste Treatment and Immobilization Plant

X-Ray Diffraction 


\section{Testing Summary}

According to Bechtel National, Inc. (BNI) Test Specification 24590-PTF-TSP-RT-06-006, Rev. 0, "Simulant Development to Support the Development and Demonstration of Leaching and Ultrafiltration Pretreatment Processes," simulants for boehmite, gibbsite, and filtration are to be developed that can be used in subsequent bench and integrated testing of the leaching/filtration processes for the Hanford Tank Waste Treatment and Immobilization Plant (WTP). These simulants will then be used to demonstrate the leaching process and to help refine processing conditions that may impact safety-basis considerations (Smith 2006). This report documents the results of the filtration simulant development completed in accordance with the test plan TP-RPP-WTP-469, Rev. 0 (Russell and Smith 2007) (WTP Doc. No. 24590-101-TSA-W000-0004-182-00001, Rev. 00A) prepared and approved in response to the cited test specification. Note that the development of the boehmite and gibbsite simulants is covered in separate reports. Report WTP-RPT-176 covers gibbsite simulant development, and report WTP-RPT-184 covers boehmite simulant development.

This report also includes the results of the filter fouling with fines particles performed in accordance with the test plan TP-RPP-WTP-509, Rev. 0 (Daniel and Shimskey 2007) (WTP Doc. No. 24590-101-TSAW000-0004-72-00019, Rev. 00A) prepared and approved in response to Test Specification 24590-WTPTSP-RT-07-004, Rev. 0 (Sundar 2007).

\section{Objective}

The test objectives for the work addressed in TP-RPP-WTP-469, Rev. 0 (Russell and Smith 2007) are summarized in Table S.1 along with a discussion of how the objectives were met. The overall objective of the work described in this report was to develop a filtration simulant that appropriately mimics the performance of the actual waste for use in subsequent testing and to provide a technical performance basis for the use of this simulant.

The test objectives for the work addressed in TP-RPP-WTP-509, Rev. 0 (Daniel and Shimskey 2007) are summarized in Table S.2 along with a discussion of how the objectives were met. The overall objective of the work from the test plan described in this report was to determine the filter fouling effect of the fineparticle fraction of the simulant.

Table S.1. Test Objectives from TP-RPP-WTP-469, Rev. 0

\begin{tabular}{||l|c|l||}
\hline Test Objective & $\begin{array}{c}\text { Objective } \\
\text { Met? (Y/N) }\end{array}$ & Discussion \\
\hline $\begin{array}{l}\text { 1) } \\
\begin{array}{l}\text { Develop and characterize a } \\
\text { gibbsite component simulant for } \\
\text { testing aluminum leaching and } \\
\text { provide a basis for the selected } \\
\text { simulant. }\end{array}\end{array}$ & NA & $\begin{array}{l}\text { This objective was addressed in report WTP-RPT- } \\
176, \text { Rev. 0. }\end{array}$ \\
\hline
\end{tabular}


Table S.1 (Contd)

\begin{tabular}{|c|c|c|}
\hline Test Objective & $\begin{array}{c}\text { Objective } \\
\text { Met? (Y/N) }\end{array}$ & Discussion \\
\hline $\begin{array}{l}\text { 2) Develop and characterize a } \\
\text { boehmite component simulant for } \\
\text { testing aluminum leaching and } \\
\text { provide a basis for the selected } \\
\text { simulant. }\end{array}$ & NA & $\begin{array}{l}\text { This objective was addressed in report WTP-RPT- } \\
184 \text {, Rev. } 0 \text {. }\end{array}$ \\
\hline $\begin{array}{l}\text { 3) Develop and characterize inert } \\
\text { ultrafiltration component } \\
\text { simulant(s) for testing the } \\
\text { ultrafiltration system and provide a } \\
\text { basis for the selected simulant(s), } \\
\text { which may include high and low } \\
\text { viscosity simulants. Also, methods } \\
\text { to adjust the filtration behavior will } \\
\text { be tested in an attempt to develop } \\
\text { simulants with various } \\
\text { compositions to accurately show } \\
\text { the variation in filter flux. }\end{array}$ & Y & $\begin{array}{l}\text { This was accomplished by testing several different } \\
\text { combinations of simulant components for } \\
\text { centrifuged solids and crossflow ultrafiltration and } \\
\text { dewatering properties as described in Sections } 3.0 \\
\text { and 4.0. }\end{array}$ \\
\hline $\begin{array}{l}\text { 4) Provide a blended simulant } \\
\text { procedure for use in Phase } 1 \\
\text { integrated demonstration unit } \\
\text { testing and demonstrate that the } \\
\text { behavior of the blended } \\
\text { components is equivalent (or } \\
\text { correlated) with the behavior of the } \\
\text { individual components. The } \\
\text { Phase } 1 \text { integrated demonstration } \\
\text { waste simulant will possess } \\
\text { characteristic chemical } \\
\text { components and physical } \\
\text { properties of a representative waste } \\
\text { that would be processed in the } \\
\text { WTP as identified from the EFRT } \\
\text { issue M4 resolution team. }\end{array}$ & Y & $\begin{array}{l}\text { The behavior of the blended simulant was } \\
\text { demonstrated by performing several crossflow } \\
\text { ultrafiltration process tests, which included } \\
\text { dewatering, caustic leaching, washing, oxidative } \\
\text { leaching, washing, and a final dewatering as } \\
\text { described in Section 6.0. The procedure for } \\
\text { preparing the filtration simulant, as well as the } \\
\text { blended simulant, is given in Appendix A. }\end{array}$ \\
\hline $\begin{array}{l}\text { 5) Evaluate available data to identify } \\
\text { other potential candidate simulants } \\
\text { that may be necessary to be } \\
\text { developed during Stage } 2 \text { of the } \\
\text { simulant development work for full } \\
\text { evaluation of the } \\
\text { leaching/ultrafiltration } \\
\text { performance. This would be due } \\
\text { to the identification of an } \\
\text { additional physical or chemical } \\
\text { property that was found to be } \\
\text { fundamental to the process. }\end{array}$ & $\mathrm{N}$ & This activity has not yet been performed. \\
\hline
\end{tabular}


Table S.2. Test Objectives from TP-RPP-WTP-509, Rev. 0

\begin{tabular}{|c|c|c|}
\hline Test Objective & $\begin{array}{c}\text { Objective } \\
\text { Met? (Y/N) }\end{array}$ & Discussion \\
\hline $\begin{array}{l}\text { Determine the effect of initial } \\
\text { aluminate ion concentration on } \\
\text { the rate of boehmite leaching in } \\
\text { caustic solutions and in the } \\
\text { presence of soluble anions in a } \\
\text { waste. The anions to be } \\
\text { considered are those that are } \\
\text { typically present in the Hanford } \\
\text { Tank Farm wastes in significant } \\
\text { amounts. This includes } \\
\text { carbonate, free-hydroxide, nitrate, } \\
\text { nitrite, oxalate, phosphate, and } \\
\text { sulfate. }\end{array}$ & NA & $\begin{array}{l}\text { This objective was addressed in report WTP-RPT- } \\
184 \text {, Rev. } 0 \text {. }\end{array}$ \\
\hline $\begin{array}{l}\text { Determine the sensitivity of the } \\
\text { rate of dissolution of boehmite to } \\
\text { soluble anions through a limited } \\
\text { number of laboratory tests. The } \\
\text { anions to be considered are those } \\
\text { that are typically present in the } \\
\text { Hanford Tank Farm wastes in } \\
\text { significant amounts. This } \\
\text { includes carbonate, free- } \\
\text { hydroxide, nitrate, nitrite, oxalate, } \\
\text { phosphate, and sulfate. }\end{array}$ & NA & $\begin{array}{l}\text { As of March 20, 2008, Pacific Northwest National } \\
\text { Laboratory (PNNL) has been released from this } \\
\text { objective by Test Exception, } 24590 \text {-WTP-TEF-RT- } \\
07-00016 \text {. }\end{array}$ \\
\hline $\begin{array}{l}\text { 3) Determine the effect of scaling the } \\
\text { length of the ultrafilter element } \\
\text { from } 2 \mathrm{ft} \text { to } 8 \mathrm{ft} \text { on the filtrate flux } \\
\text { over the expected operating range } \\
\text { of the ultrafilter using the } \\
\text { crossflow ultrafiltration unit. }\end{array}$ & NA & $\begin{array}{l}\text { This objective was addressed in report WTP-RPT- } \\
\text { 168, Rev. } 0 \text {. }\end{array}$ \\
\hline $\begin{array}{l}\text { 4) Use an 8-ft-long filter element in } \\
\text { the crossflow ultrafiltration unit to } \\
\text { determine the effect of } \\
\text { temperature on the filtration of a } \\
\text { waste simulant over the range of } \\
\text { temperature conditions for the } \\
\text { leaching processes. }\end{array}$ & NA & $\begin{array}{l}\text { This objective was addressed in report WTP-RPT- } \\
\text { 168, Rev. } 0 \text {. }\end{array}$ \\
\hline
\end{tabular}


Table S.2 (Contd)

\begin{tabular}{|c|c|c|c|}
\hline \multicolumn{2}{|c|}{ Test Objective } & \multirow{2}{*}{$\begin{array}{c}\begin{array}{c}\text { Objective } \\
\text { Met? (Y/N) }\end{array} \\
\mathrm{Y}\end{array}$} & \multirow[b]{2}{*}{ 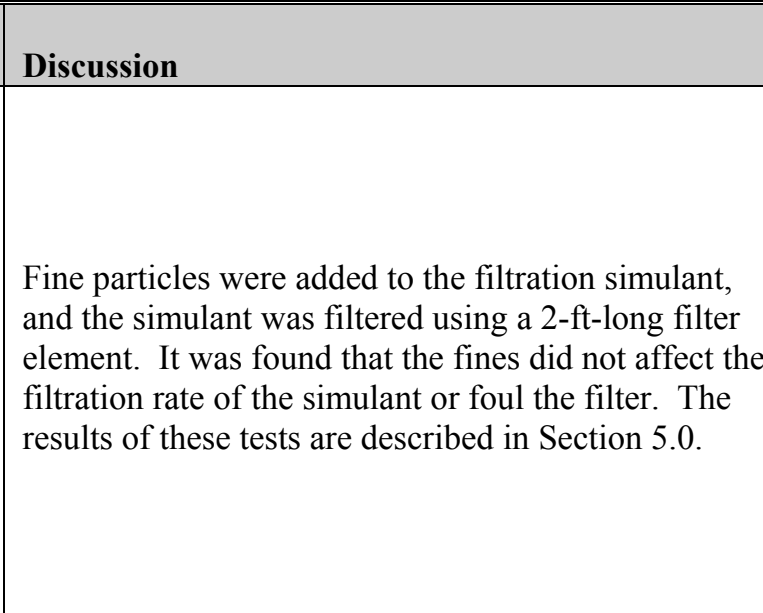 } \\
\hline & $\begin{array}{l}\text { Use a 2-ft-long filter element in } \\
\text { the crossflow ultrafiltration unit to } \\
\text { evaluate the effect of the fine- } \\
\text { particle fraction in the } \\
\text { ultrafiltration simulant on fouling } \\
\text { of the filter element over the } \\
\text { range of concentrations of } \\
\text { operating solids. The fine-particle } \\
\text { fraction is defined as those } \\
\text { particles with diameters smaller } \\
\text { than the } 10^{\text {th }} \text { percentile (i.e., the } \\
\text { dp10) of the particle-size number } \\
\text { distribution. }\end{array}$ & & \\
\hline 6) & $\begin{array}{l}\text { Perform various simulant aging } \\
\text { tests to understand the changes } \\
\text { that may occur to the simulant in } \\
\text { storage and to make sure that the } \\
\text { simulant is adequate for use in the } \\
\text { Pretreatment Engineering } \\
\text { Platform (PEP). }\end{array}$ & NA & $\begin{array}{l}\text { These results will be presented in a letter report that } \\
\text { is yet to be released. }\end{array}$ \\
\hline & $\begin{array}{l}\text { Perform Cr-simulant leaching } \\
\text { tests to establish that the Cr- } \\
\text { simulant from the larger batch } \\
\text { exhibits similar or better leaching } \\
\text { behavior than the initial trial batch } \\
\text { during caustic and oxidative } \\
\text { leaching operations. }\end{array}$ & NA & $\begin{array}{l}\text { These results will be presented in a report that is yet } \\
\text { to be released. }\end{array}$ \\
\hline 8) & $\begin{array}{l}\text { Perform leaching tests to } \\
\text { determine the mass loss, and } \\
\text { aluminum and chromium } \\
\text { dissolution rates during caustic } \\
\text { leaching under varying } \\
\text { temperature processing conditions } \\
\text { without aeration in both UFP- } \\
1 \mathrm{~A} / \mathrm{B} \text { and UFP-2A/B vessels as } \\
\text { well as to measure the effect of } \\
\text { aeration on chromium leaching in } \\
\text { UFP-2A/B. }\end{array}$ & NA & $\begin{array}{l}\text { These results will be presented in a report that is yet } \\
\text { to be released. }\end{array}$ \\
\hline 9) & $\begin{array}{l}\text { Perform leaching tests to develop } \\
\text { an accurate model for the } \\
\text { dissolution of boehmite. }\end{array}$ & NA & $\begin{array}{l}\text { These results will be presented in a report that is yet } \\
\text { to be released. }\end{array}$ \\
\hline & $\begin{array}{l}\text { Perform leaching tests to verify } \\
\text { the effect of aluminate ions on the } \\
\text { performance of the boehmite } \\
\text { component B3 during caustic } \\
\text { leach at temperatures lower than } \\
100^{\circ} \mathrm{C} \text { and to determine the effect } \\
\text { of temperature on the dissolution } \\
\text { rate of boehmite component } \mathrm{B} 7 \text {. }\end{array}$ & NA & $\begin{array}{l}\text { These results will be presented in a report that is yet } \\
\text { to be released. }\end{array}$ \\
\hline
\end{tabular}


Table S.2 (Contd)

\begin{tabular}{||l|c|l||}
\hline Test Objective & $\begin{array}{c}\text { Objective } \\
\text { Met? (Y/N) }\end{array}$ & Discussion \\
\hline 11) $\begin{array}{l}\text { Perform leaching tests to } \\
\text { determine the extent of boehmite } \\
\text { conversion one would expect } \\
\text { under leaching conditions during } \\
\text { the planned testing in PEP. }\end{array}$ & NA & $\begin{array}{l}\text { These results will be presented in a report that is yet } \\
\text { to be released. }\end{array}$ \\
\hline
\end{tabular}

\section{Success Criteria}

This work meets the fourth and fifth of the Success Criteria described in TP-RPP-WTP-469, Rev. 0 (Russell and Smith 2007). How the fourth success criterion was met is listed in Table S.3. This work also meets the fifth success criterion described in TP-RPP-WTP-509, Rev. 0 (Daniel and Shimskey 2007), which is listed in Table S.4. 
Table S.3. Results and Performance against Success Criteria of TP-RPP-WTP-469, Rev. 0

\begin{tabular}{|c|c|}
\hline List Success Criteria & $\begin{array}{l}\text { Explain How the Tests Did or Did Not } \\
\text { Meet the Success Criteria }\end{array}$ \\
\hline $\begin{array}{l}\text { 1. Development of proceduralized recipes that } \\
\text { document each simulant (boehmite, gibbsite, and } \\
\text { ultrafiltration) per "Guideline for R\&T Simulant } \\
\text { Development, Approval, Validation, and } \\
\text { Documentation." }\end{array}$ & $\begin{array}{l}\text { A filtration simulant was chosen based on the AY- } \\
\text { 102/C-106 simulant, and information needed to obtain it } \\
\text { was given in Section 3.0. } \\
\text { The other simulants are addressed in reports WTP-RPT- } \\
\text { 176, Rev. } 0 \text { and WTP-RPT-184, Rev. 0. The evaluation } \\
\text { of the composite simulant to meet the Established } \\
\text { Acceptance Criteria will be documented in a separate } \\
\text { letter report. }\end{array}$ \\
\hline $\begin{array}{l}\text { 2. Development of a gibbsite simulant that has } \\
\text { physical properties-in particular crystal size and } \\
\text { habit-similar to that observed in previous actual } \\
\text { waste samples and the development of a correlation } \\
\text { that predicts the gibbsite simulant dissolution rate as } \\
\text { a function of gibbsite properties, such as crystal size } \\
\text { and habit, as well as other physical properties. }\end{array}$ & $\begin{array}{l}\text { This criterion is addressed in report WTP-RPT-176, } \\
\text { Rev. } 0 .\end{array}$ \\
\hline $\begin{array}{l}\text { 3. Development of a boehmite simulant that has a } \\
\text { dissolution rate-in particular at } 100^{\circ} \mathrm{C}-\text { similar to } \\
\text { that observed in previous actual waste samples and } \\
\text { the development of a correlation that predicts the } \\
\text { simulant boehmite dissolution rate as a function of } \\
\text { system properties of crystal size, crystal habit, } \\
\text { operating temperature, hydroxide concentration, and } \\
\text { mixing conditions. }\end{array}$ & $\begin{array}{l}\text { This criterion is addressed in report WTP-RPT- } 184 \text {, } \\
\text { Rev. } 0 .\end{array}$ \\
\hline $\begin{array}{l}\text { 4. Provide a blended simulant procedure for use in } \\
\text { Phase } 1 \text { integrated demonstration unit testing and } \\
\text { demonstrate that the behavior of the blended } \\
\text { components is equivalent (or correlated) with the } \\
\text { behavior of the individual components. The } \\
\text { Phase } 1 \text { integrated demonstration waste simulant } \\
\text { will possess characteristic chemical components and } \\
\text { physical properties of a representative waste that } \\
\text { would be processed in the WTP as identified from } \\
\text { the External Flowsheet Review Team (EFRT) issue } \\
\text { M4 resolution team. }\end{array}$ & $\begin{array}{l}\text { This success criterion was met by including a simulant } \\
\text { makeup procedure in Appendix A of this report. }\end{array}$ \\
\hline $\begin{array}{l}\text { 5. Evaluate available data to identify other potential } \\
\text { candidate simulants that may be necessary to be } \\
\text { developed during Stage } 2 \text { of the simulant } \\
\text { development work for full evaluation of the } \\
\text { leaching/ultrafiltration performance. This would be } \\
\text { due to the identification of an additional physical or } \\
\text { chemical property that was found to be fundamental } \\
\text { to the process. }\end{array}$ & This criterion is not addressed in this report. \\
\hline
\end{tabular}


Table S.4. Results and Performance against Success Criteria of TP-RPP-WTP-509, Rev. 0

\begin{tabular}{|c|c|}
\hline List Success Criteria & $\begin{array}{l}\text { Explain How the Tests Did or Did Not } \\
\text { Meet the Success Criteria }\end{array}$ \\
\hline $\begin{array}{l}\text { 1. Development of empirical information that allows } \\
\text { determination of the effect of initial aluminate ion } \\
\text { concentration on the kinetics of boehmite leaching } \\
\text { in a waste simulant. }\end{array}$ & $\begin{array}{l}\text { This criterion is addressed in report WTP-RPT- } 184 \text {, } \\
\text { Rev. } 0 .\end{array}$ \\
\hline $\begin{array}{l}\text { 2. Determination of the sensitivity of boehmite } \\
\text { leaching to carbonate, free-hydroxide, nitrate, } \\
\text { nitrite, oxalate, phosphate, and sulfate anions in a } \\
\text { waste-simulant solution. }\end{array}$ & $\begin{array}{l}\text { As of March 20, 2008, PNNL has been released from } \\
\text { this objective by Test Exception, } 24590 \text {-WTP-TEF-RT- } \\
07-00016 \text {. }\end{array}$ \\
\hline $\begin{array}{l}\text { 3. Determination of the effect of scaling the length of } \\
\text { the ultrafilter element from } 2 \mathrm{ft} \text { to } 8 \mathrm{ft} \text { on the } \\
\text { performance of the filter over the expected process } \\
\text { operating range in transmembrane pressure, axial } \\
\text { velocity, and ultrafiltration temperature. }\end{array}$ & $\begin{array}{l}\text { This criterion is addressed in report WTP-RPT- } 168 \text {, } \\
\text { Rev. } 0 .\end{array}$ \\
\hline $\begin{array}{l}\text { 4. Determination of the effect of temperature on the } \\
\text { filtration flux for the waste simulant over the range } \\
\text { of solid concentrations and temperature conditions } \\
\text { for the leaching processes. }\end{array}$ & $\begin{array}{l}\text { This criterion is addressed in report WTP-RPT- } 168 \text {, } \\
\text { Rev. } 0 .\end{array}$ \\
\hline $\begin{array}{l}\text { 5. Determination of the effect of fine-particle } \\
\text { concentration on the propensity of the waste } \\
\text { simulant to foul the ultrafilter element over the } \\
\text { range of concentrations of operating solids in the } \\
\text { waste simulant. }\end{array}$ & $\begin{array}{l}\text { This success criterion was met by testing different } \\
\text { filtration simulants with different amounts of fines } \\
\text { added. It was found that the presence of fines in the } \\
\text { simulant did not affect the filtration rate of the simulant } \\
\text { and did not foul the filter. These results are discussed in } \\
\text { Section } 5.0 \text { of this report. }\end{array}$ \\
\hline
\end{tabular}

\section{Test Exceptions}

Test exception number 24590-WTP-TEF-RT-07-00008 was received from BNI on November 12, 2007. The test plan (TP-RPP-WTP-469, Rev. 0) only allowed for a single test to validate the performance of a blended simulant composition for use in the PEP for process demonstration. This test was carried out at a filtration temperature of $45^{\circ} \mathrm{C}$, as was the oxidative leaching operation. However, filtration temperature in the PEP during process demonstration remained undecided between $45^{\circ} \mathrm{C}$ and $25^{\circ} \mathrm{C}$. Filtration at $45^{\circ} \mathrm{C}$ could potentially lead to post-precipitation of phosphates and other soluble salts if the solution is cooled to $25^{\circ} \mathrm{C}$ before being transferred to the permeate collection vessels UFP-62A/B/C and in the subsequent ion-exchange feed vessel CXP-01. Therefore, a second test to validate the blended simulant composition for PEP process demonstration was performed at $25^{\circ} \mathrm{C}$ with the results discussed in Section 6.0.

\section{Quality Requirements}

PNNL is operated for the U.S. Department of Energy (DOE) by Battelle under Contract DE-AC0576RL01830. PNNL implements a Quality Assurance Program that is based upon the requirements as defined in DOE Order 414.1C, "Quality Assurance," and 10 CFR 830, "Energy/Nuclear Safety Management," Subpart A- "Quality Assurance Requirements." PNNL has chosen to implement the requirements of DOE Order 414.1C and 10 CFR 830, Subpart A by integrating them into the laboratory's management systems and daily operating processes. The procedures necessary to implement the requirements are documented through the laboratory's Standards-Based Management System (SBMS). 
PNNL implemented the RPP-WTP quality requirements by performing work in accordance with the River Protection Project - Waste Treatment Plant Support Program (RPP-WTP) Quality Assurance Plan (RPP-WTP-QA-001, QAP). Work was performed to the quality requirements of NQA-1-1989 Part I, Basic and Supplementary Requirements, NQA-2a-1990, Part 2.7, and DOE/RW-0333P, Rev. 13, Quality Assurance Requirements and Descriptions $(Q A R D)$. These quality requirements were implemented through the RPP-WTP Quality Assurance Manual (RPP-WTP-QA-003, QAM). The analytical requirements are implemented through RPP-WTP's Statement of Work (WTPSP-SOW-005 and RPPWTP-QA-005, respectively) with Southwest Research Institute (SWRI). The requirements of DOE/RW0333P, Rev. 13, Quality Assurance Requirements and Descriptions (QARD), were not required for this work.

A matrix that cross-references the NQA-1 and NQA-2a requirements with RPP-WTP's procedures for this work is given in TP-RPP-WTP-469. It includes justification for those requirements not implemented. Experiments that were not method-specific were performed in accordance with RPP-WTP's procedures QA-RPP-WTP-1101 "Scientific Investigations" and QA-RPP-WTP-1201 "Calibration and Control of Measuring and Testing Equipment" so that sufficient data were taken with properly calibrated measuring and test equipment (M\&TE) to obtain quality results.

RPP-WTP addressed internal verification and validation activities by conducting an independent technical review (ITR) of the final data report in accordance with PNNL's procedure QA-RPP-WTP-604. This review verifies that the reported results were traceable, inferences and conclusions were soundly based, and the reported work satisfied the Test Plan objectives. This review procedure is part of PNNL's RPPWTP QAM.

\section{R\&T Test Conditions}

The research and technology (R\&T) test conditions, as defined in the Test Specifications 24590-PTFTSP-RT-06-006, Rev. $0^{\text {(a) }}$ and 24590-WTP-TSP-RT-07-004, Rev. $0^{\text {(b) }}$ are summarized in Table S.5 and S.6, respectively.

(a) GL Smith. Nov. 2006. Simulant Development to Support the Development and Demonstration of Leaching and Ultrafiltration Pretreatment Processes. 24590-PTF-TSP-RT-06-006, Rev. 0.

(b) PS Sundar. April 2007. Simulant Testing in Support of Phase I Demonstration of the Ultrafiltration and Leaching Processes in the Integrated Test Facility. 24590-WTP-TSP-RT-07-004, Rev. 0. 
Table S.5. R\&T Test Conditions from 24590-PTF-TSP-RT-06-006, Rev. 0

\begin{tabular}{|c|c|}
\hline List R\&T Test Conditions & Were Test Conditions Followed? \\
\hline $\begin{array}{l}\text { 1) Gibbsite Simulant Development- } \\
\text { - Review the available literature and actual waste } \\
\text { testing and characterization data. } \\
\text { - Based on this review, target parameters for the } \\
\text { proposed simulant that will be developed. Note } \\
\text { that the development of these criteria must also } \\
\text { consider the requirements for scaled testing. It } \\
\text { will likely be necessary to develop simulants } \\
\text { with a range of parameters that can be adjusted } \\
\text { to provide a scaled simulant for use in the } \\
\text { integrated test platform. } \\
\text { - Search available vendors and preparation } \\
\text { methods to identify available sources of } \\
\text { boehmite materials. This review will include } \\
\text { identifying available characterization data } \\
\text { associated with each source material and will } \\
\text { recommend which boehmite source materials } \\
\text { should be obtained and tested. This } \\
\text { recommendation should consider the diversity } \\
\text { of both particle size and morphology in } \\
\text { identifying candidate samples for additional } \\
\text { testing. } \\
\text { - Prepare and test the identified boehmite source } \\
\text { materials. It is anticipated that testing will } \\
\text { involve multiple samples over a range of } \\
\text { material properties, including particle size and } \\
\text { morphology. At a minimum, the following } \\
\text { properties will be measured for each gibbsite } \\
\text { source material: } \\
\text { o Particle size } \\
\text { o Surface area } \\
\text { o Crystal pattern by X-ray diffraction (XRD) } \\
\text { o Dissolution rate under a variety of fixed } \\
\text { testing conditions measured under multiple } \\
\text { conditions. Note that sufficient data must be } \\
\text { obtained for selected samples to provide an } \\
\text { adequate description of the reaction-rate } \\
\text { equation. Further note that the temperature } \\
\text { range should be sufficient to provide a range } \\
\text { of behaviors. In addition, sufficient } \\
\text { information, including density and water } \\
\text { ofitity under various test }\end{array}$ & $\begin{array}{l}\text { Not applicable to this report. Results } \\
\text { discussed in WTP-RPT-176. }\end{array}$ \\
\hline
\end{tabular}


Table S.5 (Contd)

\begin{tabular}{|c|c|}
\hline List R\&T Test Conditions & Were Test Conditions Followed? \\
\hline $\begin{array}{l}\text { conditions. } \\
\text { - A correlation will be developed to predict the } \\
\text { dissolution rate as a function of other physical } \\
\text { characteristics. In addition, a boehmite } \\
\text { source-or blend of boehmite sources-will be } \\
\text { selected to best meet the criteria defined in 1). } \\
\text { These results will be compared against the } \\
\text { simulant basis criteria, and an appropriate } \\
\text { method to correlate simulant performance to } \\
\text { actual waste performance will be documented. }\end{array}$ & \\
\hline $\begin{array}{l}\text { 2) Boehmite Simulant Development- } \\
\text { - Review the available literature and actual waste } \\
\text { testing and characterization data. } \\
\text { - Based on this review, target parameters for the } \\
\text { proposed simulant that will be developed. Note } \\
\text { that the development of these criteria must also } \\
\text { consider the requirements for scaled testing. It } \\
\text { will likely be necessary to develop simulants } \\
\text { with a range of parameters that can be adjusted } \\
\text { to provide a scaled simulant for use in the } \\
\text { integrated test platform. } \\
\text { - Search available vendors and preparation } \\
\text { methods to identify available sources of } \\
\text { boehmite materials. This review will include } \\
\text { identifying available characterization data } \\
\text { associated with each source material and will } \\
\text { recommend which boehmite source materials } \\
\text { should be obtained and tested. This } \\
\text { recommendation should consider the diversity } \\
\text { of both particle size and morphology in } \\
\text { identifying candidate samples for additional } \\
\text { testing. } \\
\text { - Prepare and test the identified boehmite source } \\
\text { materials. It is anticipated that testing will } \\
\text { involve multiple samples over a range of } \\
\text { material properties, including particle size and } \\
\text { morphology. At a minimum, the following } \\
\text { properties will be measured for each boehmite } \\
\text { source material: } \\
\text { o Particle size } \\
\text { o Surface area } \\
\text { o Crystal pattern by XRD } \\
\text { o Dissolution rate under a variety of fixed } \\
\text { testing conditions measured under multiple } \\
\text { conditions. Note that sufficient data must be } \\
\text { obtained for selected samples to provide an } \\
\text { adequate description of the reaction-rate }\end{array}$ & $\begin{array}{l}\text { Not applicable to this report. Results } \\
\text { discussed in WTP-RPT- } 184 \text {. }\end{array}$ \\
\hline
\end{tabular}


Table S.5 (Contd)

\begin{tabular}{|c|c|}
\hline List R\&T Test Conditions & Were Test Conditions Followed? \\
\hline $\begin{array}{l}\text { equation. Further note that the temperature } \\
\text { range should be sufficient to provide a range } \\
\text { of behaviors. In addition, sufficient } \\
\text { information, including density and water } \\
\text { content, should be obtained to provide } \\
\text { meaningful correlation to actual waste } \\
\text { samples. } \\
\text { - Equilibrium solubility under various test } \\
\text { conditions. } \\
\text { - A correlation will be developed to predict the } \\
\text { dissolution rate as a function of other physical } \\
\text { characteristics. In addition, a boehmite } \\
\text { source-or blend of boehmite sources-will be } \\
\text { selected to best meet the criteria defined in 1). } \\
\text { These results will be compared against the } \\
\text { simulant basis criteria, and an appropriate } \\
\text { method to correlate simulant performance to } \\
\text { actual waste performance will be documented. }\end{array}$ & \\
\hline $\begin{array}{l}\text { 3) Filtration Simulant Development- } \\
\text { - Review the available literature and actual waste } \\
\text { testing and characterization data. Based on this } \\
\text { review, target parameters for the proposed } \\
\text { simulant will be developed. } \\
\text { - Search available preparation methods to identify } \\
\text { available sources of filtration simulant } \\
\text { materials. This review includes identification of } \\
\text { available characterization data associated with } \\
\text { each source material and will provide } \\
\text { recommendations for which filtration source } \\
\text { materials should be obtained and tested. This } \\
\text { task also evaluates whether existing preparation } \\
\text { methods should be modified to meet the target } \\
\text { parameters and whether selected components } \\
\text { from various vendors/preparation methods } \\
\text { should be blended for evaluation. } \\
\text { - Prepare and test the identified filtration simulant } \\
\text { source materials. It is anticipated that testing } \\
\text { will involve multiple samples over a range of } \\
\text { material properties. }\end{array}$ & $\begin{array}{l}\text { Based on the WTP model runs, a target } \\
\text { cycle time, and by inference, a target filter } \\
\text { flux was established to be } 0.011 \mathrm{gpm} / \mathrm{ft}^{2} \text {. } \\
\text { This is described in Section } 1.2 \text {. } \\
\text { Existing literature was reviewed, and a } \\
\text { previously developed filtration simulant } \\
\text { based on AY-102/C-106 tank waste } \\
\text { (Zamecnik et al. 2004) was chosen for } \\
\text { further development. This is described in } \\
\text { Section } 2.3 \text {. } \\
\text { Several different filtration simulants, using } \\
\text { different ratios of components, were tested } \\
\text { over a range of material properties to } \\
\text { determine how well they centrifuged. This } \\
\text { indicated how well they would filter. A } \\
\text { range of simulants was then chosen to } \\
\text { perform filtration testing. It was found that } \\
\text { there was a correlation in the centrifuge } \\
\text { behavior and the filtration behavior of the } \\
\text { simulants. }\end{array}$ \\
\hline
\end{tabular}


Table S.6. R\&T Test Conditions from 24590-WTP-TSP-RT-07-004, Rev. 0

\begin{tabular}{|c|c|}
\hline List R\&T Test Conditions & Were Test Conditions Followed? \\
\hline $\begin{array}{l}\text { 1) Boehmite Dissolution Tests-examine the impact of } \\
\text { aluminate, hydroxide, and other principal anions on } \\
\text { boehmite dissolution kinetics. }\end{array}$ & $\begin{array}{l}\text { Not applicable to this report. Results } \\
\text { discussed in WTP-RPT-184. }\end{array}$ \\
\hline $\begin{array}{l}\text { 2) Boehmite Dissolution Tests - verify the effect of } \\
\text { temperature on the dissolution of boehmite component } \\
\text { B7 and verify the effect of aluminate ion on the } \\
\text { performance of the boehmite component } \mathrm{B} 3 \text { during } \\
\text { caustic leach at temperatures lower than } 100^{\circ} \mathrm{C} \text {. }\end{array}$ & $\begin{array}{l}\text { Not applicable to this report. It will be } \\
\text { addressed in a future report. }\end{array}$ \\
\hline $\begin{array}{l}\text { 3) Boehmite Dissolution Tests - provide greater } \\
\text { discrimination on anion impact by performing tests } \\
\text { under a greater range of anion concentrations. }\end{array}$ & $\begin{array}{l}\text { Not applicable to current testing. PNNL } \\
\text { was released from this requirement by Test } \\
\text { Exception } 24590-\text { WTP-TEF-RT-07-00016. }\end{array}$ \\
\hline $\begin{array}{l}\text { 4) Filtration Tests - test a base simulant under identical } \\
\text { process conditions with } 2 \text { - } \mathrm{ft} \text { and } 8 \text {-ft filter elements. }\end{array}$ & $\begin{array}{l}\text { Not applicable to this report. Results } \\
\text { discussed in WTP-RPT-168. }\end{array}$ \\
\hline $\begin{array}{l}\text { 5) Filtration Tests-increase the fines loading in filtration } \\
\text { test base simulant to evaluate the impact of fouling on } \\
\text { filtration performance. }\end{array}$ & $\begin{array}{l}\text { Tests with differing amounts of fines } \\
\text { loading in the filtration simulant were } \\
\text { evaluated for impact of fouling on filtration } \\
\text { performance. It was found that there was no } \\
\text { effect on fouling and filtration rate with } \\
\text { fines added to the waste. This is described } \\
\text { in Section 5.0. }\end{array}$ \\
\hline $\begin{array}{l}\text { 6) Filtration Tests - use an 8-ft filter element to measure } \\
\text { the filtration rate as a function of temperature up to } 45^{\circ} \mathrm{C} \\
\text { for the base filtration simulant. }\end{array}$ & $\begin{array}{l}\text { Not applicable to this report. Results } \\
\text { discussed in WTP-RPT-168. }\end{array}$ \\
\hline $\begin{array}{l}\text { 7) Aging Tests-will be performed in the } 250 \text {-gal tote and } \\
\text { a } 1 \text {-gal container in the laboratory, a container in a heat- } \\
\text { cycled oven, and a baffled } 1 \text {-gal container that is mixed } \\
\text { in the laboratory. Samples will be taken throughout the } \\
\text { tests and characterized by particle-size distribution, } \\
\text { settling, rheology, and centrifuged-solids content to } \\
\text { evaluate the effect of aging on the behavior of the } \\
\text { simulant. }\end{array}$ & $\begin{array}{l}\text { Not applicable to this report. It will be } \\
\text { addressed in a future report. }\end{array}$ \\
\hline $\begin{array}{l}\text { 8) Chromium Simulant Leaching Tests-will be performed } \\
\text { with both a caustic leach and an oxidative leach to } \\
\text { evaluate the leaching performance of the various vendor } \\
\text { batches of Cr-simulant. }\end{array}$ & $\begin{array}{l}\text { Not applicable to this report. It will be } \\
\text { addressed in a future report. }\end{array}$ \\
\hline $\begin{array}{l}\text { 9) PEP Leaching Support Tests-are to be carried out with } \\
\text { the vendor-produced } 250 \text {-gal batch of the PEP simulant } \\
\text { and the vendor-produced CrOOH Test Batch } 1 \text { simulant } \\
\text { slurry. The tests are directed to determine the mass loss } \\
\text { and aluminum and chromium dissolution rates during } \\
\text { caustic leaching under varying temperature processing } \\
\text { conditions without aeration in both UFP-1A/B and UFP- } \\
\text { 2A/B vessels as well as to measure the effect of aeration } \\
\text { on chromium leaching in UFP-2A/B. }\end{array}$ & $\begin{array}{l}\text { Not applicable to this report. It will be } \\
\text { addressed in a future report. }\end{array}$ \\
\hline $\begin{array}{l}\text { 10) PEP Leaching Support Tests-will be performed using } \\
\text { a vendor-produced } 250 \text {-gal batch of the PEP simulant. } \\
\text { The tests are directed to measure the extent of boehmite } \\
\text { conversion expected under leaching conditions during } \\
\text { the planned testing in the PEP. }\end{array}$ & $\begin{array}{l}\text { Not applicable to this report. It will be } \\
\text { addressed in a future report. }\end{array}$ \\
\hline
\end{tabular}




\section{Simulant Use}

The use of actual Hanford tank waste in the PEP is not possible because of safety, cost, and volume. To address the need for demonstration of separation and leaching processes at PEP, PNNL developed a waste simulant that mimics the chemical, leaching, and ultrafiltration behaviors of actual tank waste according to Test Plan TP-RPP-WTP-469. The development of the filtration portion of this simulant is described in this report. The reasoning behind the simulant composition, a comparison of it to the actual tank waste, and a description of it are described in this report.

\section{Discrepancies and Follow-on Tests}

None. 



\subsection{Introduction}

After separating the high-level waste (HLW) from the low activity waste (LAW) liquid stream by ultrafiltration in the Pretreatment Facility (PTF), the concentrated HLW will undergo caustic and oxidative leaching processes to dissolve and wash out materials that would otherwise limit HLW loading in the immobilized waste glass (aluminum, chromium, phosphates, and sulfates). The current design calls for the leaching processes to be carried out in the ultrafiltration process vessels (UFP-1a, UPF-1b, UFP-2a and UFP-2b). The concentrated HLW solids are sequentially caustic leached, washed, and oxidatively leached, if required, and then washed once more during pretreatment. The caustic leaching dissolves the aluminum in the HLW solids, while the oxidative leaching oxidizes the chromium with sodium permanganate $\left(\mathrm{NaMnO}_{4}\right)$ in a mild caustic solution. The HLW solids are concentrated after each leach and washed using the crossflow ultrafiltration system.

In October 2005, a team of experts from industry, national laboratories, and universities (referred to as the External Flowsheet Review Team or EFRT) was assembled by Bechtel National, Inc. (BNI) to conduct a thorough and critical review of the process flowsheet for the design of the Hanford Tank Waste Treatment and Immobilization Plant (WTP). Among the several issues the EFRT identified from the critical review of the process flowsheet (Lucas 2006; CCN 132846 2006; CCN 132847 2006), the following are considered relevant to work reported here.

- Issue M4: It has not been demonstrated that the WTP's design is sufficiently flexible to reliably process all of the Hanford tank farm wastes at design throughputs.

- Issue M6: Many of the process operating limits have not been defined. Further testing is required to define process limits for WTP unit operations. Without this more complete understanding of each process, it will be difficult or impossible to define a practical operating range for each unit operation.

- Issue M12: Neither the caustic leaching nor the oxidative leaching process has been demonstrated at greater than bench-scale size. The small-scale experiments are capable of defining the leaching chemistry. However, they are limited in their capability to predict the effectiveness of these processes without a scale-up demonstration.

- Issue M13: For wastes requiring leaching, a combination of inadequate filter flux and area will likely limit throughput to the HLW or LAW vitrification facilities.

This report addresses a portion of the work required for the resolution of Issue M12. This work developed ultrafiltration simulants that can be used in the laboratory and in the integrated demonstration testing portion in Tasks 4 and 5 of the M-12 EFRT issue response plan (Barnes and Voke 2006). This work interfaces with the responses being developed to resolve the other issues cited. For instance, the test plan (TP-RPP-WTP-469, Rev. 0) draws on the establishment of the ultrafilter specifications in response to Issue M13. The requirements to define the simulant are specified in Section 3.3.3 of the M12 Issue Response Plan (IRP). This report provides important data needed to prepare a blended simulant to meet those performance targets.

The simulant development approach is based on the development of component simulants that can be blended to form a wide variety of filtration simulants. The simulant components are shown in Figure 1.1. Note that the "inert solids component" is principally an iron oxyhydroxide slurry with other metal oxides also present. The selection and preparation of these components are described in the reports identified. 
Filtration Simulant Components

\begin{tabular}{l}
$\begin{array}{l}\text { Gibbsite Component from } \\
\text { WTP-RPT-176 }\end{array}$ \\
\begin{tabular}{|l|}
\hline Boehmite Component \\
from WTP-RPT-184
\end{tabular} \\
\hline $\begin{array}{l}\text { Chromium Component } \\
\text { from WTP-RPT-164 }\end{array}$ \\
\hline
\end{tabular}

Inert Solids Component
from this report:
WTP-RPT-183

Water soluble component

Oxalate

Other components to be
added at a later date
e.g., phosphate

Figure 1.1. Components of Blended Simulant

A fundamental premise is that this approach would allow blending of the different components to simulate a wide variety of feeds to be treated in the WTP. For example, a given feed from the planned feed vector could be selected, and the appropriate components would then be blended to achieve a representation of that particular feed. Using the blending of component simulants allows the representation of a much broader spectrum of potential feeds in the Pretreatment Engineering Platform (PEP).

BNI plans to carry out process development and scale-up testing using the PEP to demonstrate the design effectiveness of both the caustic and the oxidative leaching processes over the entire applicable range of Hanford tank farm wastes (Lucas 2006). Scale-up testing will require substantial volumes of feed. Therefore, it was necessary to develop simulants that mimic the chemical, leaching, and ultrafiltration behaviors for actual waste groups over the range observed for the process development and demonstration. The leaching and filtration performance data obtained from actual waste testing served as benchmarks for defining simulant characteristics and behaviors and as a basis for revising the parameters used in evaluating WTP process performance using the appropriate process models.

\subsection{Simulant Development Strategy}

The simulant development strategy was based on a two-phased approach. The first phase included simulant development and the validation of initial single-component chemical and physical simulants for boehmite, gibbsite, chromium, and filtration. The data obtained from actual waste testing (TP-RPP-WTP467, Rev. 1) served as benchmarks for defining the simulant characteristics and behaviors to develop chemical, rheological, and physical simulants that more closely simulate actual waste. They also serve as 
a basis for revising the parameters used in evaluating WTP process performance using the appropriate process models.

The second phase of the simulant development work will involve refinement of the first four component simulants based on additional tank waste characterization data. In addition, the other component simulants, such as phosphate, will be developed during this stage. This report only addresses the first phase of the simulant development work relating to the filtration simulant development.

The primary focus of this report is on the development of the "inert solids component" of the simulant. The initial composition of this inert solids component was based on a previous simulant developed for Tanks AY-102/C-106 (Zamecnik et al. 2004). This simulant is sometimes referred to as the SemiIntegrated Pilot Plant (SIPP) simulant. This current simulant development task can be broken into three steps. The first two steps can be discussed in reference to Figure 1.2. The first step was to assess the ability to adjust the high-solids filtration behavior.

The intent was to adjust the bulk components to adjust the high-solids behavior (the right hand portion of Figure 1.2) from right to as far left as possible as shown in the figure. This portion of the task is described in Section 3. After selecting the modified composition of the bulk inert solids component, an attempt was made to adjust the low-solids behavior by adding a small fraction of fines material. This effort is described in Sections 4 and 5. Here, various types and concentrations of fines were added in an attempt to decrease the low-solids filtration performance (the left-hand portion of Figure 1.2). At this point, a simulant component for further testing was chosen. The final step in the process was to test the integrated filtration behavior of the simulant (see Section 6). 


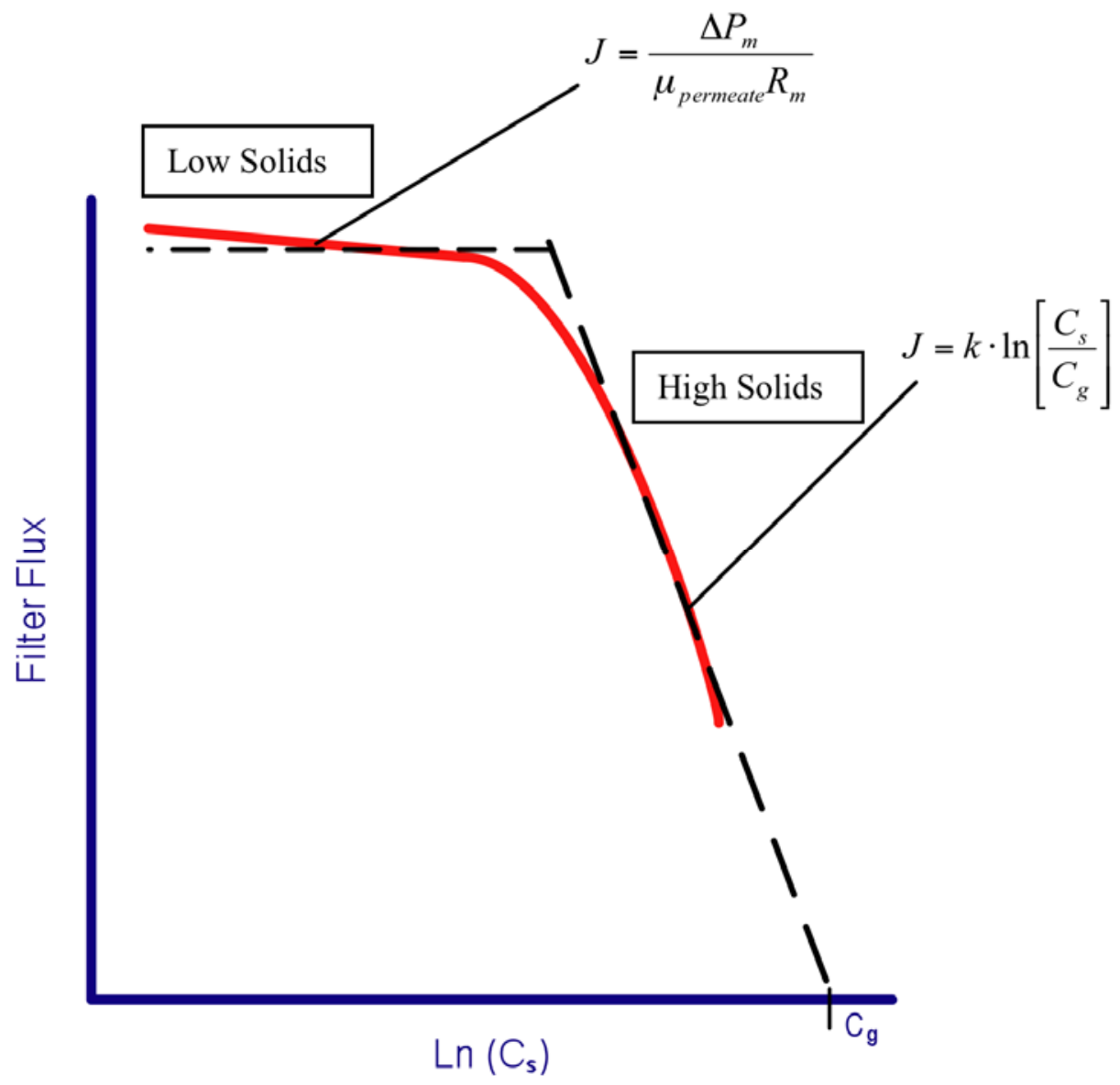

Figure 1.2. Example of a Dewatering Curve at a Constant Transmembrane Pressure (TMP) and Axial Velocity (AV)

\subsection{Simulant Criteria}

As indicated in Figure 1.1, the simulant that was under development was a blend of five primary components - boehmite, gibbsite, oxalate, inert solids, and chromium solids. While the primary focus of this report is upon the development of the inert solids component, the ultimate filtration behavior was dependent upon the blend of these simulant components used.

The IRP for issue M-12 directs the project to develop a simulant that "shall be based upon an $80 \%$ confidence level that the composition is bounded based upon projected sludge mass loss, batch size and treatment time" (Barnes and Voke 2006). To meet the requirements for mass loss, the WTP project has specified that the simulant will be a blend of the components in the ratios shown in Table 1.1 (Sundar 2008). Testing reported in Sections 3.0 through 6.0 in this report evaluated the performance of both the inert solids phase by itself and the inert phase blended with the other components in the ratios outlined in Table 1.1. 
Table 1.1. Simulant Component Ratios

\begin{tabular}{||l|c|}
\hline \multicolumn{1}{|c|}{ Component } & Wt Fraction \\
\hline Boehmite & 0.346 \\
\hline Gibbsite & 0.346 \\
\hline Chromium as $\mathrm{CrO}(\mathrm{OH})$ & 0.026 \\
\hline Sodium Oxalate & 0.100 \\
\hline Inert Components & 0.181 \\
\hline
\end{tabular}

The primary criterion for the inert component of the filtration simulant is to adjust the filtration behavior. The target for this was to achieve a duration of 4.6 days for a complete leaching cycle (with both caustic and oxidative leaching in UFP-2). To accommodate this 4.6-day duration, the approximate filtration process times as shown in Table 1.2 would be estimated. These values represent targets for this simulant development effort. Failure to meet these targets will not invalidate the simulant - but will simply require a translation before eventual implementation to WTP process models. These cycle times were obtained from WTP and were based on the results for G2 Model Run No. MRQ-07-00002 for the baseline design process conditions. Note that the lower filter flux during washing is due to the high-solids content throughout the duration of the washing process.

Table 1.2. Complete Leaching Cycle Time Requirements

\begin{tabular}{||l|c|c||}
\hline \multicolumn{1}{|c|}{ Process Time } & $\begin{array}{c}\text { Target } \\
\text { Duration (h) }\end{array}$ & $\begin{array}{c}\text { Approximate Filter } \\
\text { Flux }\left(\mathbf{g p m} / \mathbf{f t}^{2}\right)\end{array}$ \\
\hline Initial Dewater & 31.5 & 0.011 \\
\hline Caustic Leach & 26.6 & $\mathrm{NA}$ \\
\hline Post Leach Dewater & 10.5 & 0.018 \\
\hline Wash & 31 & 0.007 \\
\hline Oxidative Leach & 6 & $\mathrm{NA}$ \\
\hline $\begin{array}{l}\text { Post Oxidative } \\
\text { Leach/Wash }\end{array}$ & 8.5 & 0.023 \\
\hline Total & 114 & 0.011 \\
\hline
\end{tabular}





\subsection{Experimental Methods and Analyses}

This section describes the experimental equipment and analyses used to perform the filtration and leaching tests for the filtration simulant development task.

\subsection{Filtration/Leaching Apparatus}

The testing apparatus was a bench-top system mounted on a skid that allowed up to 25 liters of a simulant waste solution to be circulated through a tubular filter that measures filter feed flow rates, filtrate flow rates, system pressures, and temperatures simultaneously. Note that the volume of this reservoir was chosen to maintain the same filter surface area to feed slurry volume as is present in the full-scale facility. The testing apparatus used a heat exchanger on the main flow loop to cool the feed solution during filtration operations and had a heater on the main holding tank to perform leaching at elevated temperatures.

\subsubsection{Cell Unit Filter}

The WTP PTF will be designed to use crossflow ultrafiltration to separate the LAW liquid streams from the HLW slurry streams through the process. The filter elements are porous sintered metal tubes. The filter feed flows through the inside of the filter element axially while the feed permeate passes through the tube walls radially. Filtration occurs when the pressure differential between the inside and outside walls of the filter element (known as the transmembrane pressure [TMP]) is high enough to drive the slurry permeate through the tubular walls. The axial flow across the filter walls minimizes solid buildup and allows filtration to occur continuously with minimal downtime for back-pulsing to remove the solids buildup.

The filters purchased for this testing were supplied by the Mott Corporation, ${ }^{(a)}$ using the same specifications $^{(b)}$ for the filters being purchased for the WTP PTF. The filters were made with 316 stainless steel and have an effective filtration rating of $0.1 \mu \mathrm{m}$. The dimensions of the filter element used in these tests are shown in Figure 2.1.

(a) Mott Corporation, 84 Spring Lane, Farmington, CT 06032.

(b) BNI Specification WTP-070110. 

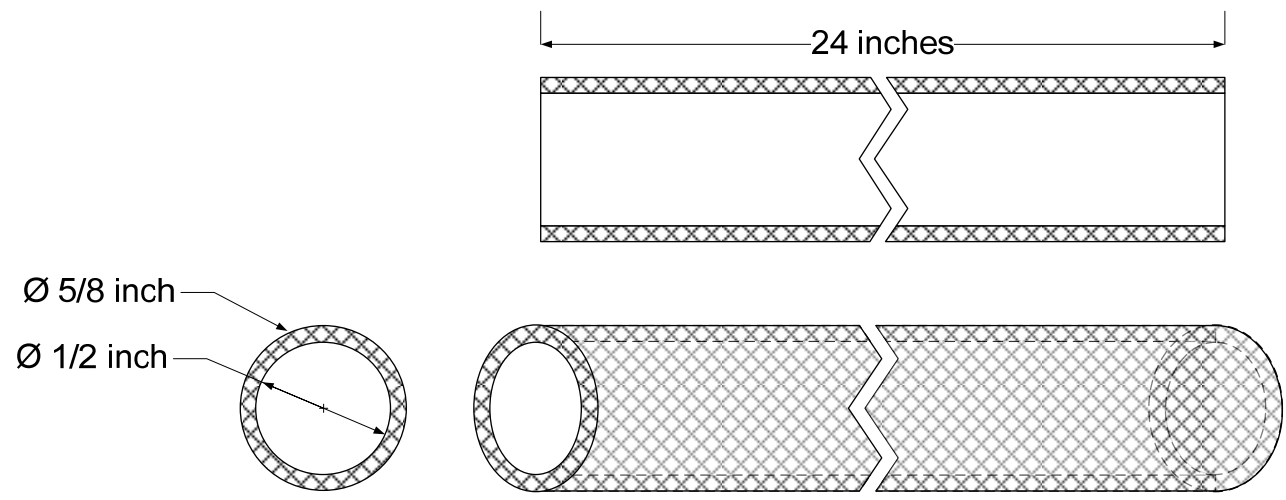

Figure 2.1. Crossflow Ultrafiltration Element

The filter element for the laboratory simulant development task was received already installed in a tubein-tube configuration with an outer tube surrounding the filter element to capture the permeate while the inlet and the outlet of the filter (which extend past the shell and provide access to the inside diameter of the filter) were welded to steel tubing of a matching outer and inner diameter. The shell side had two $3 / 8$-inch stainless steel tubes exiting from the filter assembly, one in the center to collect filtrate from the filter, and the other near the inlet of the filter to function as a drain. Pressure ports $(1 / 4-$ inch stainless steel tubing) were installed on the inlet and outlet connections to the assembly to measure the pressure inside the filter. O-ring face seal fittings (Swagelok ${ }^{(a)} \mathrm{VCO}^{\circledR}$ ) were also placed on the inlet and outlet filter feed tube connections for easy installation to the filtration/leaching skid. Figure 2.2 and Figure 2.3 show the crossflow ultrafiltration assembly.

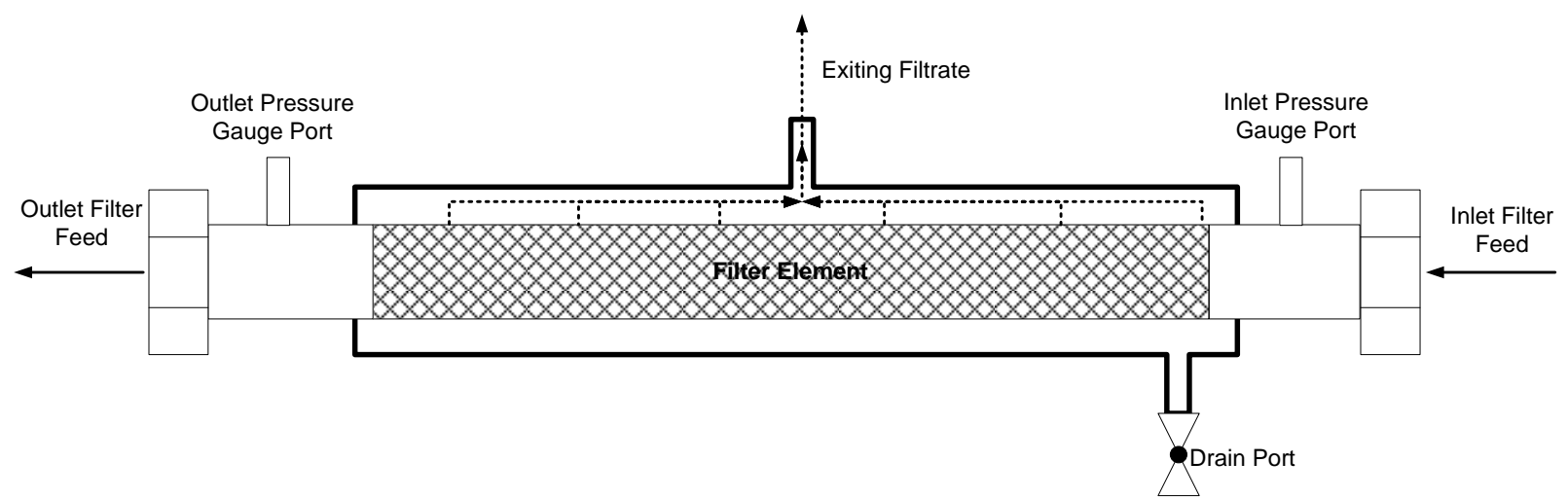

Figure 2.2. Crossflow Ultrafiltration Assembly Sketch (Not to Scale)

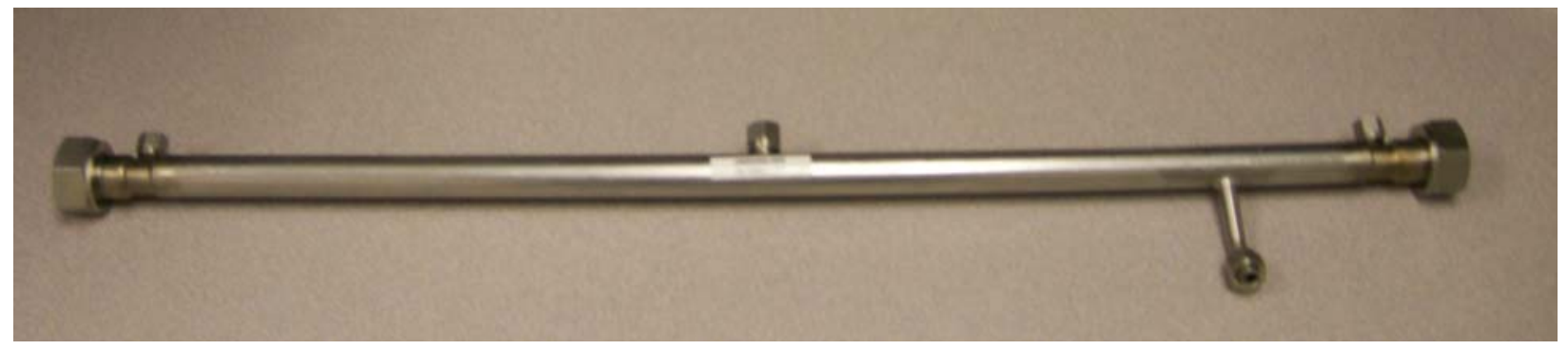

(a) Swagelok Company, 31400 Aurora Road, Solon, Ohio, 44139. 


\section{Figure 2.3. Crossflow Ultrafiltration Assembly}

\subsubsection{Cross Flow Ultrafiltration/Leaching Apparatus}

The filter described in the section above was installed in a bench-top testing apparatus that circulates the test filtration simulants through the inside of the filter and diverts the filter permeate to a collection bottle or recycles it back into the slurry reservoir. Figure 2.4 shows a piping diagram of the testing apparatus. Figure 2.5 is a photograph of the assembled testing apparatus. The testing apparatus is commonly referred to as the crossflow ultrafiltration testing apparatus.

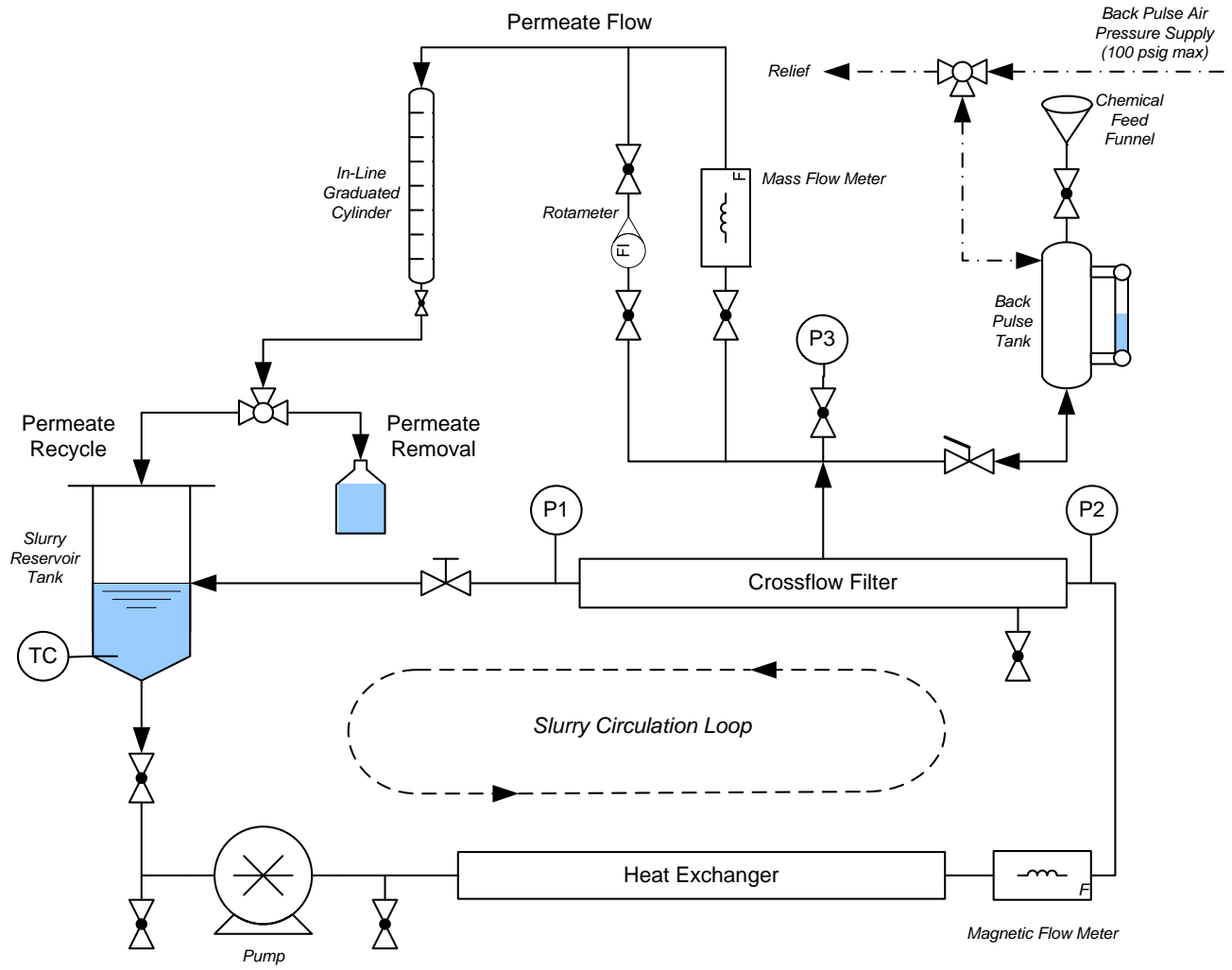

Figure 2.4. Piping Diagram of Crossflow Ultrafiltration Testing Apparatus (Not to Scale) 


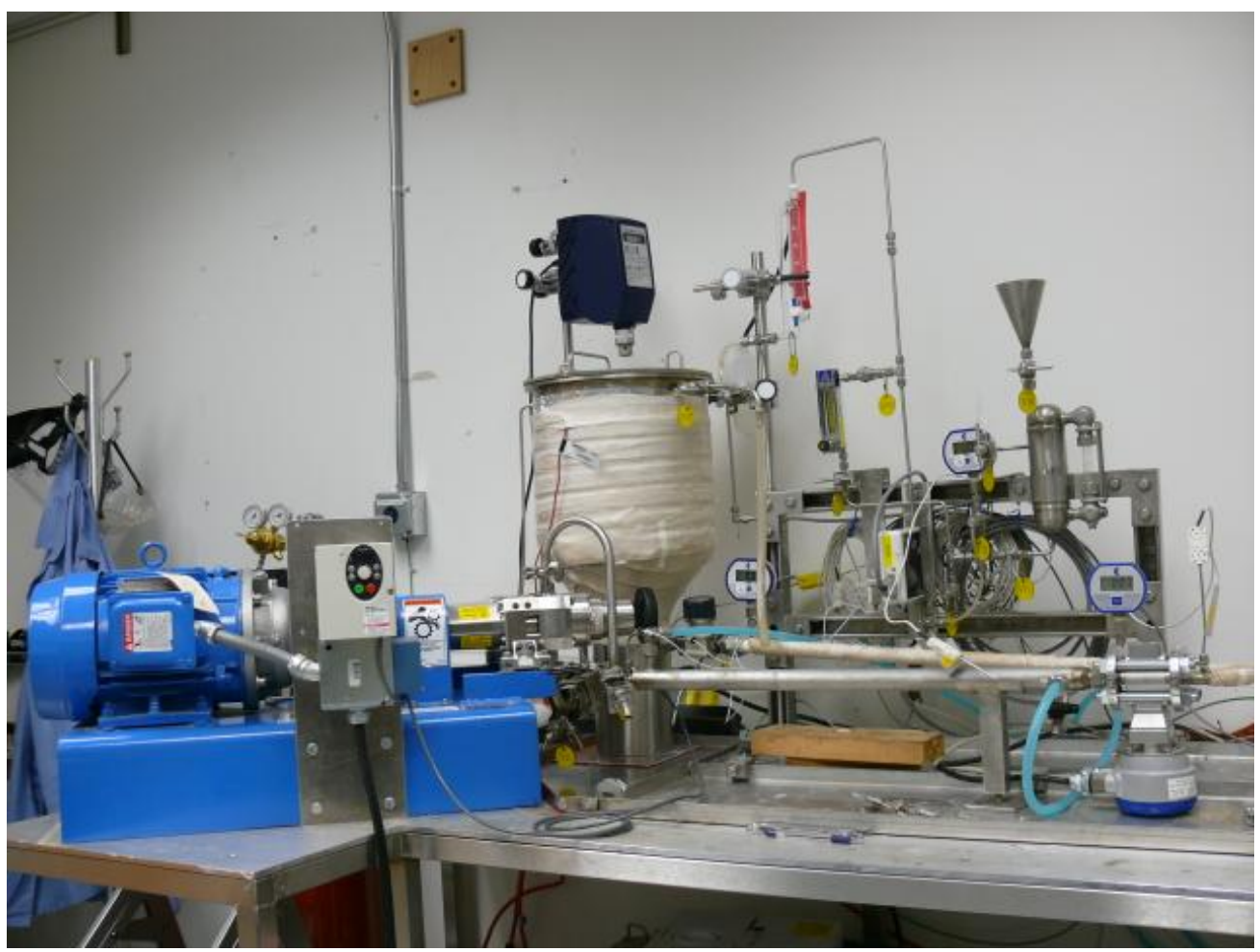

\section{Figure 2.5. Crossflow Ultrafiltration Testing Apparatus}

The crossflow ultrafiltration testing apparatus has four main parts:

- Slurry reservoir tank

- Slurry recirculation loop

- Permeate flow loop

- Permeate back-pulse chamber.

The slurry reservoir was a cylindrical 304L stainless steel tank. There were two different tanks, one of 10-liter and the other of 25-liter capacity, that could be used with the testing apparatus depending on the test that was to be performed. Note that the volume of this reservoir was chosen to maintain the same filter surface area to tank volume as is present in the full-scale facility. The larger reservoir, as shown in Figure 2.5, permitted scaled leaching tests to be performed. The smaller reservoir allowed smaller volumes of simulant to be used. Agitation in the tank was provided with an overhead mixer using a 2-inch diameter, three-blade marine propeller. To allow the system to be easily drained, the bottom of the tanks were sloped at a $15^{\circ}$ angle. Baffles were installed on the tank wall to confirm that the slurry mixing was homogenous. Heat tape was installed around the walls of the tank for leaching at elevated temperatures. The heat tape was connected to a temperature controller that adjusted the electrical load to the heat tape based on a thermocouple input. A dual, Type-K thermocouple was installed inside the reservoir tank (extending just below the overhead mixing impeller) to measure the temperature of the slurry inside the reservoir. One of the thermocouple elements was connected to the heat tape's temperature controller and the other to a data-collection system. 
The slurry recirculation loop directed slurry flow from the slurry reservoir, through the filter, and back into the slurry reservoir for filtration operations. The bottom of the slurry reservoir was connected to the suction side of the slurry recirculation pump - a progressive cavity rotary lobe pump. The discharge of the pump flowed through a single-pass shell-and-tube heat exchanger used to remove excess heat from the system caused by mechanical energy input from the mixer and pump, as well as heat generated from frictional flow.

An exterior chiller circulated a water/antifreeze mixture through the exterior shell of the heat exchanger to remove heat away from the circulating slurry on the tube side of the heat exchanger. The chiller controlled the chilling fluid temperature by monitoring the temperature of the slurry exiting the heat exchanger via a resistance temperature detector (RTD) installed in the discharge line.

The slurry then flowed through a magnetic flow sensor that monitored the volumetric flow of the slurry inside the slurry recirculation loop. The sensor's output was displayed on an external panel meter that generated an analog output signal monitored by a data-collection system. The data from this device were used to calculate the axial velocity (AV) inside the filter element.

The flowing slurry then entered the filter. Digital pressure gauges were installed on the inlet and outlet ports of the filter, which displayed the pressure at both locations in pounds per inch squared-gauge (psig) with an uncertainty of \pm 1 psig. The gauges also transmit analog output signals to the data-collection system. The data from these devices were used to calculate the average pressure inside the filter and the axial pressure drop across the element.

A manual pinch valve was located at the filter's discharge. The valve was used to adjust the pressure inside the filter to drive permeate flow through the filter membrane wall. It was also connected to the slurry reservoir tank and was closed completely when the reservoir tank was isolated for leaching.

The permeate flow loop started at the center of the filter assembly where a polyethylene tube connected the filter to a manifold of $1 / 4$-inch stainless steel piping that directed the filter permeate through a series of measurement devices. A digital pressure gauge was installed at this point to measure the pressure on the permeate side of the filter in psig. Like the other two digital gauges, this instrument transmitted an analog output signal to the data-collection system. The TMP across the filter was then calculated by subtracting the pressure on the permeate side of the filter from the average pressure of the slurry inside the filter.

Flow from the filter was either diverted through a mass flow meter that could be calibrated up to $180 \mathrm{~mL} / \mathrm{min}$ or to a user-calibrated rotameter that can measure flow up to $30 \mathrm{~mL} / \mathrm{s}$. The mass flow meter also measured density of the permeate flow and transmitted two analog output signals to the datacollection system for the volumetric flow rate and the density. An in-line glass cylinder was installed on the discharge of both meters to take manual measurements of the permeate flow rate. Measurements were taken by closing a valve at the bottom of the cylinder and allowing the permeate to fill the glass cylinder. Liquid volume in the glass cylinder was measured by volume markings on the outside. The permeate flow rate was calculated from observed changes in permeate volume in the cylinder over a measured time interval. 
Permeate exited through a 3-way valve connected to the slurry reservoir tank. This valve directed permeate either back to the slurry reservoir tank to be mixed back with the slurry or to a sampling hose used to collect permeate into sample containers.

The permeate back-pulse chamber was to the right of the permeate flow loop and connected to the filter at the same location as the permeate pressure gauge. The chamber was an approximately $500-\mathrm{mL}$ steel vessel with a sight glass to track the permeate volume inside the chamber. The vessel had three entry ports:

- $1 / 4$-inch line with a two-way toggle valve on the bottom connecting the vessel to the permeate side of the filter

- $1 / 4$-inch line with a two-way valve connecting the top of the vessel to a funnel

- 1/4-inch line with a three-way valve connecting the top of the vessel to a compressed air line and vent line connected to the top of the slurry reservoir tank.

The bottom line was used to direct permeate flow between the chamber and the filter. The funnel on the top of the chamber was used to introduce cleaning and rinse solutions directly to the vessel. The compressed gas line was used to pressurize the fluid in the chamber and to vent the chamber to atmospheric pressure.

To back-pulse the filter, the vessel was first vented to atmospheric pressure. Next, permeate was allowed to fill the chamber by opening the toggle valve. Once the chamber was half full of permeate (as seen through the sight glass), the toggle valve was closed. The three-way valve was then positioned to allow compressed gas at 80 psig to fill the chamber and pressurize the fluid. The three-way valve was then positioned to isolate the now pressurized chamber. The slurry pressure inside the filter was then dropped below the pressure of the compressed gas line $(<20 \mathrm{psig})$. The toggle valve at the bottom of the tank was opened, allowing the pressurized permeate inside the chamber to flow backwards through the filter element. The toggle valve was closed when permeate level was below the visible portion of the sight glass. After the back pulse was completed, the three-way valve was positioned to vent the chamber back to atmospheric pressure.

\subsubsection{Instrumentation and Data-Acquisition System}

Most of the sensors on the testing apparatus transmit analog data to an external data-acquisition collection system (DACS) manufactured by National Instruments. ${ }^{(a)}$ This system relayed the analog data to a LabView data-collection program operating on a computer desktop system using Windows XP, Service Pack 2. The software program scales the analog data and simultaneously records the data electronically and displays it on the computer's monitor. The program was verified by Software Test Plan RPP-WTPQA-010, and all reportable data were measured on calibrated instrumentation, including the external DACS board. Figure 2.6 shows a diagram of the electronic sensors attached to the DACS, and Figure 2.7 shows screenshots from the data-collection program.

(a) National Instruments Corporation, 11500 N Mopac Expwy, Austin, TX 78759-3504. 
National Instruments Field Point Modular DACS

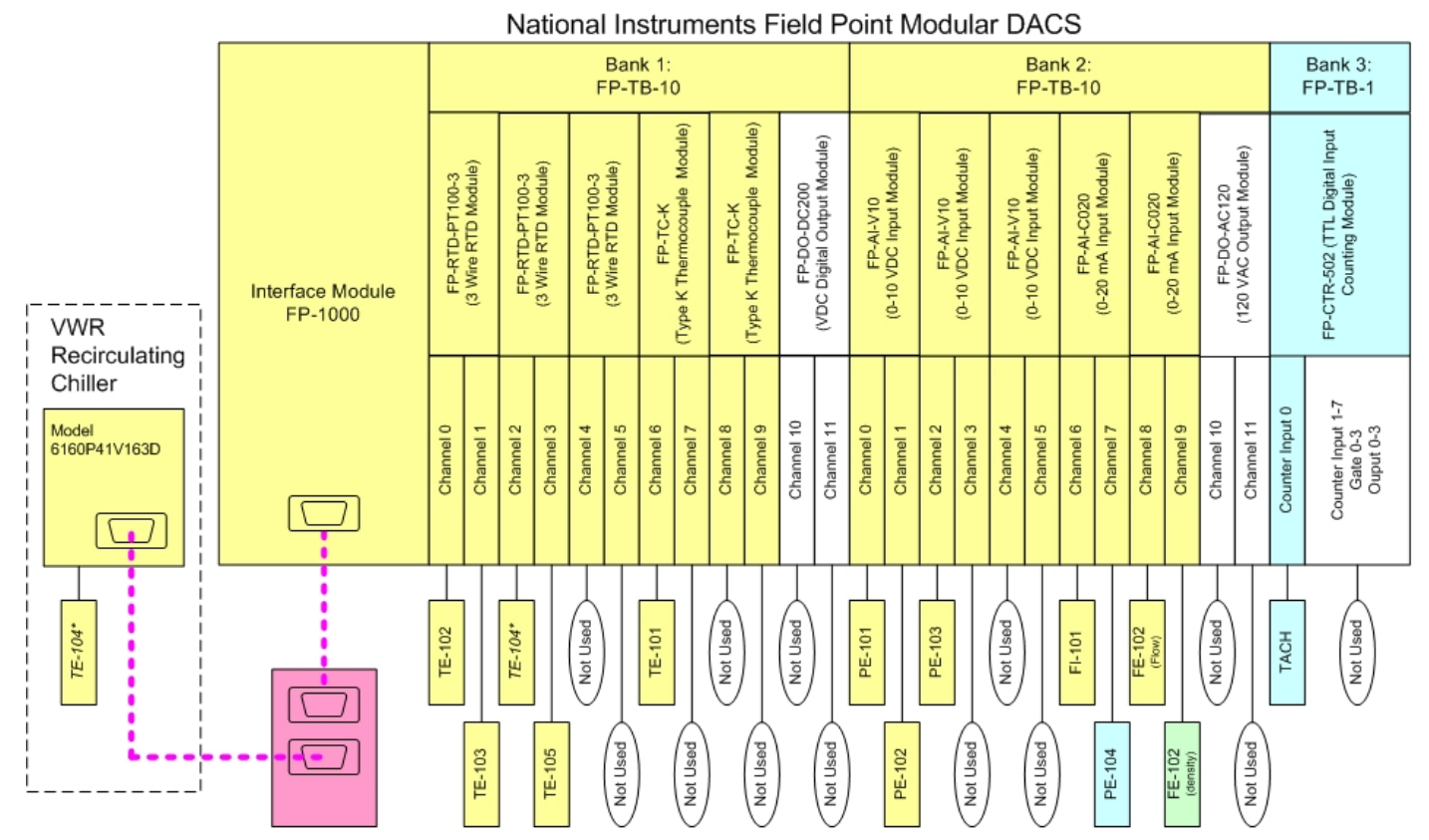

\begin{tabular}{|c|c|c|c|}
\hline$\square$ Windows XP PC & M\&TE Data & Indication Only & * Note: TE-104 can only be wired to \\
\hline - RS-232 Communication & User Calibration & Not Used & Point system - not both. \\
\hline
\end{tabular}

Figure 2.6. Diagram of DACS System

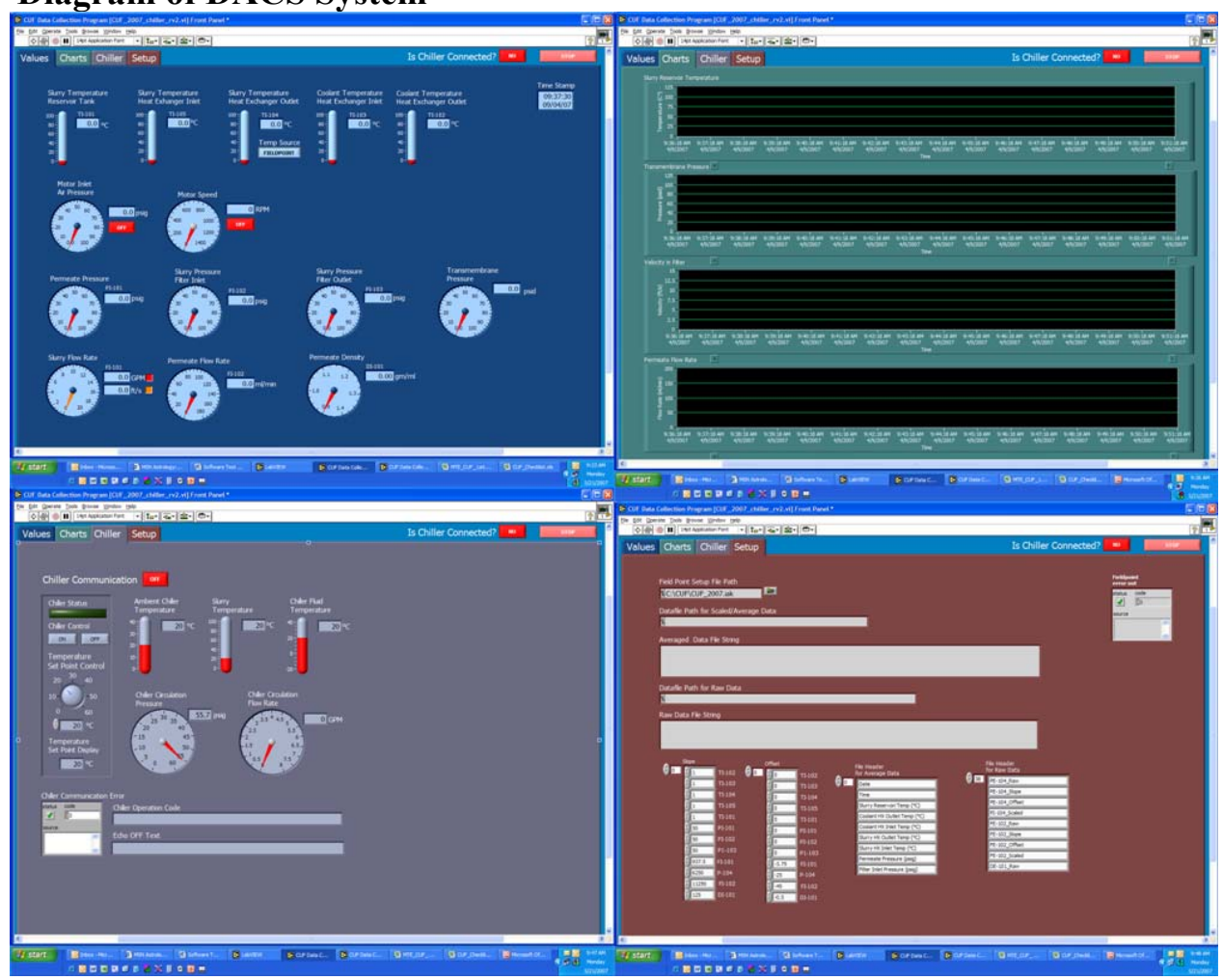


Figure 2.7. Digital Images of DACS Display Windows

\subsubsection{Operations of Crossflow Ultrafiltration and Sampling}

The crossflow ultrafiltration system was developed to operate in several different modes to simulate the filtration and leaching processes of the WTP Pretreatment system. Filtration operation occurred in a recycling or dewatering mode. During recycling operations, permeate was returned to the slurry reservoir tank. By returning permeate back into the slurry, the undissolved solids (UDS) concentration in the slurry was maintained at a steady-state condition. The crossflow ultrafiltration unit was operated in this mode to understand how the effects of time, pressure, and AV impact the filtration of slurry while maintaining the physical properties of the slurry. During dewatering operations, permeate from the filter was diverted to a collection vessel, operating the system at a constant TMP and axial flow rate, thus altering the UDS concentration of the slurry. The crossflow ultrafiltration unit was operated in this mode to understand how the slurry's rheological and filtration properties changed with its UDS concentration. Chemical leaching occurred in the slurry reservoir tank when isolated from the slurry circulation loop. Isolating the slurry reservoir tank for leaching operations required draining the slurry and permeate inside the crossflow ultrafiltration unit piping first. Once the tank was isolated from the slurry circulation loop, the slurry and permeate were returned to the slurry reservoir tank along with the leaching agent. The heat tape surrounding the slurry reservoir was used to heat the vessel during the leaching operations.

Samples were collected throughout testing to measure the physical and chemical properties of the waste slurry or permeate. Slurry samples were collected from two separate locations on the system. Large slurry samples $(>100 \mathrm{~mL})$, such as for rheology measurement, were collected using the drain valve on the pump discharge while the pump was running. Small slurry samples were taken directly from the slurry reservoir tank. Permeate samples were collected during dewatering operations directly from the dewatering sample hose.

\subsubsection{Baseline Testing of Filter}

The crossflow ultrafiltration unit slurry and permeate piping was initially cleaned with a laboratory detergent (Alconox ${ }^{(a)}$ at 1:100 dilution) to remove cutting oils and soils from the fabrication process of the testing equipment. Afterwards, the system was rinsed with deionized (DI) water several times until the rinse solution appeared clear. The filter flux was then measured with a solution of $0.01 \mathrm{M} \mathrm{NaOH}$ to verify the cleanliness of the filter - called the clean water flux. Testing was performed at 10, 15, and 20 TMP at an AV of $11 \mathrm{ft} / \mathrm{s}$. Each pressure condition was held for 20 minutes, with a single back-pulse performed before changing the pressure.

\subsection{Filtration Data Analysis}

\subsubsection{Filtration Terms and Equations}

Filtration examined in this report as a filter flux is defined as:

(a) Alconox, Inc., 30 Glenn Street, Suite 309, White Plains, New York 10603 USA. 


$$
J=\frac{Q_{\text {permeate }}}{A_{\text {filter }}}
$$

where $J$ is the filter flux $\left(\mathrm{gpm} / \mathrm{ft}^{2}\right), Q_{\text {permeate }}$ is the volumetric permeate flow (gpm), and $A_{\text {filter }}$ is the filtration surface area $\left(\mathrm{ft}^{2}\right)$.

In this study, the filter area is assumed as the inside area of the filter element, which is defined as:

$$
A_{\text {filter }}=\pi D_{i_{\text {filter }}} L_{\text {filter }}
$$

where $D_{i_{\text {fitter }}}$ is the filter element inside diameter, and $L_{\text {filter }}$ is the filter element length.

The permeate volumetric flow rate is corrected for viscosity and surface tension effects because of the permeate temperature deviation from $25^{\circ} \mathrm{C}$. This generally results in a very small correction in that the temperature control for this system is typically within $\pm 3^{\circ} \mathrm{C}$. In WTP-RPT-043 (Geeting et al. 2002), the corrected permeate flow rate at a given temperature $\mathrm{T}\left({ }^{\circ} \mathrm{C}\right)$ is defined as:

$$
\begin{aligned}
Q_{25^{\circ} \mathrm{C}} & =Q_{T} e^{2500\left[\frac{1}{T+273}-\frac{1}{298}\right]} \\
J_{25^{\circ} \mathrm{C}} & =J_{T} e^{2500\left[\frac{1}{T+273}-\frac{1}{298}\right]}
\end{aligned}
$$

The exponential term in Equation 2.3 is discussed in WTP-RPT-168. ${ }^{\text {(a) }}$

The pressure drop across the filter (the TMP) was calculated in these tests as:

$$
T M P=\Delta P_{m}=\frac{\left(P_{\text {inlet }}+P_{\text {outlet }}\right)}{2}-P_{\text {permeate }}
$$

where $P_{\text {inlet }}$ is the pressure at the filter inlet, $P_{\text {outlet }}$ is the pressure at the filter outlet, and $P_{\text {permeate }}$ is the pressure at the permeate side of the filter.

The AV inside the filter is calculated by dividing the volumetric slurry flow of the filter by the crosssection area of the inside diameter of the filter:

$$
A V=\frac{Q_{\text {slurry }}}{S_{a}}=\frac{Q_{\text {slurry }}}{\frac{\pi}{4} D_{i_{\text {fiter }}} 2}
$$

where $S_{a}$ is the cross-sectional area of the axial flow, and $\mathrm{Q}_{\text {slurry }}$ is the volumetric slurry flow rate in the axial direction.

(a) RC Daniel et al. 2008. Characterization of Filtration Scale-Up and Fouling Performance. WPT-RPT-168 Rev. A, Pacific Northwest National Laboratory, Richland, Washington. 
The Darcy equation describes filter flux as:

$$
J=\frac{\Delta P_{m}}{\mu_{\text {permeate }} R_{m}}
$$

where $\Delta P_{m}$ is the pressure drop across filter membrane, $\mu_{\text {permeate }}$ is the viscosity of the permeate, and $R_{m}$ is the overall resistance of the filter membrane.

The overall filter resistance term is the sum of the resistance of the actual filter, the resistance of the filter cake that forms on the surface of the filter, and the resistance due to fouling of the filter. For dilute slurries and when turbulent flow conditions exist, the filter resistance is usually constant, and the TMP and permeate viscosity are the controlling operational parameters. During dewatering, the slurry's flow properties change, and the filter cake resistance becomes more significant.

When this occurs, the Darcy equation loses applicability, as the cake resistance changes with AV and slurry concentration. Eventually, the slurry can only be dewatered to a maximum UDS concentration limit at a given TMP. This limit is known as the gel concentration. As the simulant slurry's solid concentration approaches the gel concentration, the filter flux can be described as

$$
J=k \cdot \ln \left[\frac{C_{s}}{C_{g}}\right]
$$

where $C_{s}$ is the slurry UDS concentration, $C_{g}$ is the slurry gel concentration at a given TMP, and $k$ is a constant for a given TMP and AV (note that $\mathrm{k}$ is a negative value).

When the flux is impacted by the UDS concentration, the influence of AV becomes significant as well because of the way the AV affects the thickness of the filter cake inside the filter.

\subsubsection{Filtration Test Matrix}

To understand the impact of the TMP and AV on the filter flux of the waste slurry, a filtration test matrix was developed to understand their individual effects. Like the clean water slurry flux testing described in Section 2.1.5, the simulant slurry was circulated through the filtration testing apparatus while the slurry permeate leaving the filter was recycled back to the slurry reservoir. By recycling permeate in this way, the UDS concentration of the slurry remained constant (steady-state conditions). Using a TMP of 40 psid and an AV of 13 feet per second ( $\mathrm{ft} / \mathrm{s}$ ) as the baseline condition, testing conditions were varied to demonstrate how the flux changes as TMP and AV deviate from the baseline condition. Table 2.1 outlines the target conditions for the testing performed.

\section{Table 2.1. Filtration Test Matrix Operating Conditions}




\begin{tabular}{|c|c|c|c||}
\hline $\begin{array}{c}\text { Test } \\
\text { Number }\end{array}$ & $\begin{array}{c}\text { Duration } \\
\text { (hours) }\end{array}$ & $\begin{array}{c}\text { Target TMP } \\
\text { (psid) }\end{array}$ & $\begin{array}{c}\text { Target AV } \\
\text { (ft/s) }\end{array}$ \\
\hline 1 & 1 & 40 & 13 \\
\hline 2 & 1 & 40 & 9 \\
\hline 3 & 1 & 40 & 17 \\
\hline 4 & 1 & 20 & 13 \\
\hline 5 & 1 & 60 & 13 \\
\hline 6 & 1 & 40 & 13 \\
\hline
\end{tabular}

Each filtration condition was maintained for at least an hour while permeate was recycled back to the slurry reservoir tank. Before test conditions were changed, a back-pulse was performed on the filter to provide similar starting conditions for each condition by removing the filter cake build-up on the filter. Typically, the back-pulse occurred after the slurry pressure was below 20 psig and with the back-pulse chamber pressurized to $80 \mathrm{psig}$. The initial test at the baseline condition was performed to observe how the filter flux varied with time to track possible fouling due to the simulant slurry.

When the slurry is at low concentrations, the system is expected to be controlled by the TMP (Equation 2.6) with little impact from the AV. However, once the slurry is concentrated and the flow properties change, it is expected that the AV will have some effect on the filtration of the system.

\subsubsection{Dewatering Operation Analysis}

During dewatering operations of the simulant slurries, the TMP and AV were maintained at the baseline condition of $40 \mathrm{psid}$ and $13 \mathrm{ft} / \mathrm{s}$. By maintaining the operating conditions of the filtration, the primary effect on filtration should be the slurry concentration. As the slurry's UDS changes, the filter flux can be monitored and graphically charted, as shown in Figure 2.8. As discussed earlier, the filter flux is initially expected to follow Equation 2.6 for low-solids concentrations, which will appear as a horizontal line on the chart when the TMP is held constant. But as the slurry begins to concentrate, the filtration behavior of the slurry is expected to change and begin to follow Equation 2.7 instead. The analysis also predicts the slurry's gel UDS concentration described in Section 2.2.1. This value can be compared to the measured centrifuge UDS of the slurry, which has been indicated as a good method of estimating the gel concentration (Peterson et al. 2007).

\subsubsection{Effects of Rheology and Particle Size}

Rheology and particle-size samples were taken during testing operations to characterize the solids in the slurry and their impact on flow and filtration behavior. As slurries concentrate, their flow behavior changes by becoming more viscous and less Newtonian. This influences the cross-flow behavior of the filter directly and the formation of filter cake. Particle size also can impact the gel concentration of the slurry and possibly affect the filter fouling. Because the slurries are sheared during filtration, the particle size of the slurry may change, especially if the initial solids are agglomerated. Chemical leaching has a similar impact, as well, in changing the particle size of the slurry. 


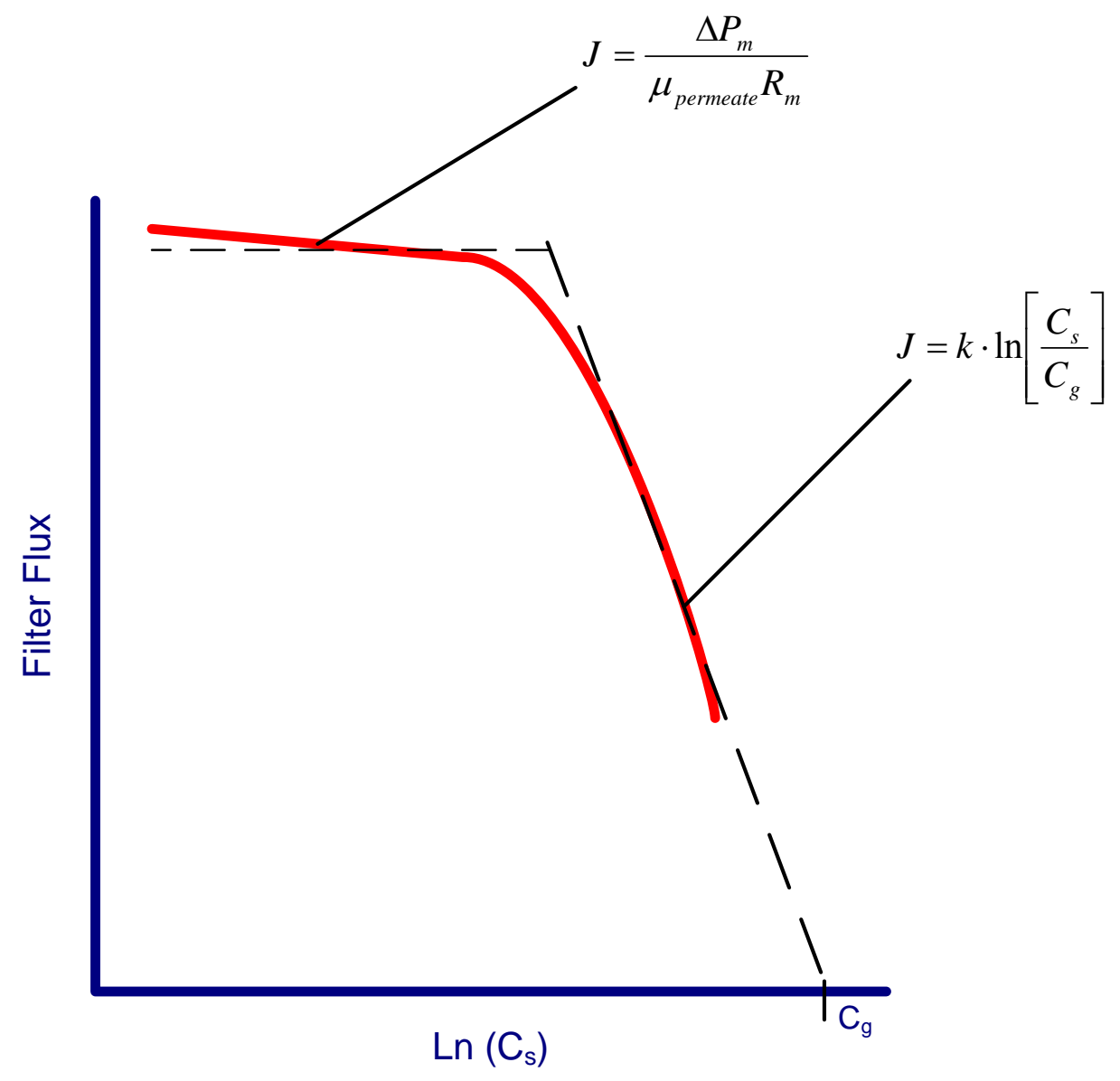

Figure 2.8. Example of a Dewatering Curve at a Constant TMP and AV

\subsection{Simulant Preparation}

Prior work has identified two primary sources of potential simulants. The first source was from Golcar et al. (2000). In that report, they developed two simulants. The first was for Tanks AZ-101 and AZ-102. The second simulant was for Tank C-106. Both of these simulants consisted of a blend of commercially available materials, including hematite, boehmite, gibbsite, and zirconium hydroxide. The second source of potential simulant was from Zamencnik et al. (2004) and was fabricated to simulate a mixture of Tanks AY-102 and C-106, referred to as AY-102/C-106 and also known as the SIPP simulant. It used a more complex hydroxide precipitation route to produce the iron-bearing portion of the simulant. As this process is more representative of the method by which this phase was formed in the HLW tanks, this route of simulant production was chosen for further development.

The initial inert filtration simulant was based on the composition of the AY-102/C-106 tank waste sludge, minus the gibbsite, boehmite, chromium, and minor metals, and was prepared as described by Zamecnik et al. 2004. Figure 2.9 shows a flowsheet of the inert filtration simulant preparation. The initial simulant 
was composed of a basic tank waste simulant having the components listed in Table 2.2 through Table 2.4.

Table 2.2 shows the components of the sludge solids consisting primarily of iron. The insoluble hydroxide solids are produced when $\mathrm{NaOH}$ is added to the metal nitrate solution to a $\mathrm{pH}$ of 10 to 11 . The $\mathrm{KMnO}_{4}$ and $\mathrm{Mn}\left(\mathrm{NO}_{3}\right)_{2}$ are pre-reacted to produce insoluble $\mathrm{MnO}_{2}$ before the nitrate salts are added by mixing them together in DI water. The excess nitrate is then washed from the slurry using the simple supernate that only contains the major salt species (hydroxide, phosphate, oxalate, carbonate, and nitrite).

Table 2.3 shows the chemical components used to produce the sodium aluminosilicate (NAS) simulant component. The NAS was formed as a separate step in the simulant preparation process by dissolving the sodium aluminate in one caustic solution and sodium metasilicate with sodium carbonate in another caustic solution. Then each solution was heated to $40 \pm 2{ }^{\circ} \mathrm{C}$, mixed together to react them, and then filtered and washed to remove the unreacted components. Table 2.4 shows the chemical components used to produce the simulant supernate and included both the nitrate and non-nitrate anions present in the waste.

The combined simulant was tested in the centrifuge and then in the laboratory-scale crossflow ultrafiltration system. The composition that was chosen was then used as the starting ultrafiltration simulant. See Appendix A for the recipes used to make this ultrafiltration simulant. 


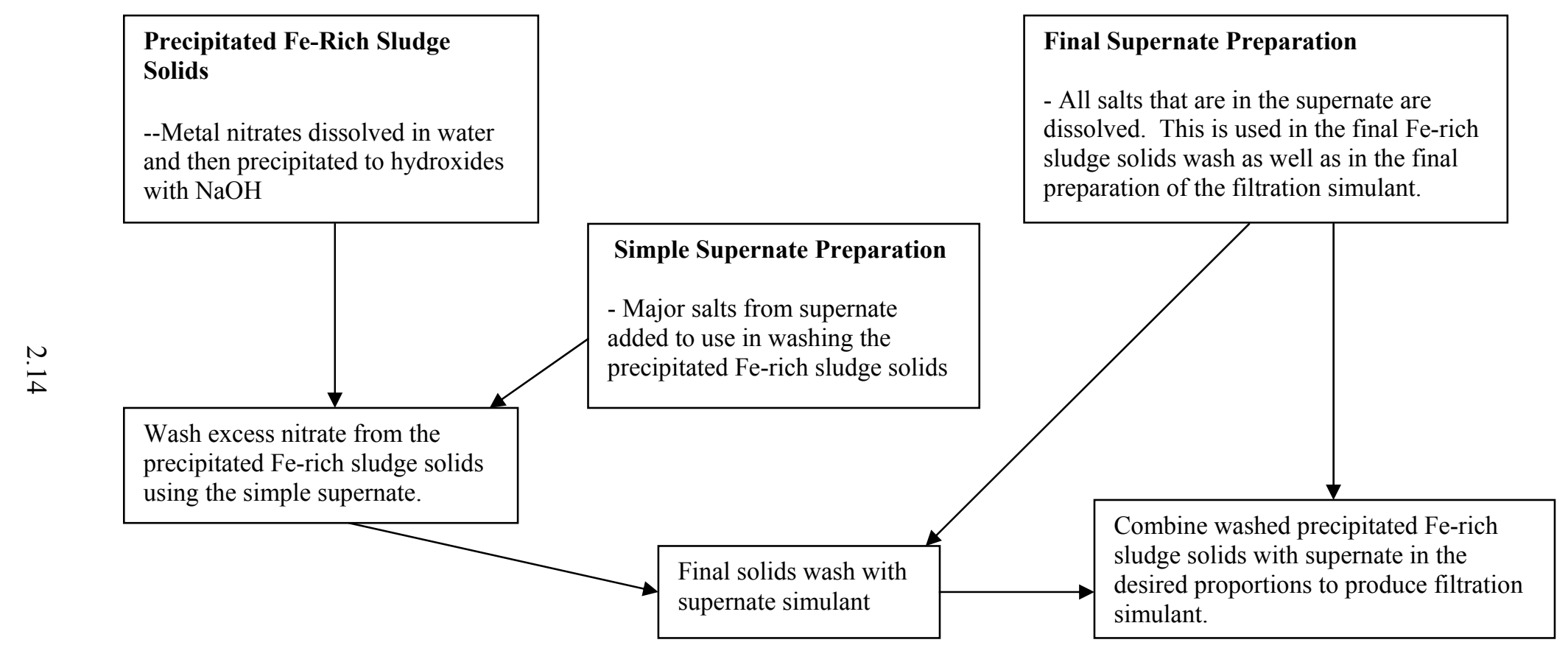

Final Filtration Simulant

Figure 2.9. Flowsheet of Filtration Simulant Preparation 
Table 2.2. Chemical Components Used to Produce Starting Simulant Sludge Solids

\begin{tabular}{||l|c|c|}
\hline \multicolumn{1}{|c|}{ Sludge Solids } & Compound & $\begin{array}{c}\text { Concentration } \\
\text { (g/kg) }\end{array}$ \\
\hline Zirconyl nitrate & $\mathrm{ZrO}\left(\mathrm{NO}_{3}\right)_{2}-\mathrm{xH}_{2} \mathrm{O} \times \sim 6$ & 34.6 \\
\hline Sodium hydroxide & $\mathrm{NaOH}$ & $8 \mathrm{M}$ to $\mathrm{pH} 10$ \\
\hline Sodium phosphate & $\mathrm{Na}_{3} \mathrm{PO}_{4}-12 \mathrm{H}_{2} \mathrm{O}$ & 101.0 \\
\hline Sodium oxalate & $\mathrm{Na}_{2} \mathrm{C}_{2} \mathrm{O}_{4}$ & 134.0 \\
\hline Potassium permanganate & $\mathrm{KMnO}_{4}$ & 87.3 \\
\hline Manganous nitrate $(50 \mathrm{wt} \%$ soln $)$ & $\mathrm{Mn}_{2}\left(\mathrm{NO}_{3}\right)_{2}$ & 297.0 \\
\hline Calcium nitrate & $\mathrm{Ca}\left(\mathrm{NO}_{3}\right)_{2}-4 \mathrm{H}_{2} \mathrm{O}$ & 48.5 \\
\hline Ferric nitrate & $\mathrm{Fe}\left(\mathrm{NO}_{3}\right)_{3}-9 \mathrm{H}_{2} \mathrm{O}$ & 2562.0 \\
\hline Magnesium nitrate & $\mathrm{Mg}\left(\mathrm{NO}_{3}\right)_{2}-6 \mathrm{H}_{2} \mathrm{O}$ & 34.3 \\
\hline Neodymium nitrate & $\mathrm{Nd}\left(\mathrm{NO}_{3}\right)_{3}-6 \mathrm{H}_{2} \mathrm{O}$ & 26.3 \\
\hline Nickel nitrate & $\mathrm{Ni}\left(\mathrm{NO}_{3}\right)_{2}-6 \mathrm{H}_{2} \mathrm{O}$ & 57.4 \\
\hline Cerium nitrate & $\mathrm{Ce}\left(\mathrm{NO}_{3}\right)_{3}-6 \mathrm{H}_{2} \mathrm{O}$ & 13.0 \\
\hline Lead nitrate & ${\mathrm{Pb}\left(\mathrm{NO}_{3}\right)_{2}}_{2}$ & 25.9 \\
\hline
\end{tabular}

Table 2.3. Chemical Components Used to Produce Starting Simulant Sodium Aluminosilicate

\begin{tabular}{||c|c|c||}
\hline $\begin{array}{c}\text { Sodium } \\
\text { Aluminosilicate } \\
\text { (NAS) }\end{array}$ & Compound & $\begin{array}{c}\text { Concentration } \\
\text { (g/kg) }\end{array}$ \\
\hline Sodium hydroxide & $\mathrm{NaOH}$ & 2112 \\
\hline Sodium aluminate & $\mathrm{NaAlO}_{2}-3 \mathrm{H}_{2} \mathrm{O}$ & 1197 \\
\hline Sodium carbonate & $\mathrm{Na}_{2} \mathrm{CO}_{3}$ & 1865 \\
\hline Sodium metasilicate & $\mathrm{Na}_{2} \mathrm{SiO}_{3}-9 \mathrm{H}_{2} \mathrm{O}$ & 2001 \\
\hline
\end{tabular}

Table 2.4. Chemical Components Used to Produce Starting Simulant Supernate

\begin{tabular}{|l|c|c||}
\hline \multicolumn{1}{|c|}{ Supernate } & Compound & $\begin{array}{c}\text { Concentration } \\
\text { (g/kg) }\end{array}$ \\
\hline Potassium nitrate & $\mathrm{KNO}_{3}$ & 0.4235 \\
\hline Sodium phosphate & $\mathrm{Na}_{3} \mathrm{PO}_{4}-12 \mathrm{H}_{2} \mathrm{O}$ & 15.38 \\
\hline Sodium metasilicate & $\mathrm{Na}_{2} \mathrm{SiO}_{3}-9 \mathrm{H}_{2} \mathrm{O}$ & 0.5455 \\
\hline Sodium sulfate & $\mathrm{Na}_{2} \mathrm{SO}_{4}$ & 2.671 \\
\hline Sodium hydroxide & $\mathrm{NaOH}_{3}$ & 15.38 \\
\hline Sodium acetate & $\mathrm{NaCH}_{3} \mathrm{COO}-3 \mathrm{H}_{2} \mathrm{O}$ & 1.034 \\
\hline Sodium oxalate & $\mathrm{Na}_{2} \mathrm{C}_{2} \mathrm{O}_{4}$ & 5.303 \\
\hline Sodium nitrite & $\mathrm{NaNO}_{2}$ & 6.494 \\
\hline
\end{tabular}





\subsection{High-Solids Filtration Performance}

The primary objective of this first task was to evaluate the existing inert filtration simulant to assess the impact of varying the individual components of the inert material with an emphasis on changing the highsolids filtration behavior. Based on prior experience, it was expected that the presence of components (such as boehmite and gibbsite) would produce significantly higher filter fluxes than required to meet the duration criterion. Therefore, a primary objective of this phase of work was to identify a mix of inert components that would decrease the high-solids filtration fluxes. The initial inert filtration simulant was based on the composition of the AY-102/C-106 tank waste sludge, minus the gibbsite, boehmite, chromium, and minor metals (Zamecnik et al. 2004). This starting simulant was selected primarily because an existing fabrication protocol existed for it, and extensive filtration trials had been performed with it. The simulant composition was then varied by adjusting the amounts of sodium aluminosilicate and inert components, such as zirconium oxide, in an attempt to identify a blend that would produce the lowest possible filter flux. In addition, blends of these inert components were evaluated with leaching components, boehmite, and gibbsite to assess their impact on filtration performance.

\subsection{Ultrafiltration Simulant Centrifuge Screening Tests}

The first step in this process was to screen the simulant formulations using a centrifuged solids measurement. Prior work has shown that centrifuge solids measurements are a good metric of high-solids filtration behavior (Peterson et al. 2007). The effect of the following independent variables on the centrifuging behavior of these simulants and how it related to the filter flux using the crossflow ultrafiltration system was investigated. Note that these components represent the primary components in the simulant and offer the greatest opportunity to see significant changes in performance.

- Sludge solids to NAS ratio

- Mixed-phase simulant to inert components ratio.

\subsubsection{Centrifuge Screening Test Results}

Slurry solids initially concentrate by settling in a supernate until all the particles are interacting to form a self-supporting superstructure at a concentration called the gel point. To cause further concentration of the slurry solids, an increased crushing force must be applied to the slurry gel to cause the slurry solids to occupy a smaller volume. This can be done in at least two ways: one is by increasing the gravitational field experienced by the slurry solids causing the structure to collapse under its own weight, and the second is to press the gelled solids against a filter membrane and squeeze the gel with the pressure gradient, causing supernate to pass through the filter membrane. In both cases, the pressure experienced by a layer of slurry will increase with depth into the gel layer. In the case of increased gravitation, it is the overburden weight of the slurry solids that develops the pressure while it is the net hydrodynamic pressure of the supernate flowing through the gel layer that generates the compressive pressure on the gel layer. The similarity in geometries of the two situations suggest that one operation (i.e., increasing the effective gravitational field by using a centrifuge) could be used to predict the behavior of a slurry under similar pressure conditions developed under the cross flow filtration operation (a much more labor and time intensive process). Hence, it was thought that centrifugation of the simulants would produce data 
that could be used to predict the relative behavior of the slurries during cross flow filtration in response to the TMP.

The basis for comparing centrifugal action on various slurries comes from applying a model for compressive yield stress on tank waste slurries (Rector and Bunker 1995). Here the compressive yield stress $\mathrm{P}(\Phi)$ is a function of fitting parameters $\mathrm{c}$ and $\mathrm{n}$, and the volume fractions $\Phi$ and $\Phi_{\mathrm{g}}$ where $\Phi_{\mathrm{g}}$ is the gel point slurry solids volume fraction as shown in the following equation:

$$
\mathrm{P}(\Phi)=\mathrm{c}\left\{\left[\Phi / \Phi_{\mathrm{g}}\right]^{\mathrm{n}}-1\right\} \quad \Phi>\Phi_{\mathrm{g}}
$$

Here $\mathrm{c}$ and $\mathrm{n}$ are determined for a particular slurry for which at least three data points at different centrifuge settings are available by choosing $\mathrm{c}$ and $\mathrm{n}$ to minimize the error using the model equation, and $\Phi_{\mathrm{g}}$ is taken from the settling $(1 \mathrm{G})$ data. These parameter values are given in Table 3.1 for slurry simulants \#7, \#8, and \#10. See Table 2.2 and Table 2.3 for their description.

Table 3.1. Parameters for the Compressive Yield Strength

\begin{tabular}{||c|c|c|c||}
\hline \hline Simulant ID & $\# \mathbf{7}$ & $\mathbf{\# 8}$ & $\# \mathbf{1 0}$ \\
\hline $\mathrm{c}$ (psi) & 0.0010 & 0.0012 & 1.3 \\
\hline $\mathrm{n}$ (unitless) & 12.4 & 7.22 & 2.75 \\
\hline$\Phi_{\mathrm{g}}$ (unitless) & 13.8 & 5.86 & 4.35 \\
\hline
\end{tabular}

Rearranging Equation 3.1 to give $\Phi$ as a function of $\mathrm{P}$, one obtains:

$$
\Phi=\Phi_{\mathrm{g}}[\{\mathrm{P} / \mathrm{c}\}+1]^{1 / \mathrm{n}}
$$

This gives the volume fraction $(\Phi)$ in terms of initial volume fraction at the gel point $\left(\Phi_{\mathrm{g}}\right)$ and pressure of compression (P). The pressure of compression is due to the net weight of the slurry solids in the supernate. This pressure can be calculated from the weight percent solids and the density of those solids, or it can be calculated based on the volume fraction of the slurry particles and their density. Both approaches require that some assumptions or approximations be made. For the first case, one assumes that the solids are made up of primarily fully dense particles of known density while the second approach recognizes that the primary particles for some solids (i.e., iron oxyhydroxide) have agglomerated to form flocs that are mostly open space filled with supernate. It is the flocculated systems that have low volume fraction gel points and more readily crushable gel point structures.

By calculating $\mathrm{P}$ at various levels in the slurry column, $\Phi(\mathrm{P})$ can be calculated using Equation 3.2, and since $\Phi$ is directly proportional to weight percent solids in the slurry, the weight percent solids versus pressure exerted by the UDS curves can be determined.

To test the centrifuged solids of the initial simulant, the composition was varied in order to adjust the filter flux. Changes that were evaluated included the sludge solids (primarily iron oxyhydroxide) to NAS ratio and the addition of an inert compound (zirconium oxide) to adjust the particle size while adjusting the suspended solids content using the supernate simulant. Changing the ratio of the sludge solids to NAS changes the centrifuge solids density. It was hypothesized that higher sludge solids to NAS ratio would produce a lower centrifuge solids density and result in a lower filter flux while a lower sludge solids to NAS ratio would produce a higher centrifuge solids density and result in a higher filter flux. The 
initial sludge solids to NAS ratio in the original simulant prepared by Zamenik et al. (2004) was 2.1 to 1. As seen in Table 3.2, this ratio was adjusted higher and lower to assess the impact of changing concentration. In addition, the impact of various inert components was assessed.

Table 3.2. Ultrafiltration Simulant Component Test Ratios

\begin{tabular}{|c|c|c|c|}
\hline Simulant & $\begin{array}{l}\text { Ratio of Sludge } \\
\text { Solids to NAS }\end{array}$ & $\begin{array}{l}\text { Ratio of Bulk Inert } \\
\text { Components to } \\
\text { Sludge Solids }\end{array}$ & Solids Ratios-Mass Fractions \\
\hline$\# 1$ & $2.1: 1$ & 0 & na \\
\hline$\# 2$ & $2.1: 1$ & $0.5: 1$ & na \\
\hline$\# 3$ & $1.1: 1$ & 0 & na \\
\hline$\# 4$ & $3.1: 1$ & 0 & na \\
\hline$\# 5$ & $1.1: 1$ & $0.5: 1$ & na \\
\hline$\# 6$ & $3.1: 1$ & $0.5: 1$ & na \\
\hline \#7 & $1: 0$ & $0: 1$ & $\begin{array}{c}\text { unleached boehmite- } 0.35 \text {, unleached } \\
\text { gibbsite- } 0.35 \text {, sodium oxalate- } 0.20 \text {, } \\
\text { sludge- } 0.20\end{array}$ \\
\hline$\# 8$ & $1: 0$ & $0: 1$ & $\begin{array}{c}\text { leached boehmite- } 0.40, \text { sodium } \\
\text { oxalate- } 0.20 \text {, sludge- } 0.40\end{array}$ \\
\hline$\# 9$ & $1: 1$ & $0: 1$ & $\begin{array}{c}\text { leached boehmite- } 0.40 \text {, sodium } \\
\text { oxalate- } 0.20 \text {, sludge- } 0.20 \text {, NAS- } 0.20\end{array}$ \\
\hline$\# 10$ & $1: 0$ & 0 & na \\
\hline
\end{tabular}

The centrifuge screening test matrix presented in Table 3.2 and Table 3.3 includes the sludge solids to NAS ratio and the bulk inert solids (zirconium oxide) to base sludge ratio as variables with each simulant containing a total of $10-\mathrm{wt} \%$ solids. These samples were centrifuged and examined to see how they dewatered by measuring the percent centrifuged solids. The target was to achieve a $10-\mathrm{wt} \%$ to $40-\mathrm{wt} \%$ centrifuged solids range based on actual waste results, shown in Figure 3.1. All of the actual tank waste samples tested displayed this range of centrifuged solids. Based on these centrifuge results, three samples (\#7, 8, and 10) were chosen to be tested in the crossflow ultrafiltration unit to determine their actual filtration rates.

A wide range of slurry solids concentrations is characteristic of actual wastes when centrifuged at $1000 \mathrm{G}$, as shown in Figure 3.1. Comparing Figure 3.2 and Figure 3.3, the slurry simulants tested show a similar range of solids content between each other after centrifuging at $1000 \mathrm{G}$. These simulants all began as mixtures of supernate and solids and had an average UDS of $10.5 \mathrm{wt} \%$ (total range was $9.0 \mathrm{wt} \%$ to $11.7 \mathrm{wt} \%$ ). This consistency of behavior after centrifuging provides further support for using the centrifugation procedure to screen various simulants for behavior matching given actual waste slurries. Figure 3.3 shows the effect of gravity on slurry volume over the test range ( $1 \mathrm{G}$ to $4,500 \mathrm{G})$. The solids weight percent is calculated on the basis of mass of UDS divided by the mass of the slurry (volume $\times$ density). All of the data necessary to make these calculations are given in Appendix B. 
Table 3.3. Ultrafiltration Simulants for the Screening Test Matrix

\begin{tabular}{|c|c|c|c|c|c|c|c||}
\hline Simulant & $\begin{array}{c}\text { Sludge } \\
\text { Solids } \\
(\mathbf{w t \% )}\end{array}$ & $\begin{array}{c}\text { NAS } \\
(\mathbf{w t \% )}\end{array}$ & $\begin{array}{c}\mathbf{Z r O} \\
\mathbf{( w t \% )}\end{array}$ & $\begin{array}{c}\text { Boehmite } \\
\mathbf{( w t \% )}\end{array}$ & $\begin{array}{c}\text { Gibbsite } \\
\mathbf{( w t \% )}\end{array}$ & $\begin{array}{c}\text { Oxalate } \\
\mathbf{( w t \% )}\end{array}$ & $\begin{array}{c}\text { Leached } \\
\text { Boehmite } \\
\mathbf{( w t \% )}\end{array}$ \\
\hline$\# 1$ & 6.77 & 3.23 & 0 & 0 & 0 & 0 & 0 \\
\hline$\# 2$ & 5.06 & 2.41 & 2.53 & 0 & 0 & 0 & 0 \\
\hline$\# 3$ & 5.24 & 4.76 & 0 & 0 & 0 & 0 & 0 \\
\hline$\# 4$ & 7.56 & 2.44 & 0 & 0 & 0 & 0 & 0 \\
\hline$\# 5$ & 4.15 & 3.77 & 2.08 & 0 & 0 & 0 & 0 \\
\hline$\# 6$ & 5.49 & 1.77 & 2.74 & 0 & 0 & 0 & 0 \\
\hline$\# 7$ & 2.0 & 0 & 0 & 3.5 & 3.5 & 1.0 & 0 \\
\hline$\# 8$ & 4.0 & 0 & 0 & 0 & 0 & 2.0 & 4.0 \\
\hline$\# 9$ & 2.0 & 2.0 & 0 & 0 & 0 & 2.0 & 4.0 \\
\hline$\# 10$ & 10.0 & 0 & 0 & 0 & 0 & 0 & 0 \\
\hline
\end{tabular}

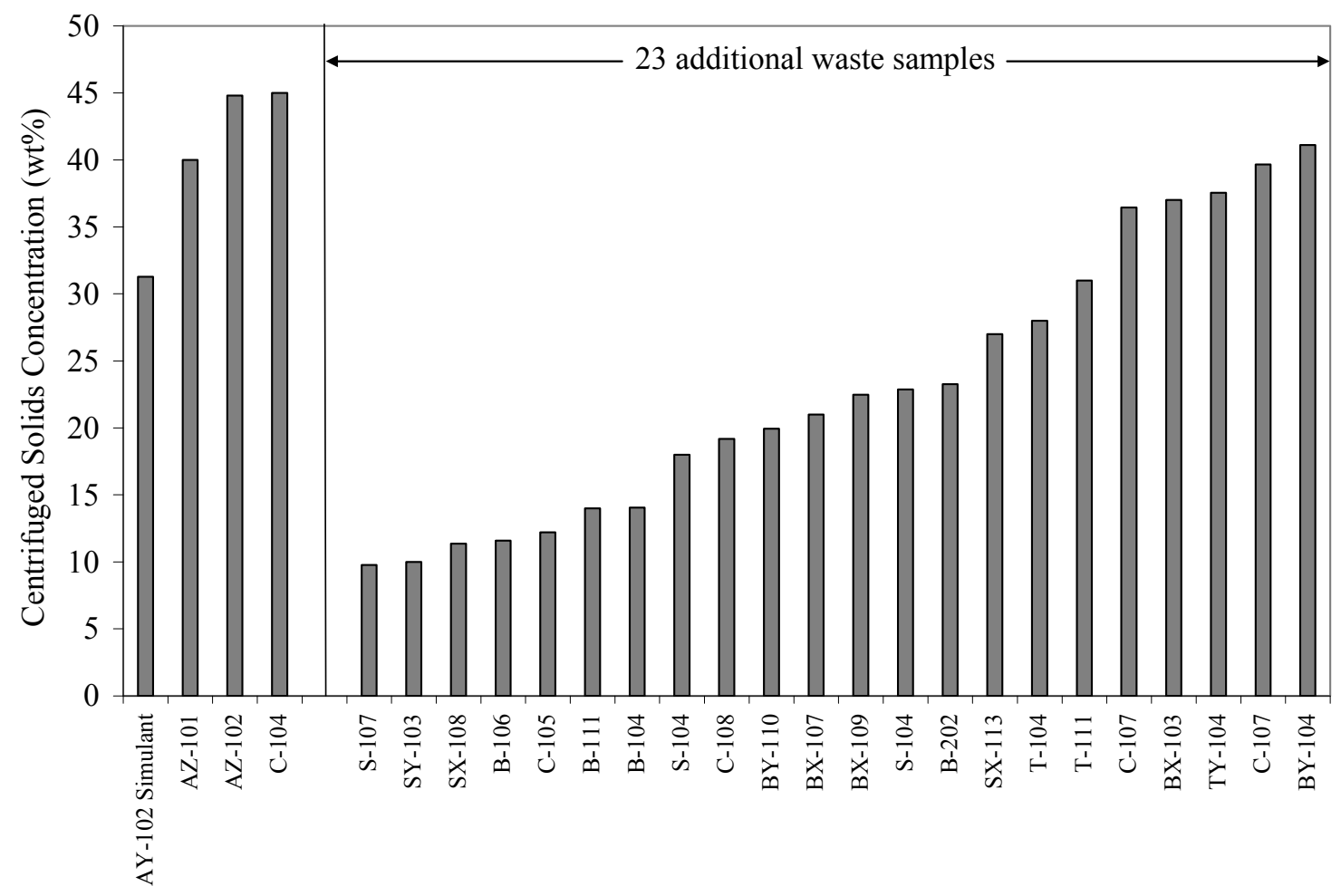

Figure 3.1. Measured Wt\% Solids of Tank Waste Samples Centrifuged at $1000 \mathrm{G}$ for 30 Minutes 


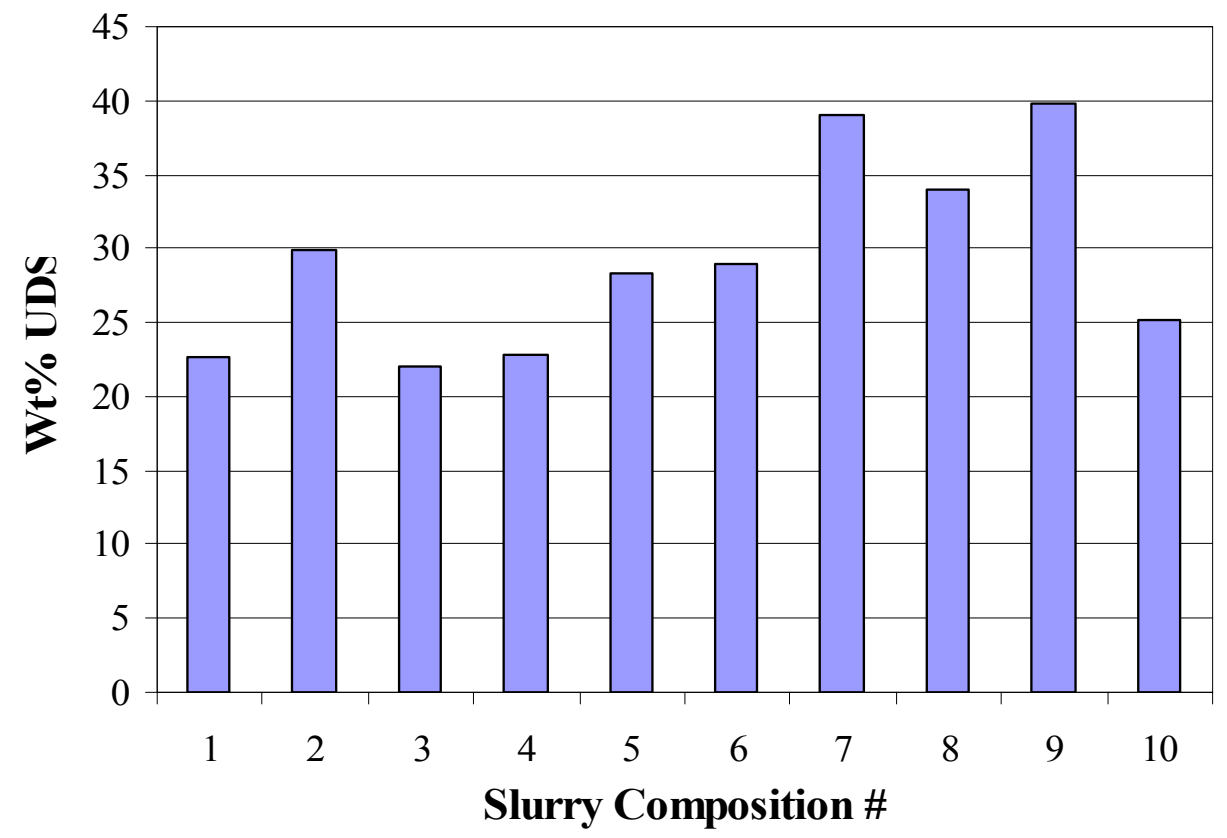

Figure 3.2. Simulant Slurry Wt\% UDS after Centrifugation at 1000 G for 30 Minutes (see Table 3.3 for slurry compositions)

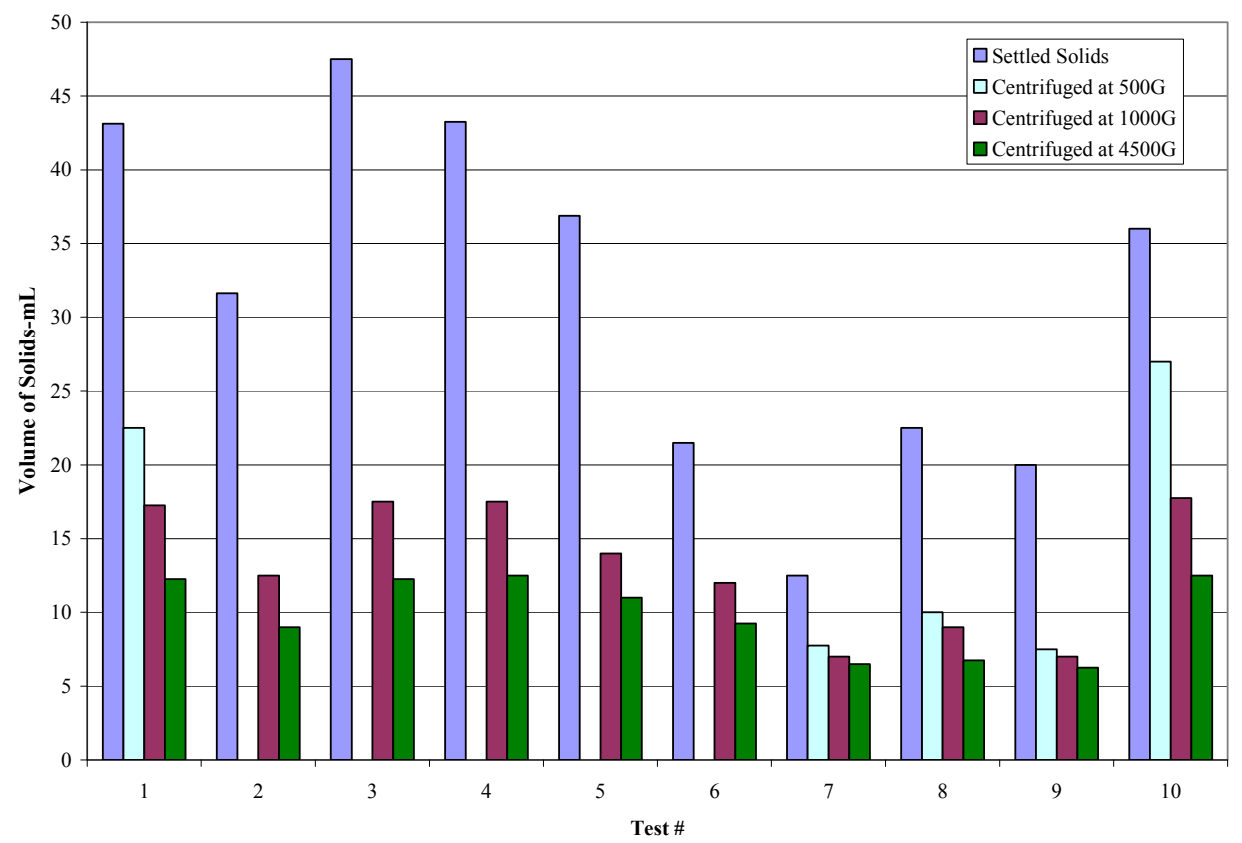

Figure 3.3. Centrifugation Results for the Centrifuge Simulants (see Table 3.3 for slurry compositions)

The comparison of the effects of variable amounts of the filtration simulant constituents considered can be seen in Figure 3.4. The concentration factor was calculated from the initial volume divided by the centrifuged volume on the basis of the volume at $4500 \mathrm{G}$. From these tests, it appears that adjusting the 
NAS to Fe ratio does not have an impact on solids concentration, and the leaching components (boehmite and gibbsite) appear to have the biggest effect as shown in Figure 3.4.

$1000 \mathrm{G}$ concentration factor

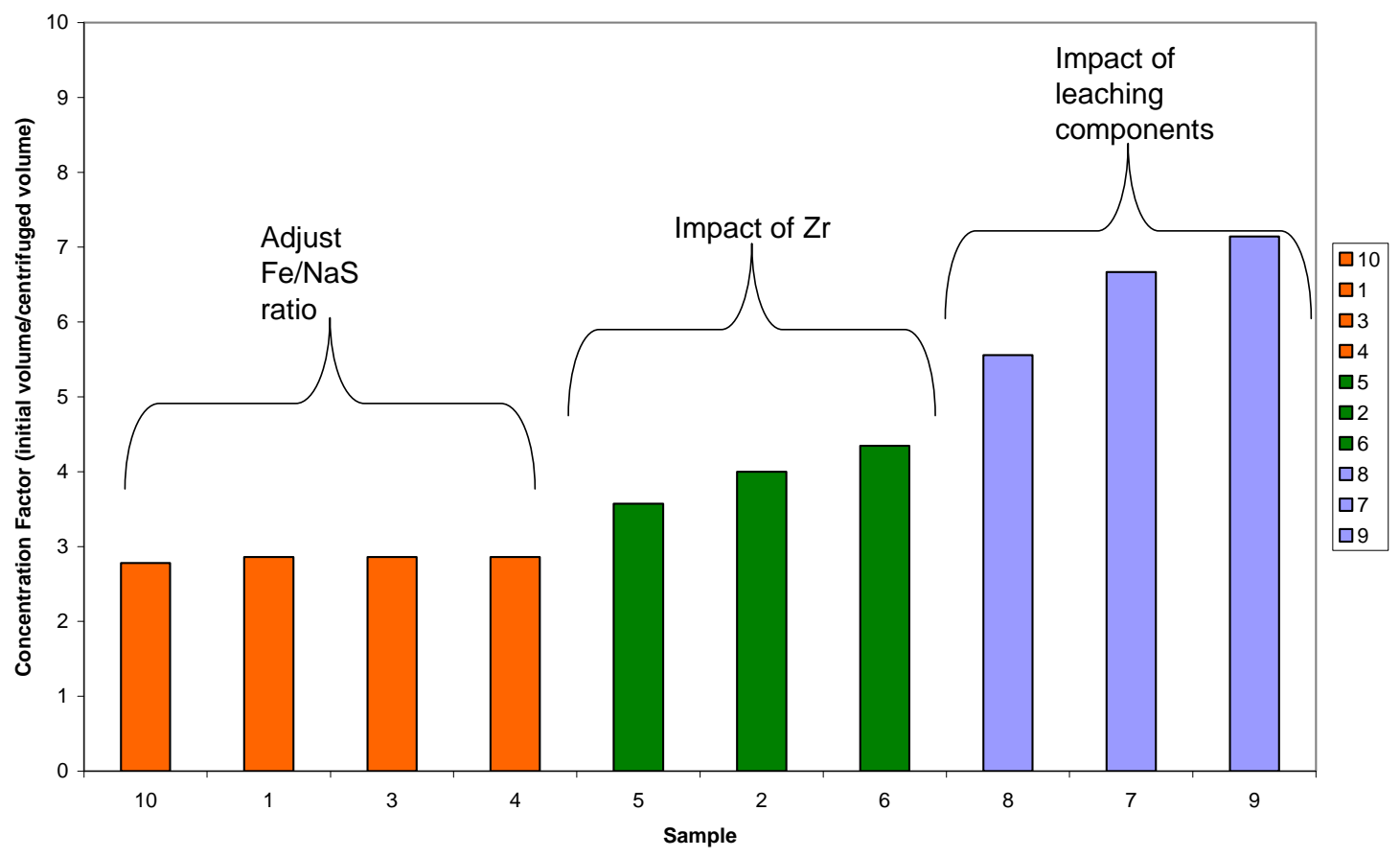

Figure 3.4. Observed Effect of Indicated Variables on Centrifuged Solids Volume in Response to Centrifugation at $1000 \mathrm{G}$ for Samples in Table 3.3

Three simulants (\#7, \#8, and \#10), which show a full range of settling properties, were chosen to be tested in the crossflow ultrafiltration unit to determine the maximum concentration achievable at a TMP of 40 psid and $13 \mathrm{ft} / \mathrm{s} \mathrm{AV}$. These filtration tests were part of a larger matrix that will be discussed further in Section 4.0.

The average solids concentration was measured at four different conditions, $1 \mathrm{G}$ (as received-settled), $500 \mathrm{G}, 1000 \mathrm{G}$, and $4500 \mathrm{G}$ each for 30 minutes for each slurry composition in Table 3.3. From this, estimates were made of the compressive yield stress using Equation 3.1. Note that these are estimates because the compressive pressure due to gravity in the slurry solids column ranges from zero at the top of the column to a maximum at the bottom of the column, so the degree of compaction will be lower at the top and greatest at the bottom. In a similar way, the TMP puts a compressive stress on the filter cake in the crossflow ultrafiltration unit. Appendix B summarizes the data acquired from these tests.

The results of the calculations described earlier as applied to slurry simulants \#7, \#8, and \#10 are shown in Figure 3.5. Note that the results plotted in Figure 3.5 are given in weight percent UDS, which is based on the volume fraction calculated using the parameters given in Table 3.4 and the model equation for $\Phi$. Note also that the values calculated for the plot relate to the maximum pressure generated at the base of the slurry column. The averaged results shown in Table 3.4 are based on column height after test completion (see Appendix B). Note again that the results plotted in Figure 3.5 are not the results given in 
Table 3.4. The results given in Table 3.4 are the averaged wt $\%$ UDS over the entire slurry column height in Figure 3.3. The results are given for the measured averaged gel point slurry solids concentrations for the three simulants after experiencing $1 \mathrm{G}, 500 \mathrm{G}, 1000 \mathrm{G}$, and $4500 \mathrm{G}$ centrifuge accelerations. These results indicate that the presence of the leaching components (gibbsite and bohemite) cause an increase in the gel point.

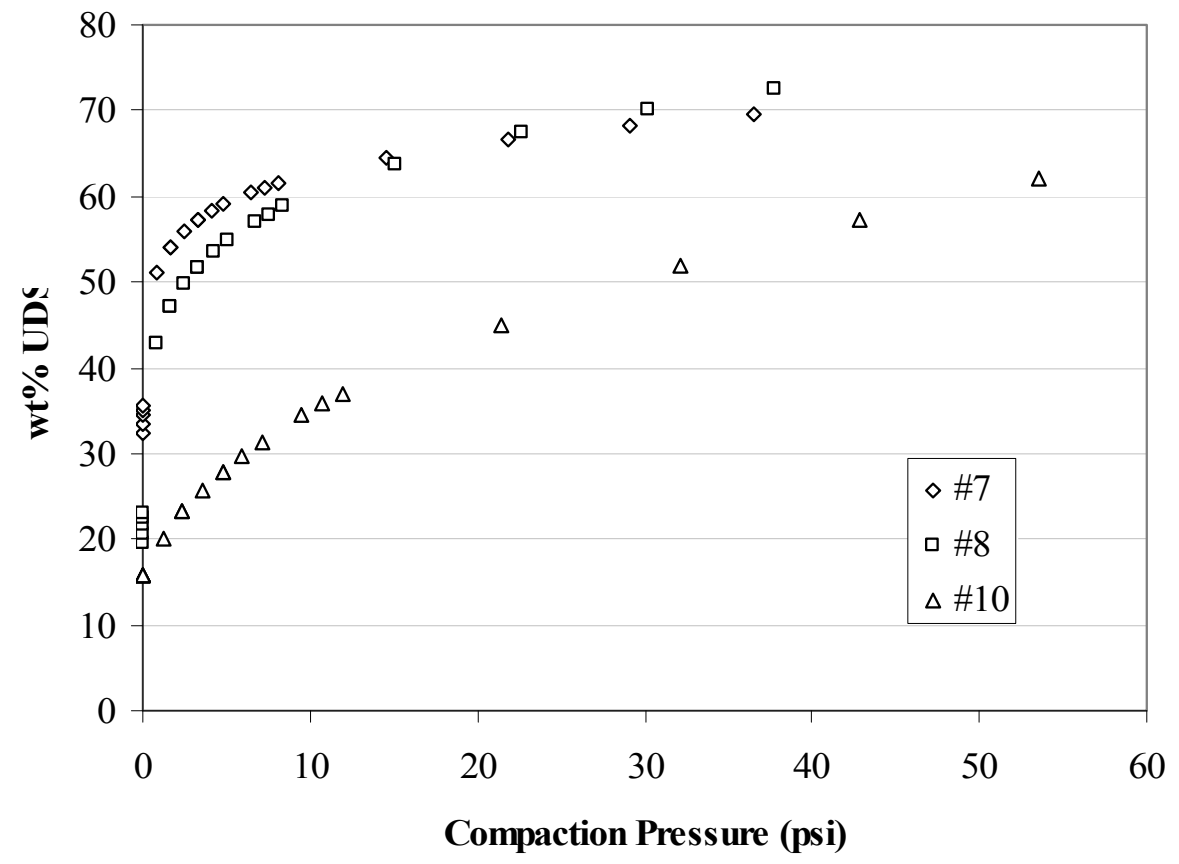

Figure 3.5. Wt\% UDS in Settled Slurry Simulant as a Function of Centrifuge Generated Compaction Pressure for Crossflow Ultrafiltration Slurry Simulants \#7, \#8, and \#10

Table 3.4. Averaged Gel Point as a Function of Centrifugal Force

\begin{tabular}{|c|c|c|c|c||}
\hline $\begin{array}{c}\text { Simulant } \\
\text { Slurry }\end{array}$ & $\begin{array}{c}\text { Gel Point } \\
-\mathbf{1 ~ G}\end{array}$ & $\begin{array}{c}\text { Gel Point } \\
-\mathbf{5 0 0} \text { G }\end{array}$ & $\begin{array}{c}\text { Gel Point } \\
\mathbf{- 1 0 0 0} \text { G }\end{array}$ & $\begin{array}{c}\text { Gel Point } \\
\mathbf{- 4 5 0 0} \text { G }\end{array}$ \\
\hline \multicolumn{4}{|c|}{ Average Wt\% UDS in gel volume } \\
\hline$\# 7$ & 33 & 38 & 40 & 47 \\
\hline$\# 8$ & 15 & 21 & 23 & 29 \\
\hline$\# 10$ & 12 & 14 & 15 & 20 \\
\hline
\end{tabular}

\subsubsection{Simulant Physical Characterization}

Particle-size characterization of these simulants was accomplished using a Mastersizer $2000^{(\mathrm{a})}$ with a Hydro $\mu \mathrm{P}$ wet dispersion accessory. The Hydro $\mu \mathrm{P}$ wet dispersion accessory consists of a $20-\mathrm{mL}$ sample flow cell with a variable and independent pump and ultrasound transducer. Both flow and sonication can be controlled independently and altered during measurement. As such, measurements can be made before, during, and after sample sonication, allowing determination of the influence of each on the distribution of particle sizes within the sample.

(a) Malvern Instruments, Inc., Southborough, MA 01772. 
Particle-size distributions (PSDs) of the simulants for Tests \#1 through \#10 consisted of particles ranging from $0.2 \mu \mathrm{m}$ to $720 \mu \mathrm{m}$. The distributions are at least bimodal, but most likely have particles of several different sizes since the peaks in the distribution are very broad compared to monodisperse systems. Table 3.5 shows the results of the PSD analysis on a volume basis. Sonication appears to have a significant effect on the PSD of these simulants except for simulants \#5, \#7, and \#9. In these simulants, the smaller particle sizes remain essentially the same; however, the larger particles tend to increase in \#1, $\# 6$, and \#10 with the $\mathrm{d}_{90}$ values almost doubling, indicating that sonication was promoting the growth of agglomerates. The data indicate that agglomeration in simulants $\# 2$ through $\# 4$ and $\# 8$ are disturbed by sonication at power as low as $10 \mathrm{~W}$, resulting in the largest particles observed in the unsonicated sample being eliminated and shifting the distribution to smaller particle diameters. Agglomeration of the particles occurs shortly after removing the sonication from the sample, resulting in a similar PSD to that observed before sonication. The smallest particles created by sonication do not appear to reagglomerate as quickly as the large particles as observed by the lack of change in the lower end of the PSD $\left(\mathrm{d}_{10}\right.$ and PSD from $0.2 \mu \mathrm{m}$ to $1 \mu \mathrm{m}$ ) after removing the sonication. Note that a range of particle behaviors with sonication have been observed with actual waste samples. However, matching particle size or agglomeration behavior were not criteria for the simulant selection, and, as such, this information should generally be considered background information regarding the simulant formulation.

Table 3.5. Results of the PSD Analysis on a Volume Basis for the Centrifuge Simulants

\begin{tabular}{|c|c|c|c|c|c|c|}
\hline \multirow{2}{*}{$\begin{array}{c}\text { Test } \\
\text { Simulant }\end{array}$} & \multicolumn{5}{|c|}{ Particle Diameter $(\boldsymbol{\mu m})$} \\
\cline { 2 - 7 } & \multicolumn{3}{|c|}{ Before Sonication } & \multicolumn{3}{c|}{ During Sonication } \\
\hline 1 & $\mathbf{d}(\mathbf{1 0})$ & $\mathbf{d ( 5 0 )}$ & $\mathbf{d}(\mathbf{9 0})$ & $\mathbf{d}(\mathbf{1 0})$ & $\mathbf{d}(\mathbf{5 0})$ & $\mathbf{d}(\mathbf{9 0})$ \\
\hline 2 & 1.2 & 6.6 & 130 & 1.0 & 4.0 & 210 \\
\hline 3 & 0.89 & 4.0 & 71 & 0.63 & 2.8 & 10 \\
\hline 4 & 0.98 & 3.2 & 32 & 0.84 & 2.7 & 8.5 \\
\hline 5 & 1.1 & 3.7 & 39 & 0.94 & 3.2 & 11 \\
\hline 6 & 0.80 & 2.4 & 8.0 & 0.57 & 2.2 & 6.7 \\
\hline 7 & 0.90 & 4.0 & 45 & 0.68 & 3.7 & 79 \\
\hline 8 & 1.2 & 5.9 & 14 & 1.1 & 5.6 & 13 \\
\hline 9 & 0.70 & 2.2 & 14 & 0.63 & 1.9 & 8.4 \\
\hline 10 & 0.66 & 2.1 & 18 & 0.57 & 1.8 & 18 \\
\hline
\end{tabular}

Rheology data were obtained on a Haake Rheostress RS600 rheometer with a Z41 Searle type measuring system where both speed and torque are measured at the rotating shaft. The rheometer was operated in the controlled rate mode. This geometry required approximately $13 \mathrm{~mL}$ of sample and had a gap of $6 \mathrm{~mm}$. The samples were shaken before they were measured to produce a fully suspended material. Shear stress was measured as a function of shear rate over a range of 0 to $1000 \mathrm{~s}^{-1}$. Measurements were made with both increasing and decreasing shear rate. These data are fit to a Bingham-Plastic rheology model. If Taylor vortices were observed, affected data were excluded from the model.

The Bingham-Plastic models for the rheograms for each of the simulants are shown in Table 3.6. The rheogram was modeled on the combined up (increasing shear rate) and down (decreasing shear rate) curves over the entire range of data that provided valid laminar flow. A Newtonian model is provided for 
simulant \#7, which did not exhibit a substantial yield stress $(0.02 \mathrm{~Pa}$ whereas all of the others were greater than $0.10 \mathrm{~Pa}$ ).

Table 3.6. Bingham Plastic Model Fits for the Centrifuge Simulants

\begin{tabular}{|c|c|c|c|}
\hline \multirow[b]{2}{*}{ Test Simulant } & \multicolumn{2}{|c|}{ Bingham Plastic Model Fit Parameters } & \multirow[b]{2}{*}{$\begin{array}{c}\text { Newtonian Model Fit } \\
\text { Viscosity (cP) }\end{array}$} \\
\hline & Yield Stress (Pa) & $\begin{array}{c}\text { Plastic Consistency } \\
\text { (cP) }\end{array}$ & \\
\hline 1 & 0.58 & 5.3 & \\
\hline 2 & 0.10 & 1.7 & \\
\hline 3 & 0.48 & 4.9 & \\
\hline 4 & 0.56 & 5.3 & \\
\hline 5 & 0.31 & 4.3 & \\
\hline 6 & 0.31 & 4.3 & \\
\hline 7 & 0.02 & 3.0 & 3.0 \\
\hline 8 & 0.20 & 3.8 & \\
\hline 9 & 0.18 & 3.9 & \\
\hline 10 & 0.86 & 5.7 & \\
\hline
\end{tabular}

\subsection{Screening Test Outcome}

As indicated in Figure 3.4, varying the Fe to NAS ratio did not significantly change the slurry weight percent UDS upon centrifugation. Since this value is a reasonable predictor of filtration behavior, it is expected that the Fe to NAS ratio would not have a significant impact on the filtration behavior. Thus, a decision was made to omit the NAS component from the simulant, as this simplified both the fabrication of the simulant and the understanding of the leaching behavior for other Al-bearing components.

Note that the presence of the leaching components is expected to result in higher filter fluxes. Therefore, the target was to attempt to achieve the lowest possible filter flux from the base inert material. Also, adding $\mathrm{ZrO}_{2}$ appeared to result in an increase in the slurry weight percent UDS upon centrifugation. Thus, $\mathrm{ZrO}_{2}$ was also omitted. As such, the sludge simulant solids (Table 2.2) were selected for the primary inert component for further filtration tests since they produced the lowest slurry weight percent UDS and therefore should produce the lowest filter flux and longest cycle time. 



\subsection{Filtration Screening Tests}

The next step in the process was to start assessing the impact of fines on filtration behavior with a particular goal of decreasing the low-solids filter flux. In addition, these tests were designed to confirm the projected high-solids filtration behavior based on the assessment in Section 3. As indicated in Table 1.2, the target flux ranged from 0.011 to $0.023 \mathrm{gpm} / \mathrm{ft}^{2}$, depending upon the process condition. The objective of this work was to attempt to achieve filter fluxes in this range.

As part of this test strategy, different amounts of inert fines ( $<1$ micron in size) were added to the simulant in an attempt to achieve lower initial filter fluxes. These inert fines were zirconium oxide. The size and amount of fines added was based on the $d_{5}$ or $d_{10}$ PSD of various actual tank waste samples. The $d_{5}$ and $d_{10}$ were chosen based on the expected fouling by only a small fraction of very small particles. On average, the various tank wastes are similar in PSD as seen in Table 4.1 (Geeting et al. 2003; Lumetta et al. 1996; Rapko et al. 1995; Temer and Villarreal 1996; Temer and Villarreal 1997; Lumetta et al. 1997).

Table 4.1. Size of Fines in Actual Tank Waste

\begin{tabular}{|l|c|c|c|c|}
\hline \multirow{2}{*}{} & \multicolumn{2}{|c|}{ Initial Tank Wastes } & \multicolumn{2}{c|}{ Treated Tank Wastes } \\
\cline { 2 - 5 } & Volume Dist. & Number Dist. & Volume Dist. & Number Dist. \\
\hline $\mathrm{d}_{5}(\mu \mathrm{m})$ & 0.69 & 0.32 & 0.87 & 0.35 \\
\hline $\mathrm{d}_{10}(\mu \mathrm{m})$ & 1.26 & 0.37 & 1.38 & 0.40 \\
\hline
\end{tabular}

The filtration screening tests consisted of three parts, the low-solids concentration matrix run conditions, the dewatering profile, and the high-solids concentration matrix run conditions. The results from each of these parts will be described and discussed as a unit, which includes all of the simulant compositions as indicated in Table 4.2.

\subsection{Screening Test Matrix}

Table 4.2 provides the sequence of tests performed as part of this test matrix. The test plan calls for the test matrix to examine the following variables: centrifuged solids percentage, PSD, and simulant aging. The filtration test matrix involved measuring the filter flux at various TMPs and AVs to observe the effects of these parameters. This filtration test matrix is provided in Table 2.1. The approach for evaluating each of these variables is outlined first. Then, the results for each variable are discussed in turn. Appendix D provides the letter for WTP approval of this test matrix.

\subsubsection{Centrifuged Solids Tests}

The intent of these tests was to confirm the expected filtration behavior predicted from Section 3. The impact of centrifuged solids concentration on filtration behavior was evaluated by comparing Tests $\mathrm{C}$, P3, and P4. As seen in Figure 3.4, these represent a range of conditions (Simulant \#8, \#10, and \#7 from Table 3.2). 
Table 4.2. Screening Test Matrix

\begin{tabular}{|c|c|c|c|c|c|c|c|c|c|}
\hline & \multirow[b]{2}{*}{ Test } & \multicolumn{5}{|c|}{ "Ratio of Solids Fractions } & \multirow{2}{*}{$\begin{array}{l}\text { Wt } \% \\
\text { UDS }\end{array}$} & \multirow[b]{2}{*}{ Condition } & \multirow[b]{2}{*}{ Notes } \\
\hline & & Sludge Simulant & Boehmite & Oxalate & Gibbsite & Fines & & & \\
\hline \multirow{7}{*}{$\begin{array}{l}\text { Simulant \#8-- } \\
\text { Leached Simulant }\end{array}$} & $\mathrm{C} 1 \mathrm{a}$ & 0.4 & 0.4 & 0.2 & 0 & 0 & 5 & Perform Filtration Test Matrix & 1 \\
\hline & $\mathrm{C} 1 \mathrm{~b}$ & 0.4 & 0.4 & 0.2 & 0 & 0 & $5-20$ & Dewater & 1 \\
\hline & $\mathrm{C} 1 \mathrm{c}$ & 0.4 & 0.4 & 0.2 & 0 & 0 & 20 & Perform Filtration Test Matrix & 1,2 \\
\hline & $\mathrm{P} 1$ & 0.4 & 0.4 & 0.2 & 0 & $0.0408 \mathrm{~g} \mathrm{ZrO}_{2}$ & 5 & \begin{tabular}{|l} 
Perform Filtration Test Matrix \\
\end{tabular} & 1 \\
\hline & $\mathrm{P} 2 \mathrm{a}$ & 0.4 & 0.4 & 0.2 & 0 & $0.0856 \mathrm{~g} \mathrm{ZrO}_{2}$ & 5 & \begin{tabular}{|l} 
Perform Filtration Test Matrix \\
\end{tabular} & 1 \\
\hline & $\mathrm{P} 2 \mathrm{~b}$ & 0.4 & 0.4 & 0.2 & 0 & 0.00015 & $5-20$ & Dewater & 1 \\
\hline & $\mathrm{P} 2 \mathrm{c}$ & 0.4 & 0.4 & 0.2 & 0 & 0.0006 & 20 & Perform Filtration Test Matrix & 1,3 \\
\hline \multicolumn{10}{|c|}{ Clean The Filter } \\
\hline \multirow[t]{3}{*}{$\begin{array}{l}\text { Simulant } \# 10- \\
\text { Sludge Simulant } \\
\text { Only }\end{array}$} & $\mathrm{P} 3 \mathrm{a}$ & 1 & 0 & 0 & 0 & 0 & 5 & Perform Filtration Test Matrix & \\
\hline & $\mathrm{P} 3 \mathrm{~b}$ & 1 & 0 & 0 & 0 & 0 & $5-20$ & Dewater & \\
\hline & $\mathrm{P} 3 \mathrm{c}$ & 1 & 0 & 0 & 0 & 0 & 20 & Perform Filtration Test Matrix & 3 \\
\hline \multicolumn{10}{|c|}{ Clean the Filter } \\
\hline \multirow{7}{*}{$\begin{array}{l}\text { Simulant \#7 - } \\
\text { Initial Feed } \\
\text { Simulant }\end{array}$} & $\mathrm{P} 4 \mathrm{a}$ & 0.2 & 0.35 & 0.1 & 0.35 & 0 & 5 & Perform Filtration Test Matrix & \\
\hline & $\mathrm{P} 4 \mathrm{~b}$ & 0.2 & 0.35 & 0.1 & 0.35 & 0 & $5-20$ & Dewater & \\
\hline & $\mathrm{P} 4 \mathrm{c}$ & 0.2 & 0.35 & 0.1 & 0.35 & 0 & 20 & Perform Filtration Test Matrix & 2 \\
\hline & P5 & 0.2 & 0.35 & 0.1 & 0.35 & $0.0458 \mathrm{~g} \mathrm{ZrO}_{2}$ & 5 & Perform Filtration Test Matrix & \\
\hline & P6a & 0.2 & 0.35 & 0.1 & 0.35 & $0.0688 \mathrm{~g} \mathrm{ZrO}_{2}$ & 5 & Perform Filtration Test Matrix & \\
\hline & $\mathrm{P} 6 \mathrm{~b}$ & 0.2 & 0.35 & 0.1 & 0.35 & 0.00014 & $5-20$ & Dewater & \\
\hline & P6c & 0.2 & 0.35 & 0.1 & 0.35 & 0.0005 & 20 & Perform Filtration Test Matrix & 3 \\
\hline \multicolumn{10}{|c|}{ Clean the Filter } \\
\hline \multirow[t]{3}{*}{ Aged Simulant \#8 } & $\mathrm{P} 7 \mathrm{a}$ & 0.4 & 0.4 & 0.2 & 0 & 0 & 5 & Perform Filtration Test Matrix & 1,4 \\
\hline & $\mathrm{P} 7 \mathrm{~b}$ & 0.4 & 0.4 & 0.2 & 0 & 0 & $5-20$ & Dewater & 1,4 \\
\hline & $\mathrm{P} 7 \mathrm{c}$ & 0.4 & 0.4 & 0.2 & 0 & 0 & 20 & Perform Filtration Test Matrix & 1,4 \\
\hline \multicolumn{10}{|c|}{$\begin{array}{l}\text { Notes: } \\
1 \text { - Uses leached boehmite, } 8 \text { hours at } 100^{\circ} \mathrm{C} \text {. } \\
2 \text { - Add back supernatant at end of test. } \\
3 \text { - Clean filter after the test. } \\
4 \text { - Simulant aged prior to use. }\end{array}$} \\
\hline
\end{tabular}




\subsubsection{Particle-Size Distribution (Fines) Tests}

The purpose of this series of tests was to assess the impact of adding fines on filter fluxes. Table 4.3 provides the PSD for the Simulant \#8 sample (from Table 4.2) and the $\mathrm{ZrO}_{2}$ fines. Based on these compositions, adding 0.00007 grams of $\mathrm{ZrO}_{2}$ fines/gram of insoluble solids should result in lowering the number count $\mathrm{d}_{5}$ for the sample to approximately 0.32 microns. Bringing the total to 0.00015 grams of $\mathrm{ZrO}_{2}$ fines/gram of insoluble solids should result in a $\mathrm{d}_{10}$ for the sample of approximately 0.32 microns. These $d_{5}$ and $d_{10}$ values are approximately equivalent (and as close as can be practically predicted) to the targets ( 0.32 and 0.37 microns for actual waste samples). Two separate groups of tests were done to examine the impact of fines on filtration behavior. These results will be discussed in Section 4.2.

Table 4.3. PSD Analysis for Simulant \#8 and for Proposed $\mathrm{ZrO}_{2}$ Fines

\begin{tabular}{||c|c|c|c|c||}
\hline \multirow{2}{*}{} & \multicolumn{2}{|c|}{ Simulant \#8 } & \multicolumn{2}{c|}{$\begin{array}{c}\text { Fines (Alfa Aesar } \mathbf{Z r O}_{2} \\
\text { Powder) }\end{array}$} \\
\cline { 2 - 5 } & Volume & Number & Volume & Number \\
\hline $\mathrm{d}_{5}$ & 0.82 & 0.54 & 0.11 & 0.091 \\
\hline $\mathrm{d}_{10}$ & 0.98 & 0.58 & 0.12 & 0.094 \\
\hline $\mathrm{d}_{20}$ & 1.3 & 0.64 & 0.14 & 0.10 \\
\hline $\mathrm{d}_{30}$ & 1.9 & 0.70 & 0.17 & 0.11 \\
\hline $\mathrm{d}_{40}$ & 3.0 & 0.76 & 0.20 & 0.11 \\
\hline $\mathrm{d}_{50}$ & 4.8 & 0.83 & 0.24 & 0.12 \\
\hline $\mathrm{d}_{60}$ & 6.7 & 0.90 & 0.32 & 0.13 \\
\hline $\mathrm{d}_{70}$ & 8.5 & 0.99 & 0.46 & 0.14 \\
\hline $\mathrm{d}_{80}$ & 11 & 1.1 & 0.72 & 0.16 \\
\hline $\mathrm{d}_{90}$ & 14 & 1.4 & 1.2 & 0.19 \\
\hline $\mathrm{d}_{95}$ & 18 & 1.7 & 1.7 & 0.23 \\
\hline \hline
\end{tabular}

\subsubsection{Aging Test}

The purpose of this test was to assess whether aging the simulant significantly changed the filter flux. Tests $\mathrm{C} 1$ and $\mathrm{P} 7$ were compared to evaluate the impact of aging on filtration behavior, with Test P7 being aged and Test $\mathrm{C} 1$ not aged with the same composition. Before starting Test $\mathrm{P} 7$, the simulant was aged by maintaining the temperature at $98^{\circ} \mathrm{C}$ for 10 days while continuously mixing with an overhead stirrer at $120 \mathrm{rpm}$ to accelerate the aging process of the simulant. Previous work (Eibling 2005) has shown that heat treatment (up to 32 hours at boiling temperatures) will accelerate the crystallization of selected components of the simulant. In particular, they found that the iron components converted from an amorphous phase to hematite and siderite. These changes in crystallinity also resulted in changes in the rheological properties of the simulant. It is generally expected that these reactions will have reached completion in 10 days at elevated temperature. However, it is recognized that this approach does not completely simulate the extended storage of actual waste, but represents the best currently available approach. 


\subsection{Initial Feed Characterization}

Physical-property measurements of the low-solids slurry are detailed in Table 4.4. The physical properties were all very similar for the slurries with densities ranging from $1.19 \mathrm{~g} / \mathrm{mL}$ to $1.22 \mathrm{~g} / \mathrm{mL}$ and the UDS ranging from $3.4 \mathrm{wt} \%$ to $5.5 \mathrm{wt} \%$.

Table 4.4. Physical-Property Measurements of the Low-Solids Slurries

\begin{tabular}{||l|c|c|c|c|c|c|c|c||}
\hline \multicolumn{1}{|c|}{ Test ID } & C1 & P1 & P2 & P3 & P4 & P5 & P6 & P7 \\
\hline Slurry Density $(\mathrm{g} / \mathrm{mL})$ & 1.21 & 1.21 & 1.21 & 1.19 & 1.22 & 1.22 & 1.22 & 1.21 \\
\hline Supernate Density $(\mathrm{g} / \mathrm{mL})$ & 1.14 & 1.14 & 1.14 & 1.13 & 1.12 & 1.12 & 1.12 & 1.14 \\
\hline Total Solids $(\mathrm{wt} \%)$ & 17.5 & 18.2 & 18.7 & 18.1 & 18.7 & 19 & 18.3 & 19.1 \\
\hline Dissolved Solids (wt\%) & 14.6 & 14.6 & 15.0 & 14.6 & 14.3 & 14.3 & 14.3 & 14.5 \\
\hline UDS (wt\%) & 3.40 & 4.22 & 4.35 & 4.10 & 5.13 & 5.48 & 4.67 & 5.38 \\
\hline
\end{tabular}

PSD measurements were performed on the slurry samples using an S3000 Microtrac Analyzer according to procedure TPR-RPP-WTP-222, Rev. 3. Nominally 0.2 grams of each sample (run in duplicate) was placed into approximately 10 grams of DI water, and 2 to 3 drops of Darvan ${ }^{\circledR}$ 821A Dispersing Agent was added. The resultant slurry was de-agglomerated using an ultrasonic horn (MICROGON Ultrasonic Cell Disrupter) intermittently for 15 to 20 seconds. A transfer pipette was used to mix the slurry and transfer the required amount to the analyzer. The amount of the slurry sample aliquot required for analysis varied with the actual mass of the sample and the volume of DI water in the sonicated sample. Neither the amount of sample nor the amount of water was critical to the analytical process since the internal system software visually indicated to the analyst the amount needed for analysis. Repeated measurements were made on each sample, both with and without sonication.

Some typical PSDs are shown in Figure 4.1 through Figure 4.3. These plots are shown in volume distribution to show the effect of sonication on the agglomeration, which cannot be seen with a number distribution since the number count of agglomerates is so low. These results either show little or no effect of sonication on the PSD, such as shown in Figure 4.1, or definite interaction with the slurry, causing agglomerates to disperse as in Figure 4.2 or to form as in Figure 4.3. In the case of the lack of change in Figure 4.1, fine zirconia had been added to the P2 slurry and may be the reason for the lack of change. 


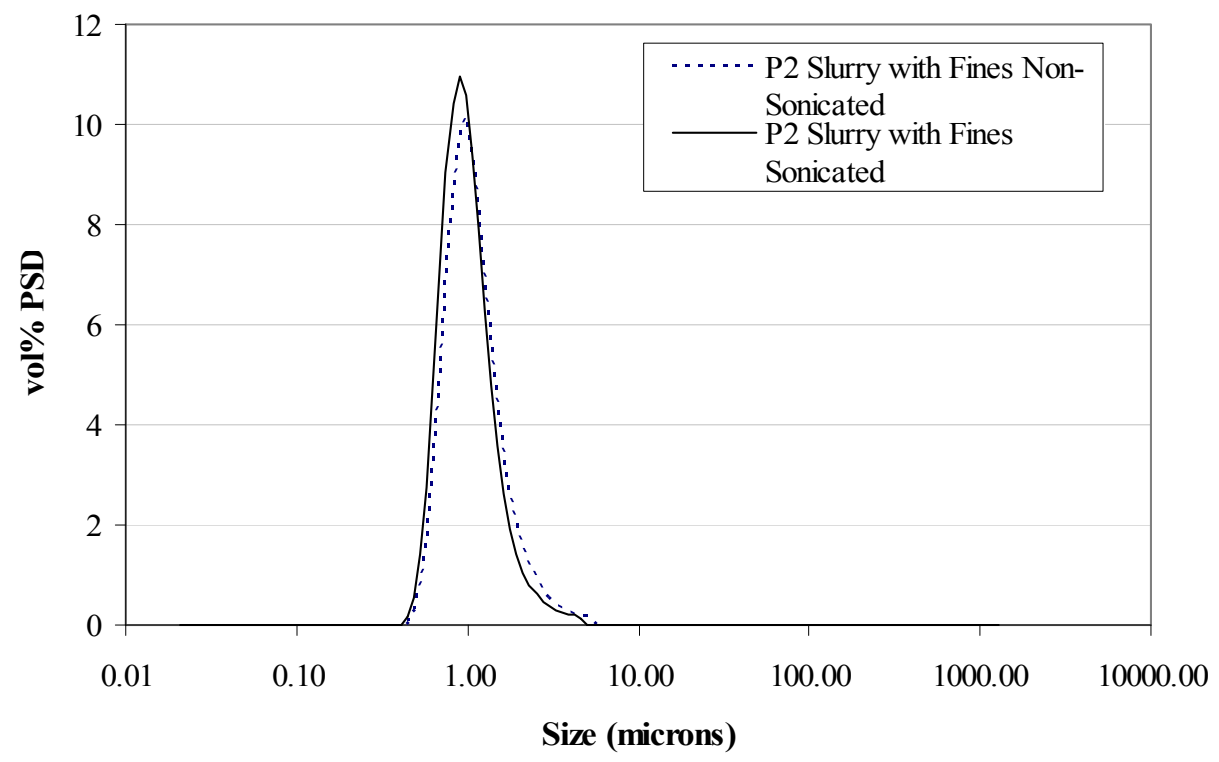

Figure 4.1. Example of No Effect of Sonication on P2 Slurry with Fines

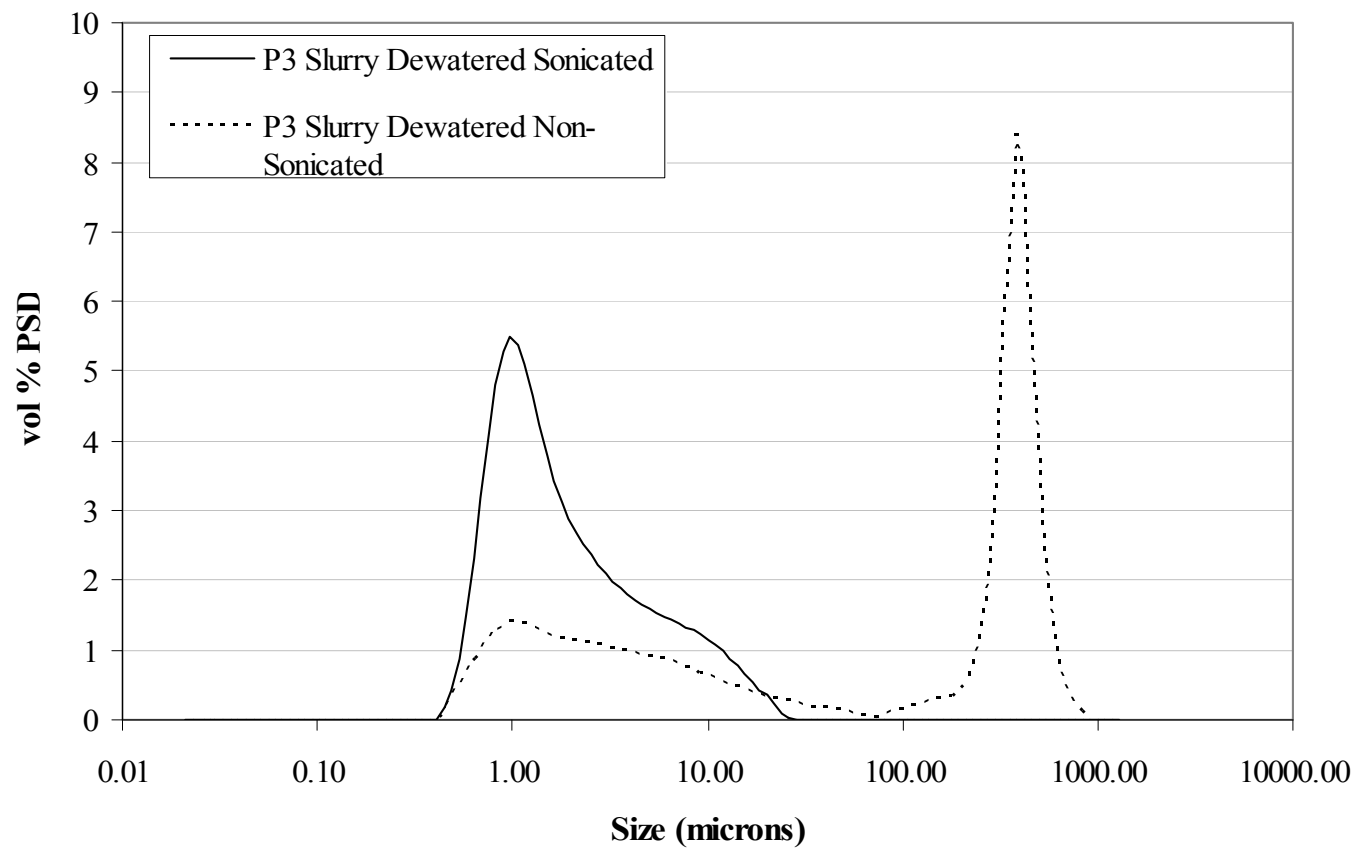

Figure 4.2. Example of Agglomerate Disruption by Sonication of Dewatered P3 Slurry 


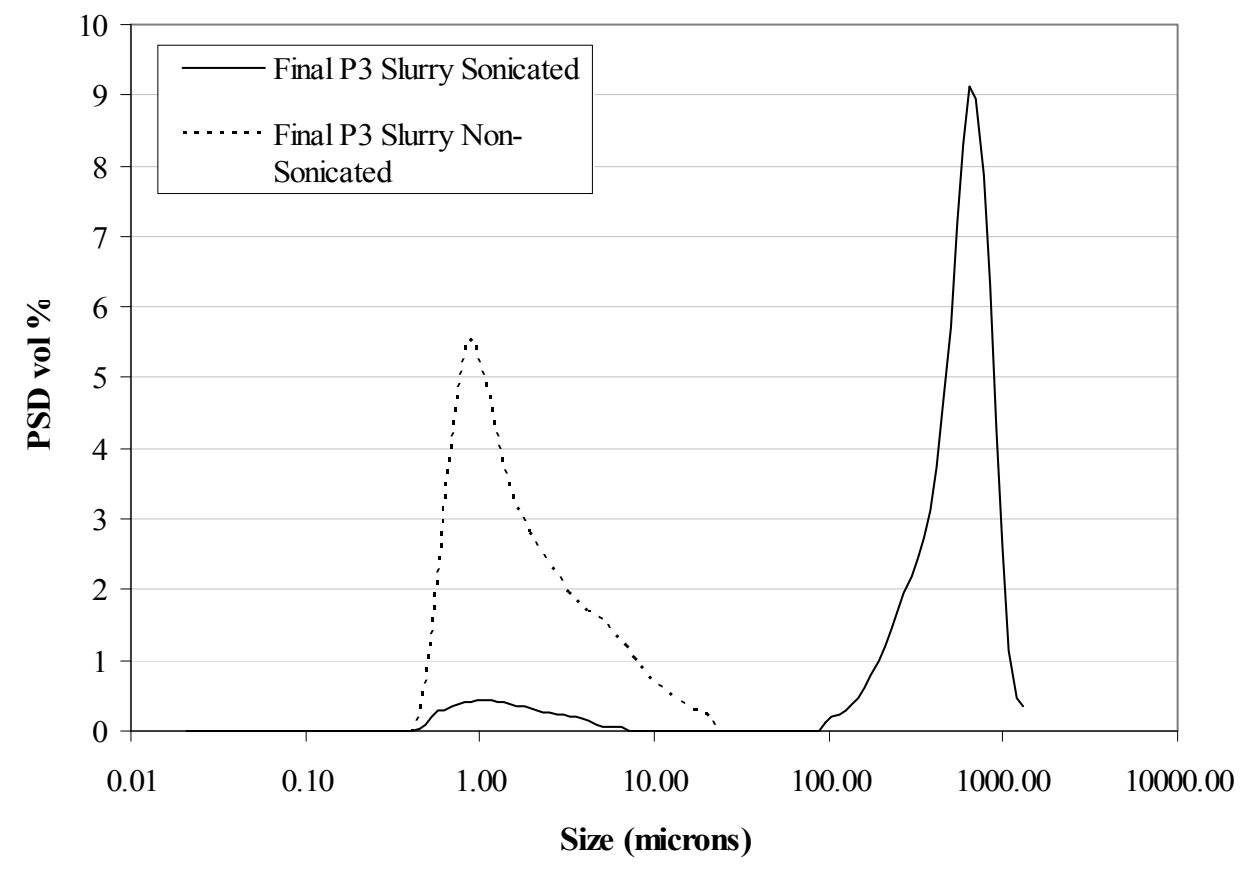

Figure 4.3. Example of Agglomerate Formation by Sonication of Final P3 Slurry

\subsection{Centrifuged Solids Tests}

As indicated above, Tests $\mathrm{C} 1 \mathrm{~b}, \mathrm{P} 3 \mathrm{~b}$, and $\mathrm{P} 4 \mathrm{~b}$ involved dewatering of the slurries to approximately $20-\mathrm{wt} \%$ UDS.

As seen in Figure 4.4, the initial flux for the leached slurry (Test C1b) is relatively high at approximately $0.06 \mathrm{gpm} / \mathrm{ft}^{2}$. However, at higher solids contents, the flux begins to decline rapidly and tracks linearly on the semi-log plot. This result is consistent with the expected result that at low-solids, the filter flux is governed by fines fouling, but as the solids content increases, the filter flux becomes controlled by cake formation. The intercept is calculated to be $31{ }^{\circ} \mathrm{wt} \%$ UDS for this test as compared to $29-\mathrm{wt} \%$ UDS by centrifuging as seen in Table 3.4 . 


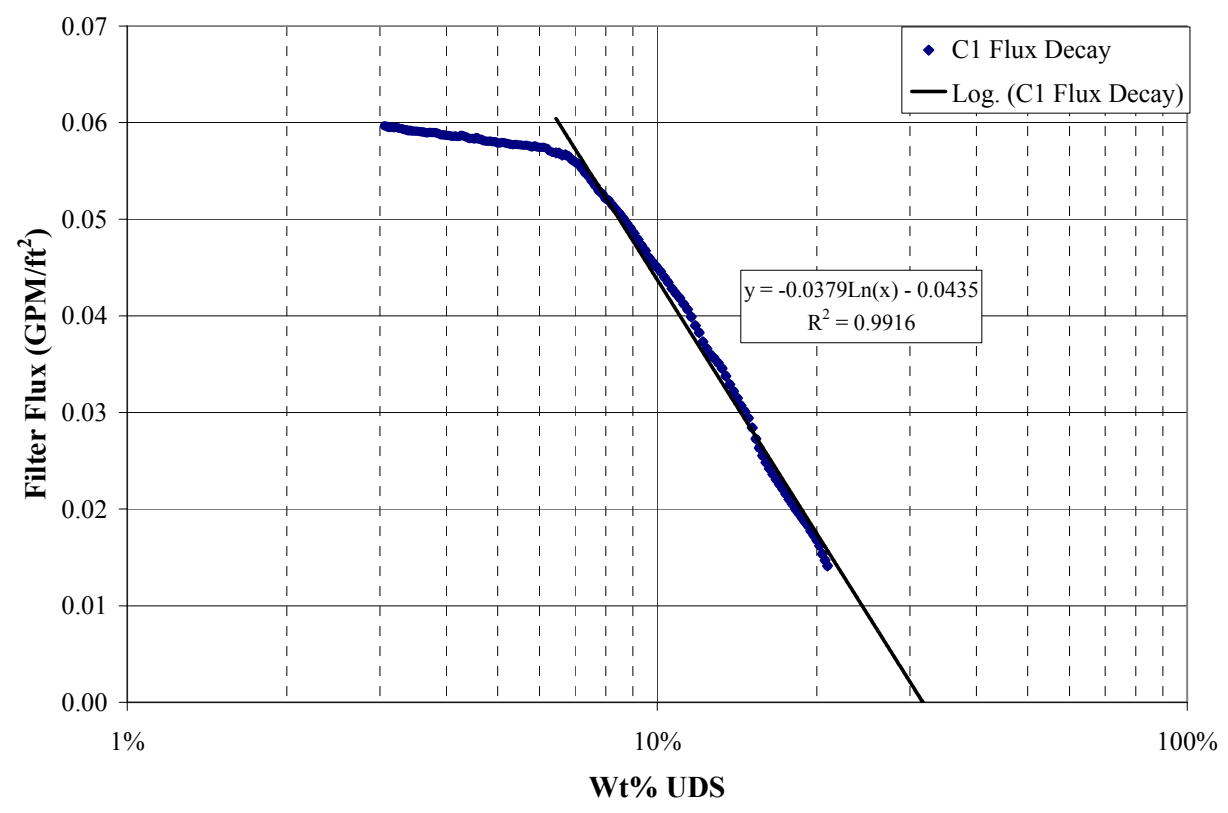

Figure 4.4. Test C1b—Leached Slurry Simulant \#8: Permeate Flux vs. Wt\% UDS

As seen in Figure 4.5, the initial flux for the inert sludge solids slurry (Test P3b) is lower at approximately $0.04 \mathrm{gpm} / \mathrm{ft}^{2}$. Again, at higher solids contents, the flux begins to decline rapidly and tracks linearly on the semi-log plot. This transition occurs at around the same solids concentration (between 6 and $8 \mathrm{wt} \%$ ), and the intercept, as expected, is lower. The intercept is calculated to be $21.4-\mathrm{wt} \%$ UDS for this test based on the crossflow ultrafiltration testing and was measured as 20 -wt $\%$ UDS with centrifuging at $4500 \mathrm{G}$. Note that at very high-solids concentration, the plot deviates from this curve. At this point, this phenomenon is not completely understood. However, this phenomenon has only been observed to date for slurries that are beyond the practical rheological operating limits of the WTP. 


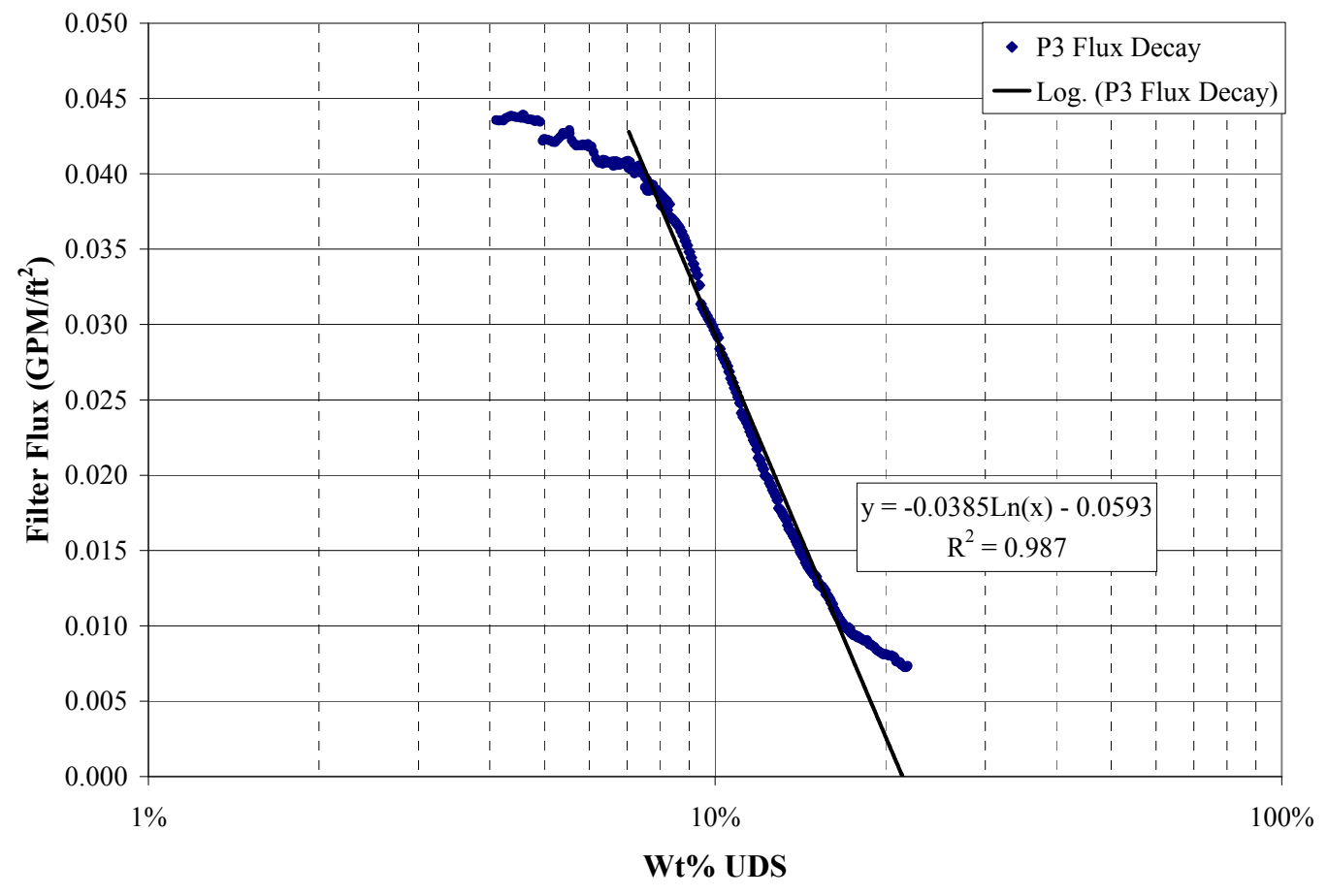

Figure 4.5. Test P3b - Inert Sludge Solids Simulant \#10: Permeate Flux vs. Wt\% UDS

As seen in Figure 4.6, the initial flux for the inert sludge solids slurry (Test P4b) is approximately $0.06 \mathrm{gpm} / \mathrm{ft}^{2}$. However, for this simulant, the flux does not begin to decline rapidly, but merely drifts down with extended operating time. These results indicate that the transition to solids-limited filter flux occurs above $30 \mathrm{wt} \%$. This lack of a transition is consistent with the relatively higher gel concentration of 47 -wt\% UDS observed in the centrifuge tests (Table 3.4). It is likely that were this simulant concentrated to $47-\mathrm{wt} \%$ UDS, a transition might be observed. 


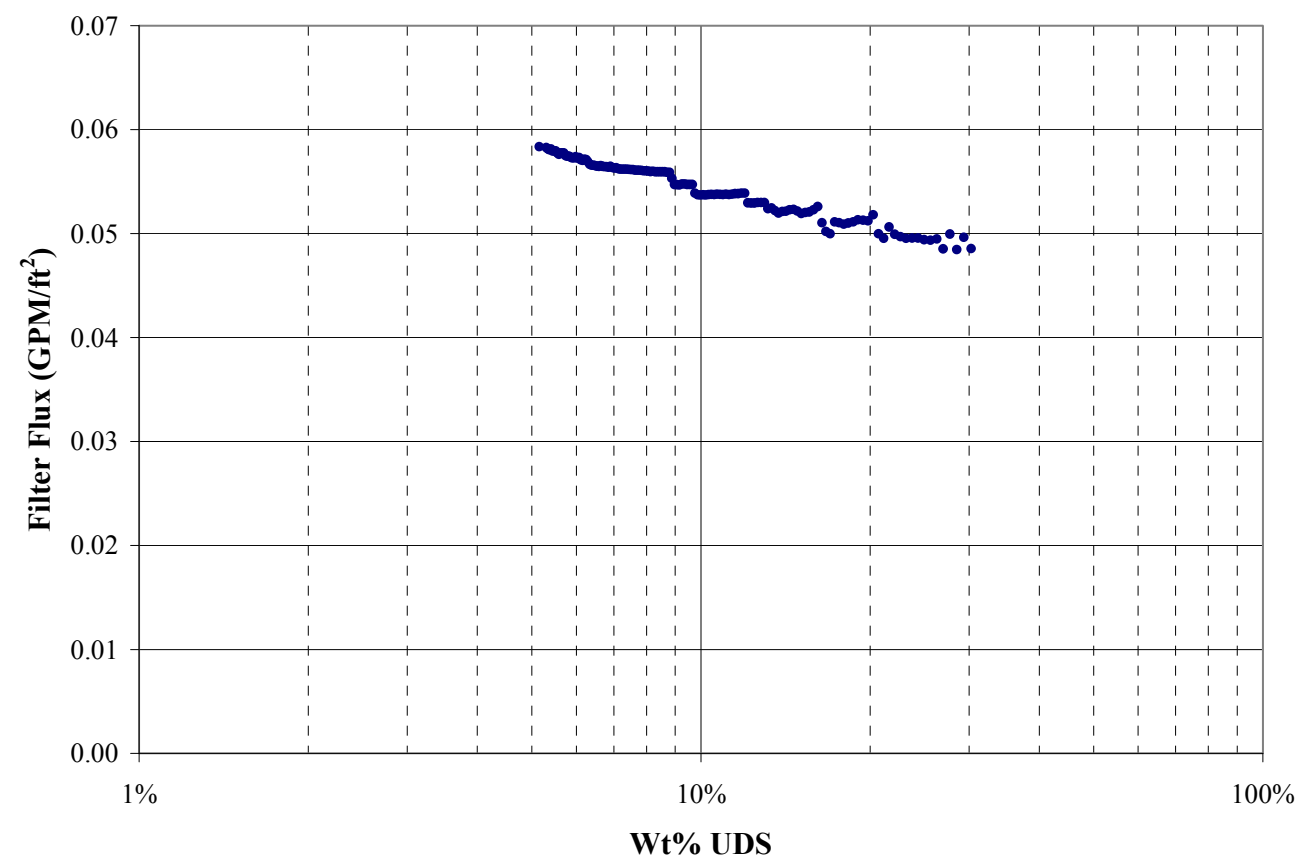

Figure 4.6. Initial Feed Simulant \#7: Permeate Flux vs. Wt\% UDS

\subsection{Fines Tests}

As indicated in Table 4.2, a series of tests were performed at low-solids concentrations to evaluate the impact of fines on filter flux. The full filter matrix test was performed on the slurry prepared as outlined in Appendix A. The UDS concentration of the slurry was approximately $4 \mathrm{wt} \%$ as measured by drying. The filter was back-pulsed between test conditions.

Tests P4a, P5, and P6a were performed to show the impact of adding inert fines for the unleached simulant (Simulant \#7) with the results shown in Figure 4.7 through Figure 4.9. The initial flux was relatively high, $0.08 \mathrm{gpm} / \mathrm{ft}^{2}$, but dropped to roughly $0.06 \mathrm{gpm} / \mathrm{ft}^{2}$ at the end of the approximately 7 hours of testing as shown in Figure 4.7. However, after returning to the original slurry volume (following tests $\mathrm{P} 4 \mathrm{~b}$ and $\mathrm{c}$ ), the filter flux had declined to approximately $0.04 \mathrm{gpm} / \mathrm{ft}^{2}$ in Test P5 (Figure 4.8). The filter flux remained effectively at $0.04 \mathrm{gpm} / \mathrm{ft}^{2}$ throughout the duration of the testing at $40 \mathrm{psid} \mathrm{TMP}$ and $13 \mathrm{ft} / \mathrm{s}$ AV with low-solids concentrations through both of the inert fines additions. The slurry concentration was $5-w t \%$ UDS in tests P5 and P6a in and Figure 4.8 and Figure 4.9. These results indicate that fines addition for the initial simulant did not produce any apparent change in the filter flux. These results do show, however, that significant fouling of the filter will occur with the baseline simulant during the dewatering operations. The flux at the end of test $\mathrm{P} 4 \mathrm{a}$ was between $0.06 \mathrm{gpm} / \mathrm{ft}^{2}$ and $0.07 \mathrm{gpm} / \mathrm{ft}^{2}$. However, after dewatering and the subsequent return to low-solids content, the flux at the same conditions (13 ft/s AV and $40 \mathrm{psid}$ TMP) was $0.05 \mathrm{gpm} / \mathrm{ft}^{2}$. 


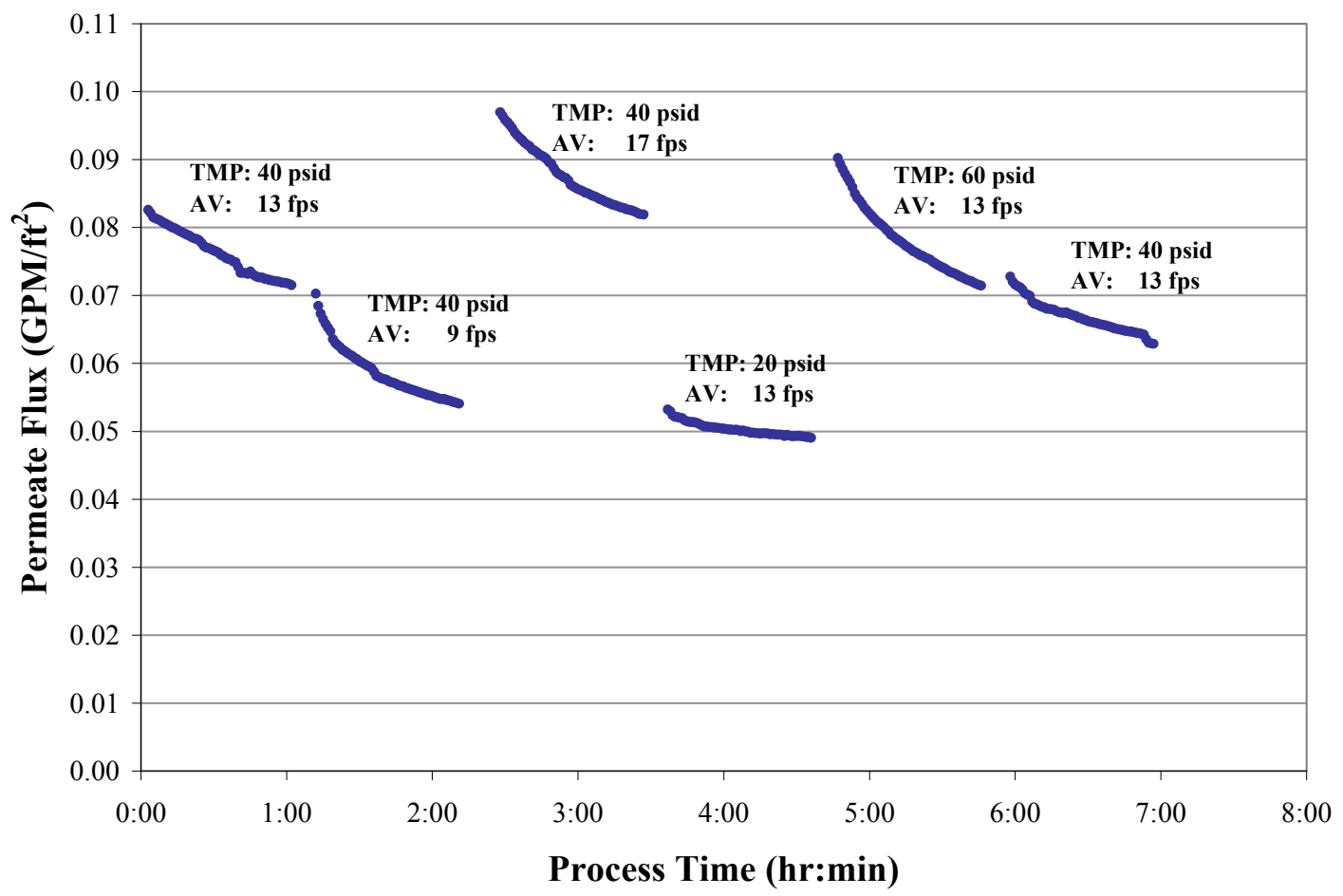

Figure 4.7. Low-Solids Filter Flux for Simulant \#7 (Test P4a) Initial Feed Based on Table 2.1

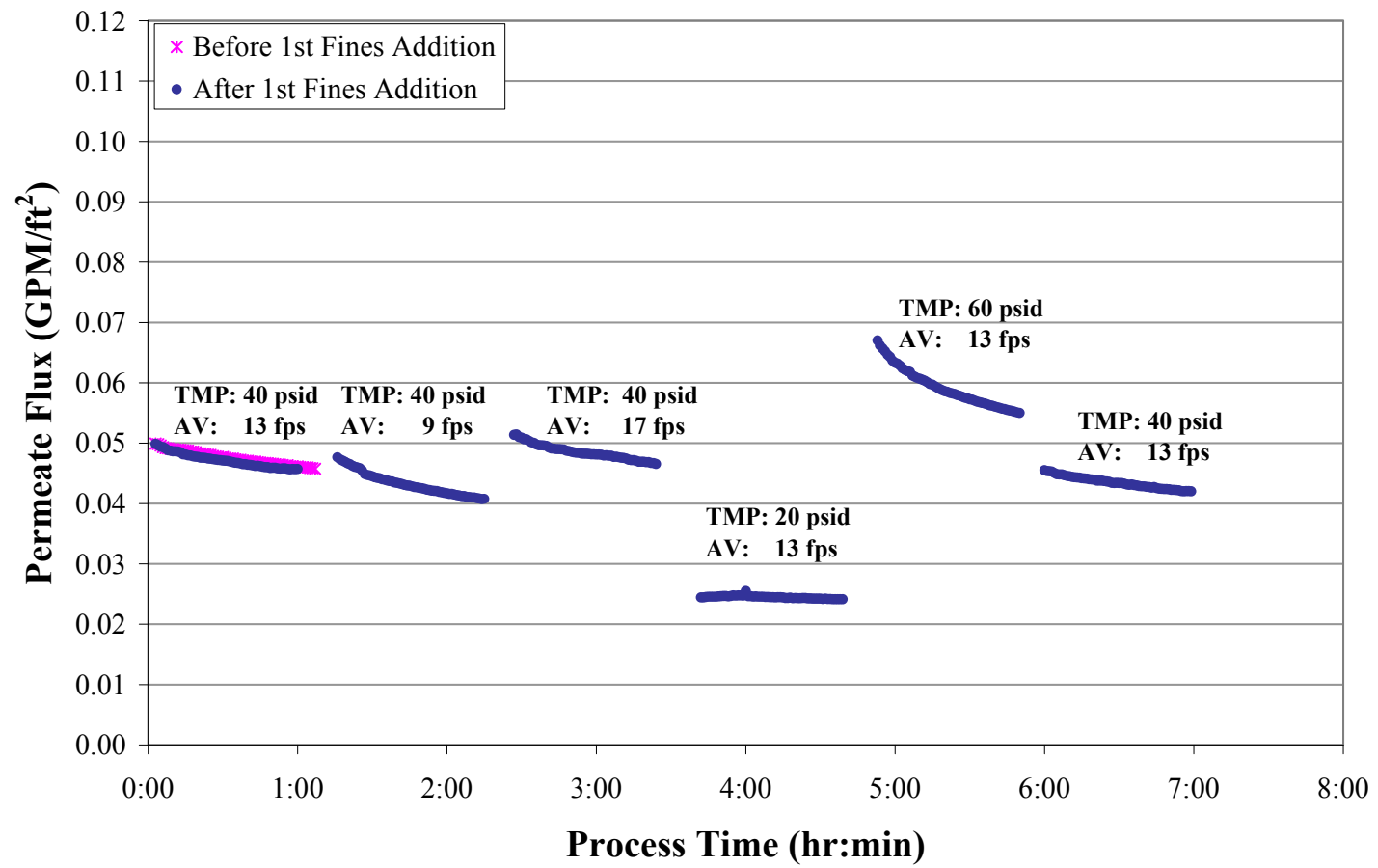

Figure 4.8. Low-Solids Filter Flux for Simulant \#7 (Test P5) with $d_{5}$ Fines Addition Based on Table 2.1 


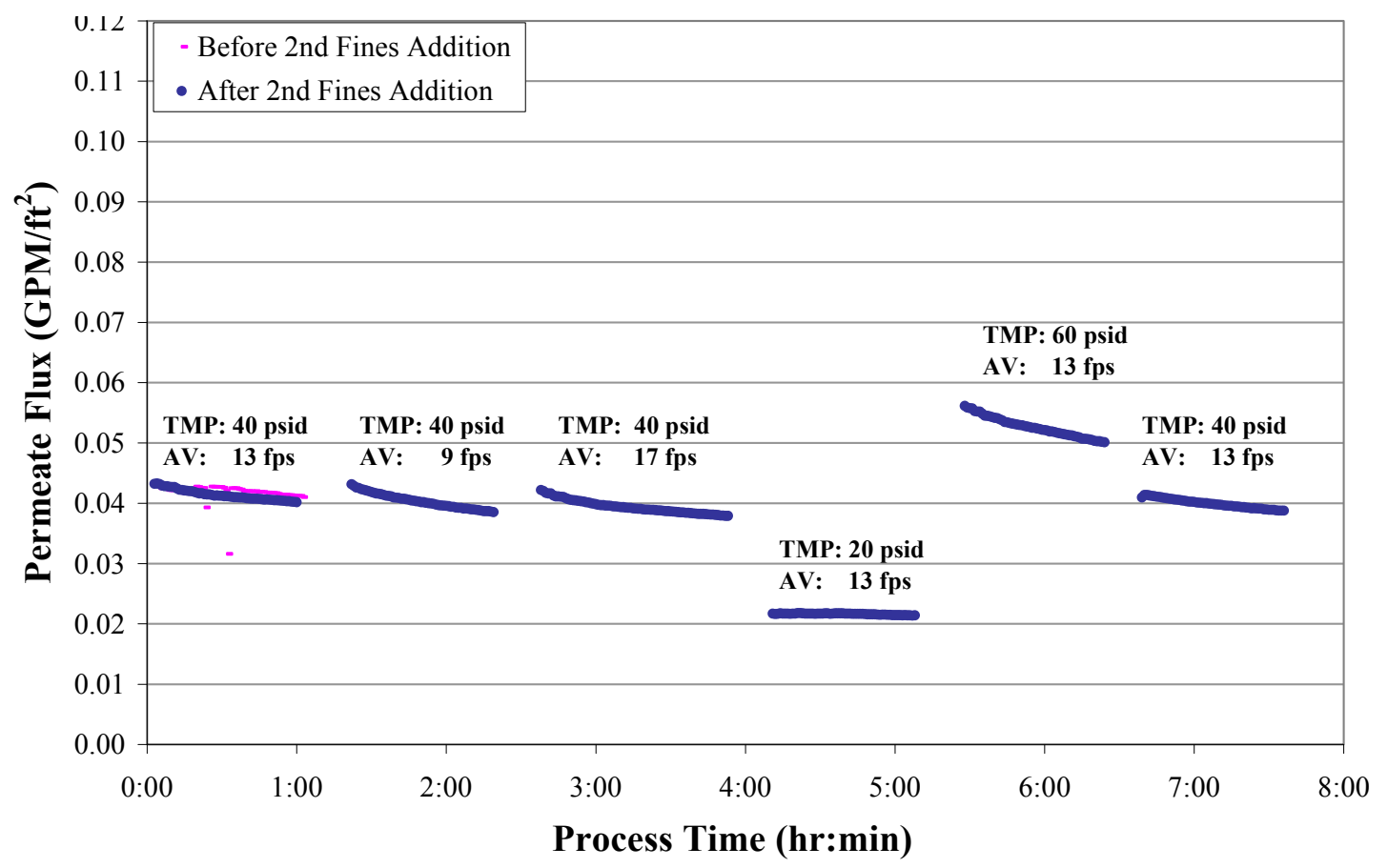

Figure 4.9. Low-Solids Filter Flux for Simulant \#7 (Test P6a) with $d_{10}$ Fines Addition Based on Table 2.1

Tests C1a, P1, and P2a examined the impact of fines on the filtration behavior after leaching. Test C1a was without fines, Test P1 a was with sufficient fines added to bring the $\mathrm{d}_{5}$ number down to about 0.32 micron, and Test $\mathrm{P} 2$ was with sufficient fines added to bring the $\mathrm{d}_{10}$ number down to around 0.32 micron. These results are shown in Figure 4.10 through Figure 4.12.

During the initial testing with Simulant \#8 (C1a), the flux ranged from $0.1 \mathrm{gpm} / \mathrm{ft}^{2}$ down to $0.04 \mathrm{gpm} / \mathrm{ft}^{2}$ at the standard filtration condition of $40 \mathrm{psid}$ TMP and $13 \mathrm{ft} / \mathrm{s} \mathrm{AV}$. The decrease in the filter flux at the standard condition indicated that progressive fouling of the filter element was occurring during the test matrix, which was not prevented by back-pulsing. Subsequently, adding fines in Tests P1 and P2a does not appear to have significantly impacted the filter flux, which ranged from $0.04 \mathrm{gpm} / \mathrm{ft}^{2}$ to $0.06 \mathrm{gpm} / \mathrm{ft}^{2}$ at a condition of $40 \mathrm{psid}$ TMP and $13 \mathrm{ft} / \mathrm{s} \mathrm{AV}$. These results again indicate that adding inert fines did not have a significant impact on the filter flux. 


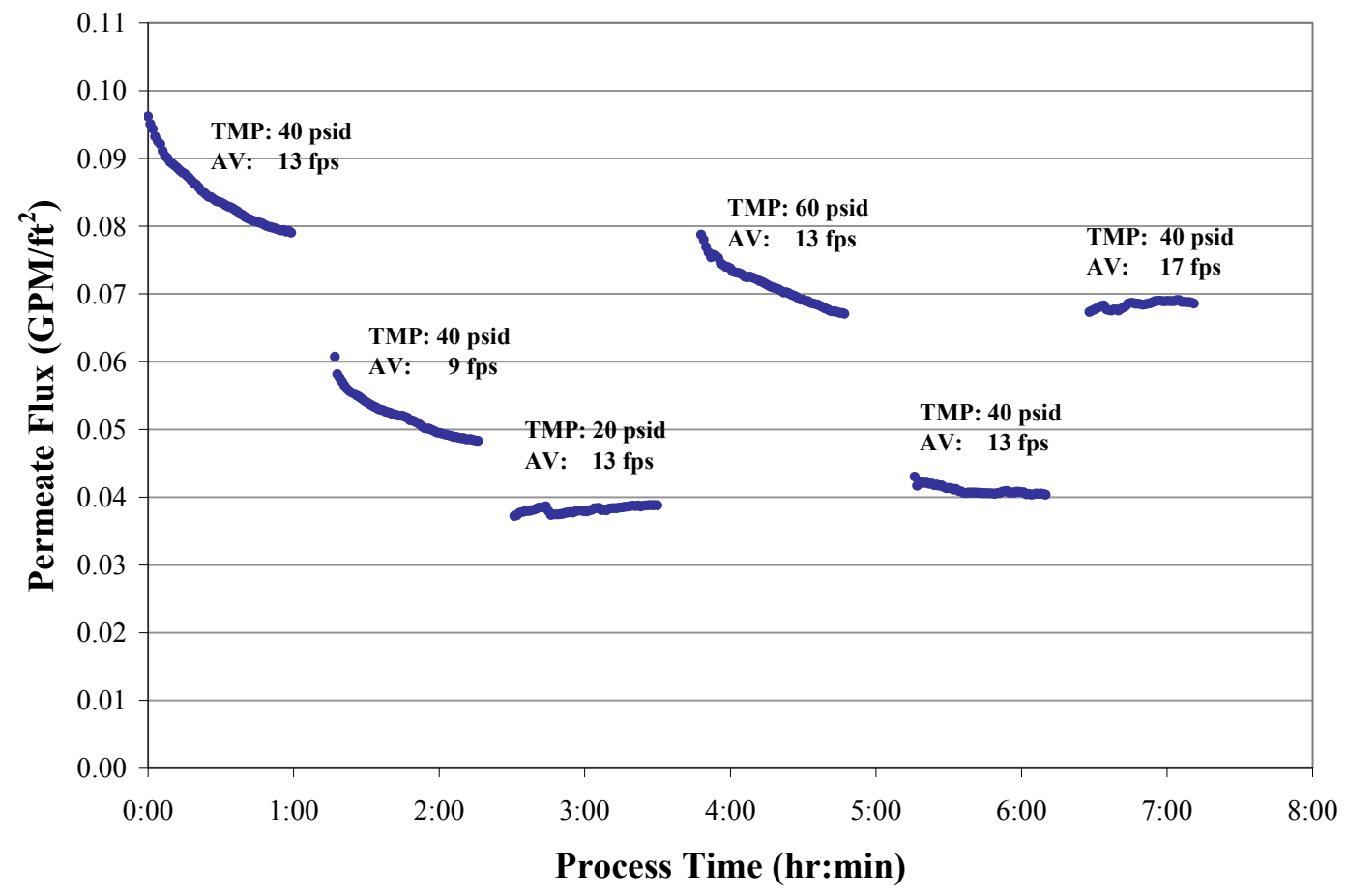

Figure 4.10. Low-Solids Filter Flux for Simulant \#8 (Test C1a) with Leached Solids Based on Table 2.1

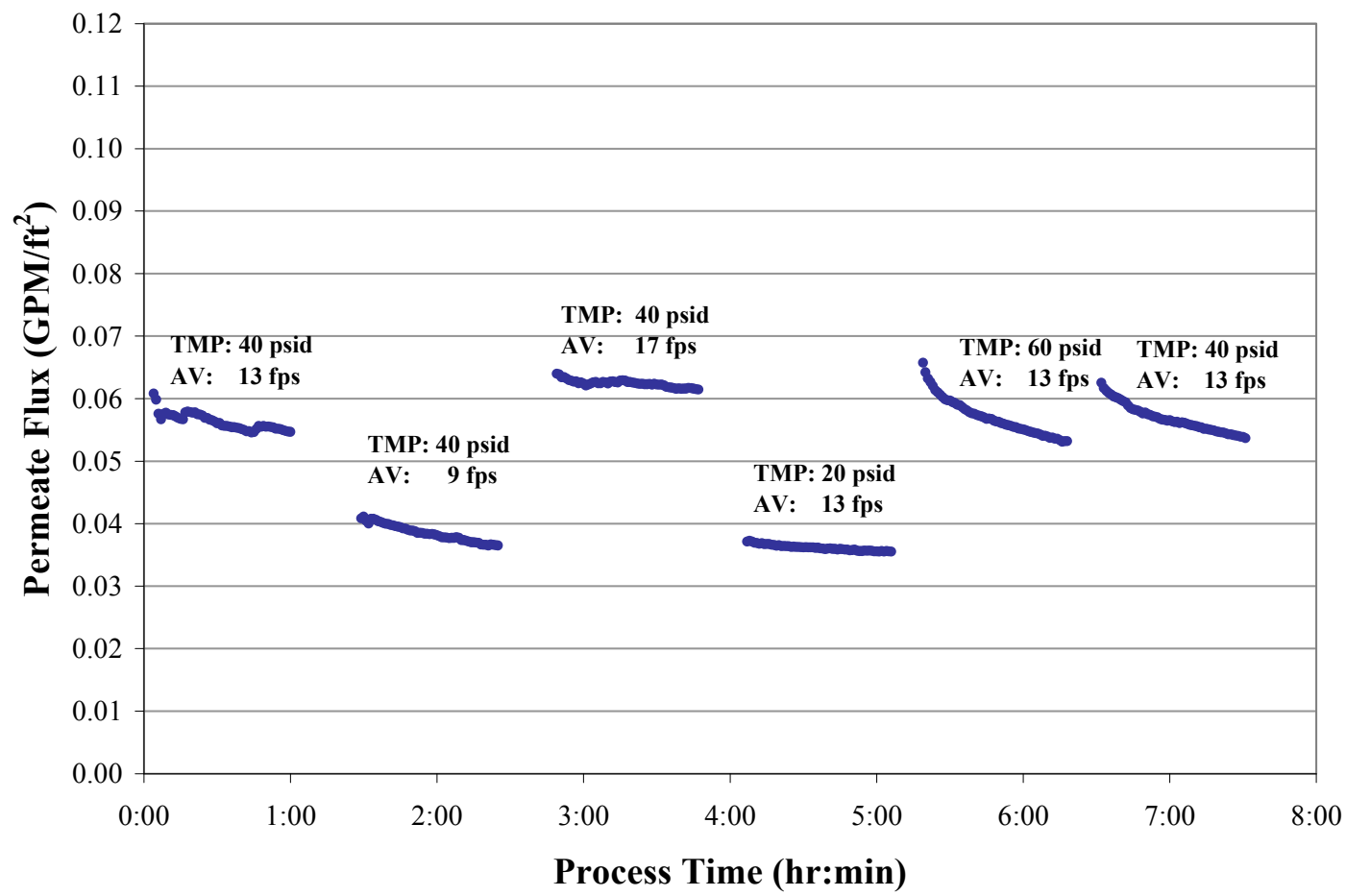

Figure 4.11. Low-Solids Filter Flux for Simulant \#8 (Test P1) with $d_{5}$ Fines Addition Based on Table 2.1 


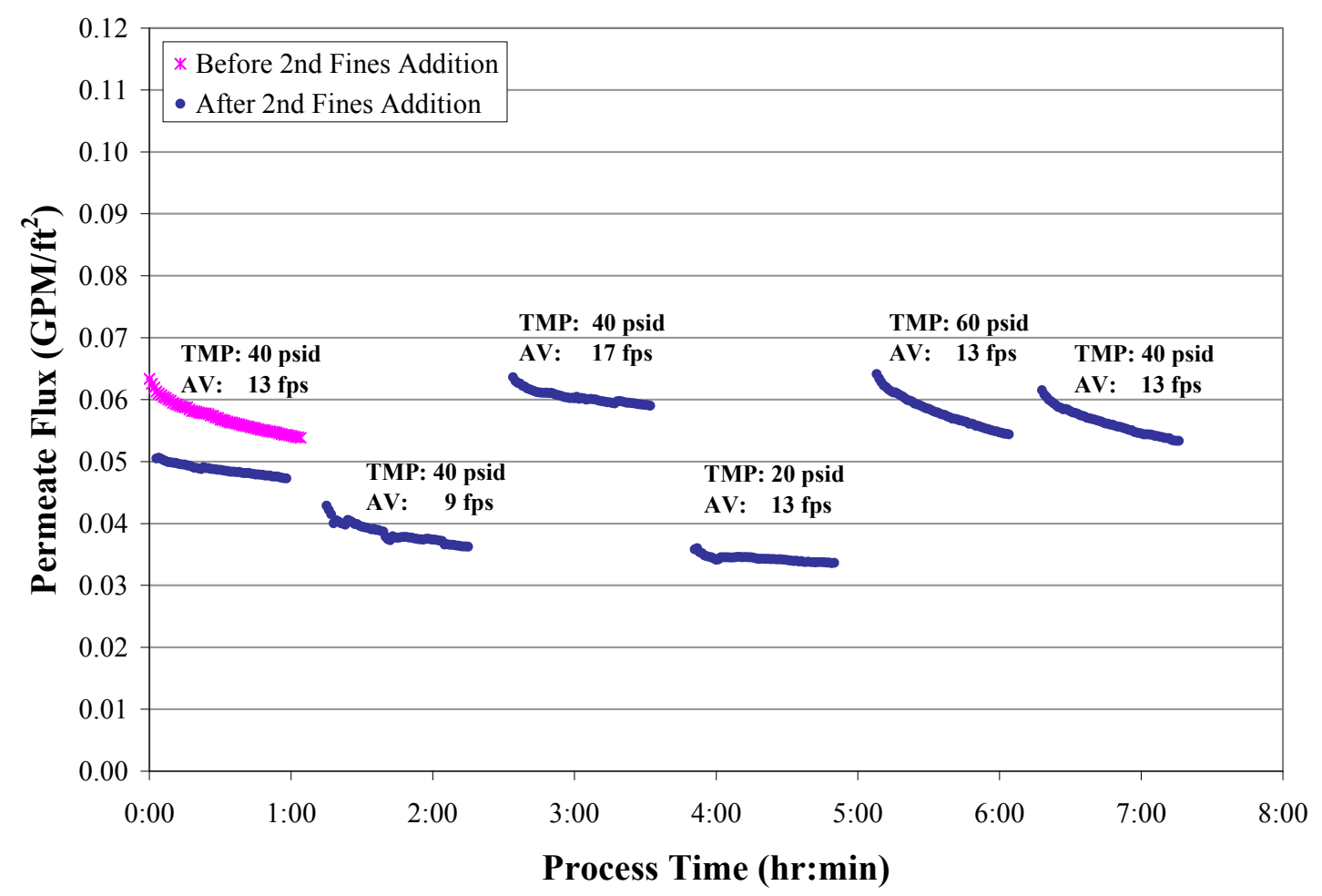

Figure 4.12. Low-Solids Filter Flux for Simulant \#8 (Test P2a) with $d_{10}$ Fines Addition Based on Table 2.1

\subsection{Aging Studies}

Figure 4.13 shows the dewater curves for tests $\mathrm{P} 7 \mathrm{~b}$ and $\mathrm{C} 1 \mathrm{~b}$. The sample for test $\mathrm{C} 1 \mathrm{~b}$ used fresh inert solids simulant while the test for P7b used aged inert solids simulant. Inspection of the graphs indicates very little difference in the gel concentration for the two simulants with both of them approaching approximately $31-\mathrm{wt} \%$ solids. There is less difference between the initial filter fluxes and the slopes of the dewater curves compared to the changes seen when changing bulk simulant components (see Figure 4.4 through Figure 4.6). These results suggest that this simulant is relatively stable with respect to aging and in particular with respect to crystallization of the iron-containing component. 


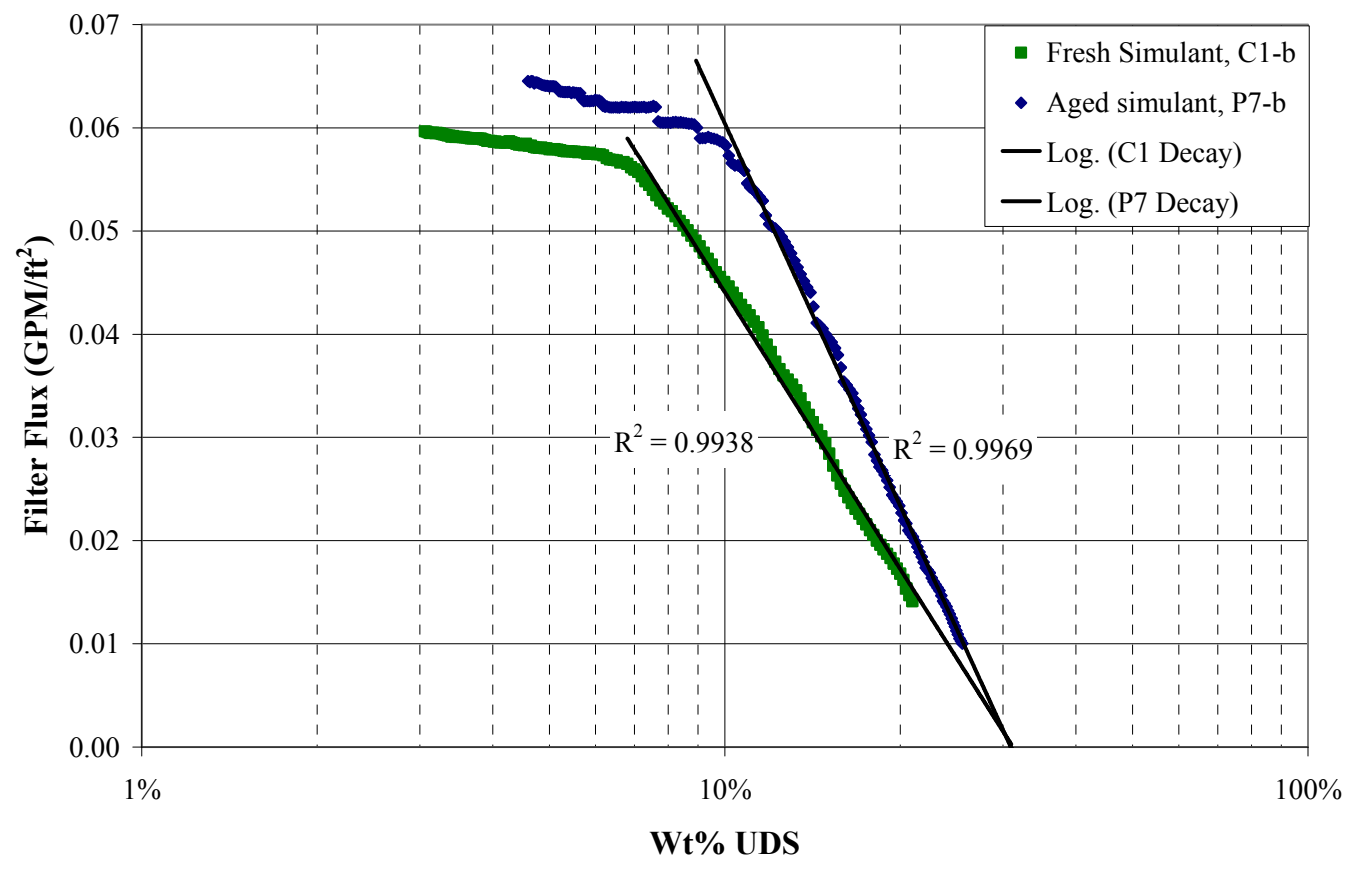

Figure 4.13. Dewatering of Aged Simulant (P7b) Compared to Fresh Simulant (C1b)

\subsection{Filtration Screening Test Outcomes}

There are three primary outcomes from the filtration screening tests. The first outcome confirmed that the centrifuged solids provide a reasonable first-level screen of filtration performance. This was validated by the dewatering of the leached slurry simulant and the inert solids simulant, both of which showed very good correlation between the gel point observed during dewatering filtration and from the measured centrifuged solids.

The second primary outcome assessed the impact of additional fines on the low-solids filter flux observed. This set of testing indicated that adding fines to reach the target number count $\mathrm{d}_{10}$ values did not significantly change the observed filter fluxes. Note, however, that these levels were relatively low concentrations. The next section of this report will assess the impact of adding larger concentrations of inert fines.

The third outcome assessed the impact of aging on the filtration behavior. The results from these tests indicated that aging of the inert solids simulant did not significantly change the gel concentration. As such, aging of the simulant was abandoned as a method of adjusting the filtration behavior. 


\subsection{Inert Fines and Filter Fouling}

As indicated in Section 4, the filter flux was effectively unchanged by adding small quantities of inert fines. The basis for the inert fines addition in Section 4 was to adjust the particle-size number count $\mathrm{d}_{10}$ of the simulant to approximately 0.4 microns. However, since adjusting the number count $\mathrm{d}_{10}$ was found to be ineffective, this phase of testing evaluated using greater amounts of inert fines required to adjust the particle size volume count $d_{10}$. The work described in this section addresses Task 6.2.3 in Test Plan TP-RPP-WTP-509, Rev. 0. In particular, the objective of the work in this section was to evaluate the effect of the fine-particle fraction in the ultrafiltration simulant on fouling of the filter element.

The average number distribution values for all tanks for $\mathrm{d}_{5}$ values were $0.32 \mu \mathrm{m}$ and $0.35 \mu \mathrm{m}$ for the initial tank wastes and treated tank wastes, respectively (Geeting et al. 2003; Lumetta et al. 1996; Rapko et al. 1995; Temer and Villarreal 1996; Temer and Villarreal 1997; Lumetta et al. 1997). The volume distribution $\mathrm{d}_{10}$ values were $1.26 \mu \mathrm{m}$ to $1.38 \mu \mathrm{m}$ for untreated and treated tank waste samples, respectively.

Simulants were prepared by Pacific Northwest National Laboratory (PNNL) with the various amounts of inert fines added to adjust the $d_{10}$ values. These simulants were then tested in the crossflow ultrafiltration unit to determine their filter flux, and the results were compared to the initial simulant.

The inert fines were materials that were insoluble and chemically inert in the slurry. The materials added as inert fines were commercially available metal oxides with reported PSDs that were primarily $<0.1$ micron, except for ferric oxide, which ranged up to 5 microns. Table 5.1 summarizes the inert materials used. The PSDs from these materials are shown in Figure 5.1. Note that the PSD is determined by light scattering and is accurate only for particles $\geq 0.1$ micron. Particles $<0.1$ micron are seen as 0.1 micron or larger. Hence, the large number of particles indicated for both the zinc oxide and the zirconium oxide at around 0.1 micron is consistent with the particle-size range reported by the manufacturer and listed in Table 5.1. The larger particle sizes seen on the tails of the peaks may have been due to agglomeration as these were measured without sonication.

Table 5.1. Inert Fines Materials Used in the Crossflow Ultrafiltration Fouling Tests

\begin{tabular}{|c|c|c|}
\hline Material & Source & Particle Size Range \\
\hline Zirconium Oxide & Alfa Aesar, Stock \# 44886, Lot \# G24R043 & $40-50 \mathrm{~nm}$ \\
\hline Ferric Oxide & Alfa Aesar, Stock \# 14680, Lot \# K14R006 & $<5$ microns \\
\hline Zinc Oxide & Alfa Aesar, Stock \# 44899, Lot \# L27Q022 & $40-100 \mathrm{~nm}$ \\
\hline
\end{tabular}




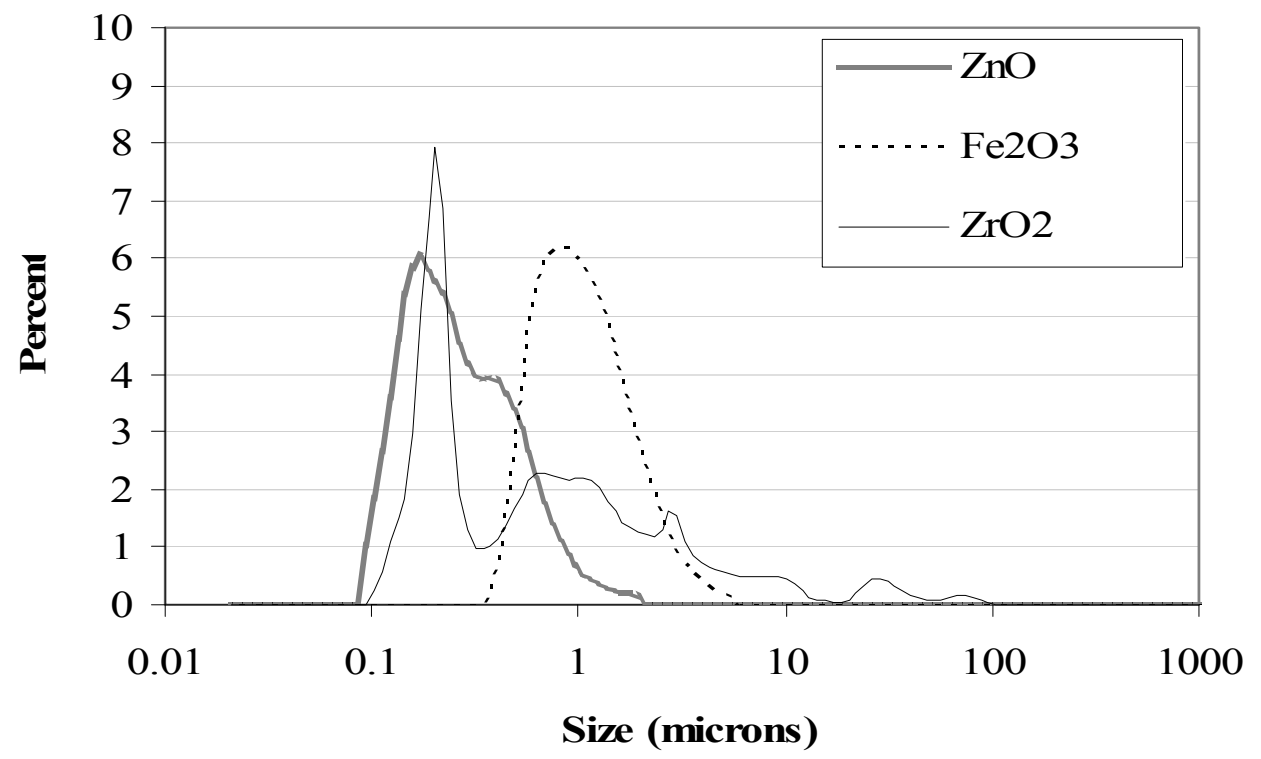

Figure 5.1. Measured PSDs for the Inert Materials Used in the Fouling Tests

Two sets of tests were performed. One set (Section 5.1, Inert Fines Filter Flux Adjustment) involved zirconium oxide and sodium oxalate added to the 5-wt\% UDS Fe-rich sludge in different amounts, and the other set (Section 5.2, Filter Fouling Tests) involved the inert fines (iron oxide and zinc oxide) being added to the supernate constituting the total UDS in the system. The tests were performed with the crossflow ultrafiltration unit running at the standard conditions of $40 \mathrm{psid}$ TMP and $13 \mathrm{ft} / \mathrm{s} \mathrm{AV}$ at a constant solids content of $5 \mathrm{wt} \%$.

\subsection{Inert Fines Filter Flux Adjustment}

In the first set of tests, with the zirconium oxide added to the PNNL prepared slurry, a series of four tests were performed. These are outlined in Figure 5.2. The intent of these tests was to assess whether the baseline flux could be adjusted by adding a significant (but still relatively small) amount of fine particulate material. 


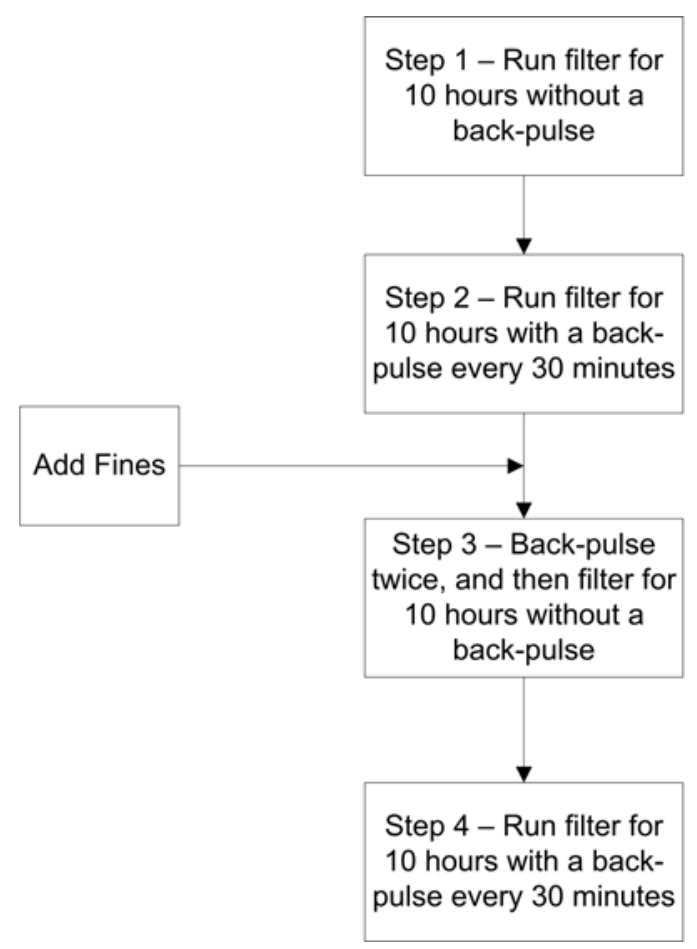

Figure 5.2. Testing Scheme for Fines Fouling Tests

As described in Figure 5.2, a steady-state filtration rate at $25^{\circ} \mathrm{C} \pm 5^{\circ} \mathrm{C}$ was established, and then a series of scheduled back-pulses were performed every 30 minutes to discover the transient and steady-state effects on the filtration rate. Then a very small fraction of the total UDS (on the order of $0.1 \mathrm{wt} \%$ ) was added as ultrafine $\mathrm{ZrO}_{2}(0.41 \mathrm{~g})$. This quantity of fines was added to decrease the volume count $\mathrm{d}_{10}$ of the simulant. The simulant was allowed to run for an additional 10 hours without back-pulsing. Then, the system was again operated for 10 hours with a back-pulse every 30 minutes. This constituted Test \#1. After this was complete, the whole process was repeated a second time with fresh slurry as Test \#2.

Figure 5.3 shows the results for the comparison between the steady-state filter fluxes (Steps 1 and 3 in Figure 5.2). Inspection of this figure indicates that there is very little difference in the steady-state filter flux with and without the added zirconium oxide. This result suggests that the decrease in the size of the $\mathrm{d}_{10}$ value had a negligible effect on the filtering behavior of the dilute iron-rich sludge simulant. 


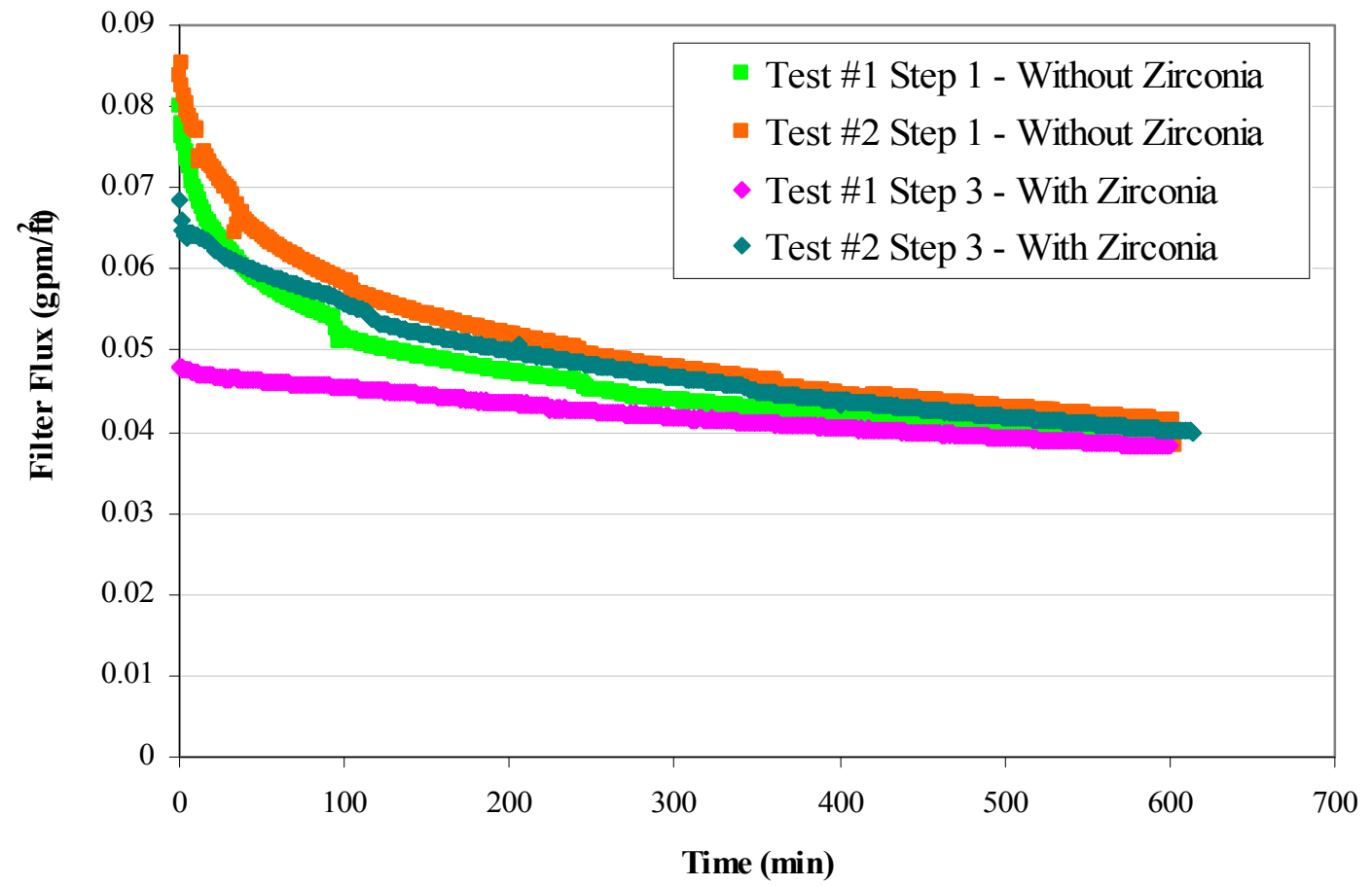

Figure 5.3. Filter Flux of Fe-Rich Slurry With and Without Zirconium Oxide and No Back-Pulsing

Figure 5.4 shows the results for the comparison between the back-pulsed filter fluxes (Steps 2 and 4 in Figure 5.2). The first test indicated that the long-term filter flux was effectively the same with and without adding the fines. The second test indicated a slight decrease in the filter flux due to fines addition. Note, however, that the difference in Step 2 between Test $\# 1$ and Test $\# 2\left(\sim 0.01 \mathrm{gpm} / \mathrm{ft}^{2}\right)$ is greater than the potential fines effect shown in Step 4 of Test $\# 2\left(\sim 0.005 \mathrm{gpm} / \mathrm{ft}^{2}\right)$. This level of uncertainty $(20 \%)$ is frequently encountered in duplicate filtration tests. 


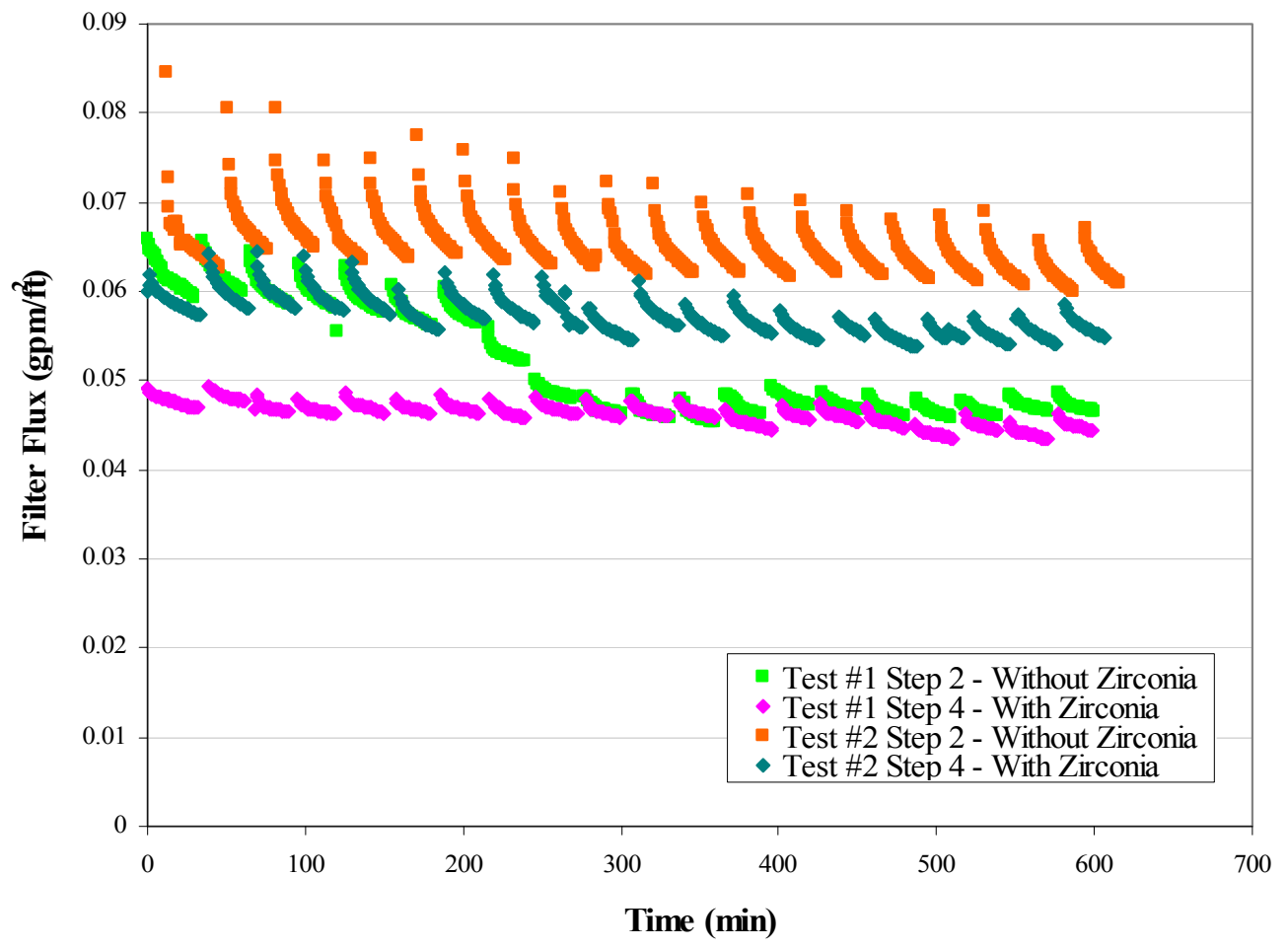

Figure 5.4. Filter Flux of Fe-Rich Slurry with and Without Zirconium Oxide and Back-Pulsing

Next, the effect of substituting ultrafine $\mathrm{ZrO}_{2}$ for $25 \mathrm{wt} \%$ of the total UDS in the iron-rich sludge simulant and the effect of temperature were tested. Therefore, these tests contained $1.25-\mathrm{wt} \% \mathrm{ZrO}_{2}$ and $3.75-\mathrm{wt} \%$ iron-rich sludge simulant solids. The sequence of testing is shown in Figure 5.5. These tests were designed to assess both the impact of adding the $\mathrm{ZrO}_{2}$ fines and the nature of the temperature dependence for low-solids filtration. The ultrafine $\mathrm{ZrO}_{2}$ still appeared to have a very small effect on the filtration behavior as shown in Figure 5.6 as at most a $0.005 \mathrm{gpm} / \mathrm{ft}^{2}$ difference was observed due to the substitution of $\mathrm{ZrO}_{2}$ for $25 \%$ of the UDS in the simulant. 
Test without fines

Step 1 - Run Filter for 10 hours at $25^{\circ} \mathrm{C}$ without backpulse

Step 2 - Run Filter for 10 hours at $25^{\circ} \mathrm{C}$ with backpulse every $30 \mathrm{~min}$

Step 3 - Backpulse twice then run Filter for 2 hours at $25^{\circ} \mathrm{C}$ without backpulse

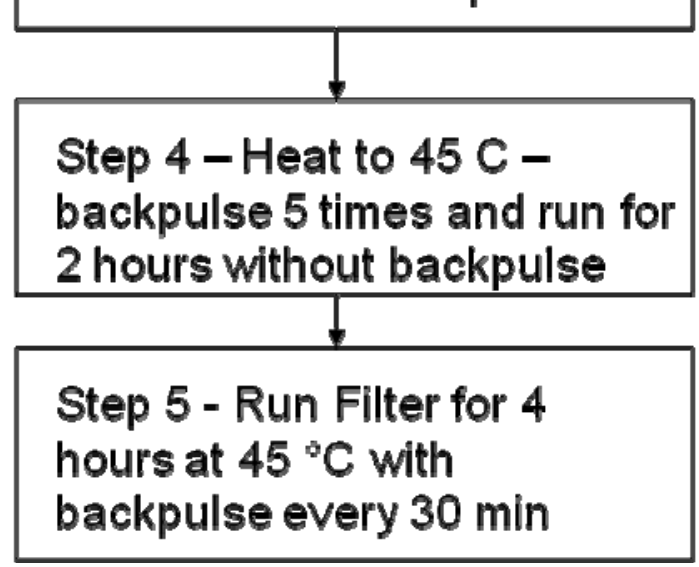

Test with fines

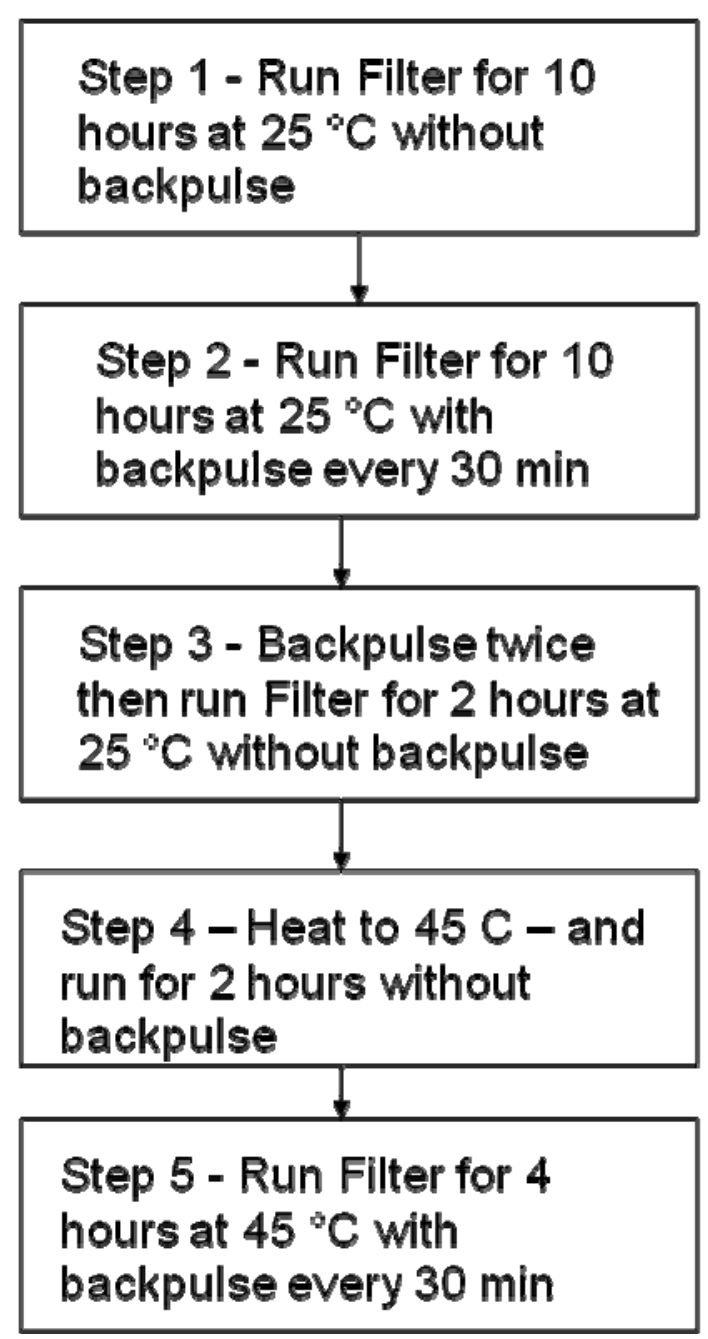

Figure 5.5. Additional Tests Performed 


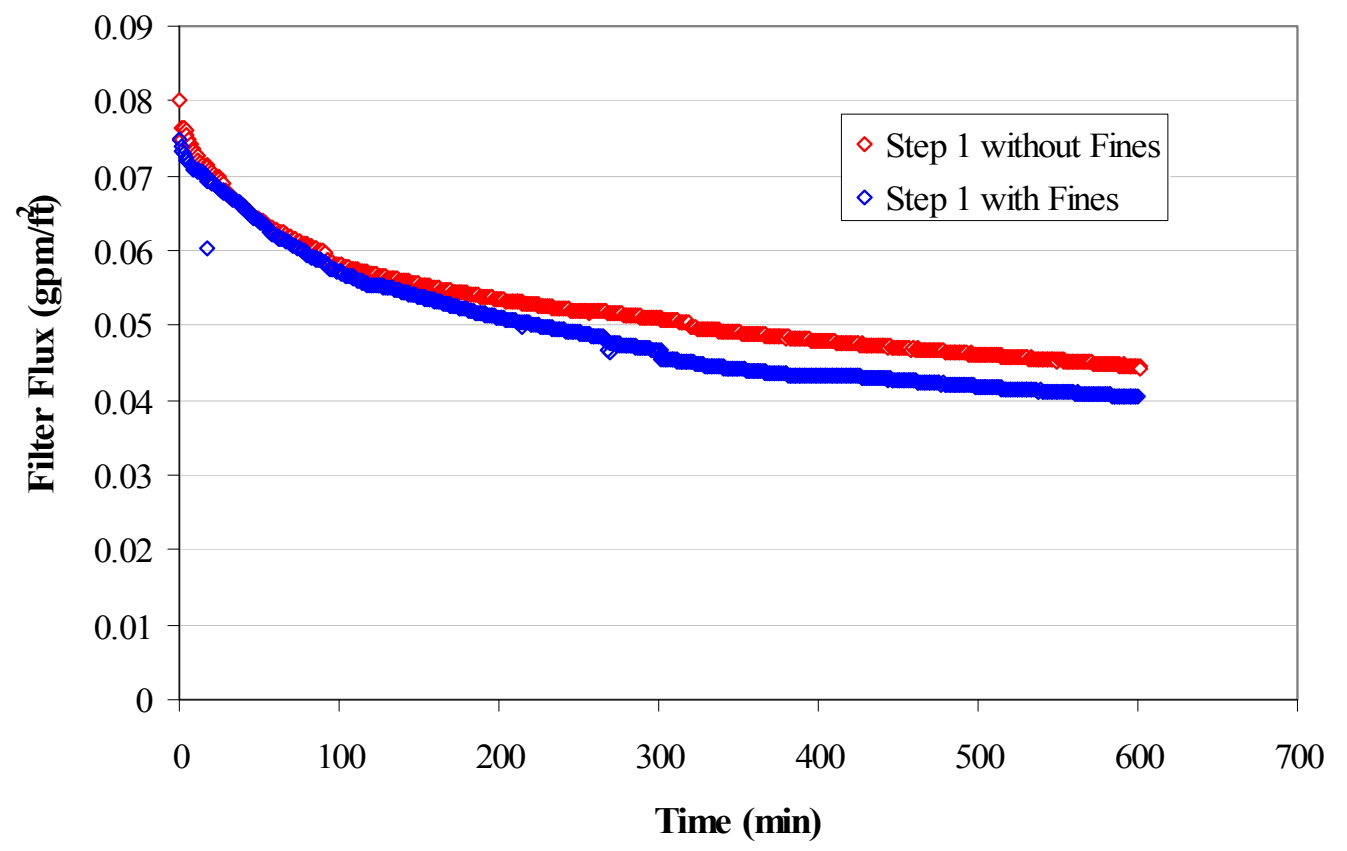

Figure 5.6. Filter Flux of Fe-Rich Slurry With and Without 25 Wt\% of the UDS Zirconium Oxide at $25^{\circ} \mathrm{C}$

However, during back-pulsing of Step 2, the $\mathrm{ZrO}_{2}$ increased the flux as shown in Figure 5.7. This is the opposite of the effect when only approximately $0.1-\mathrm{wt} \% \mathrm{ZrO}_{2}$ was added to the simulant. One possibility for this trend could be due to the abrasive nature of the $\mathrm{ZrO}_{2}$, which may have been cleaning the filter cake of the Fe-rich sludge from the filter allowing the flux to be higher.

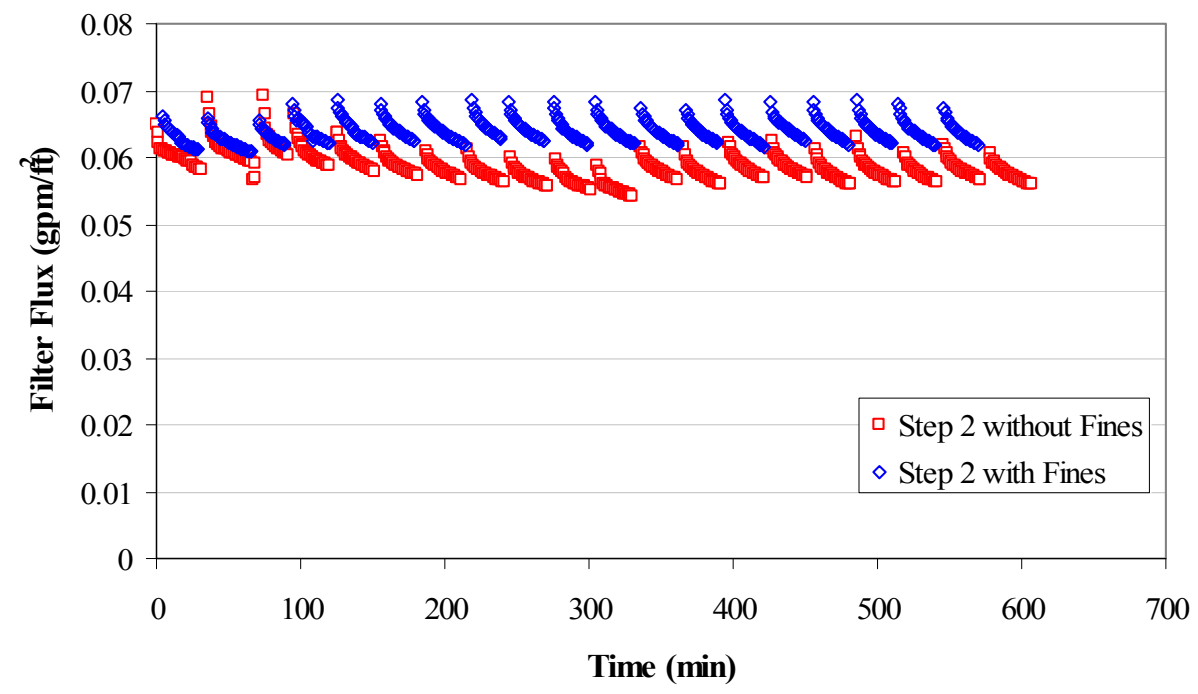

Figure 5.7. Filter Flux of Fe-Rich Slurry With and Without 25 Wt\% of the UDS Zirconium Oxide with Back-Pulsing at $25^{\circ} \mathrm{C}$ 
Figure 5.8 shows the results for Steps 3 through 5. Inspection of this figure indicates that, again, the slurry with the added fines had a higher flux, both before raising the temperature (Step 3) and after multiple back-pulses at elevated temperature (Step 5). Due to the differences in back-pulse history in Step 4, it is difficult to draw any conclusions about the impact of fines during Step 4 of the tests.

However, these results provide a very significant insight into the nature of the fouling mechanism that is occurring. Both tests indicate that, as expected, there is a significant increase in the filter flux from increasing the temperature. This is observed in the early part of Step 4 before a back-pulse occurs. This increase in filter flux is attributed to the decrease in supernate viscosity that occurs due to the temperature rise. However, a significant, additional increase is realized when the system is back-pulsed. After the back-pulse, the flux is significantly higher and continues to increase with additional back-pulses. This suggests that the foulant that is adsorbed on the surface of the filter may be desorbing, and the slurry temperature impacts this sorption process significantly. 


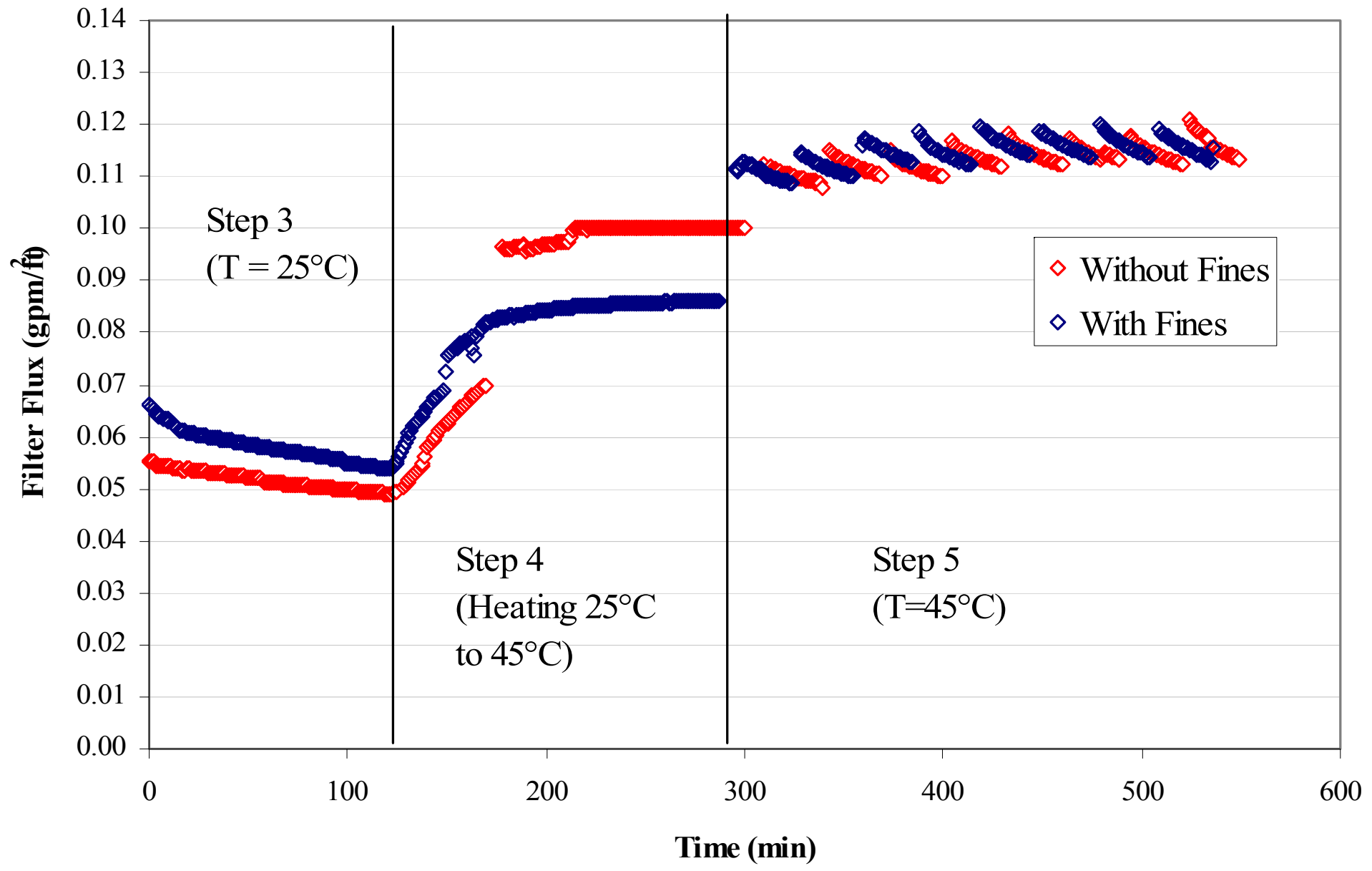

Figure 5.8. Filter Flux of Fe-Rich Slurry With and Without $25 \mathrm{Wt} \%$ Zirconium Oxide with Back-Pulsing at $45^{\circ} \mathrm{C}$ 
In the next test, sodium oxalate $\left(\mathrm{Na}_{2} \mathrm{C}_{2} \mathrm{O}_{2}\right)$ was added along with the ultrafine $\mathrm{ZrO}_{2}$ to the Fe-rich sludge simulant to determine its effect on the filtering behavior of the simulant. Again, adding sodium oxalate does not appear to have an effect (within $0.001 \mathrm{gpm} / \mathrm{ft}^{2}$ ) on the filtering behavior of the dilute Fe-rich sludge simulant as shown in Figure 5.9 with the flux being essentially the same in all three tests. For the tests with backpulsing, the flux with $\mathrm{ZrO}_{2}$ added is generally higher than without the addition of $\mathrm{ZrO}_{2}$ as seen in Figure 5.10. However, this difference may be due to the experimental error associated with this process.

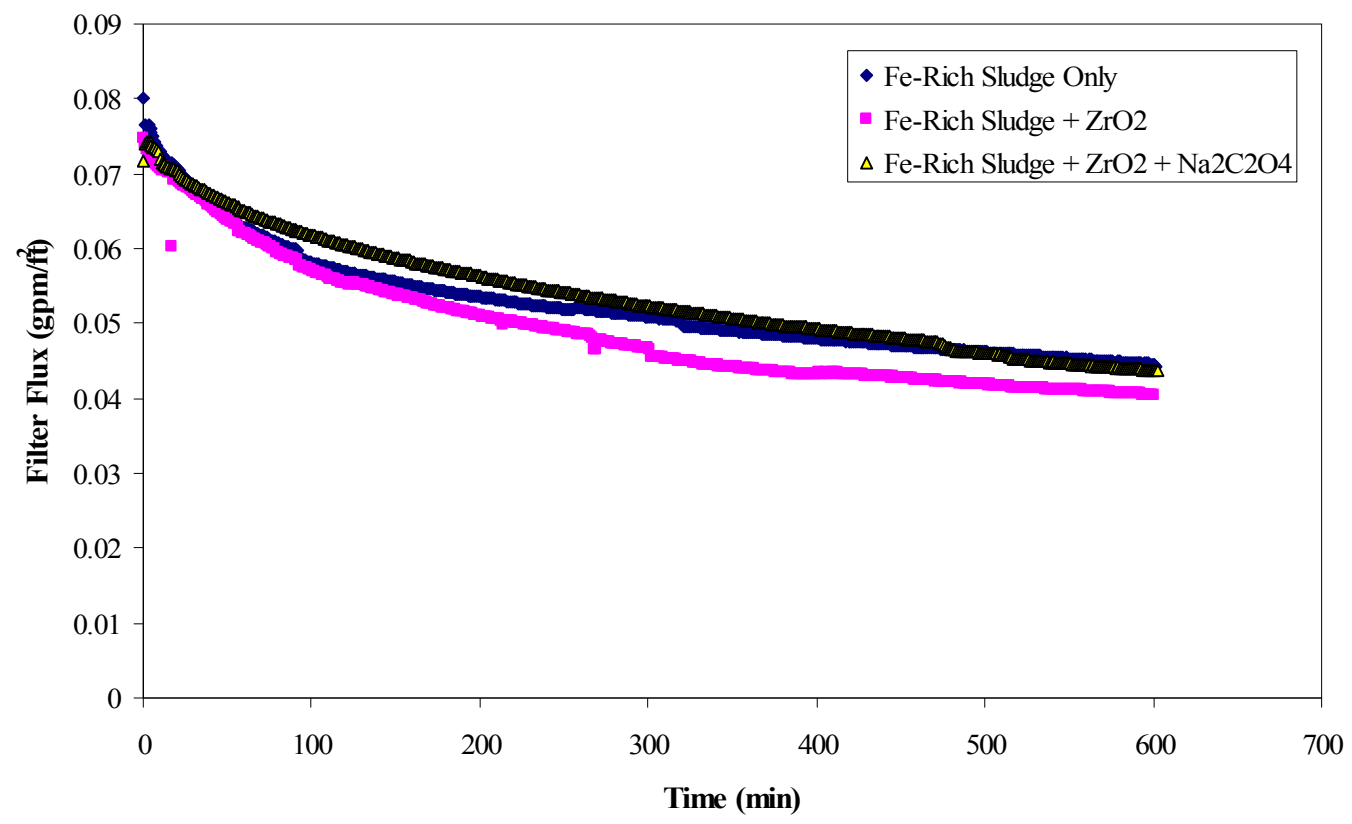

Figure 5.9. Effect of $\mathrm{ZrO}_{2}$ and $\mathrm{Na}_{2} \mathrm{C}_{2} \mathrm{O}_{4}$ on Filter Flux of Fe-Rich Slurry at $25^{\circ} \mathrm{C}$ 


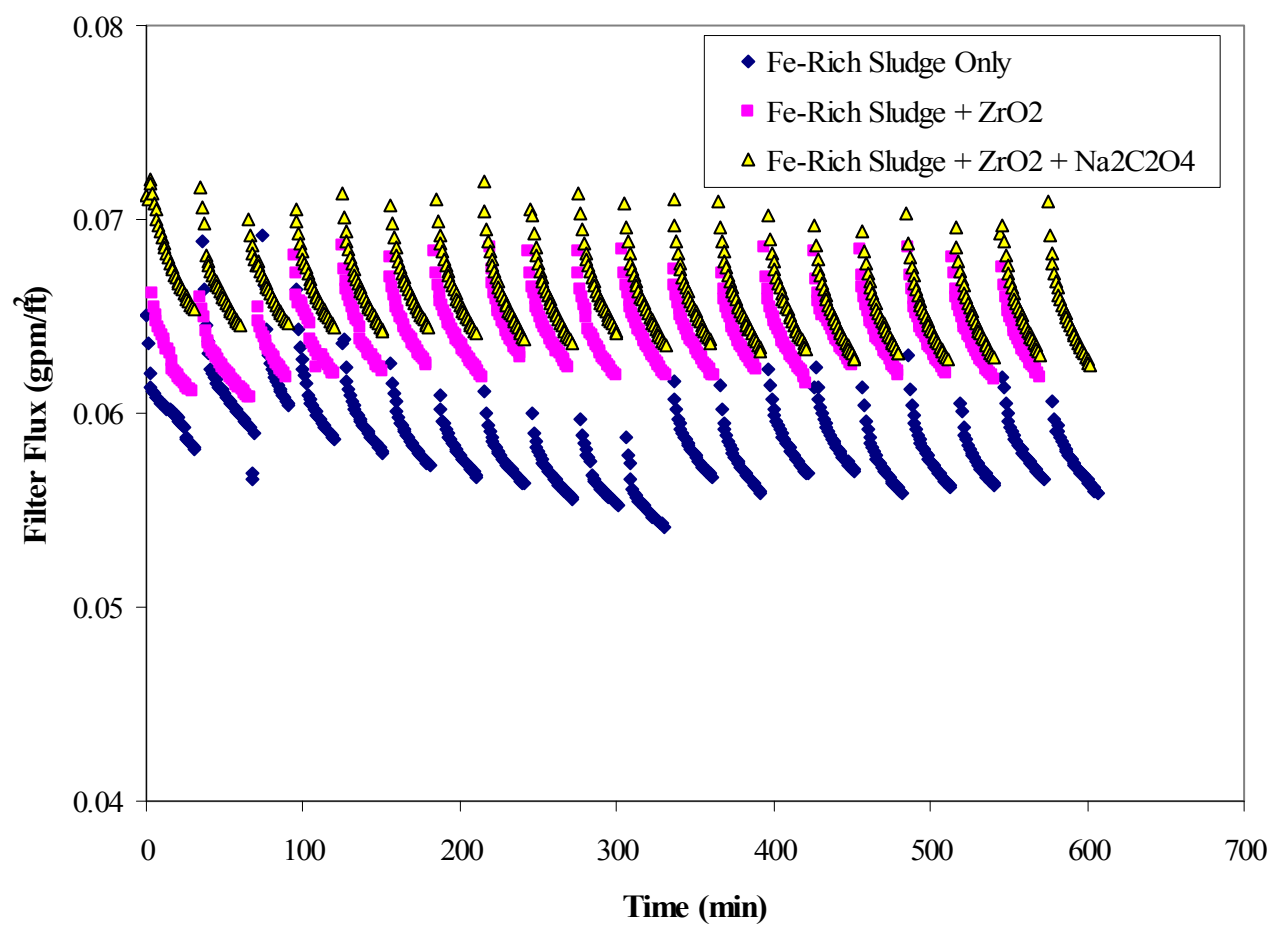

Figure 5.10. Effect of $\mathrm{ZrO}_{2}$ and $\mathrm{Na}_{2} \mathrm{C}_{2} \mathrm{O}_{4}$ on Filter Flux of Fe-Rich Slurry with Back-Pulsing at $25^{\circ} \mathrm{C}$

Baseline filter flux runs were performed with precipitated strontium carbonate $\left(\mathrm{SrCO}_{3}\right)$ before and after this series of fines testing with the $\mathrm{ZrO}_{2}$ and $\mathrm{Na}_{2} \mathrm{C}_{2} \mathrm{O}_{4}$ to determine if the filter had been permanently fouled during this testing. $\mathrm{A} \mathrm{SrCO}_{3}$ slurry was prepared to match a $0.35-\mathrm{M} \mathrm{SrCO}_{3}$ slurry used in 2002 for baseline testing of a similar Mott filter, as described in Geeting et al. (2002). This material $\left(\mathrm{SrCO}_{3}\right)$ produces stable, inert slurry, ideal for this application. The prepared slurry was placed into the crossflow ultrafiltration unit and operated with the permeate recycling back into the slurry reservoir. The filtration test was performed at $40 \mathrm{psid}$ TMP using an AV of $13 \mathrm{ft} / \mathrm{s}$. The results indicate that it is difficult to conclude there was a change in filter performance as a result of the fines fouling tests, as shown in Figure 5.11. 


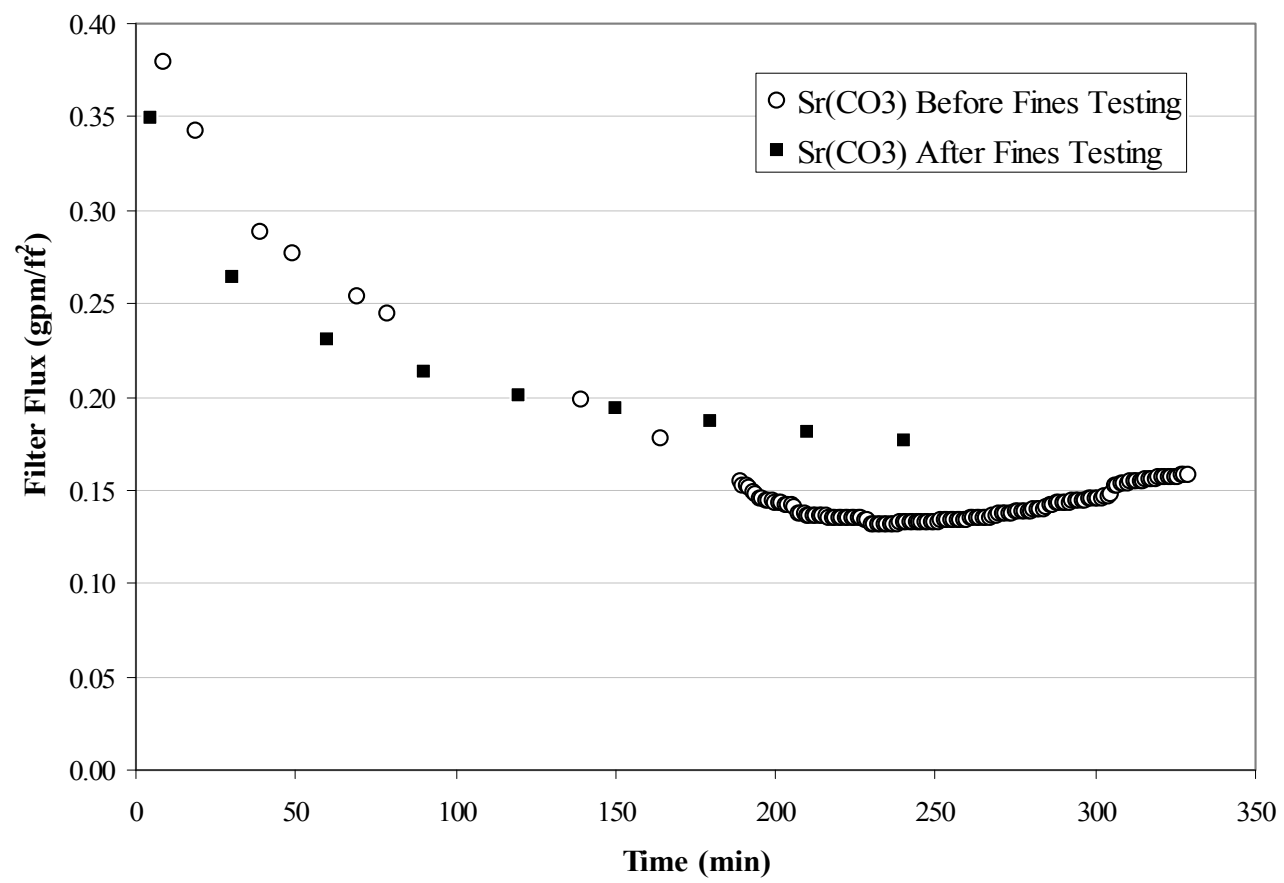

Figure 5.11. Strontium Carbonate Flux Before and After Fines Testing

\subsection{Alternate Inert Fines Tests}

The intent of this next set of tests was to evaluate whether replacing the existing inert sludge simulant with an alternative inert simulant would result in lower filter fluxes. For these tests, the pure mineral phase comprised the entire UDS load in the filter simulant with no Fe-rich sludge simulant present. One test was performed with iron oxide at 5-wt $\%$ UDS in the supernate, one test was performed with zinc oxide at $5-\mathrm{wt} \%$ UDS in the supernate, and one test was performed with zinc oxide at $20-\mathrm{wt} \%$ UDS in the supernate.

Using the iron oxide powder suspended in the supernate, a permeate flux was quickly established and remained constant at approximately $0.08 \mathrm{gpm} / \mathrm{ft}^{2}$ for over 8 hours with no progressive fouling of the filter with time observed as shown in Figure 5.12. These results indicate that the $\mathrm{Fe}_{2} \mathrm{O}_{3}$ simulant would produce significantly higher filter fluxes than the inert sludge solids simulant. 


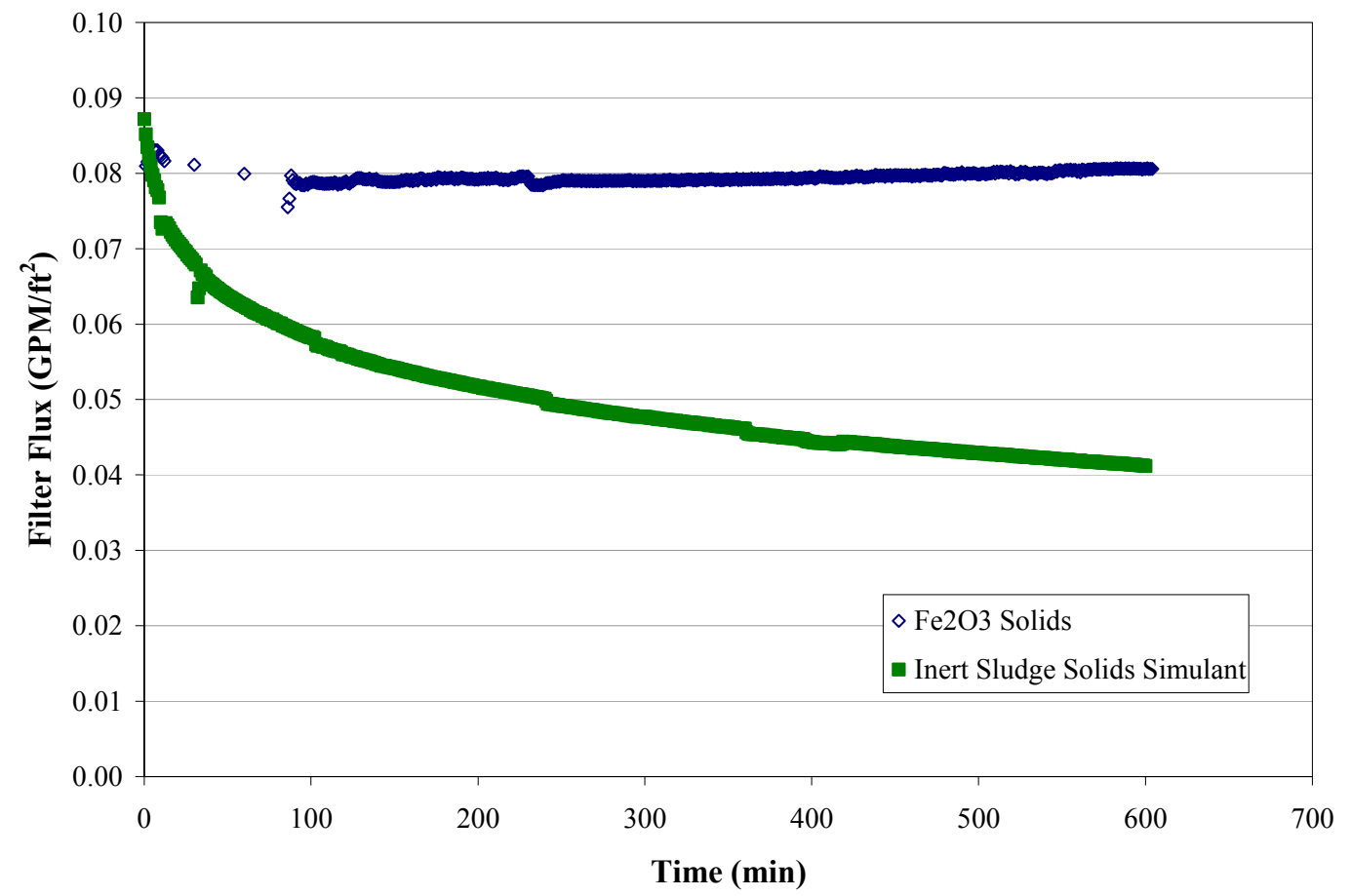

Figure 5.12. Flux of $5 \mathrm{Wt} \%$ UDS $\mathrm{Fe}_{2} \mathrm{O}_{3}$ Simulant at $25^{\circ} \mathrm{C}$

The next test used the zinc oxide powder suspended in the supernate. The flux of the 5 -wt $\%$ UDS test was off the flow meter scale with a flux of $>0.61 \mathrm{gpm} / \mathrm{ft}^{2}$ and, as the weight percent UDS increased with the dewatering, the flux was observed to decrease to a value of about $0.07 \mathrm{gpm} / \mathrm{ft}^{2}$ at $20-\mathrm{wt} \% \mathrm{UDS}$.

The 5-wt $\%$ UDS $\mathrm{ZnO}$ had a flux rate of approximately 9 times that of the 5-wt $\% \mathrm{Fe}_{2} \mathrm{O}_{3}$, and the 20 -wt $\%$ UDS $\mathrm{ZnO}$ had a similar flux rate to the 5 -wt $\%$ UDS $\mathrm{Fe}_{2} \mathrm{O}_{3}$. The $\mathrm{ZnO}$ had a smaller particle size than the $\mathrm{Fe}_{2} \mathrm{O}_{3}$, which should have caused it to foul the filter more. However, the $\mathrm{ZnO}$ appears to have limited affinity for the filter surface and does not appear to adsorb, resulting in a higher flux than the $\mathrm{SrCO}_{3}$ with not much decay of the flux over time.

The results of these tests indicate that neither of these materials has the right properties to foul the filter in spite of the fact that the zinc oxide had particle sizes in the range of $40 \mathrm{~nm}$ to $100 \mathrm{~nm}$ while the filter had a nominal $100-\mathrm{nm}$ pore size. Permeates from these tests came through perfectly clear to the unaided eye, and chemical analysis for the elements contained in the fines were all below detection limits. Therefore, the conclusion is that these materials will not tend to foul the filter, even though their particle sizes were considered small enough to enter the open porosity of the filter.

\subsection{Outcome from Inert Fines and Fines Fouling Tests}

These tests were performed in an effort to identify a mechanism to decrease the filter flux either by adding a small amount of fine particulate material or by replacing the bulk inert material with a readily available fine particulate material. Neither of these two approaches was adequate in achieving a decreased filter flux. As such, the use of these materials in the inert component of the simulant was 
abandoned in further testing. In addition, these tests were also intended to make sure that the simulant will not foul the filter prematurely and is stable with respect to filtration performance. In this respect, the precipitated hydroxide simulant was found to be satisfactory. 


\subsection{Blended Component Simulant Filtration Demonstration}

The objective of this task was to determine the filtration behavior of the PEP simulant with all of the components blended together at the bench-scale using the crossflow ultrafiltration system. Another objective was to simulate the entire pretreatment process, including the leaching processes to be used in the WTP. These tests used the blended filtration simulant that is planned to be used in the PEP tests.

The crossflow ultrafiltration blended matrix (CBM) tests used a filtration simulant that contained a blend of solids that are characteristic of actual waste, including boehmite, gibbsite, oxalate, chromium, and iron-rich sludge as shown in Table 6.1. The only significant difference in all of these simulants was the source of production. The first three simulants were blended in-house by PNNL while the final two were prepared as complete simulants by the Noah Technologies Corporation per direction from PNNL. Chemical analyses of all the blended simulants were performed before use. These analyses are provided in WTP-RPT-184, Rev. 0. Also note that only tests CBM-1 and CBM-2 contained CrOOH slurry at the start of the test. The iron-rich sludge is composed of the hydroxide waste phases that formed in the waste tanks when metal nitrate solutions (mainly iron) were treated with caustic to minimize corrosion. The iron-rich sludge composition was simplified by removing minor elements that were also toxic and is shown in

Table 6.2. Gibbsite and boehmite are the principle aluminum-containing phases found in the tank waste. Zirconium oxide in the simulant represents the insoluble, fine-grained waste phases found in the waste. This material was found to have little effect on the filtering behavior in Section 5.0 and was omitted from the later tests. Sodium oxalate is a sparingly soluble organic phase found in the waste, and a small amount of a chromium-bearing phase is known to be present in the waste also. This chromium phase was represented by a $\mathrm{CrOOH}$ slurry being added to the simulant.

The physical properties of each initial simulant were measured and are presented in Table 6.3. These data show that the slurries were all very consistent in their physical properties regardless of which vendor prepared them.

Table 6.1. Filtration Simulant UDS Composition in Grams per kg of UDS

\begin{tabular}{|c|c|c|c|c|c|}
\hline Component & $\begin{array}{c}\text { CBM-1 } \\
\text { (g) }\end{array}$ & $\begin{array}{c}\text { CBM-2 } \\
\text { (g) }\end{array}$ & $\begin{array}{c}\text { CBM-3 } \\
\text { (g) }\end{array}$ & $\begin{array}{c}\text { CBM-4 } \\
\text { (g) }\end{array}$ & $\begin{array}{c}\text { CBM-5 } \\
\text { (g) }\end{array}$ \\
\hline Fe-rich sludge & 182 & 182 & 187 & 187 & 187 \\
\hline Gibbsite & 345 & 345 & 355 & 355 & 355 \\
\hline Boehmite & 345 & 345 & 355 & 355 & 355 \\
\hline Sodium oxalate & 100 & 100 & 103 & 103 & 103 \\
\hline CrOOH slurry & 27 & 27 & $*$ & $*$ & $*$ \\
\hline Fe-rich sludge source & $\mathrm{PNNL}^{(\mathrm{a})}$ & $\mathrm{PNNL}^{\text {(a) }}$ & Optima $^{(b)}$ & Noah $^{(\mathrm{c})}$ & Noah $^{(\mathrm{c})}$ \\
\hline \multicolumn{6}{|c|}{$\begin{array}{l}\text { * The CrOOH slurry was added after the caustic leach in these simulants. } \\
\text { (a) Pacific Northwest National Laboratory, Richland, Washington. } \\
\text { (b) Optima Chemical, Douglas, Georgia. } \\
\text { (c) Noah Technologies Corporation, San Antonio, Texas. }\end{array}$} \\
\hline
\end{tabular}


Table 6.2. Compositions of Iron-Rich Sludge Used in the Blended Component Simulant Testing

\begin{tabular}{|c|c|c|c||}
\hline & $\begin{array}{c}\text { PNNL } \\
\text { (mol fraction) }\end{array}$ & $\begin{array}{c}\text { Optima } \\
\text { (mol fraction) }\end{array}$ & $\begin{array}{c}\text { Noah } \\
\text { (mol fraction) }\end{array}$ \\
\hline $\mathrm{Ba}(\mathrm{OH})_{2}$ & 0.0019 & --- & --- \\
\hline $\mathrm{Ca}(\mathrm{OH})_{2}$ & 0.0235 & 0.0237 & 0.0241 \\
\hline $\mathrm{Cd}(\mathrm{OH})_{2}$ & 0.0006 & --- & --- \\
\hline $\mathrm{Ce}(\mathrm{OH})_{3}$ & 0.0034 & 0.0035 & 0.0035 \\
\hline $\mathrm{Cu}(\mathrm{OH})_{2}$ & 0.0015 & --- & --- \\
\hline $\mathrm{Fe}(\mathrm{OH})_{3}$ & 0.7269 & 0.7324 & 0.7456 \\
\hline $\mathrm{La}(\mathrm{OH})_{3}$ & 0.0025 & 0.0026 & 0.0026 \\
\hline $\mathrm{Pb}(\mathrm{OH})_{2}$ & 0.0090 & 0.0176 & --- \\
\hline $\mathrm{Mg}(\mathrm{OH})_{2}$ & 0.0153 & 0.0154 & 0.0157 \\
\hline $\mathrm{Nd}(\mathrm{OH})_{3}$ & 0.0069 & 0.0069 & 0.0070 \\
\hline $\mathrm{Ni}(\mathrm{OH})_{2}$ & 0.0226 & 0.0228 & 0.0232 \\
\hline $\mathrm{Pr}(\mathrm{OH})_{3}$ & 0.0017 & --- & --- \\
\hline $\mathrm{RuOOH}$ & 0.0013 & --- & --- \\
\hline $\mathrm{AgOH}$ & 0.0066 & --- & --- \\
\hline $\mathrm{Sr}(\mathrm{OH})_{2}$ & 0.0038 & 0.0038 & 0.0038 \\
\hline $\mathrm{Y}(\mathrm{OH})_{3}$ & 0.0008 & --- & --- \\
\hline $\mathrm{Zn}(\mathrm{OH})_{2}$ & 0.0013 & --- & --- \\
\hline $\mathrm{ZrO}(\mathrm{OH})_{2}$ & 0.0117 & 0.0118 & 0.0120 \\
\hline $\mathrm{Hg}(\mathrm{OH})_{2}$ & 0.0004 & --- & --1624 \\
\hline $\mathrm{MnO}{ }_{2}$ & 0.1584 & 0.1595 & \\
\hline & & & \\
\hline
\end{tabular}

Table 6.3. Physical-Property Measurements of Initial Blended Component Slurries

\begin{tabular}{|l|c|c|c|c|c|}
\hline & CBM-1 & CBM-2 & CBM-3 & CBM-4 & CBM-5 \\
\hline Slurry Density (g/mL) & 1.26 & 1.26 & 1.26 & 1.26 & 1.26 \\
\hline Supernate Density $(\mathrm{g} / \mathrm{mL})$ & 1.23 & 1.23 & 1.22 & 1.23 & 1.23 \\
\hline Total Solids (wt\%) & 32.2 & 31.6 & 31.6 & 32.3 & 32.4 \\
\hline Dissolved Solids (wt\%) & 27.9 & 27.9 & 26.9 & 28.0 & 27.9 \\
\hline UDS (wt\%) & 4.3 & 3.7 & 4.7 & 4.3 & 4.5 \\
\hline
\end{tabular}

Particle-size measurements were performed on the slurry sample taken before filtration testing, shown in Figure 6.1. The pre-sonic PSD for the initial slurries all indicated a broad, continuous, and unimodal distribution that spans approximately $0.5 \mu \mathrm{m}$ to approximately $60 \mu \mathrm{m}$ and has a peak maximum at approximately $10 \mu \mathrm{m}$. The majority of the particle volume existed below $20 \mu \mathrm{m}$. Sonication appears to 
have caused some agglomeration of particles by shifting the relative population of particles to the larger end of the curve.

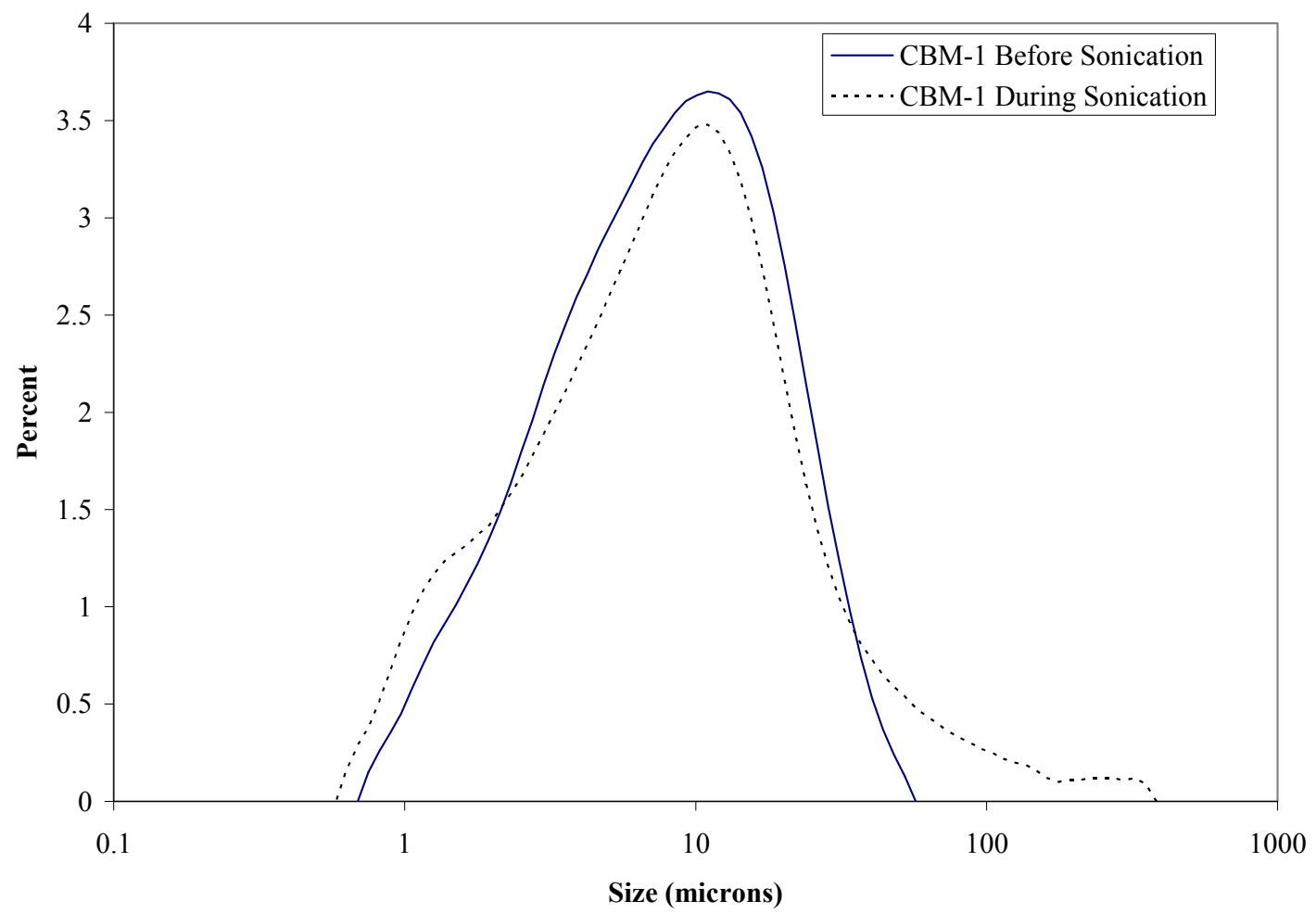

Figure 6.1. PSD Volume Distribution Showing the Effect of Sonication on CBM-1

Rheology measurements of the initial slurries were taken before filtration testing as well. The stress response was basically Newtonian with a yield stress of essentially zero (Table 6.4). All of the slurries behaved similarly over the 0 to $550 \mathrm{~s}^{-1}$ region with the shear stress increasing rapidly and appearing to be shear thinning. The slurries showed a sharp transition in slope near $600 \mathrm{~s}^{-1}$ that is consistent with the formation of Taylor vortices. Note that there appears to be a significant range in the consistency measurements for the PNNL-prepared simulants (0.0032 Pa-s to 0.006 Pa-s). The source of this variability has not been identified, but could be due to experimental error as there is higher error in measuring consistencies below $0.01 \mathrm{~Pa}$-s. However, it is not expected to significantly impact filtration performance.

Table 6.4. Results of Rheological Fitting Analysis for Initial Blended Component Slurries

\begin{tabular}{||c|c|c|c|c|c|c||}
\hline \multirow{4}{*}{ Model } & $\begin{array}{c}\text { Slurry } \\
\text { ID }\end{array}$ & $\begin{array}{c}\text { Temperature } \\
\left({ }^{\circ} \mathbf{C}\right)\end{array}$ & $\begin{array}{c}\text { Yield } \\
\text { Stress (Pa) }\end{array}$ & $\begin{array}{c}\text { Consistency } \\
(\mathbf{P a}-\mathbf{s})\end{array}$ & $\begin{array}{c}\text { Flow } \\
\text { Index }\end{array}$ & $\mathbf{R}$ \\
\hline \multirow{4}{*}{ Bingham-Plastic } & CBM-1 & 25 & $\sim 0$ & 0.005 & NA & 0.99 \\
\cline { 2 - 7 } & CBM-2 & 25 & $\sim 0$ & 0.006 & NA & 0.99 \\
\cline { 2 - 7 } & CBM-3 & 25 & $\sim 0$ & 0.0032 & NA & 0.99 \\
\cline { 2 - 7 } & CBM-4 & 25 & $\sim 0$ & 0.004 & NA & 0.99 \\
\cline { 2 - 7 } & CBM-5 & 25 & $\sim 0$ & 0.0035 & NA & 1 \\
\hline Herschel-Bulkley & CBM-1 & 25 & $\sim 0$ & $8.6 \mathrm{E}-5$ & 1.63 & 0.99 \\
\cline { 2 - 8 } & CBM-2 & 25 & $\sim 0$ & $7.3 \mathrm{E}-5$ & 1.66 & 0.99 \\
\hline
\end{tabular}




\begin{tabular}{||c|c|c|c|c|c|c||}
\hline \multirow{4}{*}{} & CBM-3 & --- & --- & --- & --- & --- \\
\cline { 2 - 7 } & CBM-4 & --- & --- & --- & --- & --- \\
\cline { 2 - 7 } & CBM-5 & 25 & $\sim 0$ & 0.004 & 0.99 & 1 \\
\hline
\end{tabular}

A total of five blended matrix tests were performed. The first test was CBM-1 (samples named CBM) with dewatering and washing at $45^{\circ} \mathrm{C}$. The next test, CBM-2 (samples named CBM25), essentially repeated CBM-1, except for the dewatering and washing of the slurry after the caustic leaching was performed at $25^{\circ} \mathrm{C}$ instead of $45^{\circ} \mathrm{C}$ to determine the effect of temperature on the filter flux. The next three tests (CBM-3, CBM-4, and CBM-5) were performed at $25^{\circ} \mathrm{C}$ to determine the capability of the simulant-producing vendor to produce the simulant at various production quantities. They were performed similar to the first two tests except that the chromium slurry was introduced after the caustic leach because of the high amount of chromium that was leached during caustic leaching in the first two tests. Also, more prototypic wash procedures and back-pulsing were used. All of the chemical analytical results and the discussion of these results are reported in WTP-RPT-184. ${ }^{(a)}$

The slurry simulant being tested was dewatered to the crossflow ultrafiltration unit's minimum operating volume at a predicted concentration of approximately $20-\mathrm{wt} \%$ UDS. Next, the slurry simulant was removed from the crossflow ultrafiltration unit to be caustic leached into the slurry reservoir tank. A known volume and concentration of $\mathrm{NaOH}$ was blended with the concentrated slurry. As before, the volume of the addition was established to include the volume of water representing the increase in the leach solution volume predicted to occur from heating with steam injection in the UFP-2 vessel of the PEP. The leach solution was heated to $100^{\circ} \mathrm{C}$ over a 5.3-hour interval. The solution was then held at $100^{\circ} \mathrm{C}$ for 12 hours. Afterwards, the solution cooled to room temperature over a 12-hour interval. At this point, the leached slurry solution in the slurry reservoir tank was allowed to enter the piping of the crossflow ultrafiltration unit, and it was again dewatered to the crossflow ultrafiltration unit's minimum operating volume. Then $0.01-\mathrm{M} \mathrm{NaOH}$ wash solutions were added to the leached slurry, which was then dewatered. Table 6.5 and Table 6.6 provide the timelines for each of these tests.

(a) RL Russell et al. 2009. "Development and Characterization of Boehmite Component Simulant." WTP-RPT-184, Rev. A, Pacific Northwest National Laboratory, Richland, Washington. 
Table 6.5. Timeline of the CBM-1 Test

\begin{tabular}{|c|c|c|c|}
\hline Time (hrs) & Process Step & Action & Samples \\
\hline 0 & Start of test & $11.25 \mathrm{~kg}$ of $5-\mathrm{wt} \%$ UDS slurry & CBM-IN-SL \\
\hline $0-5.75$ & Initial dewatering & $\begin{array}{l}\text { Removed } 33.68 \mathrm{~kg} \text { supernate and } \\
\text { added } 34.04 \mathrm{~kg} \text { feed }\end{array}$ & $\begin{array}{l}\text { CBM-DW-SL and CBM-DW- } \\
\text { FIL }\end{array}$ \\
\hline 7 & $\begin{array}{l}\text { Preparation for caustic } \\
\text { leaching }\end{array}$ & $\begin{array}{l}\text { Added } 6.94 \mathrm{~kg} 19 \mathrm{M} \mathrm{NaOH} \text { and } \\
9.54 \mathrm{~kg} \text { of DI water }\end{array}$ & \\
\hline $7.25-11.25$ & Caustic leaching & Heated to $100^{\circ} \mathrm{C}$ & CBM-LE-R-0,2,4 \\
\hline $11.25-23.25$ & Caustic leaching & Leached at $100^{\circ} \mathrm{C}$ & CBM-LE-S- $0,2,4,6,8,10,12$ \\
\hline $23.25-35.25$ & Caustic leaching & Cooled from $100^{\circ} \mathrm{C}$ to $45^{\circ} \mathrm{C}$ & CBM-LE-C-2,4,6,8,10,12 \\
\hline $36.5-43.5$ & Caustic leach dewater & Removed $22.26 \mathrm{~kg}$ supernate & CBM-LC-SL and CBM-LC-FIL \\
\hline $44.5-48$ & Caustic leach washing & $\begin{array}{l}\text { Added } 5.01 \mathrm{~kg} \text { of } 1.57 \mathrm{M} \mathrm{NaOH} \text { and } \\
\text { removed } 4.00 \mathrm{~kg} \text { supernate }\end{array}$ & CBM-W1-FIL \\
\hline $48.75-53.5$ & Caustic leach washing & $\begin{array}{l}\text { Added } 4.89 \mathrm{~kg} \text { of } 0.68 \mathrm{M} \mathrm{NaOH} \text { and } \\
\text { removed } 4.96 \mathrm{~kg} \text { supernate }\end{array}$ & $\mathrm{CBM}$ \\
\hline $54.5-55.5$ & Caustic leach washing & $\begin{array}{l}\text { Added } 4.84 \mathrm{~kg} \text { of } 0.26 \mathrm{M} \mathrm{NaOH} \text { and } \\
\text { removed } 4.92 \mathrm{~kg} \text { supernate }\end{array}$ & CBM \\
\hline $56.25-56.75$ & Caustic leach washing & $\begin{array}{l}\text { Added } 4.82 \mathrm{~kg} \text { of } 0.08 \mathrm{M} \mathrm{NaOH} \text { and } \\
\text { removed } 4.95 \mathrm{~kg} \text { supernate }\end{array}$ & CBM- \\
\hline $58-58.5$ & Caustic leach washing & $\begin{array}{l}\text { Added } 4.81 \mathrm{~kg} \text { of } 0.03 \mathrm{M} \mathrm{NaOH} \text { and } \\
\text { removed } 4.80 \mathrm{~kg} \text { supernate }\end{array}$ & CBM-W5-FIL \\
\hline $59-59.4$ & Caustic leach washing & $\begin{array}{l}\text { Added } 4.80 \mathrm{~kg} \text { of } 0.01 \mathrm{M} \mathrm{NaOH} \text { and } \\
\text { removed } 4.72 \mathrm{~kg} \text { supernate }\end{array}$ & $\begin{array}{c}\text { CBM-W6-FIL, CBM-WC-FIL, } \\
\text { and CBM-WS-SL }\end{array}$ \\
\hline 62.5 & $\begin{array}{l}\mathrm{NaOH} \text { concentration } \\
\text { adjustment }\end{array}$ & Added $9.9 \mathrm{~g}$ of $19 \mathrm{M} \mathrm{NaOH}$ & CBM-POL-SUP \\
\hline $63.75-69.75$ & Oxidative leaching & Added $640 \mathrm{~mL}$ of $0.2 \mathrm{M} \mathrm{KMnO}_{4}$ & $\begin{array}{c}\text { CBM-OL-05,1,2,4,6 and CBM- } \\
\text { OL-SL }\end{array}$ \\
\hline $71.5-72.25$ & Oxidative leach washing & $\begin{array}{l}\text { Added } 4.70 \mathrm{~kg} \text { of } 0.01 \mathrm{M} \mathrm{NaOH} \text { and } \\
\text { removed } 6.0 \mathrm{~kg} \text { supernate }\end{array}$ & No sample taken. \\
\hline 73.3-74 & Oxidative leach washing & $\begin{array}{l}\text { Added } 4.79 \mathrm{~kg} \text { of } 0.01 \mathrm{M} \mathrm{NaOH} \text { and } \\
\text { removed } 2.53 \mathrm{~kg} \text { supernate }\end{array}$ & No sample taken. \\
\hline $266-266.5$ & Oxidative leach washing & $\begin{array}{l}\text { Added } 2.33 \mathrm{~kg} \text { of } 0.01 \mathrm{M} \mathrm{NaOH} \text { and } \\
\text { removed } 2.35 \mathrm{~kg} \text { supernate. }\end{array}$ & CBM-W3-OL \\
\hline $267-267.75$ & Oxidative leach washing & $\begin{array}{l}\text { Added } 2.40 \mathrm{~kg} \text { of } 0.01 \mathrm{M} \mathrm{NaOH} \text { and } \\
\text { removed } 2.48 \mathrm{~kg} \text { supernate }\end{array}$ & CBM-FSC-SL \\
\hline
\end{tabular}


Table 6.6. Timeline of the CBM-2 Test

\begin{tabular}{|c|c|c|c|}
\hline Time (hrs) & Process Step & Action & Samples \\
\hline 0 & Start of test & $11.33 \mathrm{~kg}$ of $5-\mathrm{wt} \%$ UDS slurry & CBM25-IN-SL \\
\hline $0-14.75$ & Initial dewatering & $\begin{array}{l}\text { Added } 33.86 \mathrm{~kg} \text { slurry and } \\
\text { removed } 34.67 \mathrm{~kg} \text { supernate }\end{array}$ & $\begin{array}{l}\text { CBM25-DW-SL and } \\
\text { CBM25-DW-FIL }\end{array}$ \\
\hline 15.25 & $\begin{array}{l}\text { Preparation for caustic } \\
\text { leaching }\end{array}$ & $\begin{array}{l}\text { Added } 6.94 \mathrm{~kg} 19 \mathrm{M} \mathrm{NaOH} \text { and } \\
9.54 \mathrm{~kg} \text { DI water }\end{array}$ & No sample taken. \\
\hline $16.25-24.4$ & Caustic leaching & Heated from $25^{\circ} \mathrm{C}$ to $100^{\circ} \mathrm{C}$ & CBM25-LE-R-0,2,4 \\
\hline $24.4-36.4$ & Caustic leaching & Leached at $100^{\circ} \mathrm{C}$ & $\begin{array}{l}\text { CBM25-LE-S- } \\
0,2,4,6,8,10,12 \\
\end{array}$ \\
\hline $36.4-48.25$ & Caustic leaching & Cooled from $100^{\circ} \mathrm{C}$ to $45^{\circ} \mathrm{C}$ & $\begin{array}{l}\text { CBM25-LE-C- } \\
0,2,4,6,8,10,12 \\
\end{array}$ \\
\hline $49.25-60.4$ & Caustic leach dewater & Removed $20.30 \mathrm{~kg}$ supernate. & $\begin{array}{l}\text { CBM25-LC-SL and } \\
\text { CBM25-LC-FIL }\end{array}$ \\
\hline $60.6-64.6$ & Caustic leach washing & $\begin{array}{l}\text { Added } 5.01 \mathrm{~kg} \text { of } 1.57 \mathrm{M} \mathrm{NaOH} \\
\text { and removed } 5.56 \mathrm{~kg} \text { supernate }\end{array}$ & CBM25-W1-FIL \\
\hline $64.6-67.6$ & Caustic leach washing & $\begin{array}{l}\text { Added } 4.89 \mathrm{~kg} \text { of } 0.68 \mathrm{M} \mathrm{NaOH} \\
\text { and removed } 5.10 \mathrm{~kg} \text { supernate }\end{array}$ & CBM25-W2-FIL \\
\hline $68.6-70$ & Caustic leach washing & $\begin{array}{l}\text { Added } 4.88 \mathrm{~kg} \text { of } 0.26 \mathrm{M} \mathrm{NaOH} \\
\text { and removed } 5.06 \mathrm{~kg} \text { supernate }\end{array}$ & CBM25-W3-FIL \\
\hline $70.25-71.25$ & Caustic leach washing & $\begin{array}{l}\text { Added } 4.81 \mathrm{~kg} \text { of } 0.08 \mathrm{M} \mathrm{NaOH} \\
\text { and removed } 4.89 \mathrm{~kg} \text { supernate }\end{array}$ & CBM25-W4-FIL \\
\hline $71.8-72.8$ & Caustic leach washing & $\begin{array}{l}\text { Added } 4.80 \mathrm{~kg} \text { of } 0.03 \mathrm{M} \mathrm{NaOH} \\
\text { and removed } 4.87 \mathrm{~kg} \text { supernate }\end{array}$ & CBM25-W5-FIL \\
\hline $73-74$ & Caustic leach washing & $\begin{array}{l}\text { Added } 4.80 \mathrm{~kg} \text { of } 0.01 \mathrm{M} \mathrm{NaOH} \\
\text { and removed } 4.81 \mathrm{~kg} \text { supernate }\end{array}$ & $\begin{array}{l}\text { CBM25-W6-FIL, CBM25- } \\
\text { WC-FIL, CBM25-WS-SL, } \\
\text { and CBM25-POL-SUP }\end{array}$ \\
\hline $76-82$ & Oxidative leaching & Added $128 \mathrm{~mL}$ of $1 \mathrm{M} \mathrm{NaMnO}_{4}$ & $\begin{array}{c}\text { CBM25-OL-05,1,2,4,6 and } \\
\text { CBM25-OL-SL } \\
\end{array}$ \\
\hline $83.25-84$ & Oxidative leach washing & $\begin{array}{l}\text { Added } 4.81 \mathrm{~kg} 0.01 \text { of } \mathrm{M} \mathrm{NaOH} \\
\text { and removed } 4.87 \mathrm{~kg} \text { supernate }\end{array}$ & No sample taken. \\
\hline $84.25-86.25$ & Oxidative leach washing & $\begin{array}{l}\text { Added } 4.80 \mathrm{~kg} \text { of } 0.01 \mathrm{M} \mathrm{NaOH} \\
\text { and removed } 4.83 \mathrm{~kg} \text { supernate }\end{array}$ & No sample taken. \\
\hline $86.5-88.8$ & Oxidative leach washing & $\begin{array}{l}\text { Added } 4.80 \mathrm{~kg} \text { of } 0.01 \mathrm{M} \mathrm{NaOH} \\
\text { and removed } 4.82 \mathrm{~kg} \text { supernate }\end{array}$ & CBM25-W3-OL \\
\hline $89-91.5$ & Oxidative leach washing & $\begin{array}{l}\text { Added } 4.80 \mathrm{~kg} \text { of } 0.01 \mathrm{M} \mathrm{NaOH} \\
\text { and removed } 4.81 \mathrm{~kg} \text { supernate }\end{array}$ & CBM25-FSC-SL \\
\hline
\end{tabular}

Once the slurry was washed after caustic leaching, it was removed from the crossflow ultrafiltration unit for oxidative leaching in the slurry reservoir tank. At this point, a solution of 1-M sodium permanganate was added to the simulant slurry. The volume of sodium permanganate added was calculated to achieve a 1:1 molar ratio of $\mathrm{Mn}$ to the predicted quantity of $\mathrm{Cr}$ in the simulant solids. After the solution was added to the simulant slurry, it was mixed for 6 hours at room temperature. After 6 hours, the oxidative leached slurry was dewatered and then washed with $0.01 \mathrm{M} \mathrm{NaOH}$ and dewatered again.

Slurry and supernate samples were periodically collected throughout the tests to track the solids loading, rheology, and PSD of the slurry. 


\subsection{Filtration Temperature Effect}

Two filtration tests were performed to help determine the temperature effect on the filter flux. Appendix D provides the letter for WTP approval of this test matrix. These tests will be discussed step by step in this section.

\subsubsection{Initial Slurry Dewatering}

Initially, 9 liters of slurry were added to the reservoir tank. Then it was dewatered to a target of $20 \mathrm{wt} \%$ at a TMP of $40 \mathrm{psid}$ and an AV of $13 \mathrm{ft} / \mathrm{s}$. A $750-\mathrm{mL}$ sample of slurry was added to the reservoir tank for each $750 \mathrm{~mL}$ of filtrate removed until a total of approximately $34 \mathrm{~kg}$ of slurry had been added. The only difference in the dewatering of these tests (CBM-1 and CBM-2) was the filtration temperature. The filter temperature was held at $45^{\circ} \mathrm{C}$ for $\mathrm{CBM}-1$ and at $25^{\circ} \mathrm{C}$ for $\mathrm{CBM}-2$.

An increase in filter flux at $45^{\circ} \mathrm{C}$ was observed in CBM-1 that was significantly greater than expected based on viscosity changes alone as shown in Figure 6.2. It is generally expected that the filter flux will ratio inversely to the viscosity:

$$
\frac{J}{J_{o}}=\frac{\eta_{o}}{\eta}
$$

This ratio was applied to the filter flux data for test $\mathrm{CBM}-2$ to adjust the temperature to $45 \mathrm{C}$ using the measured viscosity of 4.12 to $2.32 \mathrm{cP}$ for $25^{\circ} \mathrm{C}$ and $45^{\circ} \mathrm{C}$, respectively. This flux was still lower than what was measured in $\mathrm{CBM}-1$ at $45^{\circ} \mathrm{C}$ flux, indicating that temperature has a significant effect on the filter flux in low-solids slurry during the initial dewatering in addition to the known effect of decreasing the viscosity.

After dewatering of the slurry simulant, the physical properties (Table 6.7), PSD (Figure 6.3), and rheology (Table 6.8) were measured again. The dewatered physical properties were almost identical in the two tests, indicating that they had been dewatered equally. Therefore, any observed filtering dissimilarites were not due to a difference in physical properties.

Initially, the PSD was different between the two slurries with CBM-2 showing two distinct particle ranges. However, after sonication, both simulants were almost identical with a mean volume distribution diameter of 6 to 8 microns, indicating that sonication seems to agglomerate the slurry to similar particle sizes. 


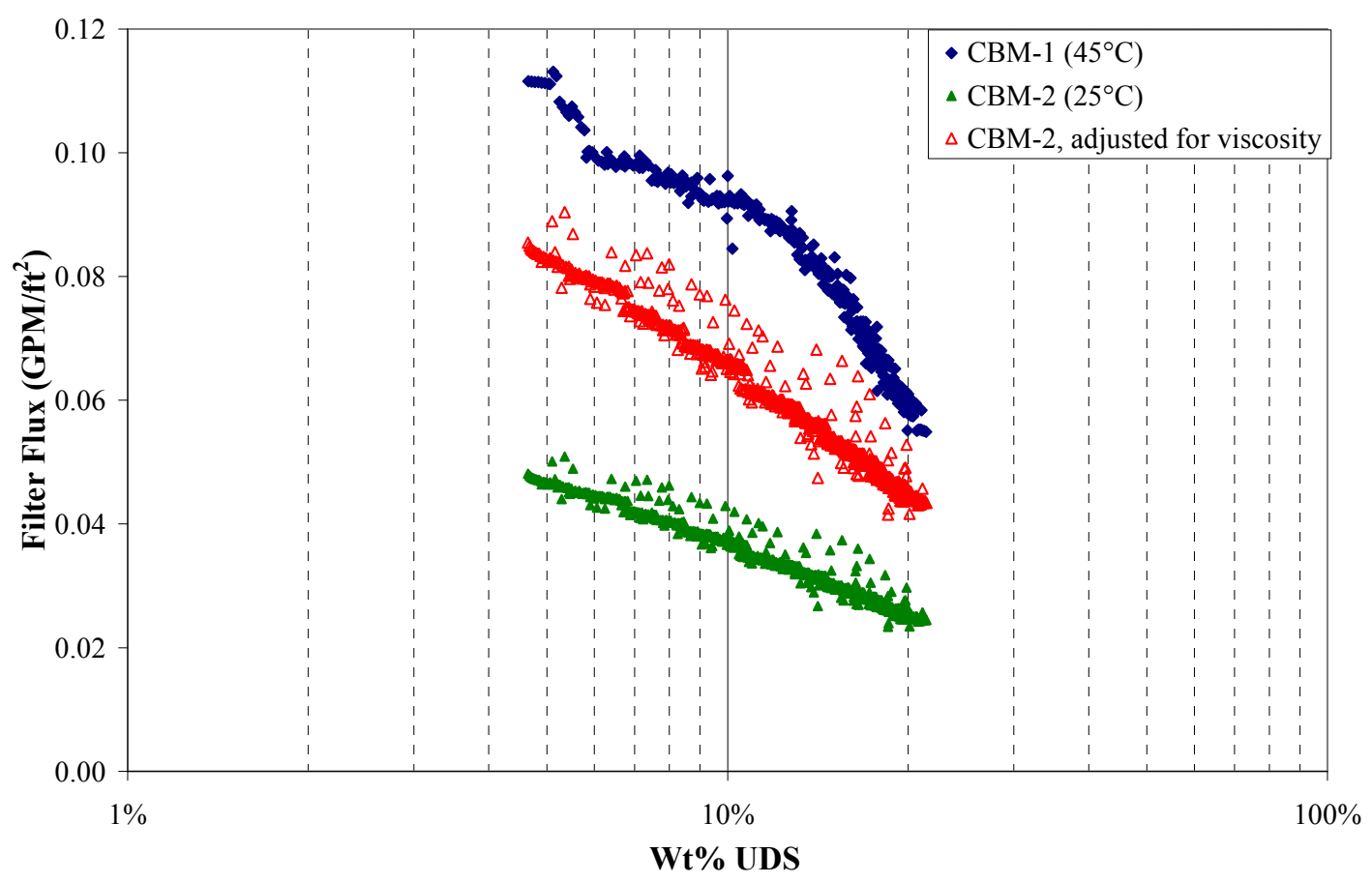

Figure 6.2. Dewatering Filter Flux for CBM-1 $\left(45^{\circ} \mathrm{C}\right)$ and $\mathrm{CBM}-2\left(25^{\circ} \mathrm{C}\right)$

Table 6.7. Physical-Property Measurements of Dewatered Blended Component Slurries

\begin{tabular}{|l|c|c|}
\hline & CBM-1 & CBM-2 \\
\hline Slurry Density $(\mathrm{g} / \mathrm{mL})$ & 1.37 & 1.36 \\
\hline Supernate Density $(\mathrm{g} / \mathrm{mL})$ & 1.23 & 1.23 \\
\hline Total Solids $(\mathrm{wt} \%)$ & 44.2 & 44.6 \\
\hline Dissolved Solids $(\mathrm{wt} \%)$ & 30.0 & 30.0 \\
\hline UDS $(w t \%)$ & 20.3 & 20.9 \\
\hline
\end{tabular}




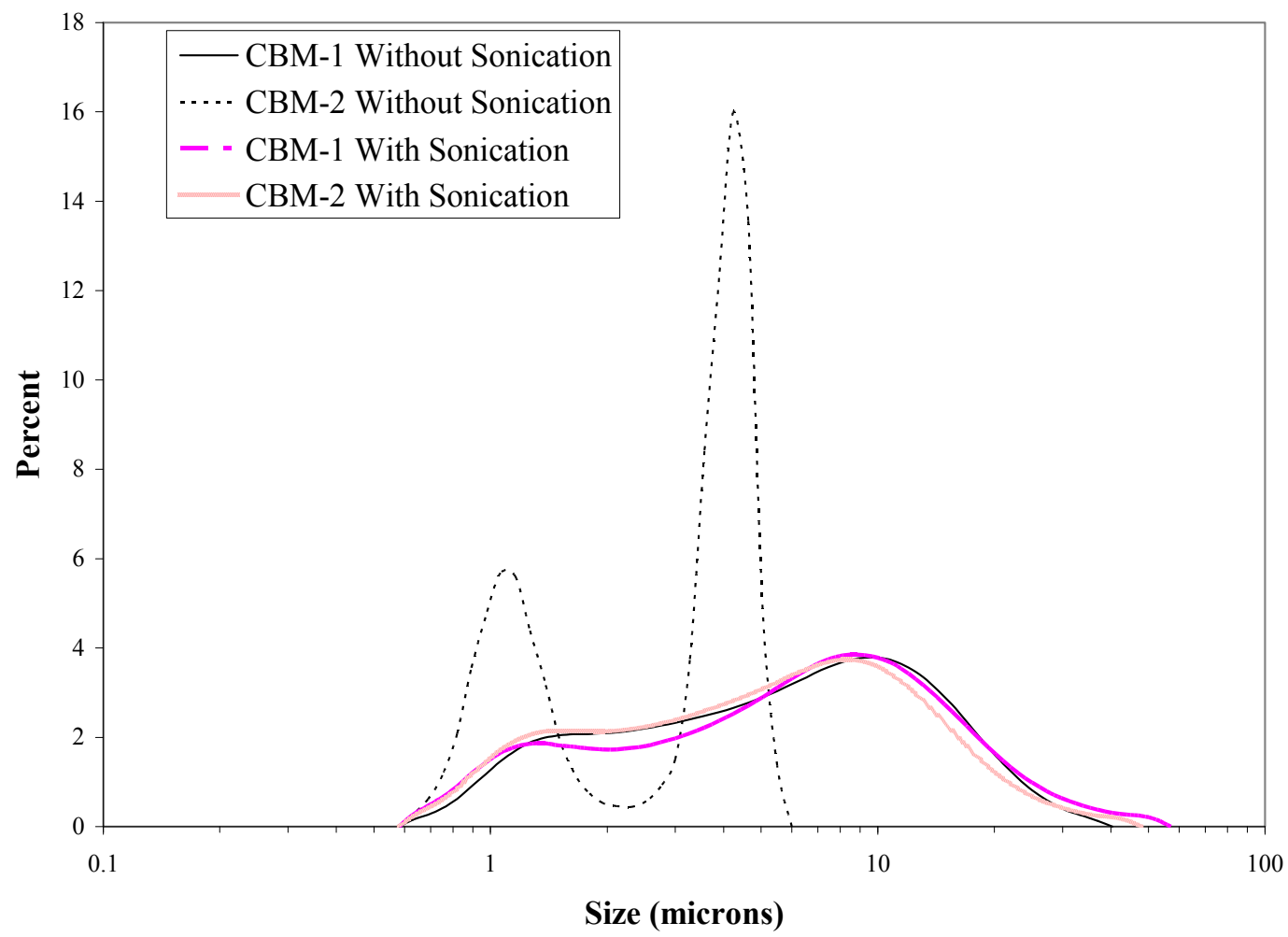

Figure 6.3. PSD Volume Distribution of Dewatered CBM-1 and CBM-2

The rheology of both slurries also behaved similarly with a non-Newtonian stress response (see Appendix $\mathrm{C}$ for an explanation of rheology models). The yield stress ranged from approximately $1.0 \mathrm{~Pa}$ to $1.7 \mathrm{~Pa}$. The consistency was still very low and was easy to pump.

Table 6.8. Results of Rheological Fitting Analysis for Dewatered Blended Component Slurries

\begin{tabular}{||c|c|c|c|c|c|c||}
\hline \multirow{2}{*}{ Model } & $\begin{array}{c}\text { Slurry } \\
\text { ID }\end{array}$ & $\begin{array}{c}\text { Temperature } \\
\left({ }^{\circ} \mathbf{C}\right)\end{array}$ & $\begin{array}{c}\text { Yield } \\
\text { Stress }(\mathbf{P a})\end{array}$ & $\begin{array}{c}\text { Consistency } \\
(\mathbf{P a}-\mathbf{s})\end{array}$ & $\begin{array}{c}\text { Flow } \\
\text { Index }\end{array}$ & $\mathbf{R}$ \\
\hline \multirow{2}{*}{ Bingham-Plastic } & CBM-1 & 25 & 1.0 & 0.008 & NA & 0.99 \\
\cline { 2 - 7 } & CBM-2 & 25 & 1.7 & 0.008 & NA & 0.99 \\
\hline \multirow{2}{*}{ Herschel-Bulkley } & CBM-1 & 25 & 1.3 & 0.004 & 1.1 & 0.99 \\
\cline { 2 - 7 } & CBM-2 & 25 & 1.7 & 0.008 & 1.0 & 0.99 \\
\hline
\end{tabular}

\subsubsection{Post-Caustic Leaching Dewatering}

After the slurry simulant was caustic leached with $\mathrm{NaOH}$ at $100^{\circ} \mathrm{C}$, the simulant was again dewatered to increase the weight percent solids and remove the caustic solution from the simulant. These results are shown in Figure 6.4 and indicate that temperature does, at least in part, account for the differences in filter flux. However, it is difficult to assess whether the differences in flux after 4 hours are associated with the difference in temperature or some other system parameters. 


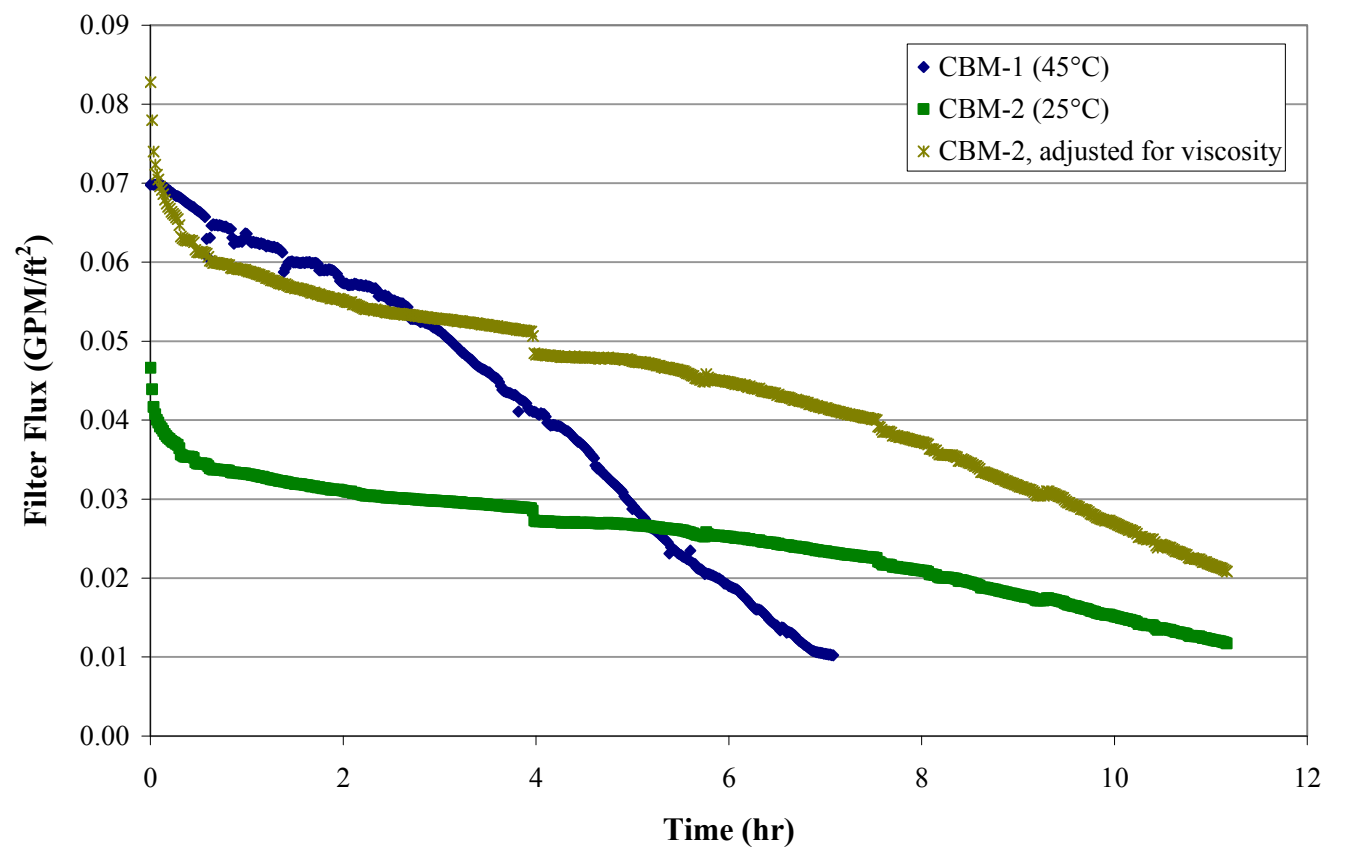

Figure 6.4. Post-Caustic Leaching Dewatering Filter Flux for $\mathrm{CBM}-1\left(45^{\circ} \mathrm{C}\right)$ and $\mathrm{CBM}-2\left(25^{\circ} \mathrm{C}\right)$

After post-caustic leaching dewatering, the physical properties (Table 6.9), PSD (Figure 6.5), and rheology (Table 6.10) were measured once again. The physical properties between the two slurries were different because of different sampling times. The first wash was added to the CBM-2 slurry before the post-caustic leached and dewatered sample was taken for CBM-2 by mistake. Therefore, CBM-2 was significantly diluted and did not provide comparable results for this point in the process. CBM-1 was sampled appropriately and did provide accurate results for this point in the process. The slurry density of CBM-2 also appears to be low but was repeated several times with a very similar value.

The particle sizes were similar between the two slurries, and sonication did not affect the particle size, indicating that there were not many agglomerations present in the slurry.

The yield stress between the two simulants was about a factor of 50 different, although both slurries exhibited non-Newtonian behavior. This was because CBM-2 had the first wash of $4.8 \mathrm{~L}$ of $1.57 \mathrm{M}$ $\mathrm{NaOH}$ added to the slurry before the sample was taken, giving CBM-2 significantly lower weight percent UDS. Therefore, CBM-1 behavior is most likely how post-caustic leached and dewatered slurry will behave.

Table 6.9. Physical-Property Measurements of Post-Caustic Leaching Dewatered Blended Component Slurries

\begin{tabular}{|l|c|c||}
\hline & CBM-1 & CBM-2 \\
\hline Slurry Density $(\mathrm{g} / \mathrm{mL})$ & 1.37 & 1.23 \\
\hline Supernate Density $(\mathrm{g} / \mathrm{mL})$ & 1.25 & 1.24 \\
\hline Total Solids $(w t \%)$ & 52.5 & 44.7 \\
\hline Dissolved Solids $(w t \%)$ & 26.8 & 29.5 \\
\hline UDS (wt\%) & 35.1 & 21.7 \\
\hline
\end{tabular}




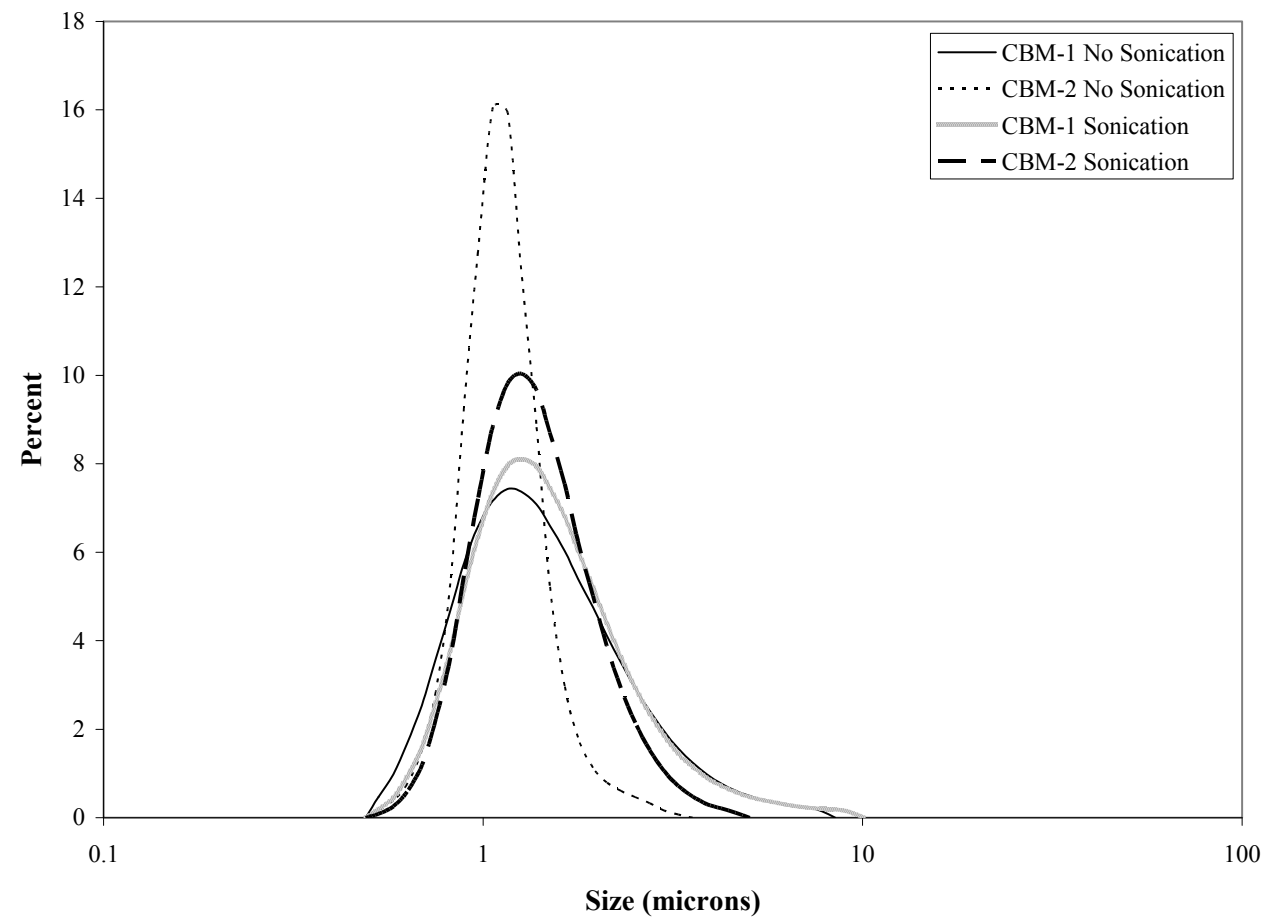

Figure 6.5. PSD Volume Distribution of Post-Caustic Leaching Dewatered CBM-1 and CBM-2

Table 6.10. Results of Rheological Fitting Analysis for Post-Caustic Leaching Dewatered Blended Component Slurries

\begin{tabular}{||c|c|c|c|c|c|c||}
\hline \multirow{2}{*}{ Model } & $\begin{array}{c}\text { Slurry } \\
\text { ID }\end{array}$ & $\begin{array}{c}\text { Temperature } \\
\left({ }^{\circ} \mathbf{C}\right)\end{array}$ & $\begin{array}{c}\text { Yield } \\
\text { Stress (Pa) }\end{array}$ & $\begin{array}{c}\text { Consistency } \\
(\mathbf{P a}-\mathbf{s})\end{array}$ & $\begin{array}{c}\text { Flow } \\
\text { Index }\end{array}$ & $\mathbf{R}$ \\
\hline \multirow{2}{*}{ Bingham-Plastic } & CBM-1 & 25 & 48 & 0.033 & NA & 0.99 \\
\cline { 2 - 7 } & CBM-2 & 25 & 1.0 & 0.007 & NA & 0.99 \\
\hline \multirow{2}{*}{ Herschel-Bulkley } & CBM-1 & 25 & 42 & 0.34 & 0.68 & 0.99 \\
\cline { 2 - 7 } & CBM-2 & 25 & 1.6 & 0.001 & 1.3 & 0.99 \\
\hline
\end{tabular}

\subsubsection{Post-Caustic Leach Washing and Dewatering}

After the caustic-leached simulant slurry had been concentrated, it was batch washed by adding $4.8 \mathrm{~L}$ of varying concentrations of $\mathrm{NaOH}$, as shown in Table 6.11, to the slurry and dewatered six times. A significant improvement in flux was observed on the third and subsequent washes (Figure 6.6 and Figure 6.7 as well as Table 6.11). The improvement was greater than that predicted by differences in viscosity at a constant filter resistance, suggesting a change in effective filter resistance. This might be attributed to the rapid dissolution of small particles in this concentration regime (potentially sodium oxalate as this is the primary species expected to dissolve during washing).

When the washes at the different temperatures were compared, it was found that the fluxes of the first two washes were similar whereas the fluxes from the last three washes were significantly higher in the $45^{\circ} \mathrm{C}$ filtration. This indicates that the effect of the increased filter resistance was stronger than the effect of the temperature for the first two washes, which may be attributed to precipitating sodium oxalate deeply 
fouling the filter. Once this resistance was removed (perhaps by the re-dissolution of the sodium oxalate), the temperature effect began to dominate once again as shown in Figure 6.8.

Table 6.11. Caustic Wash Concentrations

\begin{tabular}{|c|c|c|c|c||}
\hline & $\begin{array}{c}\text { Wash } \\
\text { Volume (L) }\end{array}$ & $\begin{array}{c}\text { NaOH Conc. of } \\
\text { Wash (M) }\end{array}$ & $\begin{array}{c}\text { Average Filter } \\
\text { Flux at 25 } \\
\left(\mathbf{g p m} / \mathbf{f t}^{\mathbf{2}} \mathbf{C}\right.\end{array}$ & $\begin{array}{c}\text { Average Filter } \\
\text { Flux at 45 } \\
\mathbf{( g p m} \mathbf{~} \mathbf{f t}^{\mathbf{2}} \mathbf{)}\end{array}$ \\
\hline Wash 1 & 4.8 & 1.57 & 0.021 & 0.023 \\
\hline Wash 2 & 4.8 & 0.68 & 0.027 & 0.019 \\
\hline Wash 3 & 4.8 & 0.26 & 0.075 & 0.16 \\
\hline Wash 4 & 4.8 & 0.08 & 0.091 & 0.18 \\
\hline Wash 5 & 4.8 & 0.03 & 0.11 & 0.18 \\
\hline Wash 6 & 4.8 & 0.01 & 0.11 & 0.18 \\
\hline
\end{tabular}

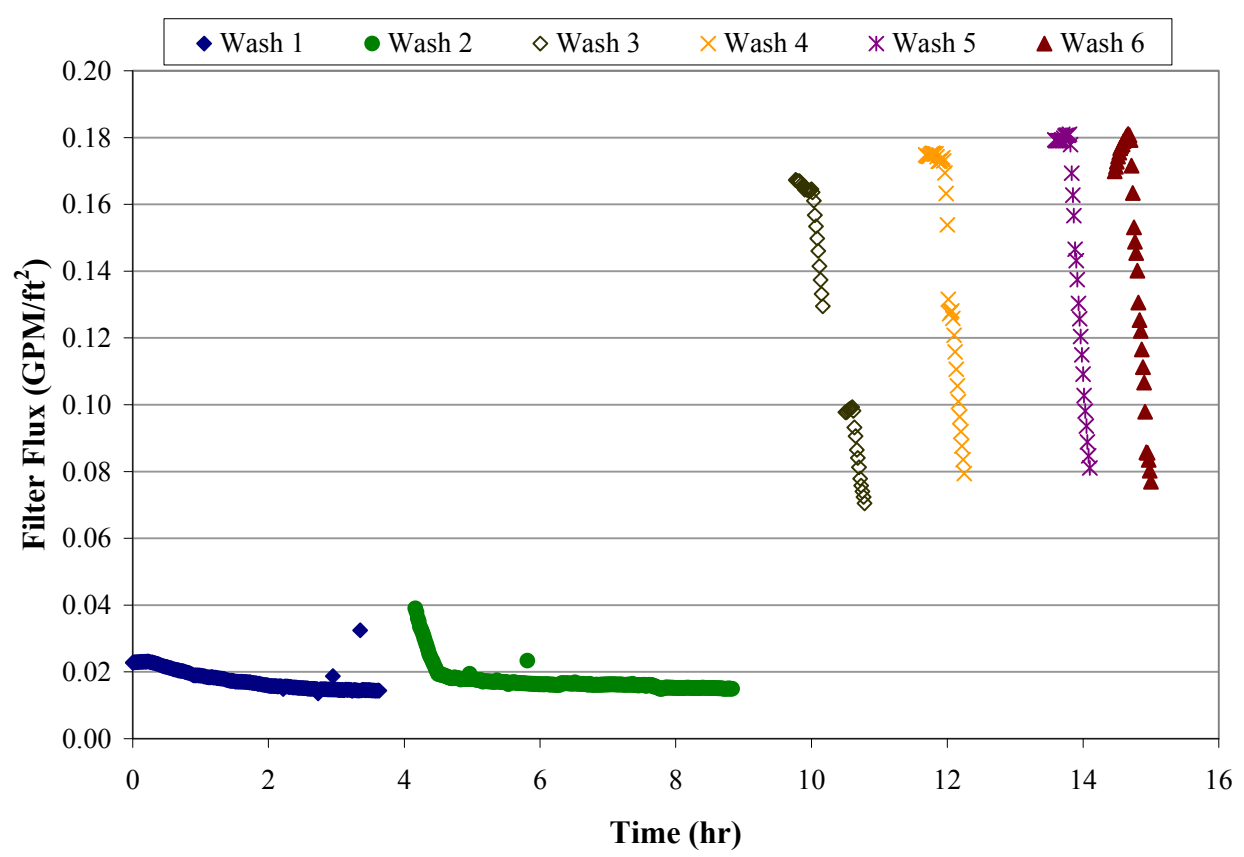

Figure 6.6. Caustic Leach Washing Filter Flux at $45^{\circ} \mathrm{C}(\mathrm{CBM}-1)$ 


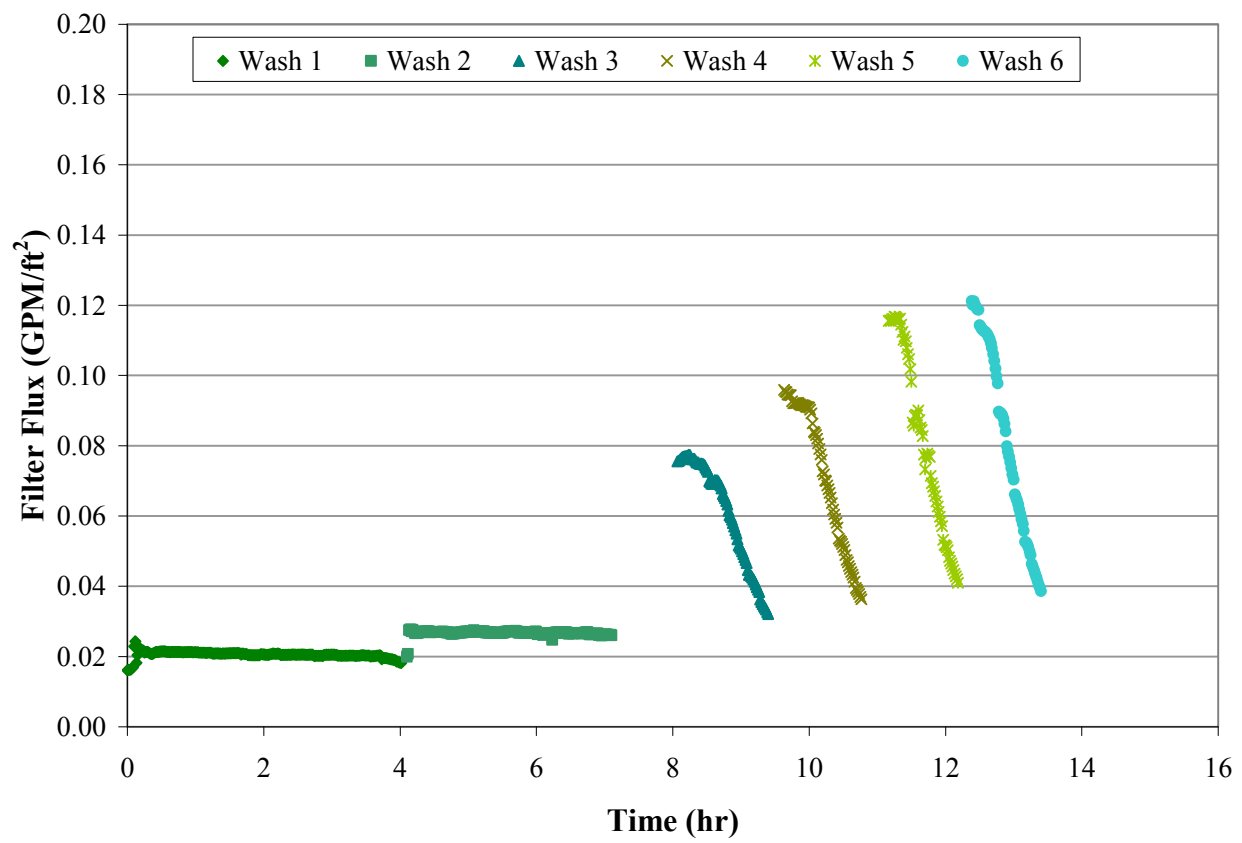

Figure 6.7. Caustic Leach Washing Filter Flux at $25^{\circ} \mathrm{C}(\mathrm{CBM}-2)$

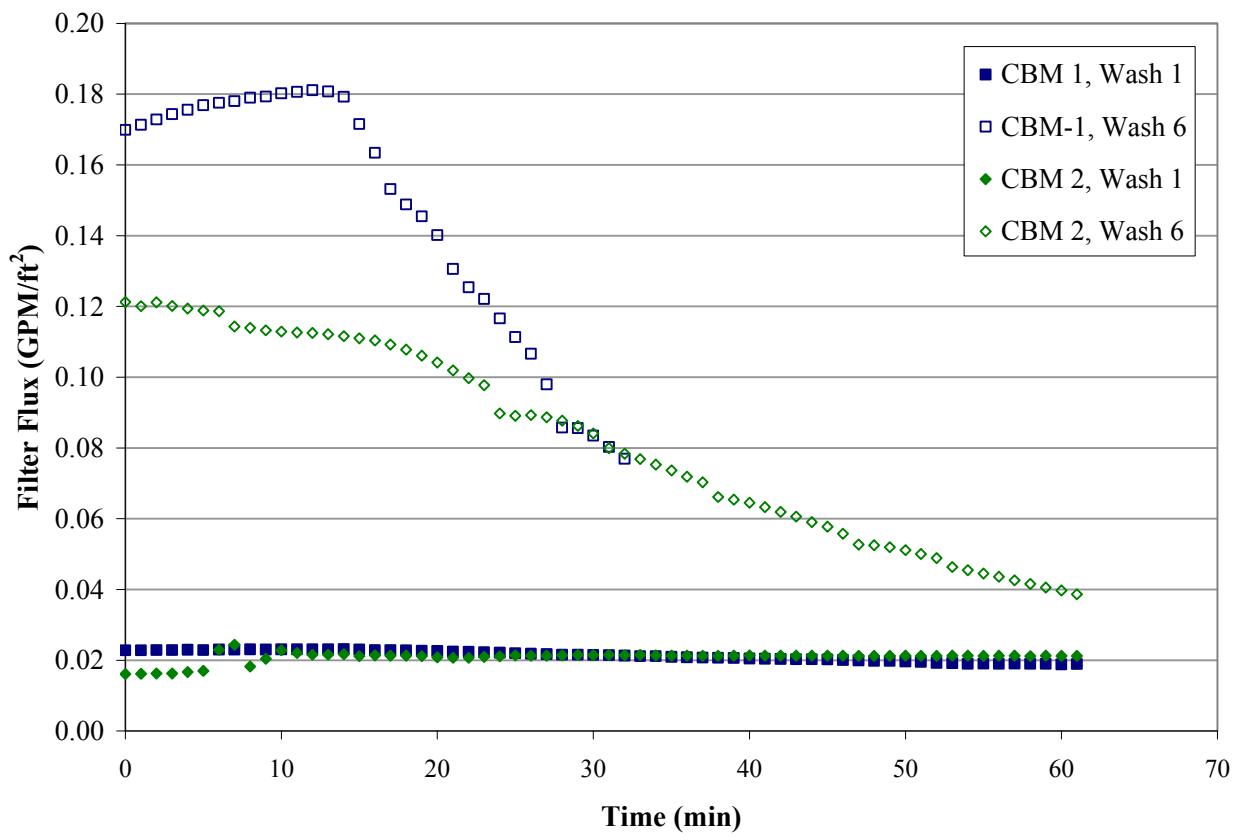

Figure 6.8. Comparison of Caustic Leach Washing Filter Fluxes at $45^{\circ}(\mathrm{CBM}-1)$ and $25^{\circ} \mathrm{C}(\mathrm{CBM}-$ 2) 
After post-caustic leach washing, the physical properties (Table 6.12), PSD (Figure 6.9), and rheology (

Table 6.13) were measured. The physical properties of weight percent UDS and densities were similar. The weight percent dissolved solids were different, indicating that CBM-1 was washed more effectively than CBM-2. The higher dissolved solids appears to be associated with sulfate.

It appears from the PSD that the sonication shifted the particle size of the CBM-1 toward the smaller particles, indicating that there was an agglomeration present that broke apart. It appears that for CBM-2, the sonication only spread the distribution but did not really change the mean particle size $(0.92 \mu \mathrm{m}$ versus $1.1 \mu \mathrm{m})$. The rheology indicated a non-Newtonian behavior for both of the slurries with a significant yield stress being present. The consistency was similar. At this time, insufficient information is available to explain these differences in rheological behavior.

Table 6.12. Physical-Property Measurements of Post-Caustic Leach Washed Blended Component Slurries

\begin{tabular}{|l|c|c|}
\hline & CBM-1 & CBM-2 \\
\hline Slurry Density (g/mL) & 1.14 & 1.18 \\
\hline Supernate Density $(\mathrm{g} / \mathrm{mL})$ & 1.06 & 1.06 \\
\hline Total Solids (wt\%) & 18.9 & 23.8 \\
\hline Dissolved Solids (wt\%) & 2.19 & 9.83 \\
\hline UDS (wt\%) & 17.1 & 15.5 \\
\hline
\end{tabular}

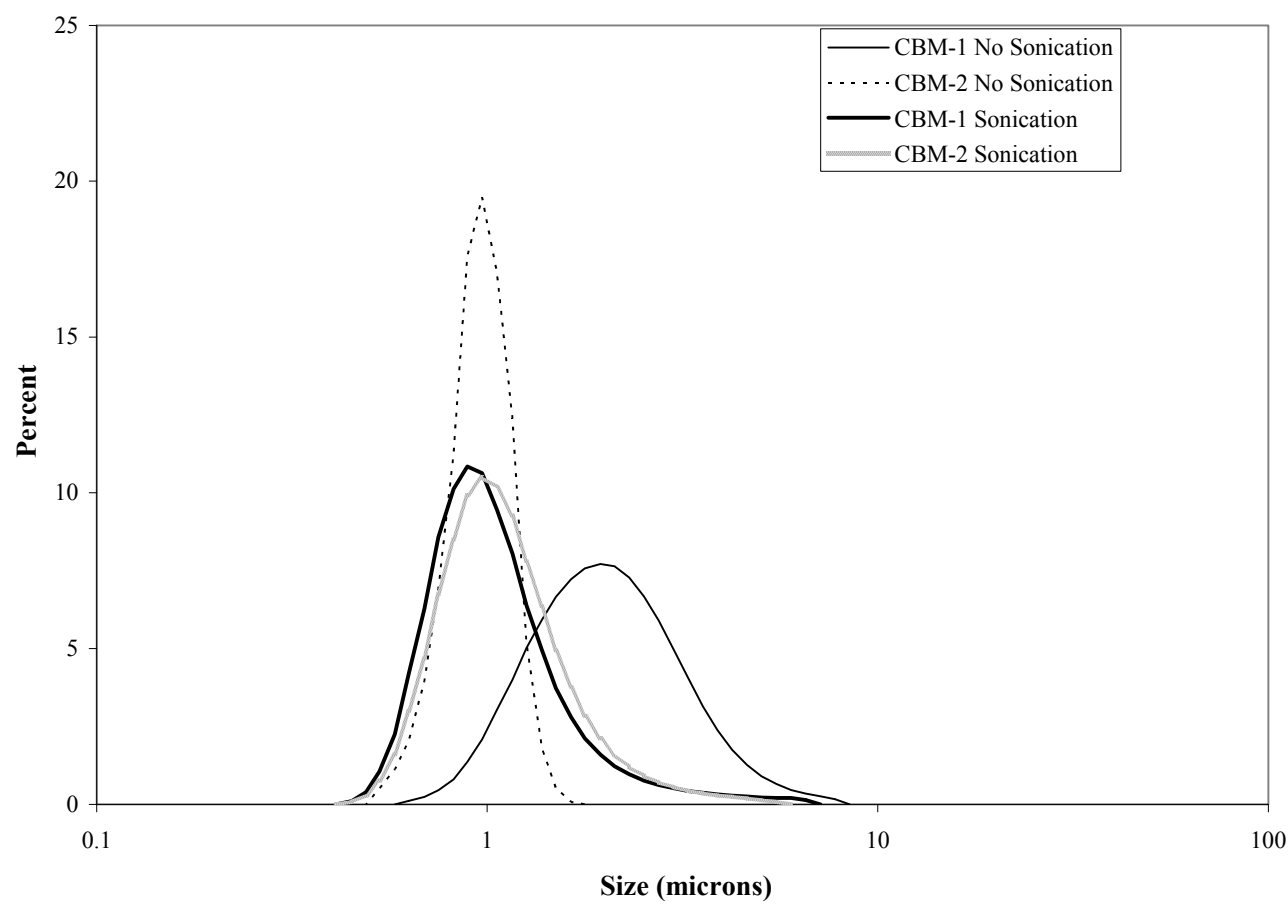

Figure 6.9. PSD Volume Distribution of Post-Caustic Leach Washed CBM-1 and CBM-2 
Table 6.13. Results of Rheological Fitting Analysis for Post-Caustic Leach Washed Blended Component Slurries

\begin{tabular}{|c|c|c|c|c|c|c||}
\hline Model & $\begin{array}{c}\text { Slurry } \\
\text { ID }\end{array}$ & $\begin{array}{c}\text { Temperature } \\
\left({ }^{\circ} \mathbf{C}\right)\end{array}$ & $\begin{array}{c}\text { Yield } \\
\text { Stress (Pa) }\end{array}$ & $\begin{array}{c}\text { Consistency } \\
(\text { Pa-s) }\end{array}$ & $\begin{array}{c}\text { Flow } \\
\text { Index }\end{array}$ & R \\
\hline $\begin{array}{c}\text { Bingham- } \\
\text { Plastic }\end{array}$ & CBM-1 & 25 & 18.1 & 0.009 & NA & 0.99 \\
\cline { 2 - 7 } & CBM-2 & 25 & 33.5 & 0.008 & NA & 0.99 \\
\hline $\begin{array}{c}\text { Herschel- } \\
\text { Bulkley }\end{array}$ & CBM-1 & 25 & 9.20 & 3.09 & 0.24 & 0.99 \\
\hline
\end{tabular}

\subsubsection{Oxidative Leach Washing and Dewatering}

After the simulant slurry had been oxidatively leached with $1 \mathrm{M}$ sodium permanganate, it was washed with $0.01 \mathrm{M} \mathrm{NaOH}$ in equal volume to the feed present and then dewatered four times consecutively. Figure 6.10 shows how the fluxes compare at the two different temperatures. The washing time was more than twice as long at $25^{\circ} \mathrm{C}$ as it was at $45^{\circ} \mathrm{C}$. However, due to a number of other experimental differences, it is difficult to draw any reliable conclusions about these tests. From these tests, it appears that the presence of permanganate did not affect the flux of the simulant because the other fluxes without permanganate also filtered near $0.04 \mathrm{gpm} / \mathrm{ft}^{2}$ or less.

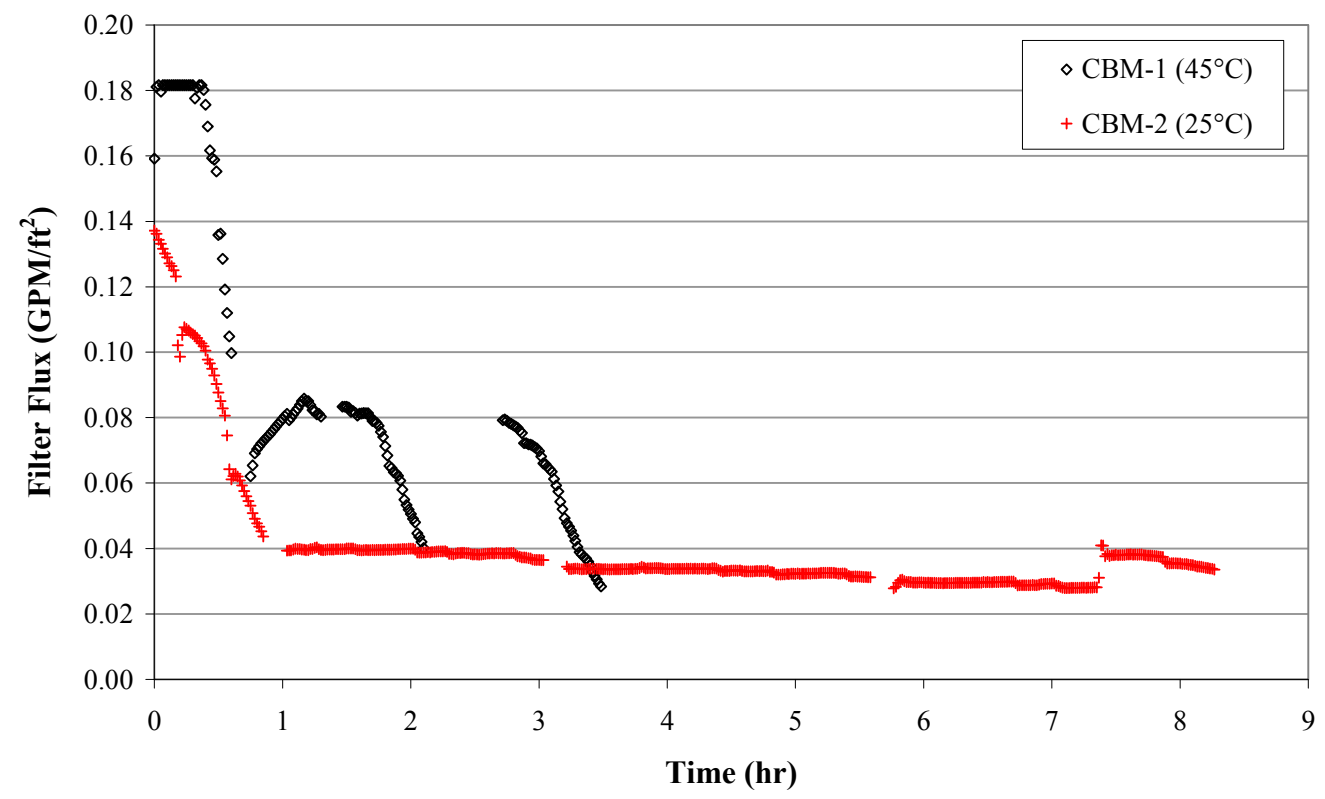

Figure 6.10. Post-Oxidative Leaching Washing Filter Fluxes at $45^{\circ} \mathrm{C}(\mathrm{CBM}-1)$ and $25^{\circ} \mathrm{C}(\mathrm{CBM}-2)$

After oxidative leaching (but before washing), the physical properties (Table 6.14), PSD (Figure 6.11), and rheology (Table 6.15) were measured. CBM-2 was dewatered further before the oxidative leaching step than CBM-1, causing CBM-2 to contain a higher UDS (22 wt $\%$ versus $16 \mathrm{wt} \%$ ), which caused the density to be higher. 
The PSDs of the two slurries before sonication were different with CBM-1 containing a unimodal peak and CBM-2 containing a bimodal peak. However, during sonication, they both shifted to a similar unimodal peak at a smaller particle size, which indicates that there was agglomeration present in both of the slurries. This agglomeration was most likely causing the difference in the initial distributions.

The rheology indicates that CBM-1 had a much lower yield stress than CBM-2 although they both exhibit non-Newtonian behavior. This difference in yield stress may have resulted from the dissimilarity in the weight percent UDS present in the slurries.

Table 6.14. Physical-Property Measurements of Post-Oxidative Leached Component Slurries

\begin{tabular}{|l|c|c||}
\hline & CBM-1 & CBM-2 \\
\hline Slurry Density $(\mathrm{g} / \mathrm{mL})$ & 1.11 & 1.17 \\
\hline Supernate Density $(\mathrm{g} / \mathrm{mL})$ & 1.00 & 1.00 \\
\hline Total Solids (wt\%) & 16.6 & 22.9 \\
\hline Dissolved Solids (wt\%) & 0.83 & 1.02 \\
\hline UDS (wt\%) & 15.9 & 22.1 \\
\hline
\end{tabular}

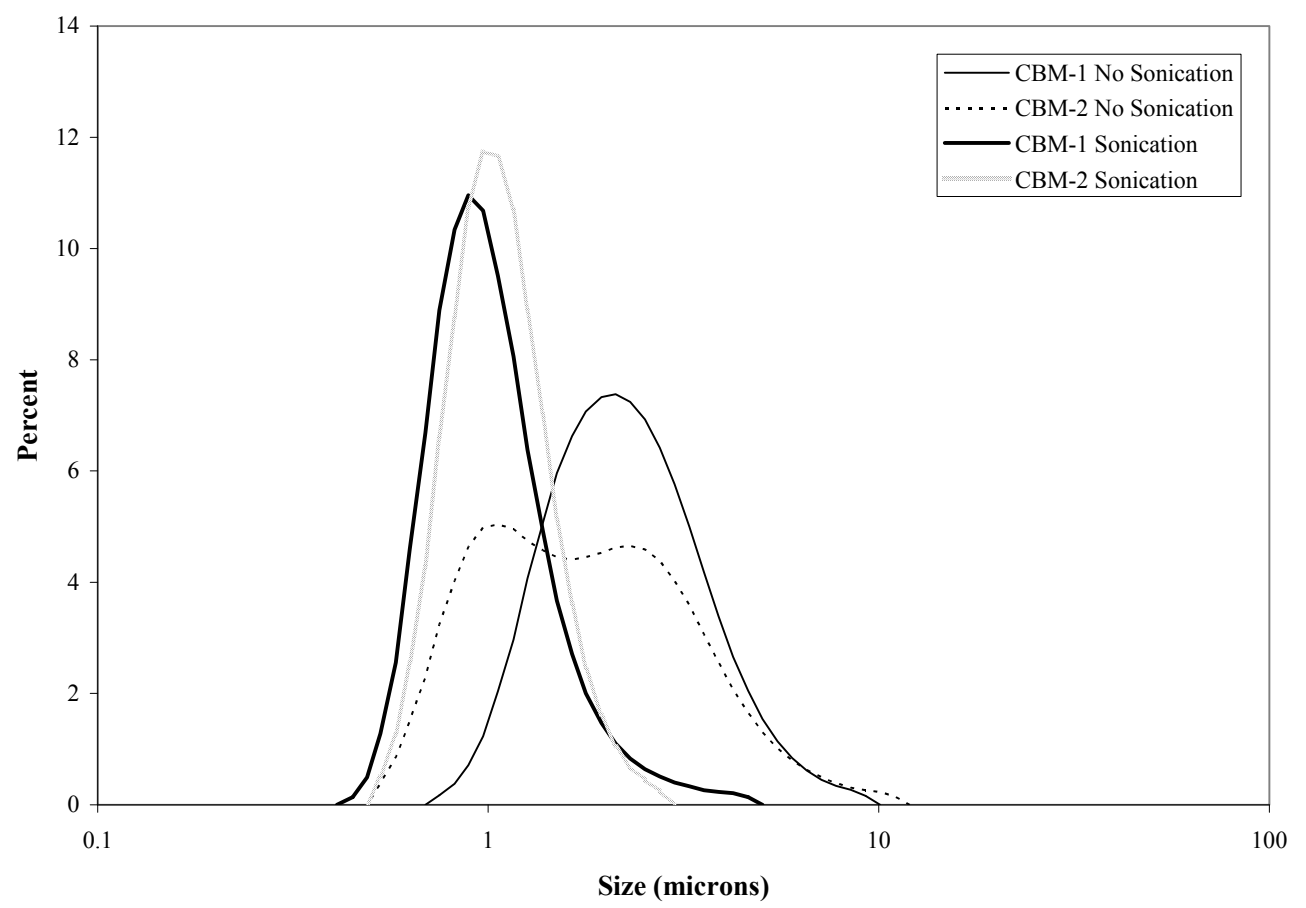

Figure 6.11. PSD Volume Distribution of Post-Oxidative Leached CBM-1 and CBM-2

Table 6.15. Results of Rheological Fitting Analysis for Post-Oxidative Leached Blended Component Slurries

\begin{tabular}{||c|c|c|c|c|c|c||}
\hline \multirow{2}{*}{ Model } & $\begin{array}{c}\text { Slurry } \\
\text { ID }\end{array}$ & $\begin{array}{c}\text { Temperature } \\
\left({ }^{\circ} \mathbf{C}\right)\end{array}$ & $\begin{array}{c}\text { Yield } \\
\text { Stress (Pa) }\end{array}$ & $\begin{array}{c}\text { Consistency } \\
(\text { Pa-s) }\end{array}$ & $\begin{array}{c}\text { Flow } \\
\text { Index }\end{array}$ & R \\
\hline \multirow{2}{*}{ Bingham-Plastic } & CBM-1 & 25 & 3.63 & 0.0057 & NA & 0.99 \\
\cline { 2 - 7 } & CBM-2 & 25 & 22.8 & 0.010 & NA & 0.99 \\
\hline Herschel-Bulkley & CBM-1 & 25 & 2.88 & 0.035 & 0.75 & 0.99 \\
\hline
\end{tabular}




\begin{tabular}{|l|l|l|l|l|l|l|}
\hline & CBM-2 & 25 & 21.7 & 0.19 & 0.57 & 0.99 \\
\hline
\end{tabular}

After oxidative leach washing, the slurry was dewatered further to obtain the target UDS of $20 \mathrm{wt} \%$. After this dewatering, the physical properties (Table 6.16), PSD (Figure 6.12), and rheology were measured on the final slurry simulant. The supernate densities were similar between the two samples. Note that CBM-1 was dewatered after oxidative leaching, while CBM-2 was not. Therefore, the final weight percent UDS in CBM-1 was $28.1 \mathrm{wt} \%$ and in CBM-2 was $22.7 \mathrm{wt} \%$, which achieved the target of a final UDS of $20 \mathrm{wt} \%$.

The PSD of the two slurries behaved similarly to the previous ones, indicating that dewatering did not affect it much. Again, the sonication showed that there was agglomeration present in the slurry that was broken apart by sonicating, resulting in the peaks shifting to a smaller particle size.

The rheology for the final slurries from both CBM-1 and CBM-2 indicated that they were rheopectic in nature. Rheopectic flow means that the fluid undergoes a shear thickening behavior. When the fluid undergoes shear, the apparent viscosities increase. This is found in fluids/solid systems with higher suspended solids concentrations under the right conditions. Thus, within a high shear environment like pumping through pipes, this material would require more energy to pump over time. At this time, the source of this rheopectic behavior has not been identified. This rheopectic behavior is not typical of the rheology of actual waste samples. It is possible that this behavior may have been associated with the high concentration of manganese dioxide solids present in this material.

Table 6.16. Physical-Property Measurements of Post-Oxidative Leached and Washed (Final) Blended Component Slurries

\begin{tabular}{|l|c|c||}
\hline & CBM-1 & CBM-2 \\
\hline Slurry Density $(\mathrm{g} / \mathrm{mL})$ & 1.24 & 1.16 \\
\hline Supernate Density $(\mathrm{g} / \mathrm{mL})$ & 1.00 & 1.00 \\
\hline Total Solids $(\mathrm{wt} \%)$ & 28.3 & 22.7 \\
\hline Dissolved Solids $(\mathrm{wt} \%)$ & 0.28 & 0.00 \\
\hline UDS $(\mathrm{wt} \%)$ & 28.1 & 22.7 \\
\hline
\end{tabular}




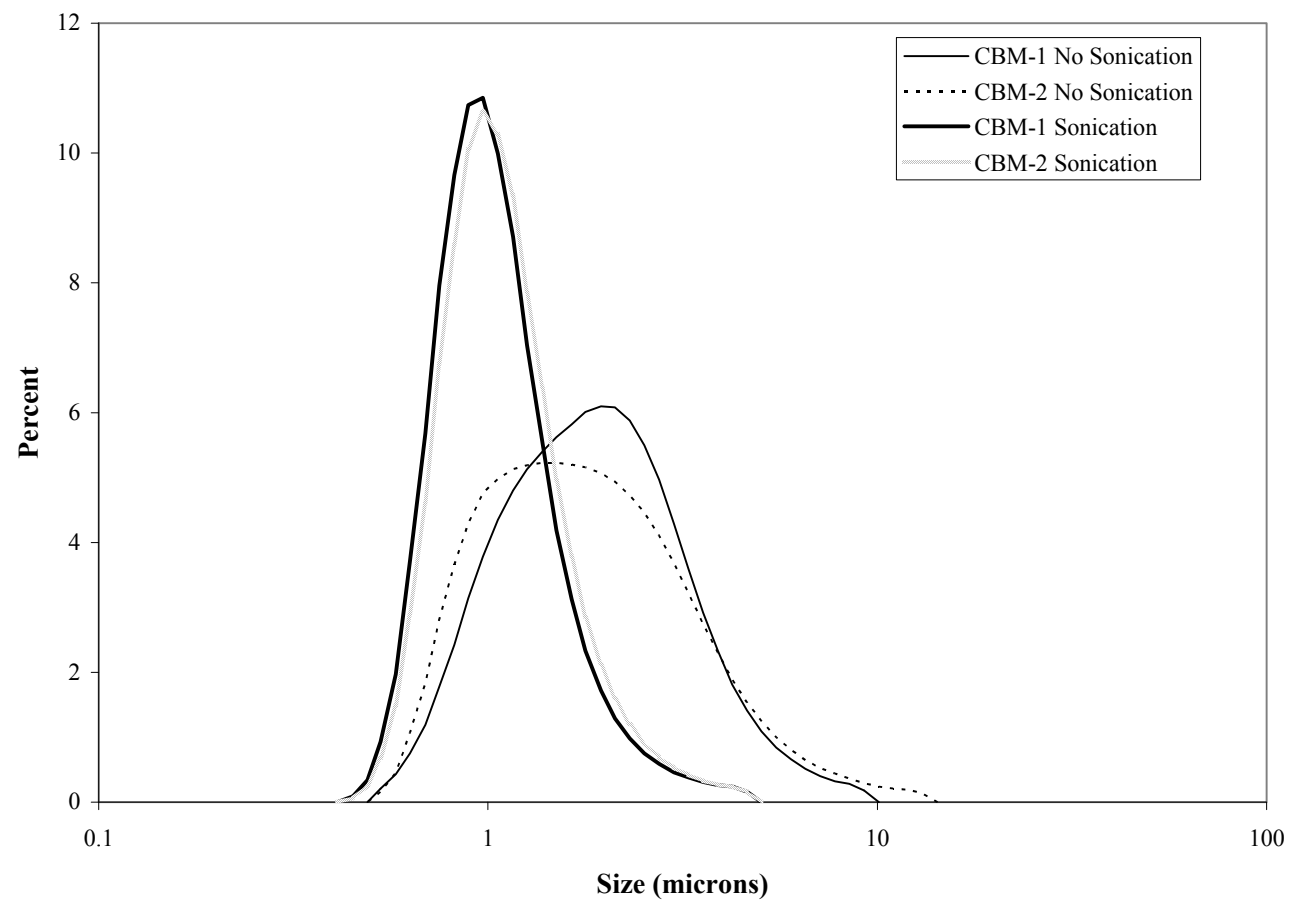

Figure 6.12. PSD Volume Distribution of Post-Oxidative Leached and Washed (Final) CBM-1 and CBM-2

\subsubsection{Filtration Temperature Effect Conclusions}

It was consistently shown throughout these tests that temperature has a major effect on the filtration rate of the simulant. Even adjusting for the change in viscosity did not account for the entire increase in the filtration rate.

An increase in filter flux at $45^{\circ} \mathrm{C}$ was observed in CBM-1 that is significantly greater than expected based on viscosity changes alone. The $25^{\circ} \mathrm{C}$ filter flux agreed with the expected flux. However, when the $25^{\circ} \mathrm{C}$ flux is projected to $45^{\circ} \mathrm{C}$, it under predicts the actually measured flux at $45^{\circ} \mathrm{C}$, indicating that temperature has a significant effect on the filter flux in a low-solids slurry during the initial dewatering. Note that the impact of temperature on filter fluxes is explored in much greater detail in report WTP-RPT-168.

The post-caustic leach dewatering results also show a significantly higher flux rate at $45^{\circ} \mathrm{C}$ than is accounted for by the different viscosities of the simulant, indicating that temperature again has a predominant effect on the flux rate. Potential sources of this increased flux include the dissolution of smaller particles at $45^{\circ} \mathrm{C}$ and formation of a larger floc size of $\mathrm{Fe}(\mathrm{OH})_{3}$.

The filtration of the supernate, after the post-caustic leach wash solutions were added, increased rapidly as they became more dilute. A significant improvement in flux was observed on the third and subsequent washes at both temperatures but was larger in the $45^{\circ} \mathrm{C}$ test. The improvement is greater than predicted by differences in viscosity at a constant filter resistance, suggesting a change in effective filter resistance. This might be attributed to the rapid dissolution of small particles within the pore of the filter media in this concentration regime (specifically sodium oxalate). 
When the washes at the different temperatures were compared, it was found that the fluxes of the first two washes were similar in spite of the temperature difference whereas the fluxes from the last three washes were significantly higher in the $45^{\circ} \mathrm{C}$ filtration. This indicates that the effect of the increased filter resistance was stronger than the effect of the temperature for the first two washes. Once this resistance was removed (perhaps by the re-dissolution of the sodium oxalate), the temperature effect began to dominate once again.

It also appears that the manganese dioxide precipitated from the addition of permanganate for oxidative leaching did not affect the flux as the post-oxidative leach dewatering flux was similar to the other fluxes without permanganate present.

\subsection{Simulant Production Scale Up}

Three crossflow ultrafiltration tests were performed to determine if the vendor-produced simulant had similar filtering characteristics in different production sizes as they scaled up the production batch volume from 15 gallons (CBM-4) to 250 gallons (CBM-5). These were compared to the filtration characteristics of a simulant produced at PNNL in a batch volume of $25 \mathrm{~L}$ (CBM-3). Table 6.17 through Table 6.19 provide the timelines for these tests.

Table 6.17. Timeline of the CBM-3 Test

\begin{tabular}{|c|c|c|c|}
\hline Time (hrs) & Process Step & Action & Samples \\
\hline 0 & Start of test & $\begin{array}{l}\text { Added } 28.37 \mathrm{~kg} \text { of } \\
5 \mathrm{wt} \% \text { UDS slurry }\end{array}$ & CBM3-IN-SL \\
\hline $0-5.5$ & Initial dewatering & $\begin{array}{c}\text { Removed } 21.68 \mathrm{~kg} \text { of } \\
\text { supernate }\end{array}$ & $\begin{array}{c}\text { CBM3-DW-SL and } \\
\text { CBM3-DW-FIL }\end{array}$ \\
\hline $6.25-7$ & $\begin{array}{l}\text { Preparation for } \\
\text { caustic leaching }\end{array}$ & $\begin{array}{l}\text { Added } 8.57 \mathrm{~kg} \text { of } \\
19 \mathrm{M} \mathrm{NaOH} \text { and } \\
7.92 \mathrm{~kg} \mathrm{DI} \text { water }\end{array}$ & No sample taken. \\
\hline $7-12.3$ & Caustic leaching & $\begin{array}{l}\text { Heated from } 25^{\circ} \mathrm{C} \text { to } \\
100^{\circ} \mathrm{C}\end{array}$ & CBM3-LE-R-0,2,4 \\
\hline $12.3-24.3$ & Caustic leaching & Leached at $100^{\circ} \mathrm{C}$ & $\begin{array}{c}\text { CBM3-LE-S- } \\
0,2,4,6,8,10,12 \\
\end{array}$ \\
\hline $24.3-36.3$ & Caustic leaching & $\begin{array}{l}\text { Cooled from } 100^{\circ} \mathrm{C} \\
\text { to } 25^{\circ} \mathrm{C}\end{array}$ & $\begin{array}{c}\text { CBM3-LE-C- } \\
0,2,4,6,8,10,12 \\
\end{array}$ \\
\hline $49.3-63.5$ & $\begin{array}{c}\text { Caustic leach } \\
\text { dewater }\end{array}$ & $\begin{array}{c}\text { Removed } 19.27 \mathrm{~kg} \text { of } \\
\text { supernate }\end{array}$ & $\begin{array}{l}\text { CBM3-LC-SL and } \\
\text { CBM3-LC-FIL }\end{array}$ \\
\hline $65-74$ & $\begin{array}{l}\text { Caustic leach } \\
\text { washing }\end{array}$ & $\begin{array}{c}\text { Added } 11.76 \mathrm{~kg} \text { of } \\
0.01 \mathrm{M} \mathrm{NaOH} \text { and } \\
\text { removed } 11.76 \mathrm{~kg} \text { of } \\
\text { supernate }\end{array}$ & $\begin{array}{l}\text { CBM3-WC-FIL and } \\
\text { CBM3-WS-SL }\end{array}$ \\
\hline 75.5 & $\begin{array}{l}\text { CrOOH slurry } \\
\text { addition }\end{array}$ & $\begin{array}{l}\text { Added } 1.73 \mathrm{~kg} \text { of } \\
\text { CrOOH slurry }\end{array}$ & No sample taken. \\
\hline 75.75 & $\begin{array}{l}\text { CrOOH slurry } \\
\text { washing }\end{array}$ & $\begin{array}{l}\text { Added } 15 \mathrm{~L} \text { of } \\
0.01 \mathrm{M} \mathrm{NaOH}\end{array}$ & No sample taken. \\
\hline $75.75-79.75$ & $\begin{array}{c}\text { CrOOH slurry } \\
\text { wash dewatering } \\
\end{array}$ & $\begin{array}{c}\text { Removed } 16.34 \mathrm{~kg} \text { of } \\
\text { supernate }\end{array}$ & CBM3-CW-SL \\
\hline
\end{tabular}


Table 6.17 (Contd)

\begin{tabular}{|c|c|c|c||}
\hline Time (hrs) & Process Step & Action & Samples \\
\hline $81.3-87.3$ & Oxidative & $\begin{array}{c}\text { Added } .326 \mathrm{~L} \text { of } 1 \mathrm{M} \\
\mathrm{NaMnO}_{4}\end{array}$ & $\begin{array}{c}\text { CBM3-OL-05,1,2,4,6, } \\
\text { CBM3-OL-SL, and } \\
\text { CBM3-OL-FIL }\end{array}$ \\
\hline $88-92.2$ & $\begin{array}{c}\text { Oxidative leach } \\
\text { washing }\end{array}$ & $\begin{array}{c}\text { Added } \sim 9 \mathrm{~kg} \text { of } \\
0.01 \mathrm{M} \mathrm{NaOH} \text { and } \\
\text { removed } 9.05 \mathrm{~kg} \text { of } \\
\text { supernate }\end{array}$ & $\begin{array}{c}\text { No sample taken. } \\
\end{array}$ \\
\hline $92.3-92.75$ & Final dewatering & $\begin{array}{c}\text { Removed } 0.95 \mathrm{~kg} \text { of } \\
\text { supernate }\end{array}$ & CBM3-FSC-SL \\
\hline
\end{tabular}

Table 6.18. Timeline of the CBM-4 Test

\begin{tabular}{|c|c|c|c|}
\hline Time (hrs) & Process Step & Action & Samples \\
\hline 0 & Start of test & $\begin{array}{l}\text { Added } 26.25 \mathrm{~kg} \text { of } \\
5 \mathrm{wt} \% \text { UDS slurry }\end{array}$ & CBM4-IN-SL \\
\hline $0-8.7$ & Initial dewatering & $\begin{array}{c}\text { Removed } 19.64 \mathrm{~kg} \text { of } \\
\text { supernate }\end{array}$ & $\begin{array}{l}\text { CBM4-DW-SL and } \\
\text { CBM4-DW-FIL }\end{array}$ \\
\hline 14 & $\begin{array}{l}\text { Preparation for } \\
\text { caustic leaching }\end{array}$ & $\begin{array}{c}\text { Added } 8.66 \mathrm{~kg} \text { of } \\
19 \mathrm{M} \mathrm{NaOH} \text { and } \\
8.08 \mathrm{~kg} \text { of DI water }\end{array}$ & No sample taken. \\
\hline $14-19.5$ & Caustic leaching & $\begin{array}{l}\text { Heated from } 25^{\circ} \mathrm{C} \text { to } \\
100^{\circ} \mathrm{C}\end{array}$ & CBM4-LE-R-0,2,4 \\
\hline $19.5-31.5$ & Caustic leaching & Leached at $100^{\circ} \mathrm{C}$ & $\begin{array}{c}\text { CBM4-LE-S- } \\
0,2,4,6,8,10,12 \\
\end{array}$ \\
\hline $31.5-43.5$ & Caustic leaching & $\begin{array}{l}\text { Cooled from } 100^{\circ} \mathrm{C} \\
\text { to } 25^{\circ} \mathrm{C}\end{array}$ & $\begin{array}{l}\text { CBM4-LE-C- } \\
0,2,4,6,8,10,12\end{array}$ \\
\hline $45-60$ & $\begin{array}{c}\text { Caustic leach } \\
\text { dewater }\end{array}$ & $\begin{array}{c}\text { Removed } 19.17 \mathrm{~kg} \text { of } \\
\text { supernate }\end{array}$ & $\begin{array}{l}\text { CBM4-LC-SL and } \\
\text { CBM4-LC-FIL }\end{array}$ \\
\hline $61-66.5$ & $\begin{array}{l}\text { Caustic leach } \\
\text { washing }\end{array}$ & $\begin{array}{c}\text { Added } 12.09 \mathrm{~kg} \text { of } \\
0.01 \mathrm{M} \mathrm{NaOH} \text { and } \\
\text { removed } 11.34 \mathrm{~kg} \text { of } \\
\text { supernate }\end{array}$ & $\begin{array}{l}\text { CBM4-WC-FIL and } \\
\text { CBM4-WS-SL }\end{array}$ \\
\hline 68 & $\begin{array}{l}\text { CrOOH slurry } \\
\text { addition }\end{array}$ & $\begin{array}{l}\text { Added } 1.73 \mathrm{~kg} \text { of } \\
\text { CrOOH slurry }\end{array}$ & No sample taken. \\
\hline 78.25 & $\begin{array}{l}\text { CrOOH slurry } \\
\text { washing }\end{array}$ & $\begin{array}{c}\text { Added } 14.92 \mathrm{~kg} \text { of } \\
0.01 \mathrm{M} \mathrm{NaOH}\end{array}$ & No sample taken. \\
\hline $78.5-80.7$ & $\begin{array}{c}\text { CrOOH slurry } \\
\text { wash dewatering }\end{array}$ & $\begin{array}{c}\text { Removed } 16.65 \mathrm{~kg} \text { of } \\
\text { supernate }\end{array}$ & CBM4-CW-SL \\
\hline $89.3-95$ & $\begin{array}{l}\text { Oxidative } \\
\text { leaching }\end{array}$ & $\begin{array}{l}\text { Added } .326 \mathrm{~L} \text { of } 1 \mathrm{M} \\
\mathrm{NaMnO}_{4}\end{array}$ & $\begin{array}{c}\text { CBM4-OL-05,1,2,4,6, } \\
\text { CBM4-OL-SL, and } \\
\text { CBM4-OL-FIL }\end{array}$ \\
\hline $96.1-98.8$ & $\begin{array}{l}\text { Oxidative leach } \\
\text { washing }\end{array}$ & $\begin{array}{c}\text { Added } 9.42 \mathrm{~kg} \text { of } \\
0.01 \mathrm{M} \mathrm{NaOH} \text { and } \\
\text { removed } 9.25 \mathrm{~kg} \text { of } \\
\text { supernate }\end{array}$ & No sample taken. \\
\hline $99-101.5$ & Final dewatering & $\begin{array}{c}\text { Removed } 0.40 \mathrm{~kg} \text { of } \\
\text { supernate }\end{array}$ & CBM4-FSC-SL \\
\hline
\end{tabular}


Table 6.19. Timeline of the CBM-5 Test

\begin{tabular}{|c|c|c|c|}
\hline Time (hrs) & Process Step & Action & Samples \\
\hline 0 & Start of test & $\begin{array}{l}\text { Added } 26.25 \mathrm{~kg} \text { of } \\
5 \mathrm{wt} \% \text { UDS slurry }\end{array}$ & CBM5-IN-SL \\
\hline $0-9.75$ & Initial dewatering & $\begin{array}{c}\text { Removed } 20.66 \mathrm{~kg} \text { of } \\
\text { supernate }\end{array}$ & $\begin{array}{l}\text { CBM5-DW-SL and } \\
\text { CBM5-DW-FIL }\end{array}$ \\
\hline 13 & $\begin{array}{l}\text { Preparation for } \\
\text { caustic leaching }\end{array}$ & $\begin{array}{c}\text { Added } 8.57 \mathrm{~kg} \text { of } \\
19 \mathrm{M} \mathrm{NaOH} \text { and } \\
7.92 \mathrm{~kg} \text { of DI water }\end{array}$ & No sample taken. \\
\hline $13-18.3$ & Caustic leaching & $\begin{array}{l}\text { Heated from } 25^{\circ} \mathrm{C} \text { to } \\
100^{\circ} \mathrm{C}\end{array}$ & CBM5-LE-R-0,2,4 \\
\hline $18.3-30.3$ & Caustic leaching & Leached at $100^{\circ} \mathrm{C}$ & $\begin{array}{c}\text { CBM5-LE-S- } \\
0,2,4,6,8,10,12 \\
\end{array}$ \\
\hline $30.3-42.3$ & Caustic leaching & $\begin{array}{l}\text { Cooled from } 100^{\circ} \mathrm{C} \\
\text { to } 25^{\circ} \mathrm{C}\end{array}$ & $\begin{array}{l}\text { CBM5-LE-C- } \\
0,2,4,6,8,10,12\end{array}$ \\
\hline $43.1-60$ & $\begin{array}{c}\text { Caustic leach } \\
\text { dewater }\end{array}$ & $\begin{array}{c}\text { Removed } 19.19 \mathrm{~kg} \text { of } \\
\text { supernate }\end{array}$ & $\begin{array}{l}\text { CBM5-LC-SL and } \\
\text { CBM5-LC-FIL }\end{array}$ \\
\hline $60.5-68.3$ & $\begin{array}{c}\text { Caustic leach } \\
\text { washing }\end{array}$ & $\begin{array}{c}\text { Added } 11.25 \mathrm{~kg} \text { of } \\
0.01 \mathrm{M} \mathrm{NaOH} \text { and } \\
\text { removed } 11.41 \mathrm{~kg} \text { of } \\
\text { supernate }\end{array}$ & $\begin{array}{l}\text { CBM5-WC-FIL and } \\
\text { CBM5-WS-SL }\end{array}$ \\
\hline 69 & $\begin{array}{l}\text { CrOOH slurry } \\
\text { addition }\end{array}$ & $\begin{array}{l}\text { Added } 1.73 \mathrm{~kg} \text { of } \\
\text { CrOOH slurry }\end{array}$ & No sample taken. \\
\hline 69 & $\begin{array}{l}\text { CrOOH slurry } \\
\text { washing }\end{array}$ & $\begin{array}{c}\text { Added } 14.36 \mathrm{~kg} \text { of } \\
0.01 \mathrm{M} \mathrm{NaOH}\end{array}$ & No sample taken. \\
\hline $69.3-71.5$ & $\begin{array}{c}\text { CrOOH slurry } \\
\text { wash dewatering }\end{array}$ & $\begin{array}{c}\text { Removed } 15.48 \mathrm{~kg} \text { of } \\
\text { supernate }\end{array}$ & CBM5-CW-SL \\
\hline $73.75-79.75$ & $\begin{array}{l}\text { Oxidative } \\
\text { leaching }\end{array}$ & $\begin{array}{c}\text { Added } .326 \mathrm{~L} \text { of } 1 \mathrm{M} \\
\mathrm{NaMnO}_{4}\end{array}$ & $\begin{array}{c}\text { CBM5-OL-05,1,2,4,6, } \\
\text { CBM5-OL-SL, and } \\
\text { CBM5-OL-FIL }\end{array}$ \\
\hline $80.3-83$ & $\begin{array}{l}\text { Oxidative leach } \\
\text { washing }\end{array}$ & $\begin{array}{c}\text { Added } 9.24 \mathrm{~kg} \text { of } \\
0.01 \mathrm{M} \mathrm{NaOH} \text { and } \\
\text { removed } 9.27 \mathrm{~kg} \text { of } \\
\text { supernate }\end{array}$ & No sample taken. \\
\hline $84-85.3$ & Final dewatering & $\begin{array}{c}\text { Removed } 1.21 \mathrm{~kg} \text { of } \\
\text { supernate }\end{array}$ & $\begin{array}{l}\text { CBM5-FSC-SL and } \\
\text { CBM5-FSC-FIL }\end{array}$ \\
\hline
\end{tabular}

\subsubsection{Initial Slurry Dewatering}

Initially, approximately $22 \mathrm{~L}$ of slurry was added to the crossflow ultrafiltration reservoir. In CBM-4 and CBM-5, approximately $9 \mathrm{~g}(0.40 \mathrm{~g} / \mathrm{L})$ of anti-foam agent (AFA) from Dow Corning was included. The AFA was included to assess its effect on filtration and impact on chromium leaching. The slurry was dewatered at a TMP of $40 \mathrm{psid}$ and an AV of $13 \mathrm{ft} / \mathrm{s}$ until approximately $21 \mathrm{~kg}$ of filtrate had been removed from the slurry.

The initial dewatering flux of CBM-4 and CBM-5 were essentially the same, whereas the CBM-3 dewatering flux was higher as shown in Figure 6.13. This may have been because of one or more of the 
following: 1) impact of AFA on filtration, 2) the filtration component simulant was produced by OPTIMA for CBM-3 whereas it was produced by NOAH Technologies for CBM-4 and CBM-5, and 3 ) the filtration component used for CBM-3 was produced in a small size batch $(25 \mathrm{~L})$ whereas the filtration components used for CBM-4 and CBM-5 were produced in larger size batches. Also, the average duration for this dewater step was approximately 10 hours, roughly $1 / 3$ of the target duration to achieve the 4.6 days total cycle duration.

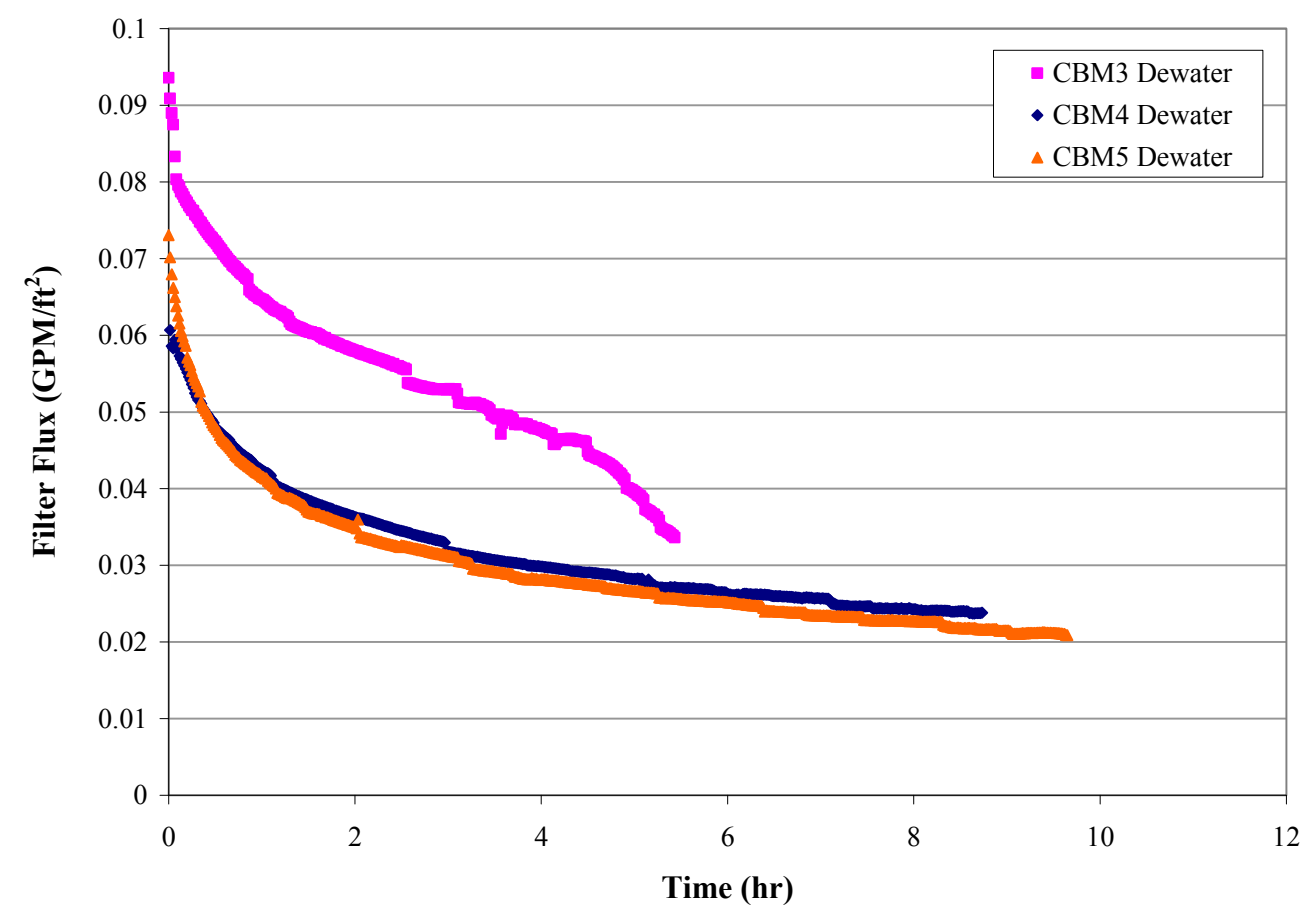

Figure 6.13. Dewatering Filter Flux for CBM-3, CBM-4, and CBM-5

After dewatering the initial slurry, the physical properties (Table 6.20), PSD (Figure 6.14), and rheology (Table 6.21) were measured. The measured physical properties of these feeds were all similar, as well as the PSDs. The PSD was bimodal with a peak at approximately 1 micron and a larger peak at approximately 10 microns. The rheology of these slurries all showed a small yield stress, indicating nonNewtonian behavior.

Table 6.20. Physical-Property Measurements of Dewatered Blended Component Slurries

\begin{tabular}{|l|c|c|c||}
\hline & CBM-3 & CBM-4 & CBM-5 \\
\hline Slurry Density (g/mL) & 1.36 & 1.37 & 1.41 \\
\hline Supernate Density (g/mL) & 1.22 & 1.23 & 1.23 \\
\hline Total Solids (wt\%) & 42.7 & 42.0 & 44.1 \\
\hline Dissolved Solids (wt\%) & 26.9 & 28.0 & 27.9 \\
\hline UDS (wt\%) & 21.7 & 19.5 & 22.5 \\
\hline
\end{tabular}




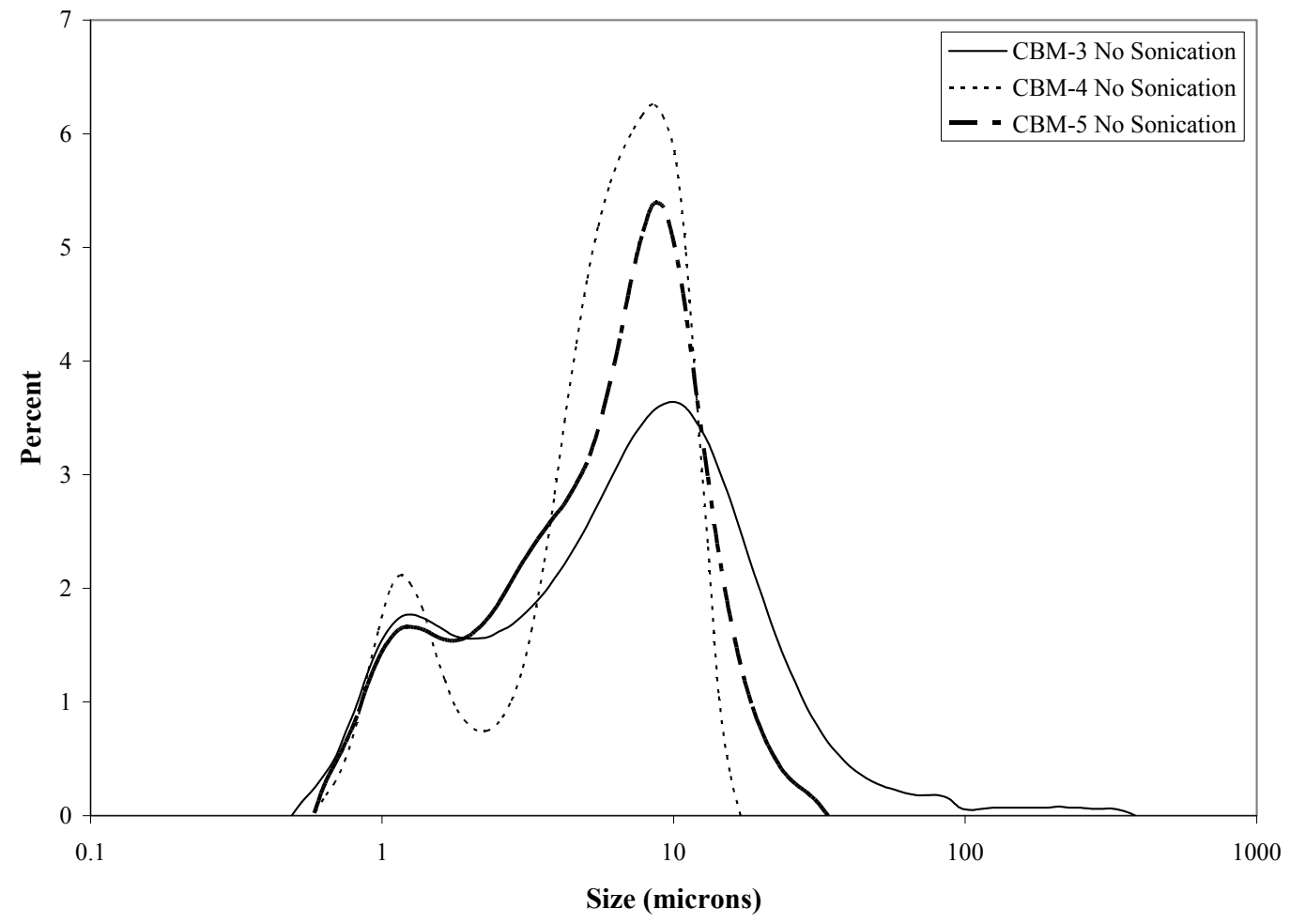

Figure 6.14. PSD Volume Distribution of CBM-3, CBM-4, and CBM-5 after Dewatering

Table 6.21. Results of Rheological Fitting Analysis for Dewatered Blended Component Slurries

\begin{tabular}{||c|c|c|c|c|c|c||}
\hline \multirow{2}{*}{ Model } & $\begin{array}{c}\text { Slurry } \\
\text { ID }\end{array}$ & $\begin{array}{c}\text { Temperature } \\
\left({ }^{\circ} \mathbf{C}\right)\end{array}$ & $\begin{array}{c}\text { Yield } \\
\text { Stress (Pa) }\end{array}$ & $\begin{array}{c}\text { Consistency } \\
(\text { Pa-s) }\end{array}$ & $\begin{array}{c}\text { Flow } \\
\text { Index }\end{array}$ & R \\
\hline \multirow{3}{*}{ Bingham-Plastic } & CBM-3 & 25 & 2.3 & 0.009 & NA & 0.99 \\
\cline { 2 - 7 } & CBM-4 & 25 & 0.97 & 0.009 & NA & 0.99 \\
\cline { 2 - 7 } & CBM-5 & 25 & 2.9 & 0.010 & NA & 0.99 \\
\hline \multirow{3}{*}{ Herschel-Bulkley } & CBM-3 & 25 & 1.8 & 0.024 & 0.85 & 1 \\
\cline { 2 - 7 } & CBM-4 & 25 & 0.67 & 0.036 & 0.78 & 0.99 \\
\cline { 2 - 7 } & CBM-5 & 25 & 2.4 & 0.027 & 0.86 & 1 \\
\hline
\end{tabular}

\subsubsection{Post-Caustic Leach Dewatering}

After the slurry simulant was caustic leached with $\mathrm{NaOH}$ at $100^{\circ} \mathrm{C}$, the simulant was again dewatered to increase the weight percent solids and remove the caustic solution from the simulant. The results show essentially the same filter flux for all three slurries (Figure 6.15). Here, the post-leach dewater step was longer than the target for meeting the total process durations (16 hours versus 10 hours from Table 1.2). 


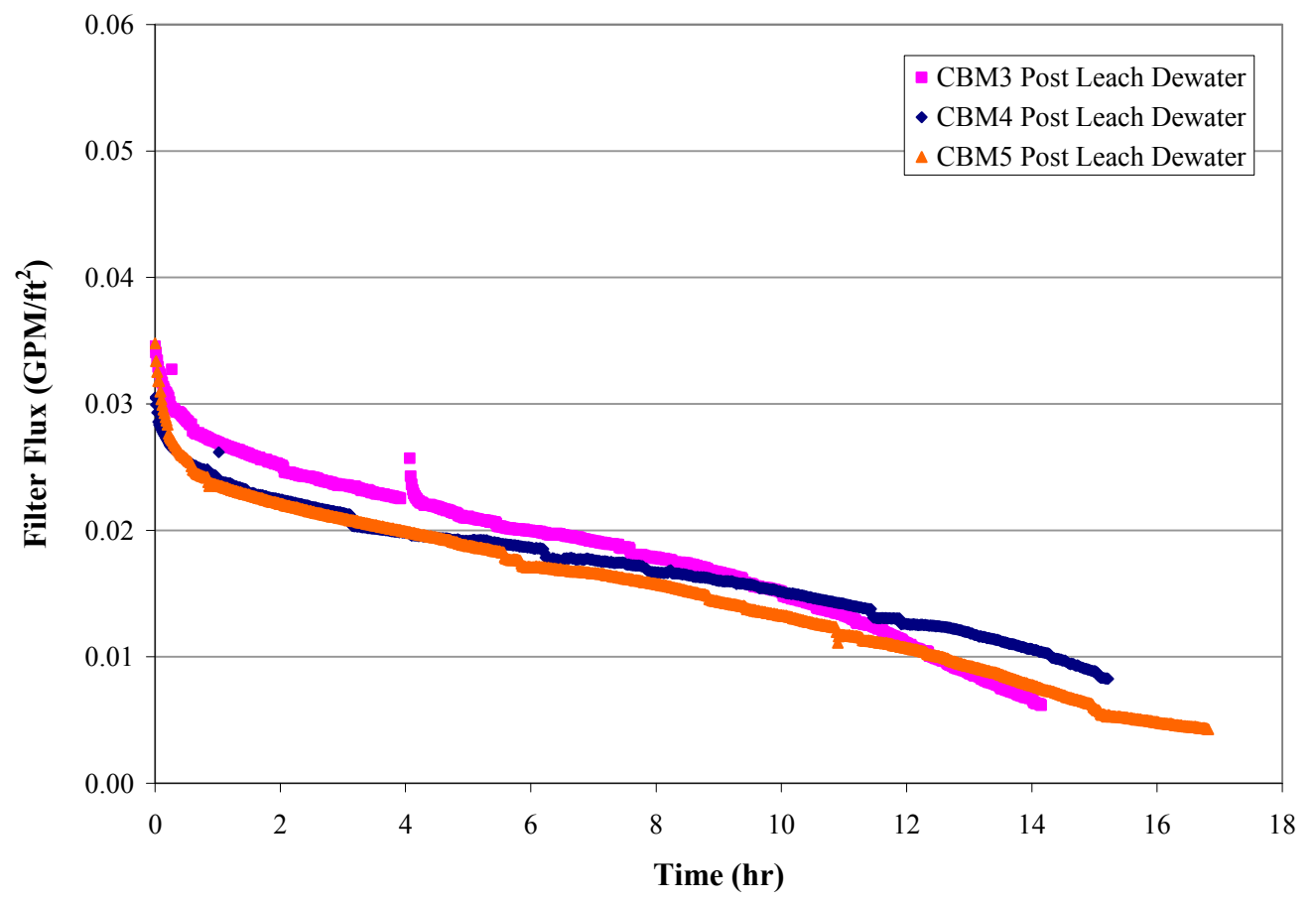

Figure 6.15. Post-Caustic Leach Dewatering Filter Flux for CBM-3, CBM-4, and CBM-5

After post-caustic leach dewatering, the physical properties (Table 6.22), PSD (Figure 6.16), and rheology (Table 6.23) were measured again. The measured physical properties of these feeds all matched very closely as well as the PSDs with a peak maximum between 1 and 2 microns. The UDS for CBM-4 was lower than the other two even though its density matched the other two.

The yield stress of CBM-4 was significantly lower than the other two. The consistency was also lower than the other two slurries. However, all three slurries exhibited non-Newtonian behavior. At this time, the reason for the variability in rheology for the various simulants has not been explained.

Table 6.22. Physical-Property Measurements of Post-Caustic Leached and Dewatered Blended Component Slurries

\begin{tabular}{|l|c|c|c|}
\hline & CBM-3 & CBM-4 & CBM-5 \\
\hline Slurry Density (g/mL) & 1.40 & 1.41 & 1.41 \\
\hline Supernate Density (g/mL) & 1.28 & 1.28 & 1.28 \\
\hline Total Solids (wt\%) & 46.8 & 42.5 & 49.4 \\
\hline Dissolved Solids (wt\%) & 39.3 & 37.8 & 42.4 \\
\hline UDS (wt\%) & 12.4 & 7.5 & 12.1 \\
\hline
\end{tabular}




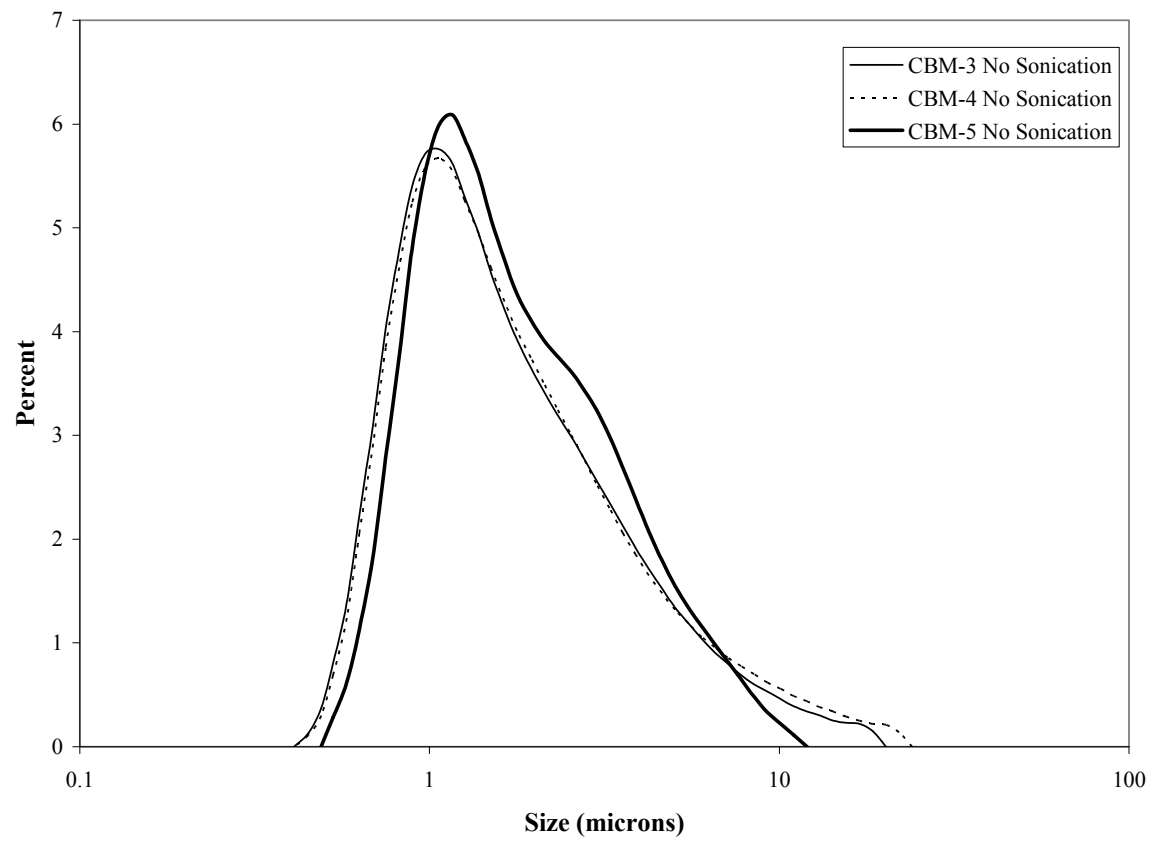

Figure 6.16. PSD Volume Distribution of CBM-3, CBM-4, and CBM-5 After Post-Caustic Leach and Dewatering

Table 6.23. Results of Rheological Fitting Analysis for Post-Caustic Leached and Dewatered Blended Component Slurries

\begin{tabular}{||c|c|c|c|c|c|c||}
\hline \multirow{2}{*}{ Model } & $\begin{array}{c}\text { Slurry } \\
\text { ID }\end{array}$ & $\begin{array}{c}\text { Temperature } \\
\left({ }^{\circ} \mathbf{C}\right)\end{array}$ & $\begin{array}{c}\text { Yield } \\
\text { Stress (Pa) }\end{array}$ & $\begin{array}{c}\text { Consistency } \\
(\text { Pa-s) }\end{array}$ & $\begin{array}{c}\text { Flow } \\
\text { Index }\end{array}$ & R \\
\hline \multirow{3}{*}{ Bingham-Plastic } & CBM-3 & 25 & 20 & 0.032 & NA & 0.99 \\
\cline { 2 - 7 } & CBM-4 & 25 & 3.8 & 0.024 & NA & 0.99 \\
\cline { 2 - 7 } & CBM-5 & 25 & 40 & 0.046 & NA & 0.99 \\
\hline \multirow{3}{*}{ Herschel-Bulkley } & CBM-3 & 25 & 15 & 0.27 & 0.71 & 1 \\
\cline { 2 - 7 } & CBM-4 & 25 & 2.4 & 0.14 & 0.72 & 0.99 \\
\cline { 2 - 7 } & CBM-5 & 25 & 32 & 0.57 & 0.65 & 0.99 \\
\hline
\end{tabular}

\subsubsection{Caustic Leach Washing and Dewatering}

After the leached simulant slurry had been concentrated, it was washed consecutively by adding $700 \mathrm{~mL}$ of $0.01 \mathrm{M} \mathrm{NaOH}$ to the slurry and dewatering 16 times. The flux of CBM-4 was higher throughout the washing than either CBM-3 or CBM-5, as shown in Figure 6.17. Towards the end of the washing, the low-solids filter fluxes of CBM-3 and CBM-5 improved significantly. Note that the high-solids filter fluxes (towards the end of each wash cycle) remained relatively low compared to those for CBM-4. The fluxes appeared to shift from a flat to a steep slope as the washes progressed with the flux improving at the beginning of each wash and then rapidly decaying. Also, the wash cycle was significantly shorter than the target based on the values given in Table 1.2 (10 hours versus 30-hour target). At this time, the reason for the higher fluxes in test CBM-4 has not been identified. 


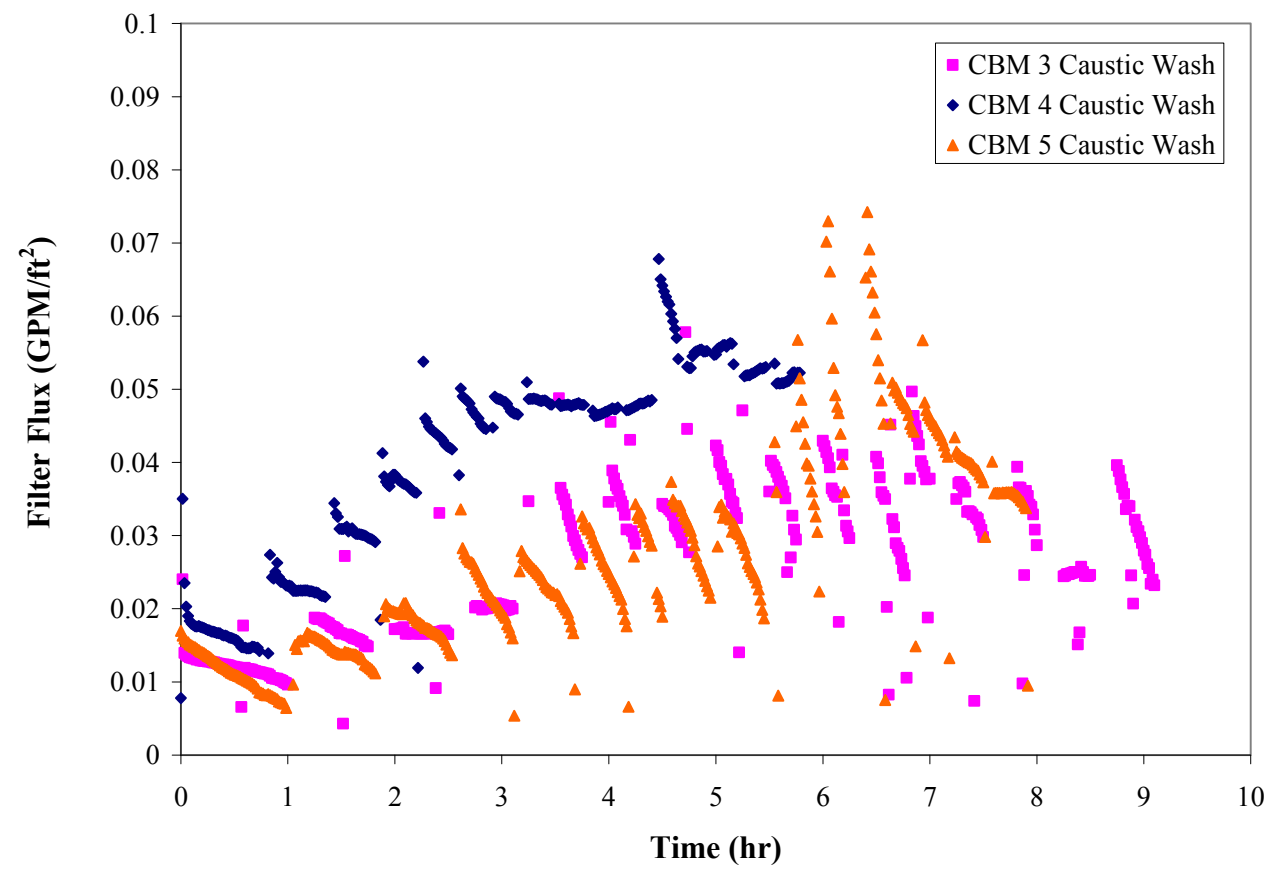

Figure 6.17. Filter Flux During Caustic Leach Washing for CBM-3, CBM-4, and CBM-5

After caustic leach washing, the physical properties (Table 6.24), PSD (Figure 6.18), and rheology (Table 6.25) were measured. CBM-4 appeared to have lower UDS concentration and a lower yield stress than either CBM-3 or CBM-5. This may have been the reason for the higher flux during the washing. However, the PSD for CBM-4 at the end of caustic leach and washing was essentially the same as CBM-5 with the peak occurring between 1.5 and 1.75. CBM-3 was not measured.

Table 6.24. Physical-Property Measurements of Caustic Leached and Washed Blended Component Slurries

\begin{tabular}{||l|c|c|c||}
\hline & CBM-3 & CBM-4 & CBM-5 \\
\hline Slurry Density (g/mL) & --- & 1.10 & 1.17 \\
\hline Supernate Density (g/mL) & --- & 1.01 & 1.00 \\
\hline Total Solids (wt\%) & 28.1 & 19.8 & 22.2 \\
\hline Dissolved Solids (wt $\%)$ & 0.40 & 0.93 & 0.29 \\
\hline UDS (wt\%) & 27.8 & 19.0 & 22.0 \\
\hline
\end{tabular}




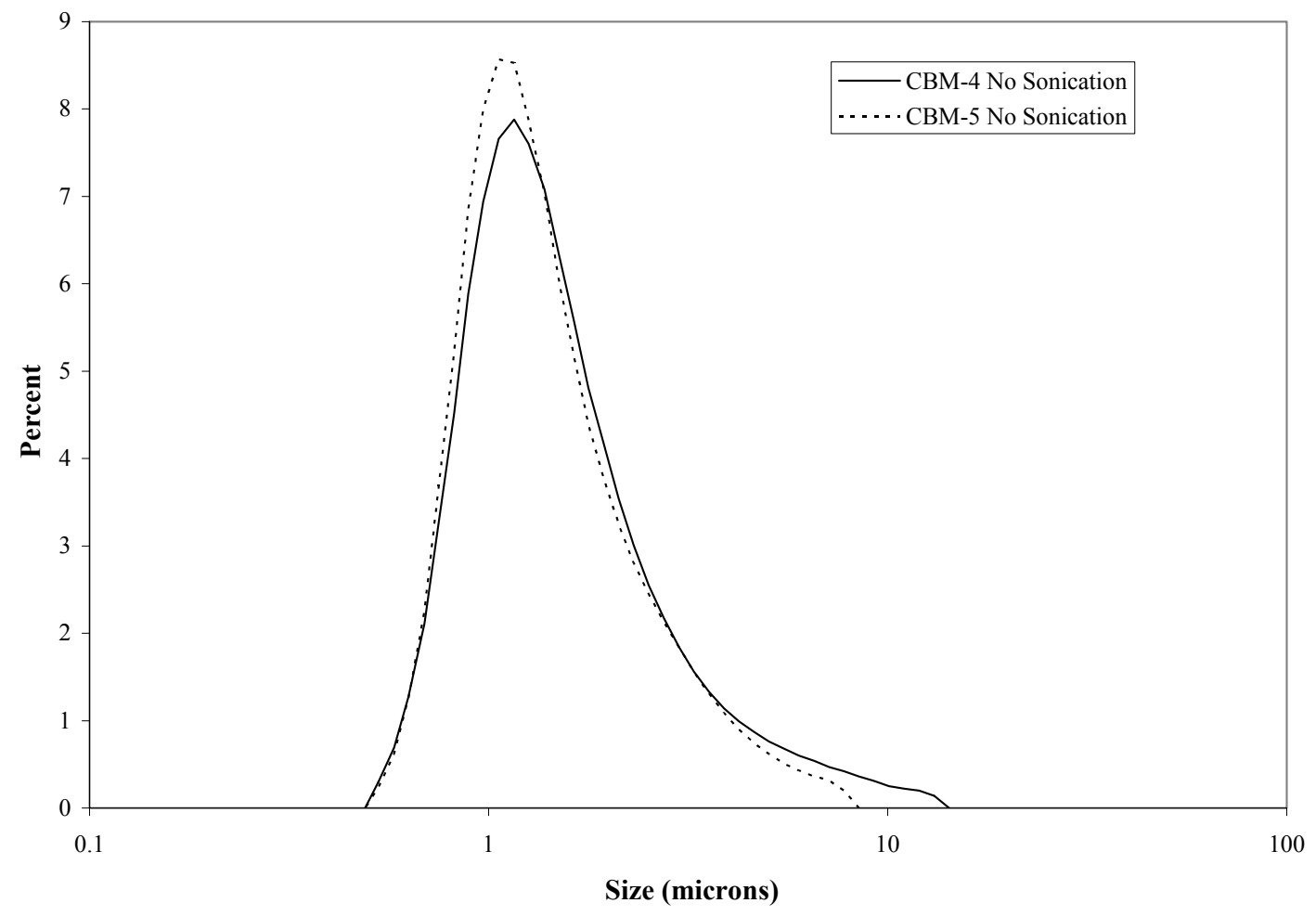

Figure 6.18. PSD Volume Distribution of CBM-3, CBM-4, and CBM-5 after Caustic Leach Washing

Table 6.25. Results of Rheological Fitting Analysis for Caustic Leached and Washed Blended Component Slurries

\begin{tabular}{||c|c|c|c|c|c|c||}
\hline \hline \multirow{3}{*}{ Model } & $\begin{array}{c}\text { Slurry } \\
\text { ID }\end{array}$ & $\begin{array}{c}\text { Temperature } \\
\left({ }^{\circ} \mathbf{C}\right)\end{array}$ & $\begin{array}{c}\text { Yield } \\
\text { Stress (Pa) }\end{array}$ & $\begin{array}{c}\text { Consistency } \\
(\text { Pa-s) }\end{array}$ & $\begin{array}{c}\text { Flow } \\
\text { Index }\end{array}$ & R \\
\hline \multirow{3}{*}{ Bingham-Plastic } & CBM-3 & 25 & 50 & 0.015 & NA & 0.94 \\
\cline { 2 - 7 } & CBM-4 & 25 & 4.8 & 0.005 & NA & 0.99 \\
\cline { 2 - 7 } & CBM-5 & 25 & --- & --- & --- & --- \\
\hline \multirow{3}{*}{ Herschel-Bulkley } & CBM-3 & 25 & 17 & 17 & 0.14 & 0.99 \\
\cline { 2 - 7 } & CBM-4 & 25 & 3.9 & 0.062 & 0.66 & 0.99 \\
\cline { 2 - 7 } & CBM-5 & 25 & 7.6 & 0.066 & 0.72 & 0.99 \\
\hline
\end{tabular}

\subsubsection{Chromium Slurry Addition}

After the washed slurry was dewatered, $1.73 \mathrm{~kg}$ of $\mathrm{CrOOH}$ slurry was added to the feed along with 15 liters of $0.01 \mathrm{M} \mathrm{NaOH}$. This was mixed thoroughly and then dewatered to a target of $17-\mathrm{wt} \%$ UDS. The CrOOH slurry was added separately after the caustic leach because during the caustic leach, approximately $80 \%$ of the $\mathrm{Cr}$ dissolved in CBM-1, which is not representative of all groups of actual waste.

All three slurries dewatered similarly with about the same permeate flux and decay beginning at approximately $0.18 \mathrm{gpm} / \mathrm{ft}^{2}$ and ending at approximately $0.02 \mathrm{gpm} / \mathrm{ft}^{2}$ as shown in Figure 6.19. 


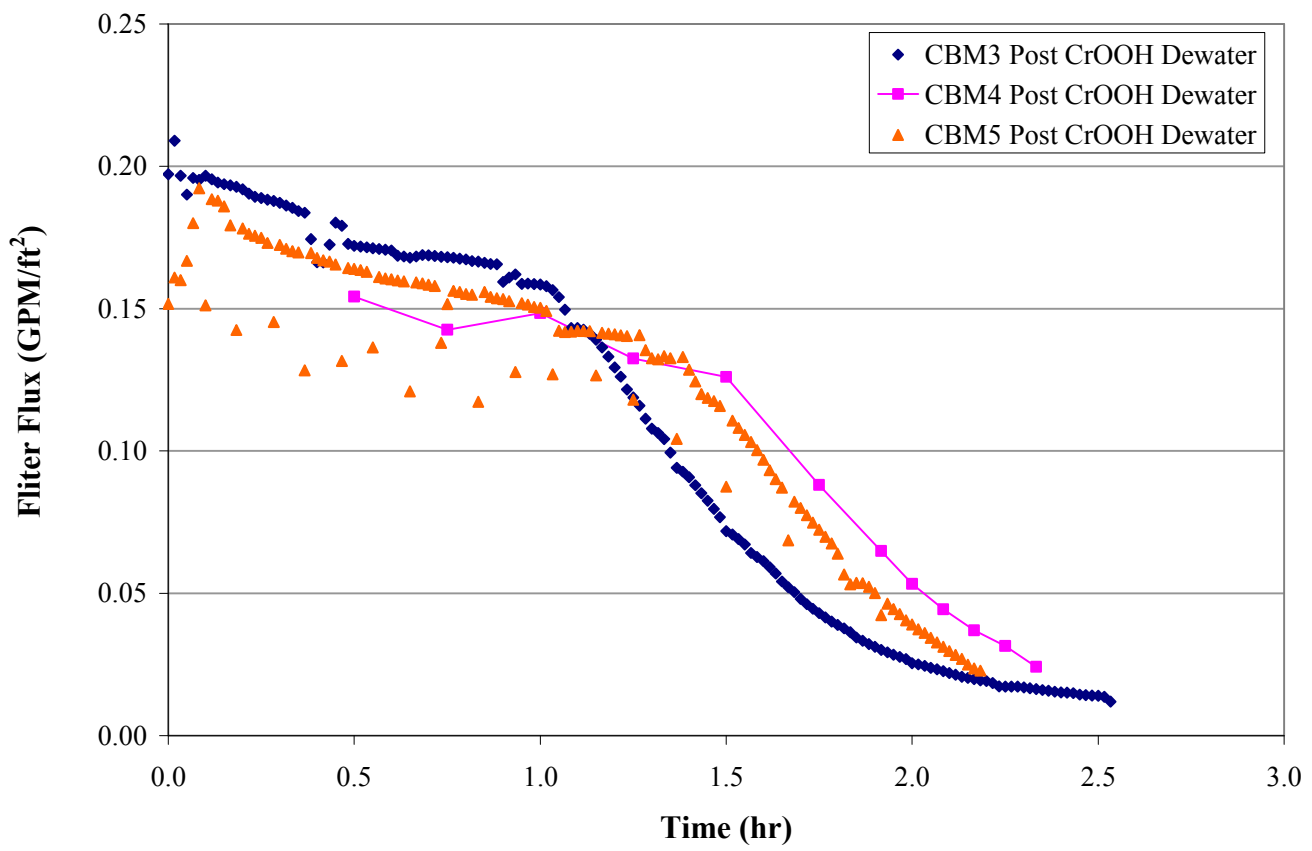

Figure 6.19. Dewatering of Slurry after CrOOH Addition in CBM-3, CBM-4, and CBM-5

After chromium addition and dewatering, the physical properties (Table 6.26), PSD (Figure 6.20), and rheology (Table 6.27) were measured. The PSD of CBM-3 was not measured. All of the physical properties and particle sizes matched well between CBM-4 and CBM-5, indicating no differences. However, CBM-3 showed much lower physical properties and rheology. CBM-5 had a much higher yield stress than CBM-4 and a lower consistency.

Table 6.26. Physical-Property Measurements of Chromium Added and Dewatered Blended Component Slurries

\begin{tabular}{|l|c|c|c||}
\hline & CBM-3 & CBM-4 & CBM-5 \\
\hline Slurry Density (g/mL) & 1.07 & 1.14 & 1.13 \\
\hline Supernate Density (g/mL) & -- & 1.01 & 1.01 \\
\hline Total Solids (wt\%) & 11.8 & 23.7 & 22.8 \\
\hline Dissolved Solids (wt\%) & 3.51 & 3.16 & 3.06 \\
\hline UDS (wt\%) & 8.62 & 21.2 & 20.4 \\
\hline
\end{tabular}




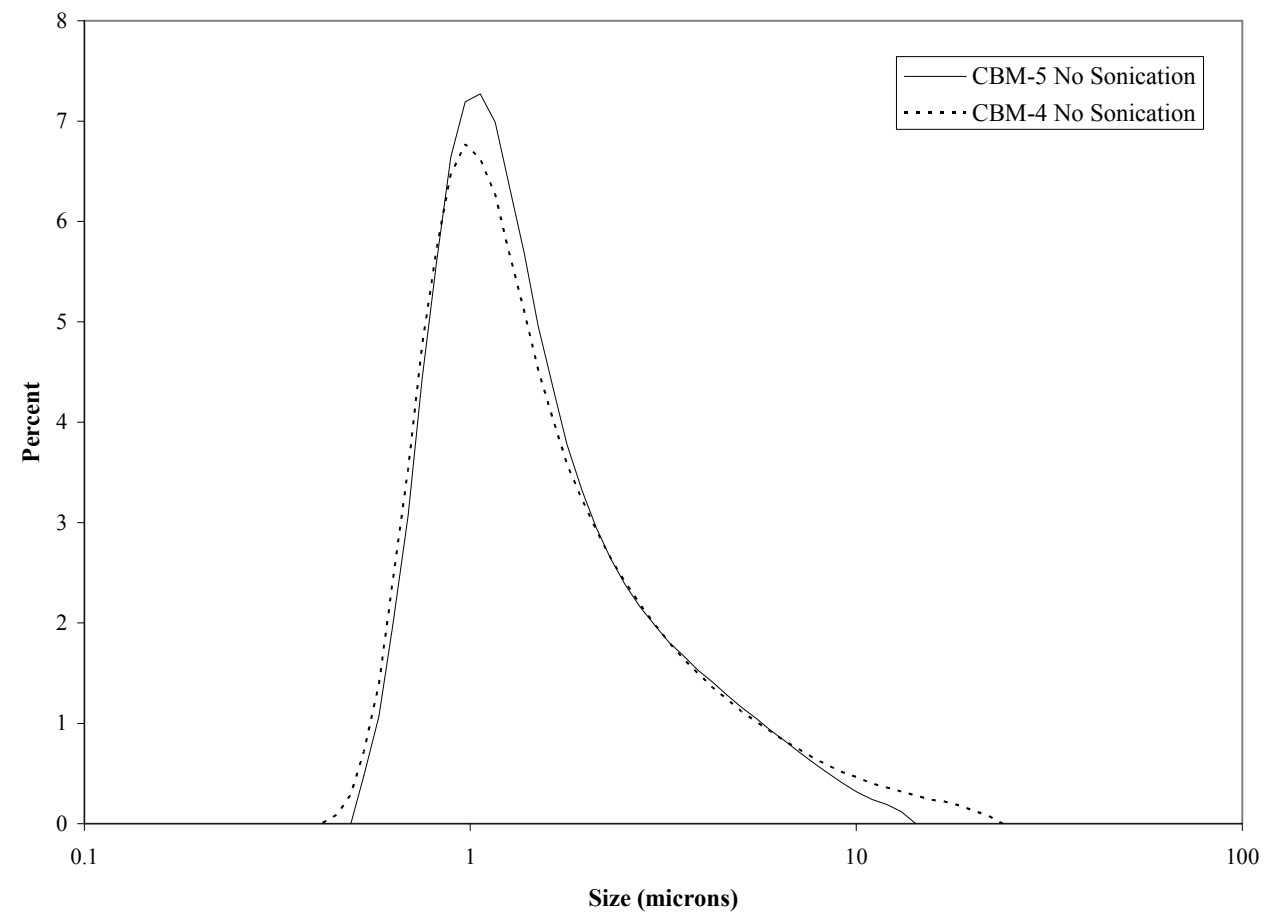

Figure 6.20. PSD Volume Distribution of CBM-4, and CBM-5 After Chromium Addition and Washing

Table 6.27. Results of Rheological Fitting Analysis for Chromium Added and Dewatered Blended Component Slurries

\begin{tabular}{||c|c|c|c|c|c|c||}
\hline \multirow{2}{*}{ Model } & $\begin{array}{c}\text { Slurry } \\
\text { ID }\end{array}$ & $\begin{array}{c}\text { Temperature } \\
\left({ }^{\circ} \mathbf{C}\right)\end{array}$ & $\begin{array}{c}\text { Yield } \\
\text { Stress (Pa) }\end{array}$ & $\begin{array}{c}\text { Consistency } \\
(\text { Pa-s) }\end{array}$ & $\begin{array}{c}\text { Flow } \\
\text { Index }\end{array}$ & R \\
\hline \multirow{3}{*}{ Bingham-Plastic } & CBM-3 & 25 & 0.86 & 0.0037 & NA & 0.99 \\
\cline { 2 - 7 } & CBM-4 & 25 & 32 & 0.015 & NA & 0.93 \\
\cline { 2 - 7 } & CBM-5 & 25 & --- & --- & --- & --- \\
\hline \multirow{3}{*}{ Herschel-Bulkley } & CBM-3 & 25 & 0.79 & 0.0055 & 0.94 & 0.99 \\
\cline { 2 - 7 } & CBM-4 & 25 & 2.4 & 16 & 0.14 & 0.98 \\
\cline { 2 - 7 } & CBM-5 & 25 & 23 & 0.80 & 0.43 & 0.99 \\
\hline
\end{tabular}

\subsubsection{Oxidative Leaching and Washing}

The slurry was oxidatively leached with $1 \mathrm{M} \mathrm{NaMnO}_{4}$ to remove the chromium from the slurry. After the slurry was leached, the physical properties (Table 6.28), PSD (Figure 6.21), and rheology (Table 6.29) were measured. The physical properties were similar for all three simulants. However, the weight percent total solids were lower in CBM-3, which made the weight percent UDS also lower.

The particle-size peaks appeared to shift a little in each slurry, which may be a result of the particle dissolution during the oxidative leaching. The rheology showed a small yield stress, with CBM-3 being lower than CBM-5, which may be due to the lower weight percent solids in CBM-3 than in CBM-5. The rheology of CBM-4 was not measured. 
Table 6.28. Physical-Property Measurements of Oxidatively Leached Blended Component Slurries

\begin{tabular}{|l|c|c|c||}
\hline & CBM-3 & CBM-4 & CBM-5 \\
\hline Slurry Density (g/mL) & 1.09 & 1.10 & 1.11 \\
\hline Supernate Density (g/mL) & --- & --- & 1.02 \\
\hline Total Solids (wt\%) & 11.03 & 15.05 & 14.49 \\
\hline Dissolved Solids (wt\%) & 2.84 & 2.56 & 2.90 \\
\hline UDS (wt\%) & 8.4 & 12.8 & 11.9 \\
\hline
\end{tabular}

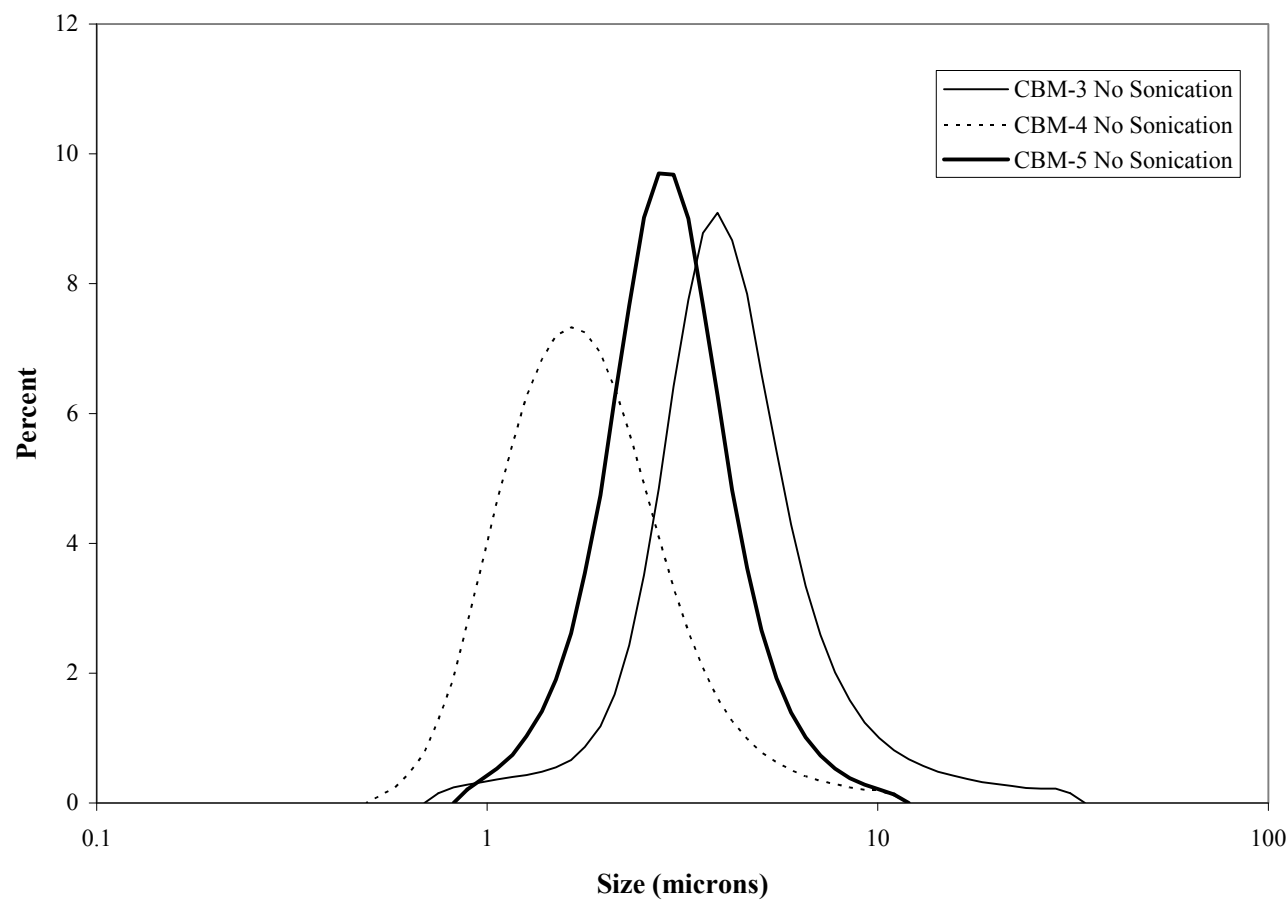

Figure 6.21. PSD Volume Distribution of CBM-3, CBM-4, and CBM-5 After Oxidative Leaching

Table 6.29. Results of Rheological Fitting Analysis for Oxidatively Leached Blended Component Slurries

\begin{tabular}{||c|c|c|c|c|c|c||}
\hline \multirow{4}{*}{ Model } & $\begin{array}{c}\text { Slurry } \\
\text { ID }\end{array}$ & $\begin{array}{c}\text { Temperature } \\
\left({ }^{\circ} \mathbf{C}\right)\end{array}$ & $\begin{array}{c}\text { Yield } \\
\text { Stress (Pa) }\end{array}$ & $\begin{array}{c}\text { Consistency } \\
(\mathbf{P a}-\mathbf{s})\end{array}$ & $\begin{array}{c}\text { Flow } \\
\text { Index }\end{array}$ & R \\
\hline \multirow{3}{*}{ Bingham-Plastic } & CBM-3 & 25 & 0.43 & 0.003 & NA & 0.99 \\
\cline { 2 - 7 } & CBM-4 & 25 & --- & --- & --- & --- \\
\cline { 2 - 7 } & CBM-5 & 25 & 0.78 & 0.003 & NA & 0.99 \\
\hline \multirow{3}{*}{ Herschel-Bulkley } & CBM-3 & 25 & 0.35 & 0.006 & 0.89 & 0.99 \\
\cline { 2 - 8 } & CBM-4 & 25 & --- & --- & --- & --- \\
\cline { 2 - 7 } & CBM-5 & 25 & 0.54 & 0.017 & 0.75 & 0.99 \\
\hline
\end{tabular}

After the oxidative leaching, the slurry was washed using 13 rinses of $700 \mathrm{~mL}$ of $0.01 \mathrm{M} \mathrm{NaOH}$ and dewatered as shown in Figure 6.22. CBM-3 and CBM-5 washed and dewatered similarly with a general downtrend in the flux. CBM-4 dewatered generally slightly slower than CBM-3 and CBM-5. After the last wash had been removed, the slurry was dewatered to approximately 20 -wt $\%$ UDS before the test was concluded. Again, filter fluxes are significantly above the target for this process, resulting in a process duration of only 3 hours versus a target of 8.5 hours. 


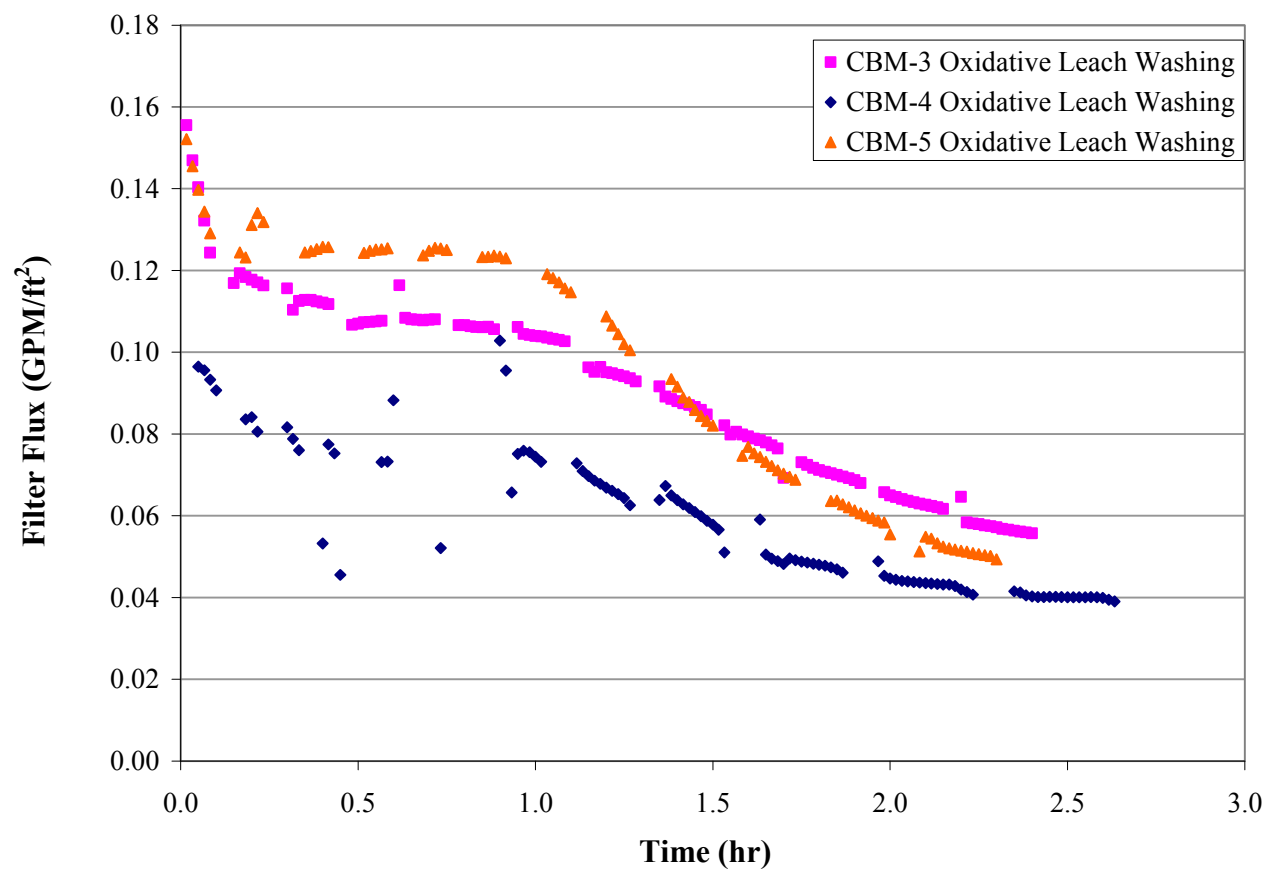

Figure 6.22. Post-Oxidative Leached Washing of CBM-3, CBM-4, and CBM-5

At the end of the dewatering, the physical properties (Table 6.30), PSD (Figure 6.23), and rheology (Table 6.31) were measured. The physical properties were all similar with the weight percent UDS being around the target of $20 \mathrm{wt} \%$. CBM-3 was higher at 24.3-wt\% UDS and showed a higher yield stress than CBM-4 and CBM-5. The yield stress of CBM-4 and CBM-5 were almost the same with the consistencies being similar also in the Bingham-Plastic model. The PSDs were similar between the three slurries with CBM-3 having a lower peak maximum and a longer tail on the larger particle size end than CBM-4 and CBM-5.

Table 6.30. Physical-Property Measurements of Final Dewatered Blended Component Slurries

\begin{tabular}{||l|c|c|c||}
\hline & CBM-3 & CBM-4 & CBM-5 \\
\hline Slurry Density (g/mL) & 1.18 & 1.17 & 1.13 \\
\hline Supernate Density (g/mL) & 0.998 & 0.999 & 0.999 \\
\hline Total Solids (wt\%) & 24.42 & 20.81 & 23.39 \\
\hline Dissolved Solids (wt\%) & 0.19 & 0.00 & 0.19 \\
\hline UDS (wt\%) & 24.3 & 20.8 & 23.2 \\
\hline
\end{tabular}




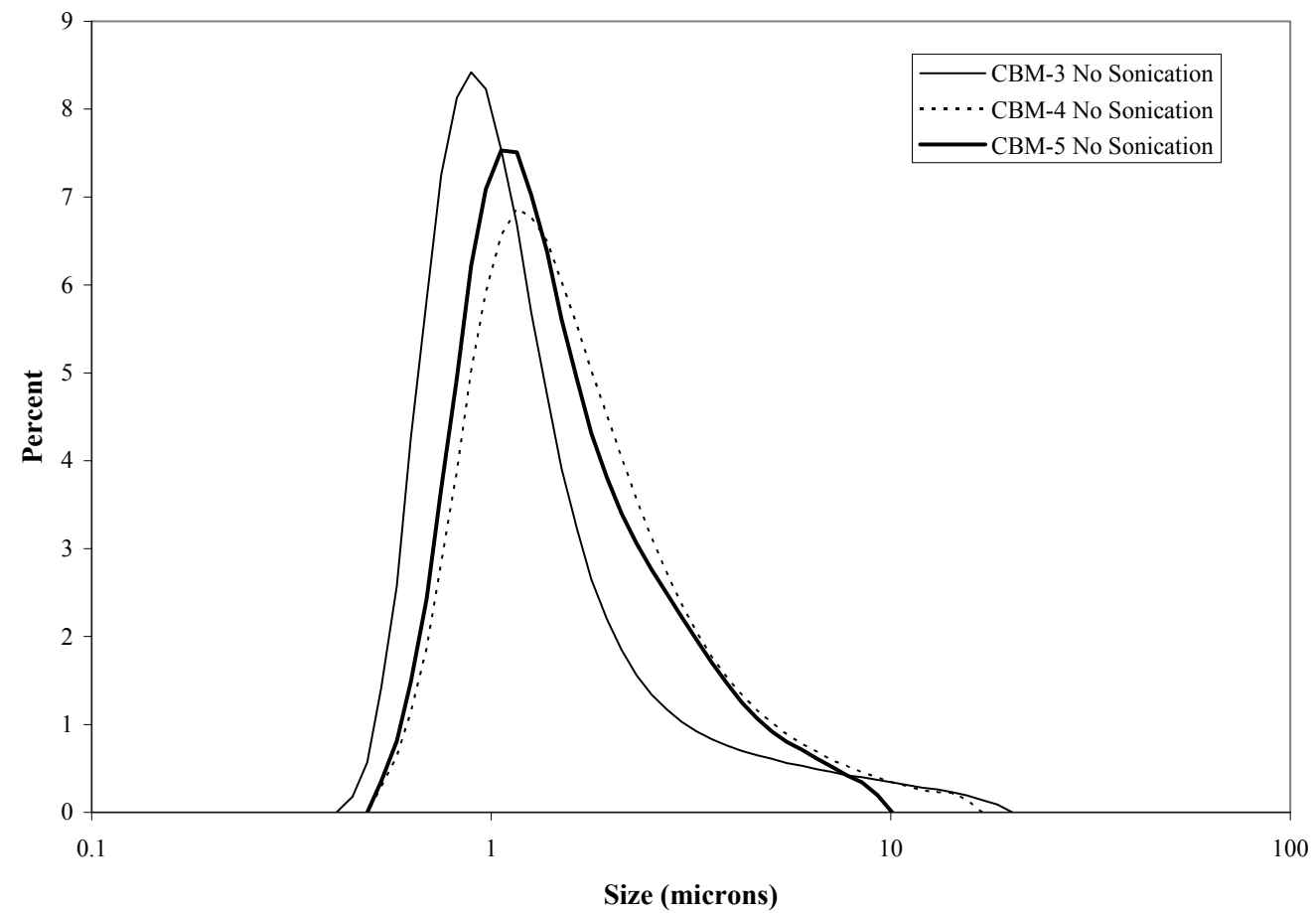

Figure 6.23. PSD Volume Distribution of the Final Slurry from CBM-3, CBM-4, and CBM-5

Table 6.31. Results of Rheological Fitting Analysis for Final Dewatered Blended Component Slurries

\begin{tabular}{|c|c|c|c|c|c|c||}
\hline \multirow{2}{*}{ Model } & $\begin{array}{c}\text { Slurry } \\
\text { ID }\end{array}$ & $\begin{array}{c}\text { Temperature } \\
\left({ }^{\circ} \mathbf{C}\right)\end{array}$ & $\begin{array}{c}\text { Yield } \\
\text { Stress (Pa) }\end{array}$ & $\begin{array}{c}\text { Consistency } \\
(\text { Pa-s) }\end{array}$ & $\begin{array}{c}\text { Flow } \\
\text { Index }\end{array}$ & $\mathbf{R}$ \\
\hline \multirow{3}{*}{ Bingham-Plastic } & CBM-3 & 25 & 48 & 0.014 & NA & 0.99 \\
\cline { 2 - 7 } & CBM-4 & 25 & 12 & 0.009 & NA & 0.99 \\
\cline { 2 - 7 } & CBM-5 & 25 & 13 & 0.009 & NA & 0.99 \\
\hline \multirow{3}{*}{ Herschel-Bulkley } & CBM-3 & 25 & 45 & 0.16 & 0.67 & 0.99 \\
\cline { 2 - 7 } & CBM-4 & 25 & 7.3 & 0.98 & 0.37 & 0.99 \\
\cline { 2 - 7 } & CBM-5 & 25 & 13 & 0.008 & 1.0 & 0.99 \\
\hline
\end{tabular}

\subsubsection{Vendor Simulant Production Conclusions}

The initial dewatering flux of CBM-4 and CBM-5 were essentially the same, whereas the CBM-3 dewatering flux was higher. This may have been because the AFA lowered the flux of the slurries as CBM-4 and CBM-5 had AFA added whereas CBM-3 did not.

After the slurry simulant was caustic leached with $\mathrm{NaOH}$ at $100^{\circ} \mathrm{C}$, the simulant was dewatered to increase the weight percent solids and remove the caustic solution from the simulant. These results show essentially the same filter flux for all three slurries, indicating that the AFA was no longer having any effect on the flux and may have been broken down by the high temperature and caustic solution during the leaching.

Towards the end of the washing, the flux of CBM-3 and CBM-5 improved significantly. The fluxes appeared to shift from a flat to a steep slope as the washes progressed with the flux improving at the 
beginning of each wash and then rapidly decaying. This might be attributed to the rapid dissolution of deeply fouled small particles in this concentration regime (specifically sodium oxalate). The more dilute the wash solution, the more sodium oxalate can dissolve and stay in solution.

All three slurries dewatered similarly after the CrOOH slurry was added and washed with approximately the same permeate flux. They also all decayed beginning at approximately $0.18 \mathrm{gpm} / \mathrm{ft}^{2}$ and ending at approximately $0.04 \mathrm{gpm} / \mathrm{ft}^{2}$. There was also a similarity in the dewatering during the post-oxidative leach washing with a general downtrend in the flux observed.

Based on these results, the slurries from the vendor produced in different size batches matched the slurry produced by PNNL, indicating that it can be replicated in different size batches by different vendors according to the recipe shown in Appendix A.

As expected at the start of testing, the filtration behavior was significantly better than required to meet the cycle time requirements. This is primarily attributed to the higher filter fluxes during the initial dewater and the washing processes. Attempts to reduce the filter flux through changing the inert bulk composition or by adding fines were unsuccessful. As such, the cycle time duration that will be achieved with this simulant will be much faster than required to meet the IRP requirements as shown in Table 6.32. Essentially, this problem was over constrained. The need to meet the leaching requirements results in significantly higher filter fluxes and makes meeting the cycle time requirements with this simulant formulation intractable.

Table 6.32. Cycle Time Requirements

\begin{tabular}{|l|c|c|}
\hline \multicolumn{1}{|c|}{ Process Time } & $\begin{array}{c}\text { Target } \\
\text { Duration (h) }\end{array}$ & $\begin{array}{c}\text { Actual } \\
\text { Time (h) }\end{array}$ \\
\hline Initial Dewater & 31.5 & 10 \\
\hline Caustic Leach & 26.6 & 30 \\
\hline Post Leach Dewater & 10.5 & 16 \\
\hline Wash & 31 & 10 \\
\hline Oxidative Leach & 6 & 6 \\
\hline Post Oxidative Leach/Wash & 8.5 & 3 \\
\hline Total & 114 & 75 \\
\hline
\end{tabular}





\subsection{References}

CCN 132846. 2006. "Comprehensive Review of the Hanford Waste Treatment Plant Flowsheet and Throughput - Assessment Conducted by an Independent Team of External Experts." Chartered by the Hanford Waste Treatment and Immobilization Plant Project at the Direction of the US Department of Energy, Office of Environmental Management, Washington DC.

CCN 132847. 2006. "Background Information and Interim Reports for the Comprehensive Review of the Hanford Waste Treatment Plant Flowsheet and Throughput - Assessment Conducted by an Independent Team of External Experts." Chartered by the Hanford Waste Treatment and Immobilization Plant Project at the Direction of the US Department of Energy, Office of Environmental Management, Washington DC.

Barnes S, and R Voke. 2006. Issue Response Plan for Implementation of External Flowsheet Review Team (EFRT) Recommendations - M12, Undemonstrated Leaching Processes. 24590-WTP-PL-ENG-060024, Rev. 0, Bechtel National, Inc., Richland, Washington.

Daniel RC, and RW Shimskey. 2007. Test Plan for Simulant Testing in Support of Phase I Demonstration of the Ultrafiltration and Leaching Processes in the Integrated Test Facility. TP-RPPWTP-509, Rev. 0, Pacific Northwest National Laboratory, Richland, Washington.

Eibling RE. 2005. Impact of Simulant Production Methods on the Physical Properties of DWPF Sludge Batch 3 Simulant. WSRC-TR-2004-0578, Rev. 0, Savannah River National Laboratory, Aiken, South Carolina.

Geeting JGH, KP Brooks, RT Hallen, LK Jagoda, AP Poloski, DR Weier, and RD Scheele. 2002. Filtration, Washing and Caustic Leaching of Hanford Tank AZ-101 Sludge. WTP-RPT-043, BattellePacific Northwest Division, Richland, Washington.

Geeting JGH, RT Hallen, LK Jagoda, AP Poloski, RD Scheele and DR Weier. 2003. Filtration, Washing, and Caustic Leaching of Hanford Tank AZ-101 Sludge. PNWD-3206, Rev. 1, Battelle-Pacific Northwest Division, Richland, Washington.

Golcar GR, KP Brooks, JG Darab, JM Davis, and LK Jagoda. 2000. Development of Inactive High-Level Waste Envelope D Simulants for Scaled Crossflow Filtration Testing. PNWD-3042, Rev. 0, BattellePacific Northwest Division, Richland, Washington.

Lucas L. 2006. Hanford Waste Treatment and Immobilization Plant (WTP) Project Response Plan for Resolution of Issues Identified by the Comprehensive Review of the WTP Flowsheet and Throughput. 24590-WTP-PL-ENG-06-0008, Rev. 0, Bechtel National, Inc., Richland, Washington.

Lumetta GJ, BM Rapko, MJ Wagner, J Liu, and YL Chen. 1996. Washing and Caustic Leaching of Hanford Tank Sludges: Results of FY 1996 Studies. PNNL-11278, Pacific Northwest National Laboratory, Richland, Washington.

Lumetta GJ, IE Burgeson, MJ Wagner, J Liu, and YL Chen. 1997. Washing and Caustic Leaching of Hanford Tank Sludge: Results of FY 1997 Studies. PNNL-11636, Pacific Northwest National Laboratory, Richland. 
Peterson RA, JGH Geeting, and RC Daniel. 2007. "Estimation of Ultrafilter Performance Based on Characterization Data." Chemical Engineering and Technology 30(8):1050-1054.

Rapko BM, GJ Lumetta, and MJ Wagner. 1995. Washing and Caustic Leaching of Hanford Tank Sludges: Results of FY1995 Studies. PNL-10712, Pacific Northwest Laboratory, Richland, Washington.

Rector DR, and BC Bunker. 1995. Effect of Colloidal Aggregation on the Sedimentation and Rheological Properties of Tank Waste. PNL-10761, Pacific Northwest Laboratory, Richland, Washington.

Russell RL, and HD Smith. 2007. Test Plan for the Development and Demonstration of Leaching and Ultrafiltration Simulants. TP-RPP-WTP-469, Rev. 0, Pacific Northwest Laboratory, Richland, Washington.

Smith GL. 2006. Characterization and Small Scale Testing of Hanford Wastes to Support the Development and Demonstration of Leaching and Ultrafiltration Pretreatment Processes. WTP Project Doc. No. 24590-PTF-TSP-RT-06-006, Rev. 0.

Sundar PS. 2007. Simulant Testing in Support of Phase I Demonstration of the Ultrafiltration and Leaching Processes in the Integrated Test Facility. WTP Project Doc. No. 24590-WTP-TSP-RT-07-004, Rev. 0.

Sundar PS. 2008. Simulant Recommendation for Phase I Testing in the Pretreatment Engineering Platform. 24590-PTF-RPT-08-006, Rev. 0, Bechtel National, Inc., Richland, Washington.

Temer DJ, and R Villarreal. 1996. Sludge Washing and Alkaline Leaching Tests on Actual Hanford Tank Sludge: FY1996 Results. LA-UR-96-2839, Los Alamos National Laboratory, Los Alamos, New Mexico.

Temer DJ, and R Villarreal. 1997. Sludge Washing and Alkaline Leaching Tests on Actual Hanford Tank Sludge: FY1997 Results. LA-UR-97-2889, Los Alamos National Laboratory, Los Alamos, New Mexico.

Zamecnik JR, PR Burket, RE Eibling, and MR Poirier. 2004. Tank 241-AY-102 Simulant Development, Ultrafiltration, and Washing. WSRC-TR-2003-00547, Rev. 0 (or SRT-RPP-2003-00240, Rev. 0), Westinghouse Savannah River Company, Aiken, South Carolina. 
Appendix A

\section{Recipe for Simulant Preparation}





\section{Appendix A: Recipe for Simulant Preparation}

The following is a step-by-step recipe for preparing the Fe-rich sludge component of the simulant used in this testing and chosen to be used in the PEP testing. This is the exact recipe that was used by PNNL to prepare the simulant. However, PEP chose to eliminate several of the minor/hazardous components from their formulation, which did not affect the simulant behavior.

\section{A.1 Preparation of "Simple Supernate" for Washing Precipitated Sludge Solids}

This preparation is for a "simple" version of the supernate simulant that is used for the initial washes of the precipitated sludge solids. This simple simulant contains the most abundant species found in the supernate simulant, but does not contain the minor species.

Note: $0.5 \%$ uncertainty on masses and volumes is sufficient.

The following recipe should be mixed in a plastic or stainless steel vessel. No glass shall be used. All additions are based on mass.

The target volume is $1 \mathrm{~L}$.

Tare weight of 2-L vessel:

1. Add to the 2-L vessel:

\begin{tabular}{|c|c|c|c|}
\hline & Mass Needed (g) & Actual Mass (g) & Resistivity of water \\
\hline Water (deionized, DI) & approximately 200.0 & & \\
\hline
\end{tabular}

2. Add to the 2-L vessel and mix:

\begin{tabular}{|c|c|c|c|}
\hline Compounds & Formula & Mass Needed (g) & Actual Mass (g) \\
\hline Sodium Sulfate & $\mathrm{Na}_{2} \mathrm{SO}_{4}$ & 2.67 & \\
\hline
\end{tabular}

3. In a separate $1-\mathrm{L}$ container, mix the following:

\begin{tabular}{|c|c|c|c|}
\hline Compounds & Formula & Mass Needed $(\mathrm{g})$ & Actual Mass $(\mathrm{g})$ \\
\hline Water (deionized) & & approximately 200.0 & \\
\hline Sodium Hydroxide & $\mathrm{NaOH}$ & 15.38 & \\
\hline Sodium Phosphate & $\mathrm{Na}_{3} \mathrm{PO}_{4} \cdot 12 \mathrm{H}_{2} \mathrm{O}$ & 15.38 & \\
\hline Sodium Oxalate & $\mathrm{Na}_{2} \mathrm{C}_{2} \mathrm{O}_{4}$ & 5.30 & \\
\hline
\end{tabular}

4. Mix thoroughly, and then add the above solution to the 2-L vessel. 
5. Add to the 2-L vessel:

\begin{tabular}{|l|c|c|c|}
\hline Compounds & Formula & Mass Needed $(\mathrm{g})$ & Actual Mass $(\mathrm{g})$ \\
\hline Sodium Carbonate & $\mathrm{Na}_{2} \mathrm{CO}_{3}$ & 102.3 & \\
\hline
\end{tabular}

6. Mix thoroughly.

7. In a separate $250-\mathrm{mL}$ container, mix the following:

\begin{tabular}{|c|c|c|c|}
\hline Compounds & Formula & Mass Needed (g) & Actual Mass (g) \\
\hline Sodium Nitrite & $\mathrm{NaNO}_{2}$ & 6.49 & \\
\hline Water (deionized) & & approximately 100 & \\
\hline
\end{tabular}

8. Add the above mixture to the 2-L vessel and mix thoroughly.

9. Add to the 2-L vessel and mix:

\begin{tabular}{|l|c|c|c|}
\hline & Total Mass Target $(\mathrm{g})$ & Added & Mass of Water to Add $(\mathrm{g})$ \\
\hline DI Water to a total mass of: & 1,000 & & approximately 350 \\
\hline
\end{tabular}

Record Final Mass of Vessel + solution:

Record Final Mass of solution:

\section{A.2 Preparation of "Supernate Simulant"}

This simulant is used for final washing of the Precipitated Sludge Solids and for makeup of the final overall simulant.

Note: $0.5 \%$ uncertainty on masses and volumes measured is sufficient.

The following recipe should be mixed in a plastic or stainless steel vessel. No glass shall be used. All additions are based on mass.

The target volume is $1 \mathrm{~L}$.

Tare weight of 2-L vessel:

1. To a 2-L vessel, add:

\begin{tabular}{|c|c|c|c|}
\hline & Mass Needed $(\mathrm{g})$ & Actual Mass $(\mathrm{g})$ & Resistivity of water \\
\hline Water (deionized, DI) & approximately 200.0 & & \\
\hline
\end{tabular}


2. Add the halides, sulfate, and nitrate to the 2-L vessel (the order of addition is not expected to be significant):

\begin{tabular}{|l|c|c|c|}
\hline Compounds & Formula & Mass Needed (g) & Actual Mass (g) \\
\hline Potassium Nitrate & $\mathrm{KNO}_{3}$ & 0.4325 & \\
\hline Sodium Chloride & $\mathrm{NaCl}$ & 0.2007 & \\
\hline Sodium Fluoride & $\mathrm{NaF}$ & 0.1345 & \\
\hline Sodium Sulfate & $\mathrm{Na}_{2} \mathrm{SO}_{4}$ & 2.671 & \\
\hline
\end{tabular}

3. In a separate $500-\mathrm{mL}$ container, mix the following (the order of addition is not expected to be significant):

\begin{tabular}{|l|l|c|c|}
\hline Compounds & Formula & Mass Needed $(\mathrm{g})$ & Actual Mass $(\mathrm{g})$ \\
\hline Water (deionized) & & approximately 200 & \\
\hline Sodium Hydroxide & $\mathrm{NaOH}$ & 15.380 & \\
\hline Potassium Hydroxide & $\mathrm{KOH}$ & 0.2691 & \\
\hline Sodium Phosphate & $\mathrm{Na}_{3} \mathrm{PO}_{4} \cdot 12 \mathrm{H}_{2} \mathrm{O}$ & 15.380 & \\
\hline Sodium Tungstate & $\mathrm{Na}_{2} \mathrm{WO}_{4} \cdot 2 \mathrm{H}_{2} \mathrm{O}$ & 0.1577 & \\
\hline Sodium Metasilicate & $\mathrm{Na}_{2} \mathrm{SiO}_{3} \cdot 9 \mathrm{H}_{2} \mathrm{O}$ & 0.5455 & \\
\hline Sodium Formate & $\mathrm{NaHCOO}$ & 0.2062 & \\
\hline Sodium Acetate & $\mathrm{NaCH}_{3} \mathrm{COO} \cdot 3 \mathrm{H}_{2} \mathrm{O}$ & 1.034 & \\
\hline Sodium Oxalate & $\mathrm{Na}_{2} \mathrm{C}_{2} \mathrm{O}_{4}$ & 5.303 & \\
\hline
\end{tabular}

4. Mix thoroughly, and then add this solution to the 2-L vessel.

5. Add to the 2-L vessel:

\begin{tabular}{|l|l|c|c|}
\hline Compounds & Formula & Mass Needed (g) & Actual Mass (g) \\
\hline Sodium Carbonate & $\mathrm{Na}_{2} \mathrm{CO}_{3}$ & 102.30 & \\
\hline
\end{tabular}

6. Mix thoroughly.

7. In a separate $250-\mathrm{mL}$ container, mix the following: 


\begin{tabular}{|l|l|c|c|}
\hline Compounds & Formula & Mass Needed (g) & Actual Mass (g) \\
\hline Water (deionized) & & approximately 100 & \\
\hline Sodium Nitrite & $\mathrm{NaNO}_{2}$ & 6.494 & \\
\hline & & & \\
\hline
\end{tabular}

8. Add to the 2-L vessel and mix thoroughly.

9. Add to the 2-L vessel and mix:

\begin{tabular}{|l|c|c|c|}
\hline & Total Mass Target $(\mathrm{g})$ & Added & Mass of Water to Add $(\mathrm{g})$ \\
\hline DI Water to a total mass of: & 1,000 & & approximately350 \\
\hline
\end{tabular}

10. Analyze the Supernate Simulant for $\mathrm{wt} \%$ total solids by drying $10 \mathrm{~mL}$ at $110^{\circ} \mathrm{C}$ until a stable weight is obtained.

$\mathrm{Wt} \%$ total solids:

11. Collect a 5- to 10-mL sample for ICP/IC analysis to confirm the correct composition.

Sample wt:

\section{A.3 Preparation of Precipitated Fe-Rich Sludge Solids}

This recipe details the steps to make precipitated Fe-rich sludge solids. The general steps involved are to dissolve metal nitrates, neutralize these nitrates to form the metal hydroxides, add trim chemicals (phosphate, oxalate, and carbonate), and wash the solids with the simple supernate and then with the supernate. Simple supernate and supernate recipes are included at the end of this procedure.

Note: $0.5 \%$ uncertainty on masses and volumes measured is sufficient.

The following preparation should be mixed in a plastic or stainless steel vessel. No glass shall be used. All additions are based on mass.

The target weight of precipitated solids is approximately $30 \mathrm{~g}$.

Tare weight of 2-L vessel:

1. Add to the 2-L vessel:

\begin{tabular}{|l|c|c|}
\hline & Mass Needed $(\mathrm{g})$ & Actual Mass $(\mathrm{g})$ \\
\hline Deionized Water & approximately 300 & \\
\hline
\end{tabular}




\section{A.3.1 Manganese Dioxide Production}

1. Add to the 2-L vessel and mix:

\begin{tabular}{|c|c|c|c|}
\hline Compounds & Formula & Mass Needed (g) & Actual Mass (g) \\
\hline Potassium Permanganate & $\mathrm{KMnO}_{4}$ & 4.37 & \\
\hline
\end{tabular}

Compound should completely dissolve.

2. Add to the 2-L vessel:

\begin{tabular}{|l|l|c|c|}
\hline Compounds & Formula & Mass Needed $(\mathrm{g})$ & Actual Mass (g) \\
\hline Manganous Nitrate Solution & $\mathrm{Mn}\left(\mathrm{NO}_{3}\right)_{2}, 50 \mathrm{Wt} \%$ solution & 14.85 & \\
\hline
\end{tabular}

3. Mix thoroughly. Mixing will produce fine black solids that will remain suspended while being agitated.

\section{A.3.2 Preparation of Metal Hydroxides}

1. Add to the 2-L vessel the following transition and other metal compounds and mix to make sure that dissolution is complete (the order of addition is not expected to be significant):

\begin{tabular}{|l|l|c|c|}
\hline \multicolumn{1}{|c|}{ Compounds } & \multicolumn{1}{|c|}{ Formula } & Mass Needed (g) & Actual Mass (g) \\
\hline Barium Nitrate & $\mathrm{Ba}\left(\mathrm{NO}_{3}\right)_{2}$ & 0.213 & \\
\hline Calcium Nitrate & $\mathrm{Ca}\left(\mathrm{NO}_{3}\right)_{2} \cdot 4 \mathrm{H}_{2} \mathrm{O}$ & 0.425 & \\
\hline Cadmium Nitrate & $\mathrm{Cd}\left(\mathrm{NO}_{3}\right)$ & 0.65 & \\
\hline Cerium Nitrate & $\mathrm{Ce}\left(\mathrm{NO}_{3}\right)_{3} \cdot 6 \mathrm{H}_{2} \mathrm{O}$ & 0.157 & \\
\hline Copper Nitrate & $\mathrm{Cu}\left(\mathrm{NO}_{3}\right)_{2} \cdot 3 \mathrm{H}_{2} \mathrm{O}$ & 128.1 & \\
\hline Ferric Nitrate & $\mathrm{Fe}\left(\mathrm{NO}_{3}\right)_{3} \cdot 9 \mathrm{H}_{2} \mathrm{O}$ & 0.482 & \\
\hline Lanthanum Nitrate & $\mathrm{La}\left(\mathrm{NO}_{3}\right)_{3} \cdot 6 \mathrm{H}_{2} \mathrm{O}$ & 1.295 & \\
\hline Lead Nitrate & $\mathrm{Pb}\left(\mathrm{NO}_{3}\right)_{2}$ & 1.72 & \\
\hline Magnesium Nitrate & $\mathrm{Mg}\left(\mathrm{NO}_{3}\right)_{2} \cdot 6 \mathrm{H}_{2} \mathrm{O}$ & 1.32 & \\
\hline Neodymium Nitrate & $\mathrm{Nd}\left(\mathrm{NO}_{3}\right)_{3} \cdot 6 \mathrm{H}_{2} \mathrm{O}$ & 2.87 & \\
\hline Nickel Nitrate & $\mathrm{Ni}\left(\mathrm{NO}_{3}\right)_{2} \cdot 6 \mathrm{H}_{2} \mathrm{O}$ & 0.33 & \\
\hline Praseodymium Nitrate & $\mathrm{Pr}\left(\mathrm{NO}_{3}\right)_{3} \cdot \mathrm{xH}_{2} \mathrm{O} \times \sim 6$ & 0.11 & \\
\hline Ruthenium Trichloride & $\mathrm{RuCl}$ & 0.486 & \\
\hline Silver Nitrate & $\mathrm{AgNO}$ & & \\
\hline
\end{tabular}




\begin{tabular}{|l|l|c|c|}
\hline \multicolumn{1}{|c|}{ Compounds } & \multicolumn{1}{|c|}{ Formula } & Mass Needed (g) & Actual Mass (g) \\
\hline Strontium Nitrate & $\mathrm{Sr}\left(\mathrm{NO}_{3}\right)_{2}$ & 0.347 & \\
\hline Yttrium Nitrate & $\mathrm{Y}\left(\mathrm{NO}_{3}\right)_{3} \cdot 6 \mathrm{H}_{2} \mathrm{O}$ & 0.14 & \\
\hline Zinc Nitrate & $\mathrm{Zn}\left(\mathrm{NO}_{3}\right)_{2} \cdot 6 \mathrm{H}_{2} \mathrm{O}$ & 0.169 & \\
\hline Zirconyl Nitrate & $\mathrm{ZrO}\left(\mathrm{NO}_{3}\right)_{2} \cdot \mathrm{xH}_{2} \mathrm{O} \times \sim 6$ & 1.73 & \\
\hline Mercuric Nitrate & $\mathrm{Hg}\left(\mathrm{NO}_{3}\right)_{2}$ & 0.052 & \\
\hline
\end{tabular}

2. Mix thoroughly to completely dissolve everything except the fine black solids of $\mathrm{MnO}_{2}$. A little DI water may be added if necessary for complete dissolution to occur.

DI water added:

\section{A.3.3 Neutralization of Nitrates}

1. Standardize a $\mathrm{pH}$ electrode with $\mathrm{pH} \mathrm{4,} \mathrm{7,} \mathrm{and} 10$ buffers.

pH 4 buffer:

Manufacturer:

Lot\#:

Exp Date:

pH 7 buffer:

Manufacturer:

Lot\#:

Exp Date:

pH 10 buffer:

Manufacturer:

Lot\#: Exp Date:

2. Place the $\mathrm{pH}$ electrode in the precipitation vessel with the metal nitrates and measure the $\mathrm{pH}$.

$\mathrm{pH}:$

Note: $\mathrm{pH}$ should be $<1$.

3. With the nitrate solution agitating, slowly add $8 \mathrm{M} \mathrm{NaOH}$ until the $\mathrm{pH}$ reaches 10 to 11 . Estimated amount of $8 \mathrm{M} \mathrm{NaOH}$ needed is $190 \mathrm{~g}$.

4. Measure the $\mathrm{pH}$.

$\mathrm{pH}:$

5. Continue mixing for 1 hour and then recheck $\mathrm{pH}$.

$\mathrm{pH}$ :

6. Add additional $8 \mathrm{M} \mathrm{NaOH}$ to return the $\mathrm{pH}$ to 10 , if it is lower.

Total $8 \mathrm{M} \mathrm{NaOH}$ added:

Final $\mathrm{pH}$ : 


\section{A.3.4 Adding Additional Reagents}

1. Add to the 2-L vessel:

\begin{tabular}{|l|l|c|c|}
\hline \multicolumn{1}{|c|}{ Compounds } & \multicolumn{1}{|c|}{ Formula } & Mass Needed $(\mathrm{g})$ & Actual Mass $(\mathrm{g})$ \\
\hline Calcium Fluoride & $\mathrm{CaF}_{2}$ & 0.205 & \\
\hline Sodium Phosphate & $\mathrm{Na}_{3} \mathrm{PO}_{4} \cdot 12 \mathrm{H}_{2} \mathrm{O}$ & 5.05 & \\
\hline
\end{tabular}

2. Combine the following in a separate $250-\mathrm{mL}$ container while stirring:

\begin{tabular}{|l|l|c|c|}
\hline \multicolumn{1}{|c|}{ Compound } & \multicolumn{1}{|c|}{ Formula } & Mass Needed $(\mathrm{g})$ & Actual Mass $(\mathrm{g})$ \\
\hline Water (deionized) & & approximately 100 & \\
\hline Sodium Oxalate & $\mathrm{Na}_{2} \mathrm{C}_{2} \mathrm{O}_{4}$ & 6.7 & \\
\hline
\end{tabular}

3. Add the sodium oxalate solution to the 2-L vessel while stirring.

4. Combine the following in a separate $250-\mathrm{mL}$ container while stirring:

\begin{tabular}{|l|l|c|c|}
\hline \multicolumn{1}{|c|}{ Compound } & \multicolumn{1}{|c|}{ Formula } & Mass Needed $(\mathrm{g})$ & Actual Mass $(\mathrm{g})$ \\
\hline Water (deionized) & & approximately100 & \\
\hline Sodium Carbonate & $\mathrm{Na}_{2} \mathrm{CO}_{3}$ & 9.50 & \\
\hline
\end{tabular}

5. Add the sodium carbonate solution to the 2-L vessel while stirring. The approximate volume at this point should be about $0.9 \mathrm{~L}$.

6. Thoroughly mix the slurry at least 1 hour to make sure that the mixing is thorough.

\section{A.3.5 Wash Precipitated Sludge Solids to Remove Nitrate}

Four washes are performed to reduce the nitrate concentration to below about $500 \mathrm{mg} / \mathrm{kg}$. The slurry is centrifuged between each wash. The total solids content of the centrifuged solids needs to be at least $25 \mathrm{wt} \%$ for sufficient washing to be completed in four washes. If less wash solution is removed during centrifuging, additional washing steps must be added. However, excessive washing is to be avoided so that the nitrate and trace compounds are not reduced too far in concentration.

The amount of wash solution required per wash is approximately three times the mass of the centrifuged solids. Three washes with the simple supernate for washing prepared in Section A.1 are used, followed by a wash with the actual supernate simulant prepared in Section A.2. Use this information to calculate the amount of wash and supernate simulant needed.

1. Centrifuge the slurry for 30 minutes at approximately $4500 \mathrm{G}$.

Time started: Time finished: 
Centrifuge speed:

2. Decant the supernate. (The supernate is waste.)

Amount of supernate decanted:

3. Combine all centrifuged slurry fractions.

Weight of centrifuged solids:

4. Measure the nitrate concentration of the slurry using the nitrate probe for indication.

$\mathrm{NO}_{3}{ }^{-}$concentration:

5. Add simple simulant for washing at approximately three times the mass of the slurry and mix thoroughly (for approximately 1 hour).

Amount of wash solution added:

6. Centrifuge the slurry for 30 minutes at approximately $4500 \mathrm{G}$.

Time started: Time finished:

Centrifuge speed:

7. Decant the supernate. (The supernate is waste.) This is the end of Wash 1.

Amount of supernate decanted:

8. Combine all centrifuged slurry fractions.

Weight of centrifuged solids:

9. Measure the nitrate concentration of the slurry using the nitrate probe for indication.

$\mathrm{NO}_{3}{ }^{-}$concentration:

10. Add simple simulant for washing at approximately three times the mass of the slurry and mix thoroughly (for approximately 1 hour).

Amount of wash solution added:

11. Centrifuge the slurry for 30 minutes at approximately $4500 \mathrm{G}$.

Time started: Time finished:

Centrifuge speed: 
12. Decant the supernate. (The supernate is waste.) This is the end of Wash 2.

Amount of supernate decanted:

13. Combine all centrifuged slurry fractions.

Weight of centrifuged solids:

14. Measure the nitrate concentration of the slurry using the nitrate probe for indication.

$\mathrm{NO}_{3}{ }^{-}$concentration:

15. Add simple simulant for washing at approximately three times the mass of the slurry and mix thoroughly (for approximately 1 hour).

Amount of wash solution added:

16. Centrifuge the slurry for 30 minutes at approximately $4500 \mathrm{G}$.

Time started: Time finished:

Centrifuge speed:

17. Decant the supernate. (The supernate is waste.) This is the end of Wash 3.

Amount of supernate decanted:

18. Combine all centrifuged slurry fractions.

Weight of centrifuged solids:

19. Measure the nitrate concentration of the slurry using the nitrate probe for indication.

$\mathrm{NO}_{3}{ }^{-}$concentration:

20. Add ACTUAL supernate simulant (the batch to be used for the final combined simulant) at approximately three times the mass of the slurry and mix thoroughly (for approximately 1 hour).

Amount of wash solution added:

21. Centrifuge the slurry for 30 minutes at approximately $4500 \mathrm{G}$.

Time started: Time finished:

Centrifuge speed:

22. Decant the supernate. (The supernate is waste.) This is the end of Wash 4. Amount of supernate decanted: 
23. Combine all centrifuged slurry fractions.

Weight of centrifuged solids:

24. Measure the nitrate concentration of the slurry using the nitrate probe for indication.

$\mathrm{NO}_{3}{ }^{-}$concentration:

25. Add ACTUAL supernate simulant (the batch to be used for the final combined simulant) at approximately three times the mass of the slurry and mix thoroughly (for approximately 1 hour).

Amount of wash solution added:

26. Add to the 2-L vessel with agitation:

\begin{tabular}{|c|l|c|c|}
\hline Compounds & Formula & Mass Needed $(\mathrm{g})$ & Actual Mass (g) \\
\hline Sodium Carbonate & $\mathrm{Na}_{2} \mathrm{CO}_{3}$ & 156.0 & \\
\hline
\end{tabular}

27. Centrifuge the slurry for 30 minutes at approximately $4500 \mathrm{G}$.

Time started:

Time finished:

Centrifuge speed:

28. Decant the supernate. (The supernate is waste.) This is the end of Wash 5.

Amount of supernate decanted:

29. Measure the nitrate concentration of the slurry using the nitrate probe for indication. If the concentration is $<350 \mathrm{mg} / \mathrm{kg}$, continue. If not, then perform another wash using Steps 29 to 34 .

$\mathrm{NO}_{3}{ }^{-}$concentration:

30. Analyze the slurry for $\mathrm{wt} \%$ total solids and $\mathrm{wt} \%$ supernate solids ( $\mathrm{wt} \%$ solids of supernate separated from the slurry) by drying at $110^{\circ} \mathrm{C}$.

$\mathrm{Wt} \%$ total solids:

$\mathrm{Wt} \%$ supernate solids: 


\section{A.4 Recipes for the Blended CUF Filtration Simulants}

The Blended CUF Filtration Simulant is made up from the list of prefabricated components shown in Table A.1. A vendor prepared the supernate and the Fe-rich sludge to the recipe described in this appendix. The gibbsite and boehmite components were commercially purchased. Noah Chemical Company made the chromium oxy-hydroxide slurry. The simulant created according to Table A.1 was used for the first two tests. The simulant created according to Table A.2, without the chromium oxyhydroxide slurry, was used for the last three tests. The chromium oxy-hydroxide slurry was added at a later stage of testing during these tests.

Table A.1. Initial Blended CUF Simulant

\begin{tabular}{|l|l|l||}
\hline \multicolumn{2}{|c|}{ Ingredients } & Preparation \\
\hline 1 & $\begin{array}{l}\text { Weigh out 31653 g of supernate (pre-shimmed to } \\
\text { correct Na concentration). }\end{array}$ & Appendix A.2 \\
\hline 2 & Add 7913 g of 5 M NaOH with mixing. & Commercially available \\
\hline 3 & Add 778.5 g gibbsite with mixing. & Commercially available (Almatis C333) \\
\hline 4 & Add 778.5 g boehmite with mixing. & $\begin{array}{l}\text { Commercially available (APYRAL } \\
\text { AOH20) }\end{array}$ \\
\hline 5 & Add 91.4 g Cr oxy-hydroxide slurry with mixing. & Purchased from Noah Chemical \\
\hline 6 & Add 225 g sodium oxalate with mixing. & Commercially available \\
\hline 7 & Add 3561 g sludge simulant with mixing. & Appendix A.3 \\
\hline 8 & Add another 638 g of 5M NaOH with mixing. & Commercially available \\
\hline 9 & Actively mix for 1 hour. & \\
\hline
\end{tabular}

Table A.2. Blended CUF Simulant with CrOOH Slurry Added Later

\begin{tabular}{|l|l|l||}
\hline \multicolumn{2}{|c|}{ Ingredients } & Preparation \\
\hline 1 & $\begin{array}{l}\text { Weigh out 24836 g of supernate (pre-shimmed to } \\
\text { correct Na concentration). }\end{array}$ & Appendix A.2 \\
\hline 2 & Add 458 g gibbsite with mixing. & Commercially available (Almatis C333) \\
\hline 3 & Add 458 g boehmite with mixing. & $\begin{array}{l}\text { Commercially available (APYRAL } \\
\text { AOH20) }\end{array}$ \\
\hline 4 & Add 131 g sodium oxalate with mixing. & Commercially available \\
\hline 5 & Add 2148 g sludge simulant with mixing. & Appendix A.3 \\
\hline 6 & Add another 379 g of 5 M NaOH with mixing. & Commercially available \\
\hline 7 & Actively mix for 1 hour. & \\
\hline
\end{tabular}



Appendix B: Centrifuge Data 



\section{Appendix B: Summary of Centrifugation Test Data}

Note that the tests were performed in duplicate (A and B). The $1 \mathrm{G}$ tests were allowed to settle for about 20 hours. The centrifuge tests were all run for 15 minutes. Some of the $4500 \mathrm{G}$ centrifuge tests were repeated for 30 minutes. The longer tests showed very little additional compression of the suspended solids column. For test \# 10, the supernate was noted to be cloudy and brown after the $500 \mathrm{G}$ runs, and the solids were not well settled. The density of the centrifuged solids was measured on solids from the 15 minute $4500 \mathrm{G}$ tests.

Table B.1. Centrifuge Data

\begin{tabular}{|c|c|c|c|c|c|c|}
\hline Sample ID & $1 \mathrm{~A}$ & 1B & $2 \mathrm{~A}$ & 2B & $\mathbf{3 A}$ & 3B \\
\hline Initial Slurry volume $(\mathrm{mL})$ & 50 & 50 & 50 & 50 & 50 & 50 \\
\hline Slurry weight $(\mathrm{g})$ & 60.3478 & 60.235 & 60.0935 & 60.1994 & 59.9481 & 59.8403 \\
\hline Slurry density $(\mathrm{g} / \mathrm{mL})$ & 1.2070 & 1.2047 & 1.2019 & 1.2040 & 1.1990 & 1.1968 \\
\hline Settled Supernate Vol after settling $\sim 20 \mathrm{hr}(\mathrm{mL})$ & 7.5 & 6.25 & 18.75 & 18 & 2.5 & 2.5 \\
\hline Settled Solids Vol after settling $\sim 20 \mathrm{hr}(\mathrm{mL})$ & 42.5 & 43.75 & 31.25 & 32 & 47.5 & 47.5 \\
\hline Vol of settled supernate in grad cylinder (mL) & 5.1 & 5.5 & 10 & 10 & 2.4 & 2.2 \\
\hline Wt of settled supernate in grad cylinder $(\mathrm{g})$ & 5.7397 & 6.2028 & 11.4473 & 11.2959 & 2.6464 & 2.3788 \\
\hline Density of settled supernate $(\mathrm{g} / \mathrm{mL})$ & 1.1254 & 1.1278 & 1.1447 & 1.1296 & 1.1027 & 1.0813 \\
\hline Vol of $500 \mathrm{G}$ centrifuged supernate $(\mathrm{mL})$ & 27.5 & 27.5 & na & na & na & na \\
\hline Vol of 500G centrifuged solids (mL) & 22.5 & 22.5 & na & na & na & na \\
\hline Vol of $1000 \mathrm{G}$ centrifuged supernate $(\mathrm{mL})$ & 32.5 & 33 & 37.5 & 37.5 & 32.5 & 32.5 \\
\hline Vol of $1000 \mathrm{G}$ centrifuged solids $(\mathrm{mL})$ & 17.5 & 17 & 12.5 & 12.5 & 17.5 & 17.5 \\
\hline Vol of $4500 \mathrm{G}$ centrifuged supernate $15 \mathrm{~min}(\mathrm{~mL})$ & 37 & 38.5 & 40.5 & 41.5 & 38 & 37.5 \\
\hline Vol of $4500 \mathrm{G}$ centrifuged solids $15 \mathrm{~min}(\mathrm{~mL})$ & 13 & 11.5 & 9.5 & 8.5 & 12 & 12.5 \\
\hline Vol of $4500 \mathrm{G}$ centrifuged supernate $30 \mathrm{~min}(\mathrm{~mL})$ & 38 & 39.5 & 41.5 & 42 & 39 & 38.5 \\
\hline Vol of $4500 \mathrm{G}$ centrifuged solids $30 \mathrm{~min}(\mathrm{~mL})$ & 12 & 10.5 & 8.5 & 8 & 11 & 11.5 \\
\hline Vol of centrifuged supernate in grad cylinder (mL) & 10 & 10 & 10 & 10 & 10 & 10 \\
\hline Wt of centrifuged supernate in grad cylinder (g) & 11.3642 & 11.4296 & 11.3875 & 11.3865 & 11.3995 & 11.4096 \\
\hline Density of centrifuged supernate $(\mathrm{g} / \mathrm{mL})$ & 1.1364 & 1.1430 & 1.1388 & 1.1387 & 1.1400 & 1.1410 \\
\hline Mass of centrifuged solids (g) & 17.1051 & 16.8891 & 14.2588 & 14.3158 & 16.9833 & 16.9663 \\
\hline Vol of centrifuged solids $(\mathrm{mL})$ & 12 & 11 & 9 & 8.5 & 11.5 & 12 \\
\hline Density of centrifuged solids $(\mathrm{g} / \mathrm{mL})$ & 1.4254 & 1.5354 & 1.5843 & 1.6842 & 1.4768 & 1.4139 \\
\hline Mass of dried solids (g) & 6.3903 & 6.3469 & 6.2267 & 6.2542 & 6.3806 & 6.3777 \\
\hline $\mathrm{wt} \%$ Undissolved solids & 10.59 & 10.54 & 10.36 & 10.39 & 10.64 & 10.66 \\
\hline Mass of supernate $(\mathrm{g})$ & 11.2156 & 11.2154 & 11.2553 & 11.1779 & 11.2524 & 11.2643 \\
\hline Mass of dried supernate $(\mathrm{g})$ & 1.6605 & 1.6626 & 1.6609 & 1.6639 & 1.7063 & 1.6669 \\
\hline $\mathrm{wt} \%$ supernate solids & 14.81 & 14.82 & 14.76 & 14.89 & 15.16 & 14.80 \\
\hline
\end{tabular}


Table B.1.a. Centrifuge Data (cont)

\begin{tabular}{|c|c|c|c|c|c|c|}
\hline Sample ID & 4A & 4B & $\mathbf{5 A}$ & 5B & 6A & 6B \\
\hline Initial Slurry volume $(\mathrm{mL})$ & 50 & 50 & 50 & 50 & 50 & 50 \\
\hline Slurry weight $(\mathrm{g})$ & 60.1283 & 60.0347 & 59.5634 & 59.7107 & 61.0472 & 61.0108 \\
\hline Slurry density $(\mathrm{g} / \mathrm{mL})$ & 1.2026 & 1.2007 & 1.1913 & 1.1942 & 1.2209 & 1.2202 \\
\hline Settled Supernate Vol after settling $\sim 20 \mathrm{hr}(\mathrm{mL})$ & 8 & 5.5 & 13.75 & 12.5 & 21 & 22 \\
\hline Settled Solids Vol after settling $\sim 20 \mathrm{hr}(\mathrm{mL})$ & 42 & 44.5 & 36.25 & 37.5 & 29 & 28 \\
\hline Vol of settled supernate in grad cylinder (mL) & 7 & 5.2 & 10 & 10 & 10 & 10 \\
\hline Wt of settled supernate in grad cylinder $(\mathrm{g})$ & 8.007 & 5.8324 & 11.3643 & 11.2452 & 11.3944 & 11.2815 \\
\hline Density of settled supernate $(\mathrm{g} / \mathrm{mL})$ & 1.1439 & 1.1216 & 1.1364 & 1.1245 & 1.1394 & 1.1282 \\
\hline Vol of 500G centrifuged supernate $(\mathrm{mL})$ & na & na & na & na & na & na \\
\hline Vol of $500 \mathrm{G}$ centrifuged solids $(\mathrm{mL})$ & na & na & na & na & na & na \\
\hline Vol of $1000 \mathrm{G}$ centrifuged supernate $(\mathrm{mL})$ & 32.5 & 32.5 & 36 & 36 & 38.5 & 37.5 \\
\hline Vol of $1000 \mathrm{G}$ centrifuged solids $(\mathrm{mL})$ & 17.5 & 17.5 & 14 & 14 & 11.5 & 12.5 \\
\hline Vol of $4500 \mathrm{G}$ centrifuged supernate $15 \mathrm{~min}(\mathrm{~mL})$ & 37.5 & 37.5 & 39 & 39 & 40.5 & 41 \\
\hline Vol of $4500 \mathrm{G}$ centrifuged solids $15 \mathrm{~min}(\mathrm{~mL})$ & 12.5 & 12.5 & 11 & 11 & 9.5 & 9 \\
\hline Vol of $4500 \mathrm{G}$ centrifuged supernate $30 \mathrm{~min}(\mathrm{~mL})$ & 38.5 & 38 & 40 & 40 & 41 & 42 \\
\hline Vol of $4500 \mathrm{G}$ centrifuged solids $30 \mathrm{~min}(\mathrm{~mL})$ & 11.5 & 12 & 10 & 10 & 9 & 8 \\
\hline Vol of centrifuged supernate in grad cylinder $(\mathrm{mL})$ & 10 & 10 & 10 & 10 & 10 & 10 \\
\hline Wt of centrifuged supernate in grad cylinder $(\mathrm{g})$ & 11.3941 & 11.4281 & 11.4103 & 11.4489 & 11.4247 & 11.4223 \\
\hline Density of centrifuged supernate $(\mathrm{g} / \mathrm{mL})$ & 1.1394 & 1.1428 & 1.1410 & 1.1449 & 1.1425 & 1.1422 \\
\hline Mass of centrifuged solids (g) & 16.8943 & 17.0301 & 14.6355 & 14.7137 & 14.3556 & 14.3268 \\
\hline Vol of centrifuged solids (mL) & 12 & 12.5 & 10.5 & 10.5 & 9.5 & 8.5 \\
\hline Density of centrifuged solids $(\mathrm{g} / \mathrm{mL})$ & 1.4079 & 1.3624 & 1.3939 & 1.4013 & 1.5111 & 1.6855 \\
\hline Mass of dried solids $(\mathrm{g})$ & 6.3228 & 6.337 & 6.2423 & 6.2638 & 6.3195 & 6.3227 \\
\hline $\mathrm{wt} \%$ Undissolved solids & 10.52 & 10.56 & 10.48 & 10.49 & 10.35 & 10.36 \\
\hline Mass of supernate $(\mathrm{g})$ & 11.2436 & 11.2783 & 11.2221 & 11.2873 & 11.2557 & 11.2297 \\
\hline Mass of dried supernate $(\mathrm{g})$ & 1.6959 & 1.7174 & 1.6748 & 1.7121 & 1.7082 & 1.682 \\
\hline $\mathrm{wt} \%$ supernate solids & 15.08 & 15.23 & 14.92 & 15.17 & 15.18 & 14.98 \\
\hline
\end{tabular}


Table B.1.b. Centrifuge Data (cont.)

\begin{tabular}{|c|c|c|c|c|c|c|c|c|}
\hline Sample ID & $7 \mathrm{~A}$ & $7 B$ & $\mathbf{8 A}$ & 8B & 9A & 9B & $10 \mathrm{~A}$ & 10B \\
\hline Initial Slurry volume (mL) & 50 & 50 & 50 & 50 & 50 & 50 & 50 & 50 \\
\hline Slurry weight (g) & 60.8267 & 60.8468 & 60.2968 & 60.0389 & 60.609 & 60.0921 & 59.4862 & 59.516 \\
\hline Slurry density $(\mathrm{g} / \mathrm{mL})$ & 1.2165 & 1.2169 & 1.2059 & 1.2008 & 1.2122 & 1.2018 & 1.1897 & 1.1903 \\
\hline Settled Supernate Vol after settling $\sim 20 \mathrm{hr}(\mathrm{mL})$ & 37.5 & 37.5 & 27.5 & 27.5 & 30 & 30 & 14 & 14 \\
\hline Settled Solids Vol after settling $\sim 20 \mathrm{hr}(\mathrm{mL})$ & 12.5 & 12.5 & 22.5 & 22.5 & 20 & 20 & 36 & 36 \\
\hline Vol of settled supernate in grad cylinder (mL) & 10 & 10 & 10 & 10 & 10 & 10 & 10 & 9.4 \\
\hline Wt of settled supernate in grad cylinder (g) & 11.2405 & 11.3724 & 11.4467 & 11.4315 & 11.4338 & 11.438 & 11.3217 & 10.5005 \\
\hline Density of settled supernate $(\mathrm{g} / \mathrm{mL})$ & 1.1241 & 1.1372 & 1.1447 & 1.1432 & 1.1434 & 1.1438 & 1.1322 & 1.1171 \\
\hline Vol of $500 \mathrm{G}$ centrifuged supernate $(\mathrm{mL})$ & 42.5 & 42 & 40 & 40 & 42.5 & 42.5 & 23 & 23 \\
\hline Vol of $500 \mathrm{G}$ centrifuged solids $(\mathrm{mL})$ & 7.5 & 8 & 10 & 10 & 7.5 & 7.5 & 27 & 27 \\
\hline Vol of $1000 \mathrm{G}$ centrifuged supernate (mL) & 42.5 & 43.5 & 41 & 41 & 43 & 43 & 32 & 33 \\
\hline Vol of $1000 \mathrm{G}$ centrifuged solids (mL) & 7.5 & 6.5 & 9 & 9 & 7 & 7 & 18 & 17.5 \\
\hline Vol of $4500 \mathrm{G}$ centrifuged supernate $15 \mathrm{~min}(\mathrm{~mL})$ & 43 & 44 & 43 & 42.5 & 44 & 43.5 & 37.5 & 37.5 \\
\hline Vol of $4500 \mathrm{G}$ centrifuged solids $15 \mathrm{~min}(\mathrm{~mL})$ & 7 & 6 & 7 & 7.5 & 6 & 6.5 & 12.5 & 12.5 \\
\hline Vol of $4500 \mathrm{G}$ centrifuged supernate $30 \mathrm{~min}(\mathrm{~mL})$ & 44 & 44.5 & na & na & na & na & na & na \\
\hline Vol of $4500 \mathrm{G}$ centrifuged solids $30 \mathrm{~min}(\mathrm{~mL})$ & 6 & 5.5 & na & na & na & na & na & na \\
\hline Vol of centrifuged supernate in grad cylinder (mL) & 10 & 10 & 10 & 10 & 10 & 10 & 10 & 10 \\
\hline Wt of centrifuged supernate in grad cylinder $(\mathrm{g})$ & 11.3961 & 11.3923 & 11.4508 & 11.4698 & 11.3925 & 11.446 & 11.1832 & 11.3912 \\
\hline Density of centrifuged supernate $(\mathrm{g} / \mathrm{mL})$ & 1.1396 & 1.1392 & 1.1451 & 1.1470 & 1.1393 & 1.1446 & 1.1183 & 1.1391 \\
\hline Mass of centrifuged solids (g) & 10.44 & 10.2847 & 11.3407 & 11.6714 & 10.3746 & 10.4557 & 18.6258 & 18.7827 \\
\hline Vol of centrifuged solids (mL) & 6.5 & 6 & 7.5 & 7.5 & 6.5 & 7.5 & 13 & 13 \\
\hline Density of centrifuged solids $(\mathrm{g} / \mathrm{mL})$ & 1.6062 & 1.7141 & 1.5121 & 1.5562 & 1.5961 & 1.3941 & 1.4328 & 1.4448 \\
\hline Mass of dried solids (g) & 5.8785 & 5.8211 & 5.3978 & 5.7405 & 5.4341 & 5.4798 & 6.8839 & 6.9603 \\
\hline $\mathrm{wt} \%$ Undissolved solids & 9.66 & 9.57 & 8.95 & 9.56 & 8.97 & 9.12 & 11.57 & 11.69 \\
\hline Mass of supernate $(\mathrm{g})$ & 11.1928 & 11.2188 & 11.3788 & 11.3687 & 11.3093 & 11.357 & 11.2164 & 11.2972 \\
\hline Mass of dried supernate $(\mathrm{g})$ & 1.6426 & 1.7192 & 1.6557 & 1.6579 & 1.66 & 1.6659 & 1.6126 & 1.6628 \\
\hline wt $\%$ supernate solids & 14.68 & 15.32 & 14.55 & 14.58 & 14.68 & 14.67 & 14.38 & 14.72 \\
\hline
\end{tabular}



Appendix C: Rheology Measurement Methods 



\section{Appendix C: Rheology Measurement Methods}

\section{C.1 Rheology Measurements}

The non-elastic flow of tank waste slurries and supernates is characterized with rotational viscometry. The typical result of such testing is a set of flow-curve data, which shows the stress response of a material to a range of applied rates-of-deformation. Specifically, flow-curve testing allows characterization of a material's shear stress, $\tau$, and response as a function of applied shear rate, $\dot{\gamma}$. Once measured, the flowcurve data can be interpreted with several constitutive equations for the viscous stress/rate-of-strain relationship. Such analysis allows the flow behavior to be described over a broad range of conditions with just a few rheological descriptors such as viscosity, yield stress, consistency, and flow index.

A concentric cylinder rotational viscometer operated in controlled-rate mode was used for flow-curve testing of tank waste slurries and supernates. Rotational viscometers operate by placing a given volume of test sample into a measurement cup of known geometry. A cylindrical rotor attached to a torque sensor is then lowered into the sample until the slurry is even with, but does not cover, the top of the rotor. A single-point determination of a fluid's flow properties is made by spinning a rotor at a known rotational speed, $\Omega$, and measuring the resisting torque, $M$, acting on the rotor. The torque acting on the rotor can be directly related to the shear stress at the rotor using the equation,

$$
\tau=\frac{M}{2 \pi H R_{I}^{2}}
$$

Shear stress has units of force per area $\left(\mathrm{N} / \mathrm{m}^{2}\right)$. The rotational rate is related to the shear rate. However, calculating the fluid shear rate at the rotor is complicated by the fact that shear rate depends on both the measurement system geometry and the fluid rheological properties. For the simplest fluids

(i.e., Newtonian fluids), the shear rate of the fluid at the rotor can be calculated given the geometry of the cup rotor shear by using the equation,

$$
\dot{\gamma}=\left(\frac{2 R_{O}^{2}}{R_{O}^{2}-R_{I}^{2}}\right) \Omega
$$

Here, the shear rate has units of inverse seconds $\left(\mathrm{s}^{-1}\right)$. Calculating the shear rate for materials showing more complex shear-stress versus shear-rate behavior (i.e., non-Newtonian fluids) requires estimates of yield stress and degree of shear-thinning or shear-thickening. As the goal of rheological testing is to determine and quantify such behavior, these values are typically not known. This requirement can be circumvented by using a cup and rotor system with a small gap $(\sim 1 \mathrm{~mm})$ for fluid shear. For fluid flow in small gap cup and rotor systems, shear-rate effects introduced by fluid properties are minimized such that Equation B.3 provides an accurate determination of shear rate for non-Newtonian materials. Shear rates examined in this study spanned the range from 1 to $1000 \mathrm{~s}^{-1}$. 
The resistance of a fluid to flow is often described in terms of the fluid's apparent viscosity, $\eta_{a p p}$, which is defined as the ratio of the shear stress to shear rate:

$$
\eta_{a p p}=\frac{\tau}{\dot{\gamma}}
$$

For Newtonian fluids, the apparent viscosity is independent of shear rate. For non-Newtonian fluids, the apparent viscosity will vary as a function of shear rate. The units of apparent viscosity are Pa.s, although it is typically reported in units of centipoise (cP; where $1 \mathrm{cP}=1 \mathrm{mPa} \cdot \mathrm{s})$.

Flow-curve data are usually combined plots of $\tau$ and $\eta_{\text {app }}$ as a function of $\dot{\gamma}$. As stated above, flow-curve data can be interpreted with several constitutive equations (i.e., flow curves), allowing characterization of that data with just a few rheological descriptors. The behavior of tank waste sludges, slurries, and supernates can be described by four common flow-curve equations:

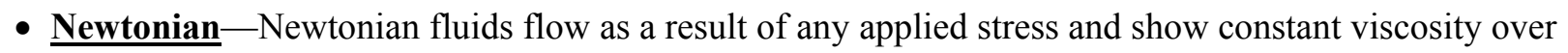
all shear conditions. The flow curve for Newtonian fluids is,

$$
\tau=\eta \dot{\gamma}
$$

where $\eta$ is the Newtonian viscosity.

- Ostwald (Power Law) - Power-law fluids flow as a result of any applied stress and have viscosities that either increase or decrease with increasing shear rate. They are described by,

$$
\tau=m \dot{\gamma}^{n}
$$

where $m$ is the power-law consistency index, and $n$ is the power-law index. Power-law fluids with $n<1$ are referred to as pseudoplastic (shear-thinning), whereas power-law fluids with $n>1$ are referred to as dilatant (shear-thickening).

- Bingham Plastic - Bingham plastics are fluids that show finite yield points. A finite stress (i.e., the yield stress), must be exceeded before these types of materials flow. Once flow is initiated, the stress response of the material is Newtonian over the rest of the shear-rate range. Bingham plastics are described by

$$
\tau=\tau_{O}^{B}+k_{B} \dot{\gamma}
$$

where $\tau_{O}^{B}$ is the Bingham yield index, and $k_{B}$ is the Bingham consistency index.

- Herschel-Bulkley - Fluids that behave in accordance with a Herschel-Bulkley model show a finite yield followed by power-law behavior over the rest of the shear-rate range. They are described by

$$
\tau=\tau_{O}^{H}+k_{H} \dot{\gamma}^{b}
$$


where $\tau_{O}^{H}$ is the Herschel-Bulkley yield index, $k_{H}$ is the Herschel-Bulkley consistency index, and b is the Herschel-Bulkley power-law index.

Power-law fluids, Bingham plastics, and Herschel-Bulkley fluids are examples of non-Newtonian fluids. In general, liquids without internal and/or interconnected structures (such as tank waste supernates) are Newtonian. Sludges and slurries are typically non-Newtonian, but their exact behavior depends on the concentration of solids and suspending phase chemistry. Sufficiently dilute slurries may show Newtonian behavior. 

Appendix D

\section{Letters of Request for Approval for Test Plan Hold Points}





\section{Appendix D: Letters of Request for Approval for Test Plan Hold Points}

July 3,2007

Mr. William L. Graves

WTP/RPP-MOA-PNNL-00077

Bechtel National Inc.

2435 Stevens Center Place, MSIN: H4-02

Richland WA 99352

Dear Sir:

\section{Proposed Test Matrix for Filtration Simulant Testing For Approval}

The purpose of this document is to provide BNI with the proposed test matrix for filtration simulant testing for approval. This approval is required per Section 6.2.1.3 in Test Plan TP-RPPWTP-469 Rev 0, Test Plan for the Development and Demonstration of Leaching and Ultrafiltration Simulants.

\section{Overview}

As indicated in the test plan, the test matrix is to assess the impact of the following independent variables on filter flux using the CUF:

Sludge solids to NAS ratio

Mixed phase simulant to inerts ratio

Simulant aging

$\mathrm{d}_{5}$ or $\mathrm{d}_{10}$ particle size distribution

However, characterization tests have previously shown that the sludge solids/NAS ratio does not significantly impact the expected filtration behavior. Therefore, the proposed test matrix does not assess the impact of this variable.

Also, the previous characterization tests have shown that gibbsite, boehmite, oxalate and leached boehmite provide the same impact as inerts on the filtration behavior. Therefore, the proposed matrix explores the use of these components in place of inert materials.

\section{Characterization results}

The characterization tests involved centrifuging samples starting at $10 \mathrm{wt} \%$ at various centrifuge conditions. The data shown in Table 1 (and Figure 1) are for $1000 \mathrm{G}$ for all the samples characterized. The component concentrations are all on a mass basis.

Inspection of Figure 1 indicates that changing the sludge solids:NAS ratio resulted in negligible change in the centrifuge behavior. These results indicate that this ratio will not provide significant control of filtration behavior. 
Figure 1 also indicates that while the filtration behavior would be affected by the addition of $\mathrm{Zr}$, the impact would be overwhelmed by the addition of the leaching components. Therefore, this parameter has been replaced in the proposed test matrix by inclusion of leaching components in the filtration test matrix.

Table 1. Filtration Characterization Results.

\begin{tabular}{|c|c|c|c|c|c|c|c|}
\hline & & & & & & & $\begin{array}{l}1000 \mathrm{G} \\
\text { concentration } \\
\text { factor }\end{array}$ \\
\hline 1A & Gibbsite & Oxalate & Boehmite & Zr & Sludge & NaS & 2.86 \\
\hline 1B & 0 & 0 & 0 & 0 & 0.68 & 0.32 & 2.94 \\
\hline 2A & 0 & 0 & 0 & 0 & 0.68 & 0.32 & 4.00 \\
\hline 2B & 0 & 0 & 0 & 0.5 & 0.34 & 0.16 & 4.00 \\
\hline 3A & 0 & 0 & 0 & 0 & 0.52 & 0.48 & 2.86 \\
\hline 3B & 0 & 0 & 0 & 0 & 0.52 & 0.48 & 2.86 \\
\hline 4A & 0 & 0 & 0 & 0 & 0.76 & 0.24 & 2.86 \\
\hline 4B & 0 & 0 & 0 & 0 & 0.76 & 0.24 & 2.86 \\
\hline 5A & 0 & 0 & 0 & 0.5 & 0.26 & 0.24 & 3.57 \\
\hline 5B & 0 & 0 & 0 & 0.5 & 0.26 & 0.24 & 3.57 \\
\hline 6A & 0 & 0 & 0 & 0.5 & 0.38 & 0.12 & 4.35 \\
\hline 6B & 0 & 0 & 0 & 0.5 & 0.38 & 0.12 & 4.00 \\
\hline 7A & 0.35 & 0.1 & 0.35 & 0 & 0.2 & 0 & 6.67 \\
\hline 7B & 0.35 & 0.1 & 0.35 & 0 & 0.2 & 0 & 7.69 \\
\hline 8A & 0 & 0.2 & $0.4^{*}$ & 0 & 0.4 & 0 & 5.56 \\
\hline 8B & 0 & 0.2 & $0.4^{*}$ & 0 & 0.4 & 0 & 5.56 \\
\hline 9A & 0 & 0.2 & $0.4^{*}$ & 0 & 0.2 & 0.2 & 7.14 \\
\hline 9B & 0 & 0.2 & $0.4^{*}$ & 0 & 0.2 & 0.2 & 7.14 \\
\hline 10A & 0 & 0 & 0 & 0 & 1 & 0 & 2.78 \\
\hline 10B & 0 & 0 & 0 & 0 & 1 & 0 & 2.86 \\
\hline
\end{tabular}

* present as leached boehmite - leached for $8 \mathrm{~h}$ at $100 \mathrm{C}$. 
$1000 \mathrm{G}$ concentration factor

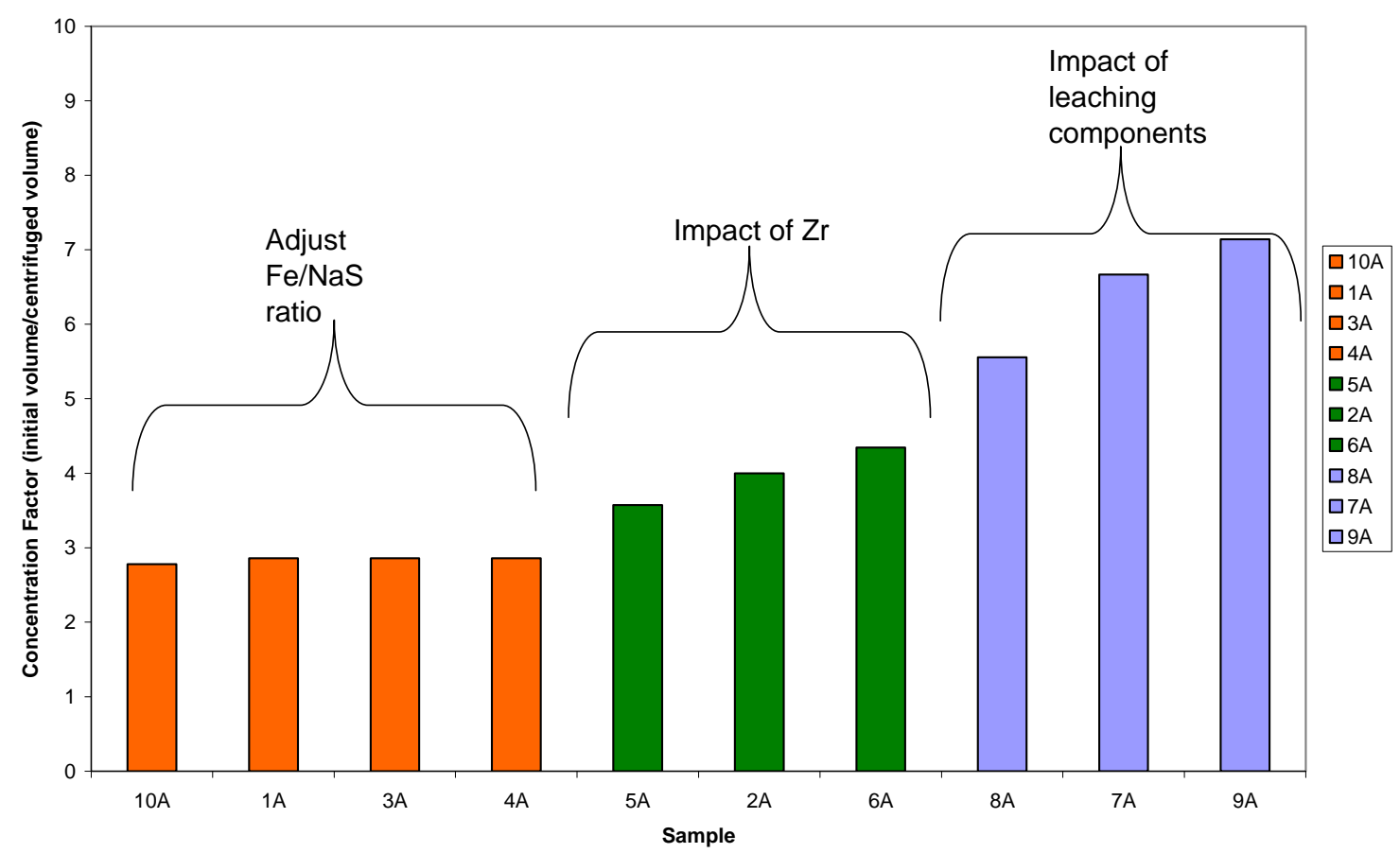

Figure $1.1000 \mathrm{G}$ centrifuge results for various samples.

\section{Proposed Test Matrix}

Table 2 provides the sequence of tests proposed as part of this test matrix. Note that the first test, $\mathrm{C} 1$, is part of the characterization testing previously authorized as part of the test plan. The subsequent tests (P1 through P7) represent the parametric tests to be approved as part of this test matrix.

The test plan calls for the test matrix to examine the following variables: particle size distribution, centrifuged solids percentage and simulant aging.

\section{Centrifuged Solids}

The impact of centrifuged solids concentration on filtration behavior will be evaluated by comparing Tests C1, P3 and P6. As seen in figure 1, these represent a range of conditions (Test 10, 8 and 9). An intermediate point (such as composition 6 from Table 1) could also be explored, however due to schedule constraints, this condition has been left out of the test matrix. 
Table 2. Proposed test matrix.

\begin{tabular}{|c|c|c|c|c|c|c|c|c|}
\hline \multirow[b]{2}{*}{ Test } & \multicolumn{5}{|c|}{ Ratio of solids fractions } & \multirow[b]{2}{*}{ wt $\%$} & \multirow[b]{2}{*}{ Condition } & \multirow[b]{2}{*}{ Notes } \\
\hline & $\begin{array}{c}\text { Sludge } \\
\text { Simulant }\end{array}$ & Boehmite & Oxalate & Gibbsite & Fines & & & \\
\hline C1-a & 0.4 & 0.4 & 0.2 & 0 & 0 & 5 & $\begin{array}{l}\text { Perform Test } \\
\text { Matrix }\end{array}$ & 1 \\
\hline c1-b & 0.4 & 0.4 & 0.2 & 0 & 0 & $5-20$ & Dewater & 1 \\
\hline C1-C & 0.4 & 0.4 & 0.2 & 0 & 0 & 20 & $\begin{array}{l}\text { Perform Test } \\
\text { Matrix }\end{array}$ & 1,2 \\
\hline P1 & 0.4 & 0.4 & 0.2 & 0 & 0.00006 & 5 & $\begin{array}{l}\text { Perform Test } \\
\text { Matrix }\end{array}$ & 1 \\
\hline $\mathrm{P} 2 \mathrm{a}$ & 0.4 & 0.4 & 0.2 & 0 & 0.00015 & 5 & $\begin{array}{l}\text { Perform Test } \\
\text { Matrix }\end{array}$ & 1 \\
\hline $\mathrm{P} 2 \mathrm{~b}$ & 0.4 & 0.4 & 0.2 & 0 & 0.00015 & $5-20$ & Dewater & 1 \\
\hline P2C & 0.38 & 0.38 & 0.19 & 0 & 0.05 & 20 & $\begin{array}{l}\text { Perform Test } \\
\text { Matrix }\end{array}$ & 1,3 \\
\hline P3a & 1 & 0 & 0 & 0 & 0 & 5 & $\begin{array}{l}\text { Perform Test } \\
\text { Matrix }\end{array}$ & \\
\hline P3b & 1 & 0 & 0 & 0 & 0 & $5-20$ & Dewater & \\
\hline P3c & 1 & 0 & 0 & 0 & 0 & 20 & $\begin{array}{l}\text { Perform Test } \\
\text { Matrix }\end{array}$ & 3 \\
\hline $\mathrm{P} 4 \mathrm{a}$ & 0.2 & 0.35 & 0.1 & 0.35 & 0 & 5 & $\begin{array}{l}\text { Perform Test } \\
\text { Matrix }\end{array}$ & \\
\hline $\mathrm{P} 4 \mathrm{~b}$ & 0.2 & 0.35 & 0.1 & 0.35 & 0 & $5-20$ & Dewater & \\
\hline P4c & 0.2 & 0.35 & 0.1 & 0.35 & 0 & 20 & $\begin{array}{l}\text { Perform Test } \\
\text { Matrix }\end{array}$ & 2 \\
\hline P5 & 0.2 & 0.35 & 0.1 & 0.35 & 0.0001 & 5 & $\begin{array}{l}\text { Perform Test } \\
\text { Matrix }\end{array}$ & \\
\hline $\mathrm{P} 6 \mathrm{a}$ & 0.2 & 0.35 & 0.1 & 0.35 & 0.00015 & 5 & $\begin{array}{l}\text { Perform Test } \\
\text { Matrix }\end{array}$ & \\
\hline $\mathrm{P} 6 \mathrm{~b}$ & 0.2 & 0.35 & 0.1 & 0.35 & 0.00015 & $5-20$ & Dewater & \\
\hline P6c & 0.190 & 0.333 & 0.095 & 0.333 & 0.05 & 20 & $\begin{array}{l}\text { Perform Test } \\
\text { Matrix }\end{array}$ & 3 \\
\hline $\mathrm{P} 7 \mathrm{a}$ & 0.4 & 0.4 & 0.2 & 0 & 0 & 5 & $\begin{array}{l}\text { Perform Test } \\
\text { Matrix }\end{array}$ & 1,4 \\
\hline $\mathrm{P} 7 \mathrm{~b}$ & 0.4 & 0.4 & 0.2 & 0 & 0 & $5-20$ & Dewater & 1,4 \\
\hline P7c & 0.4 & 0.4 & 0.2 & 0 & 0 & 20 & $\begin{array}{l}\text { Perform Test } \\
\text { Matrix }\end{array}$ & 1,4 \\
\hline
\end{tabular}

1 - uses leached boehmite $-8 \mathrm{~h}$ at $100 \mathrm{C}$

2 - add back supernatant at end of test

3 - clean filter after the test

4 - simulant aged prior to use

\section{Fines}

Table 3 provides the PSD for the Group 8 sample (from Table 1) and the proposed Zr fines. Based on these compositions, adding 0.00007 grams of Zr fines/gram of insoluble solids should result in lowering the number count $\mathrm{d} 5$ for the sample to approximately 0.32 micron. Bringing the total to 0.00015 grams of $\mathrm{Zr}$ fines/gram of insoluble solids should result in a d 10 for the sample of approximately 0.32 microns. These $\mathrm{d} 5$ and $\mathrm{d} 10$ values are approximately equivalent (and as close as can be practically predicted) to the targets ( 0.32 and 0.37 for actual waste samples). 
Table 3. PSD analysis for Sample 8 and for proposed $\mathrm{Zr}$ fines.

\begin{tabular}{ccccc} 
& \multicolumn{2}{c}{ Sample 8 } & \multicolumn{2}{c}{$\begin{array}{c}\text { Fines (Alfa Aesar Zr Powder) } \\
\text { volume }\end{array}$} \\
volume & number & number \\
\cline { 2 - 5 } d5 & 0.815 & 0.54 & 0.106 & 0.091 \\
d20 & 1.321 & 0.642 & 0.143 & 0.100 \\
d30 & 1.905 & 0.703 & 0.168 & 0.107 \\
d40 & 3.015 & 0.763 & 0.199 & 0.114 \\
d50 & 4.834 & 0.827 & 0.243 & 0.123 \\
d60 & 6.726 & 0.899 & 0.322 & 0.132 \\
d70 & 8.527 & 0.988 & 0.458 & 0.144 \\
d80 & 10.63 & 1.114 & 0.72 & 0.161 \\
d90 & 14.08 & 1.353 & 1.249 & 0.192 \\
d95 & 18.09 & 1.65 & 1.725 & 0.227
\end{tabular}

Two separate groups of tests will be done to examine the impact of fines on filtration behavior.

Tests C1, P1 and P2 will examine the impact of fines on the filtration behavior after leaching. Test C1 will be without fines, test $\mathrm{P} 1$ will add sufficient fines to bring the $\mathrm{d} 5$ number down to about 0.32 micron, test P2 will add sufficient fines to bring the d10 number down to about 0.32 micron.

Tests P4, P5 and P6 will perform a similar test sequence, but using the higher centrifuged solids feed.

\section{Aging}

Tests $\mathrm{C} 1$ and $\mathrm{P} 7$ will evaluate the impact of aging on filtration behavior. Prior to the start of test P7, the simulant will be aged (heated for an extended period - approximately 1 week to accelerate the aging process).

Please contact Reid Peterson on 376-5340 if you have any questions.

Sincerely,

Gordon H. Beeman, Manager

RPP-WTP Support Program

$\mathrm{GHB}: \mathrm{c}^{2}$

cc: Project File/LB 
November 13, 2007

Mr. Haukur R. Hazen

WTP/RPP-MOA-PNNL-00113

Bechtel National Inc.

2435 Stevens Center Place, MSIN: H4-02

Richland WA 99352

Dear Sir:

Proposed Testing for Blended Component Filtration for Approval

The purpose of this document is to provide BNI with the proposed test description for blend of components filtration testing for approval. This approval is required per Sections 6.2.1.5 in Test Plan TP-RPP-WTP-469 Rev 0, Test Plan for the Development and Demonstration of Leaching and Ultrafiltration Simulants.

\section{Overview}

Prior test work as part of this program has identified component simulants for gibbsite, boehmite and filtration behavior. Filtration tests were performed using the filtration simulant component only. The purpose of this testing is to measure the impact of the various simulant components on the filtration behavior of the simulant. The test plan calls for the test matrix to examine how the simulant components interact with each other and whether they hinder, help, or have no effect on the filtration behavior of the simulant.

Figure 1 shows that by filtering at $45^{\circ} \mathrm{C}$, the solution would become supersaturated with oxalate causing it to precipitate out as the solution is cooled to $25^{\circ} \mathrm{C}$ further downstream from the CUF. Therefore, we are proposing that filtering at $25^{\circ} \mathrm{C}$ is the better choice so that the solution does not become supersaturated in oxalate that has to be dealt with later.

\section{Proposed Test Description}

This testing will begin with a slurry simulant consisting of $5 \mathrm{wt} \%$ UDS. With this beginning $\mathrm{wt} \% \mathrm{UDS}$, the plant processing time will not be followed. The solids in this simulant will consist of $34.6 \mathrm{wt} \%$ gibbsite, $34.6 \mathrm{wt} \%$ boehmite, $18.2 \mathrm{wt} \%$ sludge simulant, $2.6 \mathrm{wt} \%$ chromium oxy-hydroxide, and $10 \%$ sodium oxalate. The supernate will consist of a solution that is $5 \mathrm{M} \mathrm{Na}$ with the approximate composition given in Table 1. The $\mathrm{NaOH}$ may be adjusted to account for solubility issues.

The following test description provides the sequence of testing steps proposed as part of this test matrix. The testing will follow the proposed WTP flowsheet from beginning to end including the concentration, the caustic and oxidative leaching, and washing steps. 


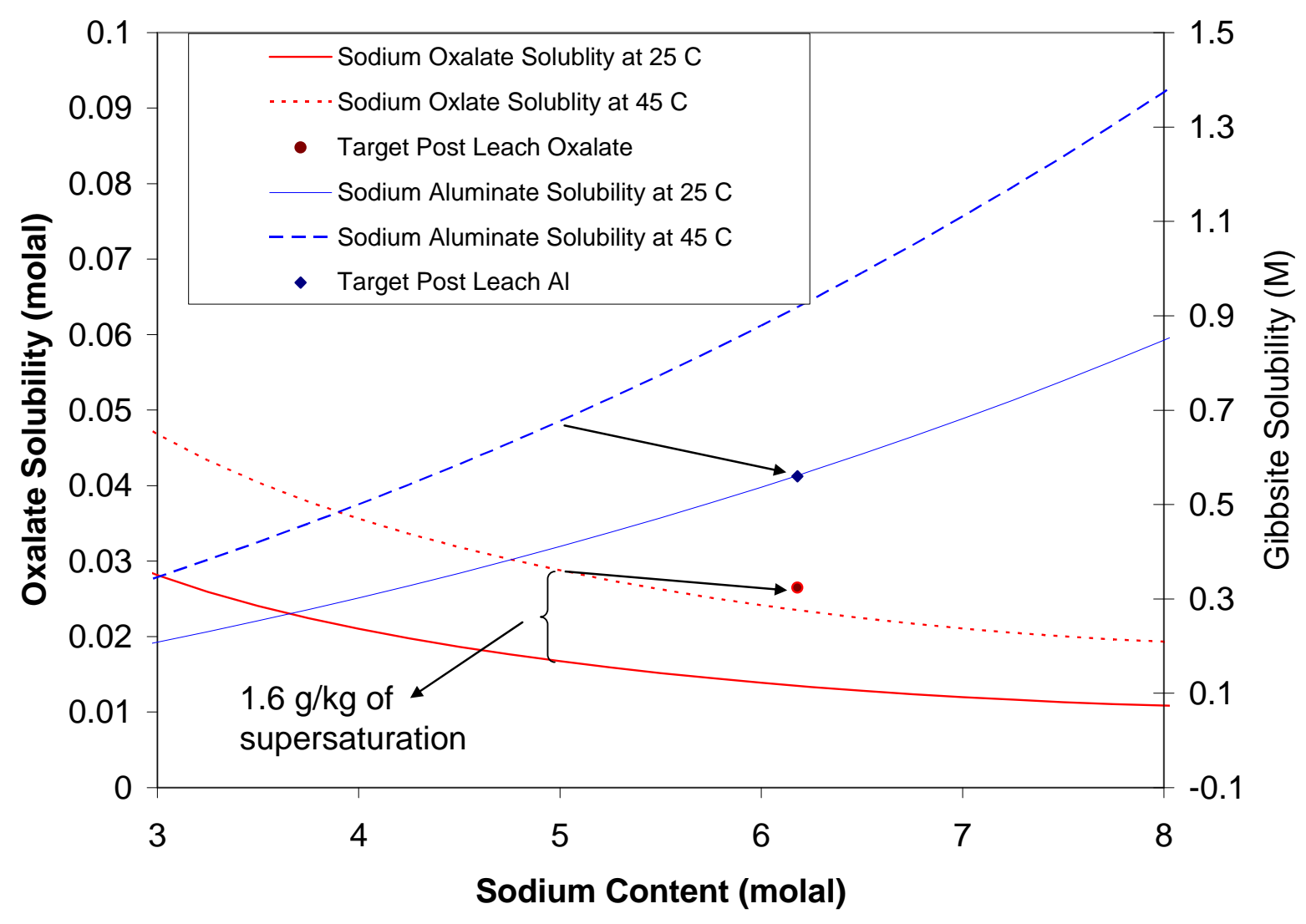

Figure 1. Oxalate Solubility at $25^{\circ} \mathrm{C}$ and $45^{\circ} \mathrm{C}$

Table 1. Approximate Supernate Composition at $5 \mathrm{M} \mathrm{Na}$

\begin{tabular}{|l|c|c|}
\hline \multicolumn{1}{|c|}{ Component } & Chemical Formula & Concentration (M) \\
\hline Aluminum nitrate & $\mathrm{Al}\left(\mathrm{NO}_{3}\right)_{3}-9 \mathrm{H}_{2} \mathrm{O}$ & 0.150 \\
\hline Sodium hydroxide & $\mathrm{NaOH}$ & 0.367 \\
\hline Sodium phosphate & $\mathrm{Na}_{3} \mathrm{PO}_{4}-12 \mathrm{H}_{2} \mathrm{O}$ & 0.019 \\
\hline Sodium sulfate & $\mathrm{Na}_{2} \mathrm{SO}_{4}$ & 0.011 \\
\hline Sodium carbonate & $\mathrm{Na}_{2} \mathrm{CO}_{3}$ & 0.663 \\
\hline Sodium oxalate & $\mathrm{Na}_{2} \mathrm{C}_{2} \mathrm{O}_{4}$ & 0.024 \\
\hline Sodium nitrite & $\mathrm{NaNO}_{2}$ & 0.831 \\
\hline Sodium nitrate & $\mathrm{NaNO}_{3}$ & 2.254 \\
\hline
\end{tabular}

\section{Dewatering:}

Dewatering will be done on the initial $\sim 5 \mathrm{wt} \%$ UDS simulant slurry at an operating volume of $\sim 9 \mathrm{~L}$. The operating volume of $9 \mathrm{~L}$ was chosen as it provides the correct volume to surface area ratio. At a UFP-2 operating volume of 12,000 gal and an active filter surface area of $1715 \mathrm{ft}^{2}$ the ratio of volume to surface area is $7 \mathrm{gal} / \mathrm{ft}^{2}$. With a filter in the CUF having an active surface area of $0.33 \mathrm{ft}^{2}$, this requires a volume of $8.7 \mathrm{~L}$ to obtain this same ratio. The slurry simulant will be dewatered to the target $20 \mathrm{wt} \%$ UDS. The supernatant will contain approximately $5 \mathrm{M} \mathrm{Na}$. 


\section{Dewater Process Steps}

- Place 9L of low-solids slurry at a target of $5 \mathrm{wt} \%$ UDS and $5 \mathrm{M}$ sodium into the CUF feed tank.

- Continue to add $750 \mathrm{~mL}$ of feed for every $750 \mathrm{~mL}$ of supernate removed from the tank.

- Dewater the slurry to a CUF volume of $9 \mathrm{~L}$ at $20 \mathrm{wt} \%$ UDS.

\section{Leaching}

Caustic leach conditions for the blended waste slurry are based on a slurry volume of $9 \mathrm{~L}$ of $20 \mathrm{wt} \%$ UDS. This requires the addition of $6.94 \mathrm{~kg}$ of $19 \mathrm{M} \mathrm{NaOH}$ and $9.55 \mathrm{~kg}$ of condensate. The final sodium concentration is expected to be $6.65 \mathrm{M}$. Add water as needed during the caustic leach lost by evaporation to maintain a constant volume.

\section{Caustic Leaching Process Steps}

- Retrieve all solids from CUF and isolate in slurry feed reservoir for leaching.

- Assuming $9 \mathrm{~L}$ of $20 \mathrm{wt} \% \mathrm{UDS}$, add $6.94 \mathrm{~kg}$ of $19 \mathrm{M} \mathrm{NaOH}$ and $9.54 \mathrm{~kg}$ of condensate to the slurry simulant. Leach for $29.3 \mathrm{~h}$ at $100(+5 /-10)^{\circ} \mathrm{C}$. These leaching conditions have been estimated to produce a solution saturated at $25^{\circ} \mathrm{C}$ at the conclusion of the leaching process.

- Heat from $45^{\circ} \mathrm{C}$ to $100^{\circ} \mathrm{C}$ in 5.3 hours

- Leach for $12 \mathrm{~h}$ at $100(+5 /-10)^{\circ} \mathrm{C}$.

- Cool from $100^{\circ} \mathrm{C}$ to $45^{\circ} \mathrm{C}$ in 12 hours

\section{Post Caustic Leach Dewater Process Steps}

- Dewater leached solids at $45^{\circ} \mathrm{C}, \mathrm{TMP}=40 \mathrm{psi}$, and $\mathrm{AV}=13 \mathrm{ft} / \mathrm{s}$. Dewater to a target of $17 \mathrm{wt} \%$ undissolved solids (UDS) or to a mass of $\sim 6.3 \mathrm{~kg}$.

\section{Post Caustic Leach Washing}

The amount of required wash solution will be divided into 5 wash steps. The amount of wash solution required will enough to reduce the $\mathrm{Na}$ concentration from $\sim 6.65 \mathrm{M}$ to $<0.25 \mathrm{M}$ by decreasing it by half every wash using six times the amount of leached solids. Wash the leached solids five successive times with $0.01 \mathrm{M} \mathrm{NaOH}$. It is estimated that the final hydroxide concentration will be approximately $0.2 \mathrm{M}$.

\section{Post Caustic Leach Washing Process Steps}

- Add 4.8L of 1.57M NaOH for wash 1 and dewater to the original volume of the CUF $(\sim 4.8$ L).

- Add 4.8L of $0.68 \mathrm{M} \mathrm{NaOH}$ for wash 2, dewater to the original volume of the CUF ( 4.8 L). 
- Add 4.8L of $0.26 \mathrm{M} \mathrm{NaOH}$ for wash 3, dewater to the original volume of the CUF ( 4.8 L).

- Add 4.8L of $0.08 \mathrm{M} \mathrm{NaOH}$ for wash 4 , dewater to the original volume of the CUF ( 4.8 L).

- Add $4.8 \mathrm{~L}$ of $0.03 \mathrm{M} \mathrm{NaOH}$ for wash 5 , dewater to the original volume of the CUF ( 4.8 L).

- Add 4.8L of $0.01 \mathrm{M} \mathrm{NaOH}$ for wash 6 , dewater to the original volume of the CUF ( 4.8 L).

- A sample of the final wash solution will be analyzed for free-hydroxide.

- If necessary, concentrated $\mathrm{NaOH}$ will be added such that the free-hydroxide concentration in the slurry is increased to $0.2 \mathrm{M}$. A solution sample will be taken for free-hydroxide determination.

\section{Oxidative Leaching Process Steps}

- Retrieve all solids from CUF and isolate in slurry feed reservoir for leaching.

- Assuming 4.11 L of $20 \mathrm{wt} \%$ UDS, $0.20 \mathrm{M}$ free-hydroxide, and all Cr remaining, add $128 \mathrm{~mL}$ of $1 \mathrm{M} \mathrm{NaMnO}_{4}$ over 1 hour, and leach for $6.0 \mathrm{~h}$ at $25^{\circ} \mathrm{C}$ temperature. These oxidative leaching conditions have been estimated based upon 1:1 mole ratio of $\mathrm{Cr}$ to $\mathrm{MnO}_{4}^{-}$.

- Sample supernatant fraction at $0.5,1,2,4$, and 6 hours during oxidative leaching and analyze supernatant fraction for metals (total $\mathrm{Cr}$ ).

\section{Post Oxidative Leach Washing Process Steps}

Four washes are necessary to obtain $90 \%$ Cr removal from the system.

- Add equal volume of inhibited water $(0.01 \mathrm{M} \mathrm{NaOH})$ for wash 1, dewater to a target of 18 $\mathrm{wt} \%$ UDS or to minimum operating volume of CUF $(\sim 2 \mathrm{~L})$.

- Add equal volume of inhibited water $(0.01 \mathrm{M} \mathrm{NaOH})$ for wash 2, dewater to a target of 19 $\mathrm{wt} \%$ UDS or to minimum operating volume of CUF $(\sim 2 \mathrm{~L})$.

- Add equal volume of inhibited water $(0.01 \mathrm{M} \mathrm{NaOH})$ for wash 3, dewater to a target of 20 $\mathrm{wt} \%$ UDS or to minimum operating volume of the CUF $(\sim 2 \mathrm{~L})$.

- Add equal volume of inhibited water $(0.01 \mathrm{M} \mathrm{NaOH})$ for wash 4, dewater to a target of 20 $\mathrm{wt} \%$ UDS or to minimum operating volume of the CUF ( 2 L).

- Drain slurry from CUF and retain for potential use, only dispose at the guidance of the client.

\section{Post Oxidative Leach Dewater Process Steps}

- Dewater leached solids at $45^{\circ} \mathrm{C}, \mathrm{TMP}=40 \mathrm{psi}$, and AV $=13 \mathrm{ft} / \mathrm{s}$. Dewater to a target of $20 \mathrm{wt} \%$ undissolved solids (UDS) or to an operating volume of CUF ( 2 L).

- Clean CUF and determine clean water $(0.01 \mathrm{M} \mathrm{NaOH})$ flux. 
Table 2. Sampling and Characterization Plan for Blended Filtration Testing

\begin{tabular}{|c|c|c|c|c|}
\hline Process Step & Analyte & Solids & Slurry & $\begin{array}{l}\text { Liquid } \\
\text { or } \\
\text { Filtrate }\end{array}$ \\
\hline \multirow{5}{*}{$\begin{array}{l}\text { Feed Dewatering } \\
\text { Slurry Concentrate }\end{array}$} & Rheology (flow curve) & & $\mathrm{X}$ & \\
\hline & Density & & $\mathrm{X}$ & \\
\hline & $\mathrm{Wt} \% \mathrm{UDS}$ & & $\mathrm{X}$ & \\
\hline & PSD & & $\mathrm{X}$ & \\
\hline & $\begin{array}{l}\text { ICP metal, see Table } 3 \text { for listing of } \\
\text { metals }\left(\mathrm{Na}_{2} \mathrm{O}_{2} \text { fusion or acid digestion for }\right. \\
\mathrm{Ni})\end{array}$ & & $\mathrm{X}$ & \\
\hline \multirow{4}{*}{$\begin{array}{l}\text { Feed Dewatering } \\
\text { Filtrate }\end{array}$} & Total dissolved solids & & & $\bar{X}$ \\
\hline & $\begin{array}{l}\text { Anions (sulfate, phosphate, nitrate, } \\
\text { oxalate) }\end{array}$ & & & $\mathrm{X}$ \\
\hline & Density & & & $\mathrm{X}$ \\
\hline & Free-hydroxide & & & $\mathrm{X}$ \\
\hline \multirow[t]{6}{*}{$\begin{array}{l}\text { Post-Caustic Leach } \\
\text { Slurry Concentrate }\end{array}$} & $\mathrm{wt} \%$ UDS & & $\mathrm{X}$ & \\
\hline & Density & & $\mathrm{X}$ & $\mathrm{X}$ \\
\hline & Rheology (flow curve) & & $\mathrm{X}$ & \\
\hline & PSD & $\mathrm{X}$ & & \\
\hline & $\begin{array}{l}\text { ICP metals (see Table } 3 \text { for listing of } \\
\text { metals) }\end{array}$ & & & $\mathrm{X}$ \\
\hline & $\begin{array}{l}\text { Anions (sulfate, phosphate, nitrate, } \\
\text { oxalate) }\end{array}$ & & & $\mathrm{X}$ \\
\hline \multirow{2}{*}{$\begin{array}{l}\text { Post-Caustic Leach } \\
\text { First and Second } \\
\text { Wash }\end{array}$} & Density & & & $\mathrm{X}$ \\
\hline & Free-hydroxide & & & $\mathrm{X}$ \\
\hline \multirow{4}{*}{$\begin{array}{l}\text { Post-Caustic Leach } \\
\text { Third Wash }\end{array}$} & Density & & & $\mathrm{X}$ \\
\hline & Free-hydroxide & & & $\mathrm{X}$ \\
\hline & $\begin{array}{l}\text { Anions (sulfate, phosphate, nitrate, } \\
\text { oxalate) }\end{array}$ & & & $\bar{X}$ \\
\hline & ICP metals (acid digest) & & & $\mathrm{X}$ \\
\hline \multirow{3}{*}{$\begin{array}{l}\text { Post-Caustic Leach } \\
\text { Combined Washes }\end{array}$} & Density & & & $\mathrm{X}$ \\
\hline & $\begin{array}{l}\text { ICP metals (see Table } 3 \text { for listing of } \\
\text { metals) }\end{array}$ & & & $\mathrm{X}$ \\
\hline & $\begin{array}{l}\text { Anions (nitrate, sulfate, phosphate, } \\
\text { oxalate) }\end{array}$ & & & $\mathrm{X}$ \\
\hline
\end{tabular}


Table 2. Sampling and Characterization Plan for Blended Filtration Testing

\begin{tabular}{|c|c|c|c|c|}
\hline Process Step & Analyte & Solids & Slurry & $\begin{array}{l}\text { Liquid } \\
\text { or } \\
\text { Filtrate }\end{array}$ \\
\hline & Free-hydroxide & & & $\bar{X}$ \\
\hline \multirow{9}{*}{$\begin{array}{l}\text { Post-Caustic Leach } \\
\text { Washed Slurry } \\
\text { Concentrate }\end{array}$} & $\mathrm{wt} \%$ UDS & & $Y$ & \\
\hline & Density & & $\mathrm{X}$ & \\
\hline & Rheology (flow curve) & & $\mathrm{X}$ & \\
\hline & PSD & $\mathrm{X}$ & & \\
\hline & BET & $X$ & & \\
\hline & XRD, SEM/EDS & $X$ & & \\
\hline & ICP metals (KOH fusion) & $X$ & & \\
\hline & ICP metals $\left(\mathrm{Na}_{2} \mathrm{O}_{2}\right.$ fusion $)(\mathrm{Ni})$ & $\mathrm{X}$ & & \\
\hline & $\begin{array}{l}\text { Anions (water-leachable) (nitrate, sulfate, } \\
\text { phosphate, oxalate) }\end{array}$ & $\mathrm{X}$ & & \\
\hline \multirow{2}{*}{$\begin{array}{l}\text { Pre-oxidative } \\
\text { Leach Supernate }\end{array}$} & TIC/TOC & & & $\mathrm{X}$ \\
\hline & Free-hydroxide & & & $\mathrm{X}$ \\
\hline \multirow{5}{*}{$\begin{array}{l}\text { Oxidatively } \\
\text { Leached Slurry } \\
\text { Concentrate }\end{array}$} & $\mathrm{wt} \%$ UDS & & $\mathrm{X}$ & \\
\hline & Density & & $\mathrm{X}$ & $\mathrm{X}$ \\
\hline & Rheology (flow curve) & & $\mathrm{X}$ & \\
\hline & PSD & $X$ & & \\
\hline & Total dissolved solids & & & $\mathrm{X}$ \\
\hline \multirow{4}{*}{$\begin{array}{l}\text { Oxidatively } \\
\text { Leached Slurry } \\
\text { Concentrate }\end{array}$} & TIC/TOC & & & $\mathrm{X}$ \\
\hline & ICP metals & & $\mathrm{X}$ & $\mathrm{X}$ \\
\hline & $\begin{array}{l}\text { Anions (sulfate, phosphate, nitrate, } \\
\text { oxalate) }\end{array}$ & & & $\mathrm{X}$ \\
\hline & Free-hydroxide & & & $\mathrm{X}$ \\
\hline \multirow{2}{*}{$\begin{array}{l}\text { Post-Oxidative } \\
\text { Leach Third Wash }\end{array}$} & Density & & & $\mathrm{X}$ \\
\hline & Free-hydroxide & & & $\mathrm{X}$ \\
\hline
\end{tabular}


Table 2. Sampling and Characterization Plan for Blended Filtration Testing

\begin{tabular}{|c|c|c|c|c|}
\hline Process Step & Analyte & Solids & Slurry & $\begin{array}{l}\text { Liquid } \\
\text { or } \\
\text { Filtrate }\end{array}$ \\
\hline & $\begin{array}{l}\text { Anions (sulfate, phosphate, nitrate, } \\
\text { oxalate) }\end{array}$ & & & $\bar{X}$ \\
\hline & ICP metals (acid digest) & & & $\bar{X}$ \\
\hline & Total dissolved solids & & & $\mathrm{X}$ \\
\hline \multirow{4}{*}{$\begin{array}{l}\text { Post-Oxidative } \\
\text { Leach Combined } \\
\text { Washes }\end{array}$} & & & & $\mathrm{X}$ \\
\hline & $\begin{array}{l}\text { ICP metals (see Table } 3 \text { for listing of } \\
\text { metals) }\end{array}$ & & & $\mathrm{X}$ \\
\hline & Free-hydroxide & & & $\mathrm{X}$ \\
\hline & $\begin{array}{l}\text { Anions (sulfate, phosphate, nitrate, } \\
\text { oxalate) }\end{array}$ & & & $\mathrm{X}$ \\
\hline \multirow{9}{*}{$\begin{array}{l}\text { Post-Oxidative } \\
\text { Leach Washed } \\
\text { Final Slurry } \\
\text { Concentrate }\end{array}$} & $\mathrm{wt} \%$ UDS & & $\mathrm{X}$ & \\
\hline & Density & & $\mathrm{X}$ & \\
\hline & Rheology (flow curve, shear strength) & & $\mathrm{X}$ & \\
\hline & PSD & $X$ & & \\
\hline & XRD, SEM/EDS, TEM/ED & $X$ & & \\
\hline & BET & $\mathrm{X}$ & & \\
\hline & $\begin{array}{l}\text { ICP metals (KOH fusion) (see Table } 3 \text { for } \\
\text { listing of metals) }\end{array}$ & $\mathrm{X}$ & & \\
\hline & ICP metal $\left(\mathrm{Na}_{2} \mathrm{O}_{2}\right.$ fusion) (Ni) & $\mathrm{X}$ & & \\
\hline & $\begin{array}{l}\text { Anions (water-leachable) (nitrate, sulfate, } \\
\text { phosphate, oxalate) }\end{array}$ & $\mathrm{X}$ & & \\
\hline
\end{tabular}


Table 3. Constituent Detection Limits for Solids and Supernatants

\begin{tabular}{|c|c|c|c|}
\hline Constituent & $\begin{array}{c}\text { Solids } \\
\mu \mathrm{g} / \mathrm{g}\end{array}$ & $\begin{array}{c}\text { Solutions } \\
\mu \mathrm{g} / \mathrm{ml}\end{array}$ & Analysis Method \\
\hline$\overline{\mathrm{Al}}$ & $3.0 \mathrm{E}+02$ & $7.5 \mathrm{E}+01$ & \multirow{13}{*}{ ICP-OES } \\
\hline $\mathrm{B}$ & $2.0 \mathrm{E}+02$ & $7.5 \mathrm{E}+01$ & \\
\hline $\mathrm{Bi}$ & $4.0 \mathrm{E}+02$ & $3.0 \mathrm{E}+01$ & \\
\hline $\mathrm{Cd}$ & $7.5 \mathrm{E}+01$ & $7.5 \mathrm{E}+01$ & \\
\hline $\mathrm{Cr}$ & $1.2 \mathrm{E}+02$ & $1.5 \mathrm{E}+01$ & \\
\hline $\mathrm{Fe}$ & $3.0 \mathrm{E}+02$ & $7.5 \mathrm{E}+01$ & \\
\hline $\mathrm{Mn}$ & $3.0 \mathrm{E}+02$ & $1.5 \mathrm{E}+01$ & \\
\hline $\mathrm{Na}$ & $3.0 \mathrm{E}+02$ & $7.5 \mathrm{E}+01$ & \\
\hline $\mathrm{Ni}$ & $1.6 \mathrm{E}+02^{(\mathrm{b})}$ & $3.0 \mathrm{E}+01$ & \\
\hline $\mathrm{Si}$ & $3.0 \mathrm{E}+03$ & $7.5 \mathrm{E}+01$ & \\
\hline $\mathrm{Sr}$ & $3.0 \mathrm{E}+02$ & $7.5 \mathrm{E}+01$ & \\
\hline $\mathrm{Zn}$ & $3.0 \mathrm{E}+02$ & $7.5 \mathrm{E}+01$ & \\
\hline $\mathrm{Zr}$ & $3.0 \mathrm{E}+02$ & $7.5 \mathrm{E}+01$ & \\
\hline Nitrite & $2.5 \mathrm{E}+02$ & $1.2 \mathrm{E}+02$ & \multirow{5}{*}{$\begin{array}{l}\text { Ion Chromatography } \\
\text { (water-soluble species) }\end{array}$} \\
\hline Nitrate & $2.5 \mathrm{E}+02$ & $1.2 \mathrm{E}+02$ & \\
\hline Phosphate & $2.5 \mathrm{E}+02$ & $1.2 \mathrm{E}+02$ & \\
\hline Sulfate & $2.5 \mathrm{E}+02$ & $1.2 \mathrm{E}+02$ & \\
\hline Oxalate & $8.0 \mathrm{E}+02$ & $4.0 \mathrm{E}+02$ & \\
\hline Hydroxide & NA & $1 \mathrm{E}-01$ & Titration \\
\hline Total organic carbon & NA & $4.0 \mathrm{E}+02$ (as C) & \multirow{2}{*}{ Hot persulfate method } \\
\hline Total inorganic carbon & NA & $2.0 \mathrm{E}+02($ as $\mathrm{C})$ & \\
\hline Density & 0.9 to $1.7 \mathrm{gm} / \mathrm{mL}$ & 0.9 to $1.7 \mathrm{gm} / \mathrm{mL}$ & Gravimetry \\
\hline
\end{tabular}

(a) $\mathrm{KOH}$ fusion for solid samples.

(b) The Ni (and $\mathrm{K}$ ) cannot be measured from the $\mathrm{KOH}$ fusion which uses a Ni crucible. The Ni will be assessed from a separate $\mathrm{Na}_{2} \mathrm{O}_{2}$ fusion which uses a $\mathrm{Zr}$ crucible where indicated in the test plan.

Please contact Reid Peterson on 376-5340 if you have any questions. 
Sincerely,

Gordon H. Beeman, Manager

RPP-WTP Support Program

$\mathrm{GHB}: \mathrm{c}^{2}$

cc: Project File/LB 
PNNL-18090

WTP-RPT-183 Rev. 0

\section{Distribution}

No. of

Copies

4 Bechtel National, Inc.

D. Ramsey

P. S. Sundar

S. Barnes
H4-02

H4-02

H4-02
No. of

Copies

9 Pacific Northwest National Laboratory

RL Russell (2) K6-24

HD Smith

K6-24

JM Billing

P7-25

RA Peterson (2)

P7-22

DE Rinehart

P8-10

Information Release

P8-55

Project File

K3-52

Distr. 1 